\title{
Light Atmosphere in Hospital Wards
}





\section{Light Atmosphere in Hospital Wards}

Revised Version

PhD Thesis

Defended in public at Aalborg University

2 April 2013

Lone Mandrup Stidsen

Department of Civil Engineering, The Faculty of Engineering and Science, Aalborg University, Aalborg, Denmark

River Publishers

Aalborg 
ISBN 978-87-93237-00-1 (e-book)

Published, sold and distributed by:

River Publishers

Niels Jernes Vej 10

9220 Aalborg Ø

Denmark

Tel.: +45369953197

www.riverpublishers.com

Copyright for this work belongs to the author, River Publishers have the sole right to distribute this work commercially.

All rights reserved (c) 2014 Lone Mandrup Stidsen.

No part of this work may be reproduced, stored in a retrieval system, or transmitted in any form or by any means, electronic, mechanical, photocopying, microfilming, recording or otherwise, without prior written permission from the Publisher. 
PREFACE 
An interest in studying qualities of light was awoken a I was a student at Kolding School of Design, at the Department of Textile design, Denmark. I studied lighting design and found interest in exploring the interplay between light, materials and the user. I was puzzled by why quantitative light qualities as light level, colour rendering and spectral distribution, were well-defined and also quite obvious and relatively easy to evaluate or measure Opposit soft qualitative qualities, as the experience of light, lighting atmosphere and the interplay between light and materials etc., were not often noted as less import to define and were not detailed decribed as well defined or defined at the same level of importace as the quantitative qualities. Maybe they were found less important or too subjective or just too difficult to handle. I found the priorities of lighting qualities both a provocation and a motivation to start focussion on a designers point of view neglected aspects important for the evaluation of quality in lighting design. To understand the background and the approach of this thesis, I will introduce my professional approach to lighting design as a textile deisgner and display some of the experiments and products that paved the way for this PhD study.

It has always been a vision for me as a designer to keep "Innovation" in mind and design specific products for a reason, not just adding another gracefull object to the world without making sure that the product can bring something new to existing designs. Therefore, one of my first designs was a luminaire of various glass (Fig. 0.1) The luminaire helped me remember the importance of daring; putting on different glasses, exploring a subject and not being too sure of how light can be experienced and what the impact of the light is. Through the years, this object has been a part of my studio or private home, always placed in a visible place.

As my final graduating project from the Kolding School of Design in 2006, I created the luminaire collection 'Jelly in a bubble' (Fig 0.2). The LED (Light Emitting Diodes) luminaires came on the marked for domestic use and the new technology urged for new products dealing with the benefit of the light source, e.g. no heat radiation in front of the source. Therefore, 'Jelly in a bubble' focused on the interplay between light and different materials and played with the effect the LED had on different accessories placed 


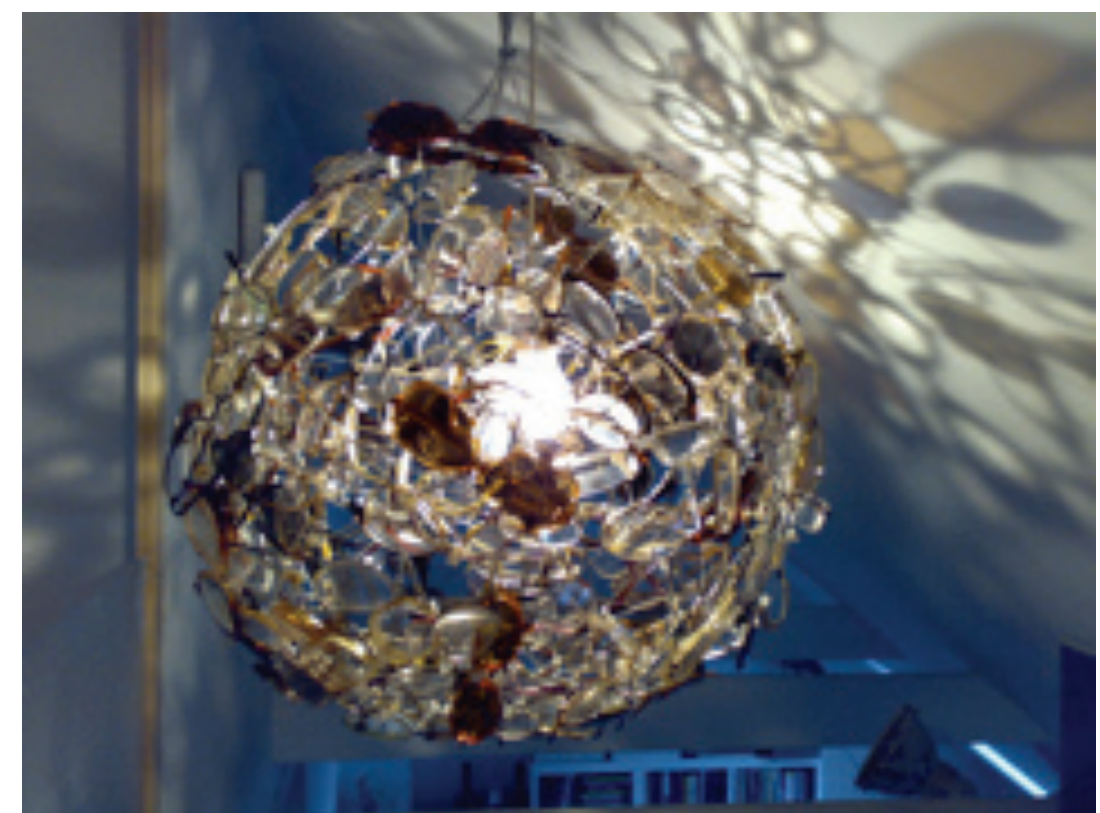

Fig. 0.1

'Brillelampen' Light installation by Lostdesign. Foto: Lone Mandrup Stidsen.

Fig. 0.2

'Jelly In a Bubble' LED luminaire design by Lostdesign. Foto: Nils Henrik Pedersen

0.2

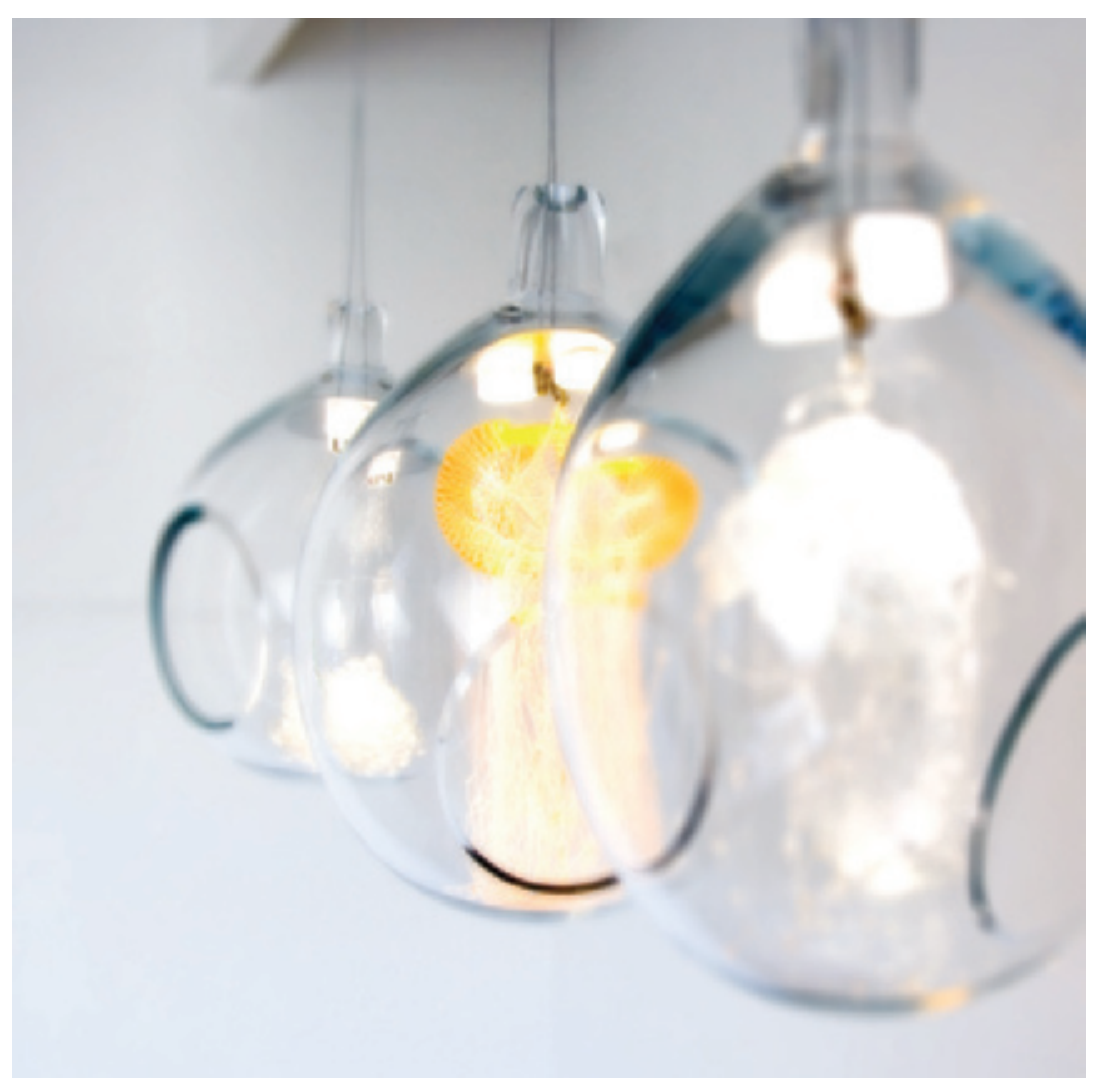


in the luminarie design depending on the light sensitive materials used. In this way, it was possible to manipulate the appearance of light and change the speed of perception and thereby the experience of the product.

During the final project, I was challenged with questions to which I could find no answers. Questions such as why design choices for illumination are so different from the equator to the northern part of Scandinavia, and a lack of understanding of the use of unshielded light bulbs or fluorescent light tubes in the private sphere. Danes often accentuate Danish lighting design as being special and unique. But is it unique? Do Danes have a distinctive or characteristic way of illuminating their surroundings? Do Danes have preferences for a specific type of light? And what is the character of the light Danes find interesting? Can a Danish lighting culture be defined? And in which way the way we illuminate our private sphere influence our daylight experience?

The study of light culture and variation in daylight fascinated me, and thus many pictures of the sky were taken (Fig 0.3). This collection of pictures illustrates the variation of light on a January morning 2008 from 7 a.m. - 8 a.m. The change of light and colours in the sky were amazing and also the effect on the environment and the colour of buildings in front were changing from purple to white.

Other projects at Kolding School of Design and 'Ungt Lys' investigated light in such different ways as weaving LED lightsources into fabrics, experimenting with light, shadow, transparence, filtering light, reflections etc. The interest was developing from the narrow perspective of light and material studying light in micro scale, looking at the light effect of the mateiral. Later studies in larger scales of light included studying illuminated spaces, creation of interesting light zones and lighting methods able to change atmosphere in a space, but also included an interest for the user perspective and how differently we experince light and quality.

The tradition of illumination and lighting quality are often topics for discussion topic in my professional and social context. My friend and families show interest in my work and often participate in discussions and exchange opinions on light subjects. In the beginning of 2009, a good friend of mine was hospitalized with terminal cancer. Therefore, 

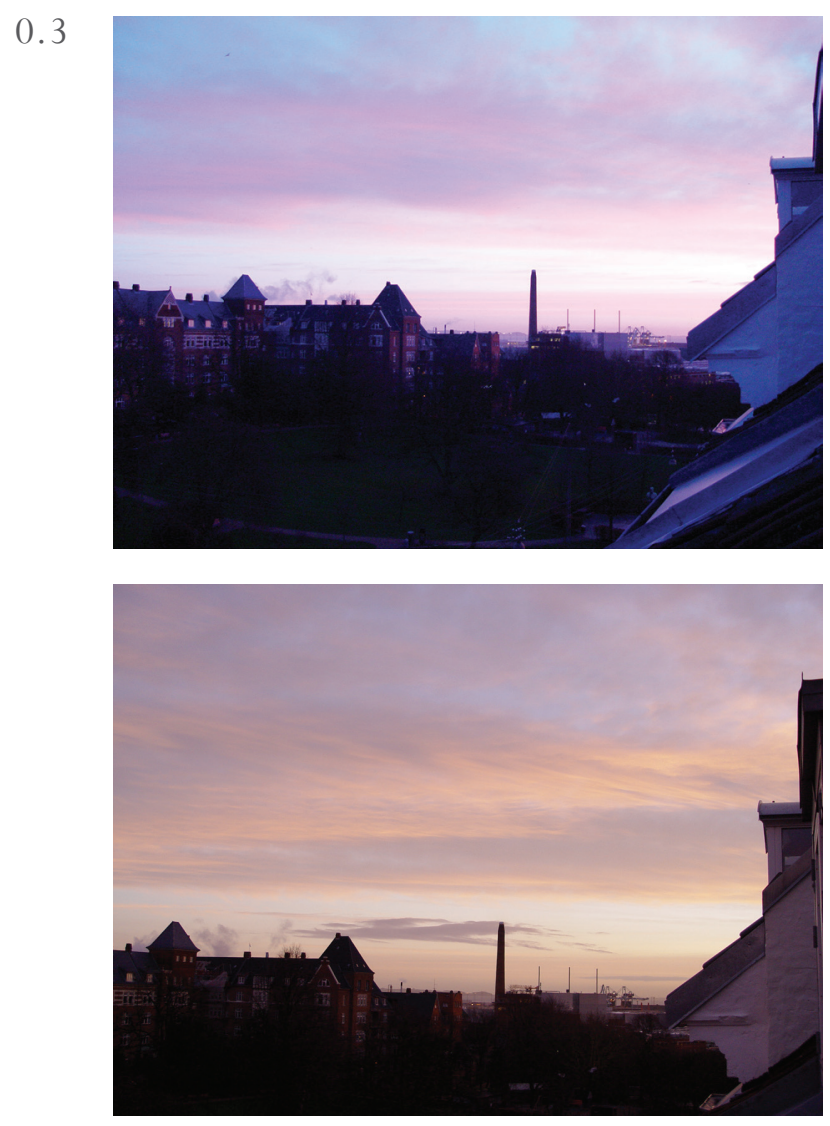

Fig. 0.3

Gallery of images $15 \mathrm{~min}$ between each image. Odensegade, Aarhus. Photo: Lone Mandrup Stidsen
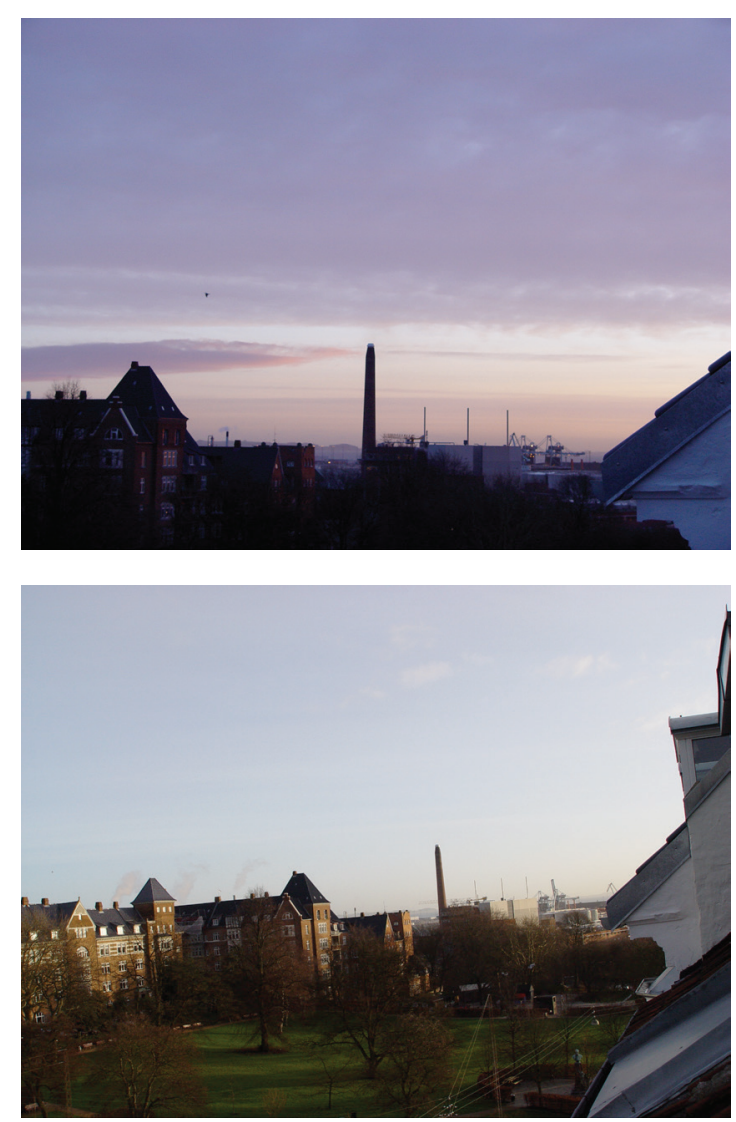
the subject of illumination of hospitals became a natural subject to discuss. For months I visited her in hospitals in Aarhus and during her last period at Hospice Djursland. My friend was very interested in my work and one day at the hospital she gave me a note where she had written central thoughts about her experience of light in hospital wards.

"In the hospital wards where I have been, a window is placed in one end of the room, and a door in the other end. The light can be divided in three zones. First, a daylight zone nearest the window, then there is a nightlight zone near the door. Lastly, the light in between where various luminaires are placed. For me, the window and the world behind the window are linked to a wish of getting well and being able to go home as soon as possible. I have been lying here looking at clouds drifting over the sky and found peace, letting the mind drift with the clouds and believing everything to be fine again. The bright light at nighttime is one of the problems not easily avoided during a hospitalization. The light between the door and the window often appears gray because the white walls underline the situation of being hospitalized." (Bjerrum 2008)

The statement made an impact on me. First of all, she was a good friend and I wanted the best for her in a difficult time, but her thoughts were also inspiring in a professional way. Her thoughts of letting the mind drift with the clouds were interesting, as it pointed out her hopes and dreams. Also, it showed that letting the mind "drift" was a central issue when hospitalized and that nature and natural elements stimulate this. Another thing was the sad observation of the light between the door and window appearing grey and underlining the situation of being hospitalized.

The experience of being a relative of or a visitor to a patient also contributed with knowledge. As a visitor in a hospital, you realize what the spatial composition of a space means. When visiting my friend in a small, two-bed hospital room, I felt that we were always too many visitors in the space. We felt like we were always sitting or standing exactly where the staff needed be so they could do their job. The illumination was basic; a lamp over the washbasin and two fluorescent light tubes covered by old fixtures. Trying to create a cosy atmosphere in the ward was not easy, and often the result was turning on the bed light and lamp over the washbasin. 
Fig. 0.4

A ward at Hospice Djursland 2009 .
Later, when my friend was admitted to Hospice Djursland, the role as a visitor changed in many ways. As the picture displays (fig 0.4), the ward design was more like a one room apartment and appeared as a living room with technical equipment suitable for the needs of the terminal patient. At the hospice, the experience was that the environment supported the patient and visitor needs in a very pleasant way. The hospital beds were flexible in a way so my friend could join social acts such as having dinner together and drinking coffee by the coffee table. Sometimes my friend was covered with blankets and duvets and brought to the terrace to enjoy the beautiful view of the meadow and the sea. When my friend was too tired and needed a rest, she could sleep just next to friends and family. Above the bed area, a window was placed creating a view to the sky and my friend could follow the progression of the day and let her mind drift with the clouds.

The illumination of the patient room in the hospice supported the diverse needs and preferences in different situations and the lighting control had many option. The only problem was that there were almost too many options to grasp when trying to create a pleasant light atmosphere. Despite too many options in lighting control, the lighting must be highlighted as a good example of pleasant light atmosphere and emphasized as inspirational. Some of the fixtures were ceiling mounted down lights, other wall
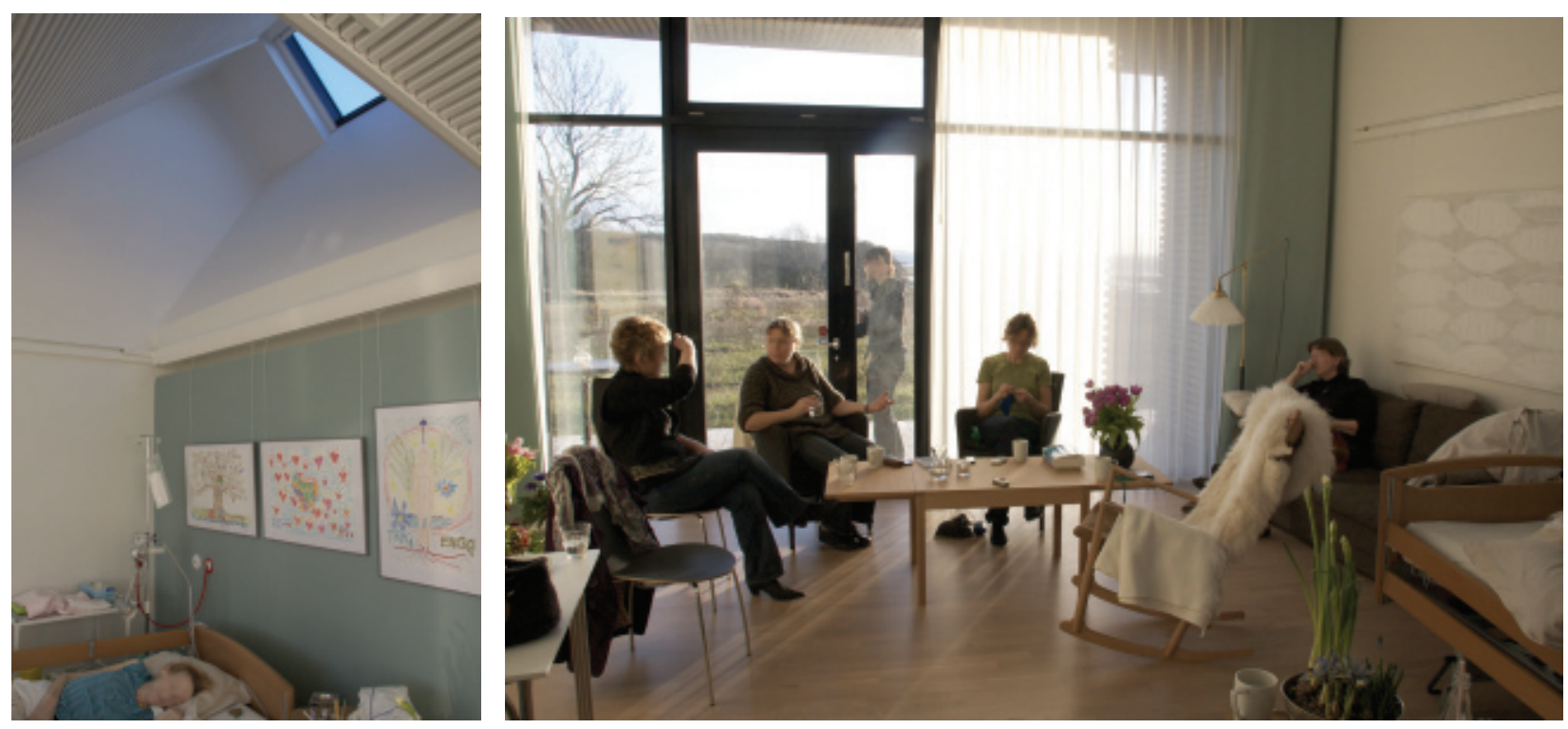
washers and floor lamps, table lamps and bed lamp. All light was placed where needed and some was even moveable. The experience was similar to a private living room, except for the hospital bed, in terms of choice of light materials and furniture. Still it appeared as a hospice ward with all that was needed and thereby created the secure feeling of being taken care of as well. The experience of the light atmosphere and interior design had an impact on me and the feeling of being a relative visiting a patient was intense, educative and inspiring. This motivated me to have hospital wards as the frame of the study of light atmosphere.

This experience created the interest of lighting design in the context of hospital architecture and I found the lighting design in wards ready to be revised and optimized in several ways.

In order to frame the study in a reliable way according to my background and interest, choices were made and even relevant subjects as daylight were downsized so as to focus on the artificial light. The downsizing is not a sign of neglecting or not recognising the importance of daylight, but an intentional choice because I found the priority of studying artificial light impact on light atmosphere crucial and wanted to create knowledge in this area. Still, daylight plays a central role in the study because daylight is an important source of inspiration in the design process and because I am convinced of the hypothesis that the way we illuminate our indoor environment ia affected by the way we experience daylight. At least in spaces intuitively illuminated as homes and private spheres and not where a light planner or an architect has been creating light atmospheres, and therefore daylight plays a central role in the project without being the research area. The underlying basis of the $\mathrm{PhD}$ study is a practical design education with an interest of innovating the field of defining lighting quality and getting a deeper understanding of the subject and creating new knowledge on sensory qualities of light. 
READING GUIDE 
The structure of the thesis is a collection of articles concatenating the entire story of the $\mathrm{PhD}$ project. The papers have been written through different stages in the research process, for which reason variation in definitions and difference in use of terms and words will appear. This mirrors the development through the research process and is an unavoidable side effect of a paper-based dissertation. Likewise, the papers explore different parameters of light atmosphere with the purpose of clarify definitions and terms and thereby demonstrate different stages and levels of understandings in depth. The common thread is a focus on light atmosphere, explorative and experimental studies of light atmosphere with the aim to innovate the concept of illumination in hospital wards. (fig 0.5) provides a visual overview of the dissertation and its context. The Thesis present the whole story and the articles is in this version excluded underlying copyrights.

Chapter 1 provides an introduction to the topic and research area, concluding with research questions and aim of the dissertation.

Chapter 2 introduces to the 'system of inquiry', 'strategies' and 'tactics' and gives overview of methods used to investigate the research questions and aim of the dissertation. Chapters 3 on light atmosphere present 'Model of Light Atmosphere'. Both theoretical and visually aspects are presented and a socio cultural aspect introduced.

Chapter 4 presents explorative studies dealing with light atmosphere. The studies presented are an admission to the hospital, optimation of light by zoning the ward, preferences for light atmosphere and trends for light.

Chapter 5 brings together the gained knowledge and display a experimental study of light atmposphere in a hospital ward.

Chapter 6 evaluates the gained knowledge from the presentation of of light atmosphere, explorative and experimental studies. The chapter discuss the findings, methods and present suggestions for future work.
Fig. 0.5

Model presenting the itterative process of the study 


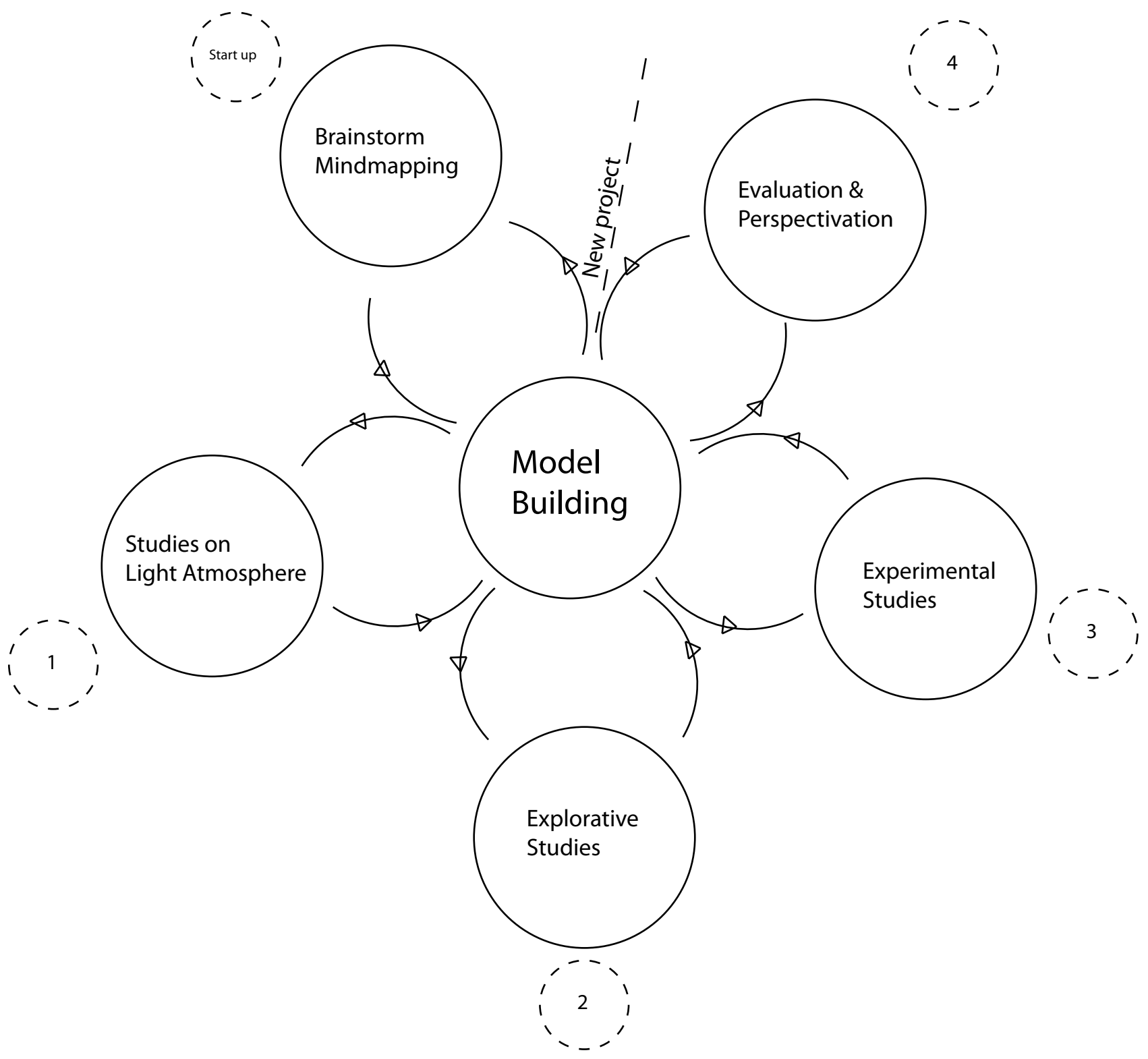



ACKNOWLEDGEMENT 
"A lot of the learning to work with light, since it doesn't form by working with the hands as clay does, is the working with the light through thoughts". James Turrell (Madsen 2002)

As James Turrell states, a development of light and illumination goes through thoughts and exchanges of opinions. This kind of development is most fruitful when exchanging opinions with other people than one self. So, through the project I have discussed and exchanged thoughts with researchers, lighting designers, architects, PhD fellows, relevant networks, family and neighbours. Thanks to all who contributed to the discussion and those who shared their thoughts with me and contributed with constructive criticism throughout the project. It is appreciated. Still, I would like to give a special thanks to Aalborg University, Department of Civil Engineering, to Philips Denmark, and to the Ministry of Science, Innovation and Higher Education for financing the project. A thanks to my supervisor Professor Poul Henning Kirkegaard for being by my side constantly, guiding me through the process, providing constructive feedback and not least showing interest in the subject and encouraging me to perform my best through the process. The supervising has contributed to a pleasurable and challenging time during the $\mathrm{PhD}$.

Philips Lighting Denmark has in addition to partly financing the project also delivered technical equipment and technical support to the experimental study at Odense University. Doing an experimental study at Odense University Hospital takes flexibility and interest from the collaborators. Thanks to Professor, Head of research, MD, DmSc Søren Overgaard and nurse Hanne Nørgaard Jensen from Odense University Hospital, and staff at 03 (Department of Orthopaedic Surgery and Traumatology) for facilitating the project and letting me use two hospital wards for the experimental research.

As a part of explorative studies, Professor Poul Henning also engaged students as well as professional support in the discussions to qualify the different methods used in the studies. 
Thanks to Niels Thuesen who used the 11 th Semester (extended Master programme) studying user zones at the ward, for helping to analyse interior design magazines and for supporting the project with engineering skills and providing figures, Dialux documentation etc. I am also grateful for the help I got from Henriette Sønderskov Bjerrum. As an anthropologist and friend, she had been supportive in many ways. First of all, for always being available for discussing methods and for helping me sort out project frustrations. Furthermore, for providing professional help and guidance through the study of preferences using methods known from anthropology. Lastly, for the great help providing supervision and supportive comments through the years.

As an exchange student at the unit of Environmental Psychology at Lund University, assistant professor Thorbjörn Laike supervised me and introduced to the field of Environmental Psychology. I am thankful for the professional feedback, interest and for the time you put into the discussions. Also, I want to thank Thorbjörn and his family for opening the doors to their home and participating in discussions on light and illumination as well as making the process of collecting questionnaires easier.

To my own family I am thankful for many years of sharing knowledge of light experiences, and for providing relevant comments, critics and not least being patient with listening to new ideas.

In conclusion, a special thanks to my dear husband Anders for being by my side and always helping. His willingness to read, comment, participate, accompanying me on different trips and, most importantly, for bearing with me when I had trouble dividing work and family time. 

SUMMARY ENGLISH<smiles>[CH]</smiles> 
At the moment, the future of hospital design is a subject of public interest and thereby also a subject of discussion. It is a fact that new hospitals have an increased focus on user perspectives and an interest for improving the physical environment in such a way it supports the user needs and preferences and thereby the experience of an admission to the hospital. Recent literature such as 'Hospitals of the senses' and 'Healing Architecture' presents research and design solutions focused on senses and experience of the design. The Danish Regions ask for 'Evidence Based Design' to future prove the hospitals by research base the design of the buildings. The present PhD project expands the existing knowledge of lighting research by focussing on the experienced light atmosphere. The project uses multi strategies of methodology based on a flexible design to elaborate on the socio-cultural aspect of light and the sensory impact of light. To frame the work, the "Model of Light Atmosphere" is created and improved throughout the study, first as an abstract model and then it is exposed for detailed study. The detailed study first of all creates a theoretical and visual context. Then explorative studies seek to investigate unknown or tacit knowledge on how light is used in a Danish context, preferences for light in different situations and investigating the hospital ward as frame for a lighting concept. The concept is installed in a hospital ward at Odense University Hospital as a "real world" study and evaluated by the patients in the ward.

The project is based on the Danish Regulation for light in hospitals (DS703), which is a supplement to the regulation of artificial lighting in workplaces (DS700). The kick-off to the project was reading the DS703, second paragraph, chapter 2 about general requirements for lighting.

"For the rest of the lighting, the light color should be chosen on the basis of the patients" needs for a pleasant and "home like" feeling. This will in most cases mean a color temperature that is higher than $3000 \mathrm{~K}$ and a reasonably good color rendering of $R a>80$ (DS703).

In general, measurable parameters such as the amount of Lux, the composition of CRI and degree of Kelvin is described precisely in a way so the designer can handle the requirements. But what does it mean to create a 'home-like' and 'pleasant or appealing' light in this context? Does the composition of CRI and degree of Kelvin tell it all? Is it
Fig 0.6

'Model of Light Atmosphere' 


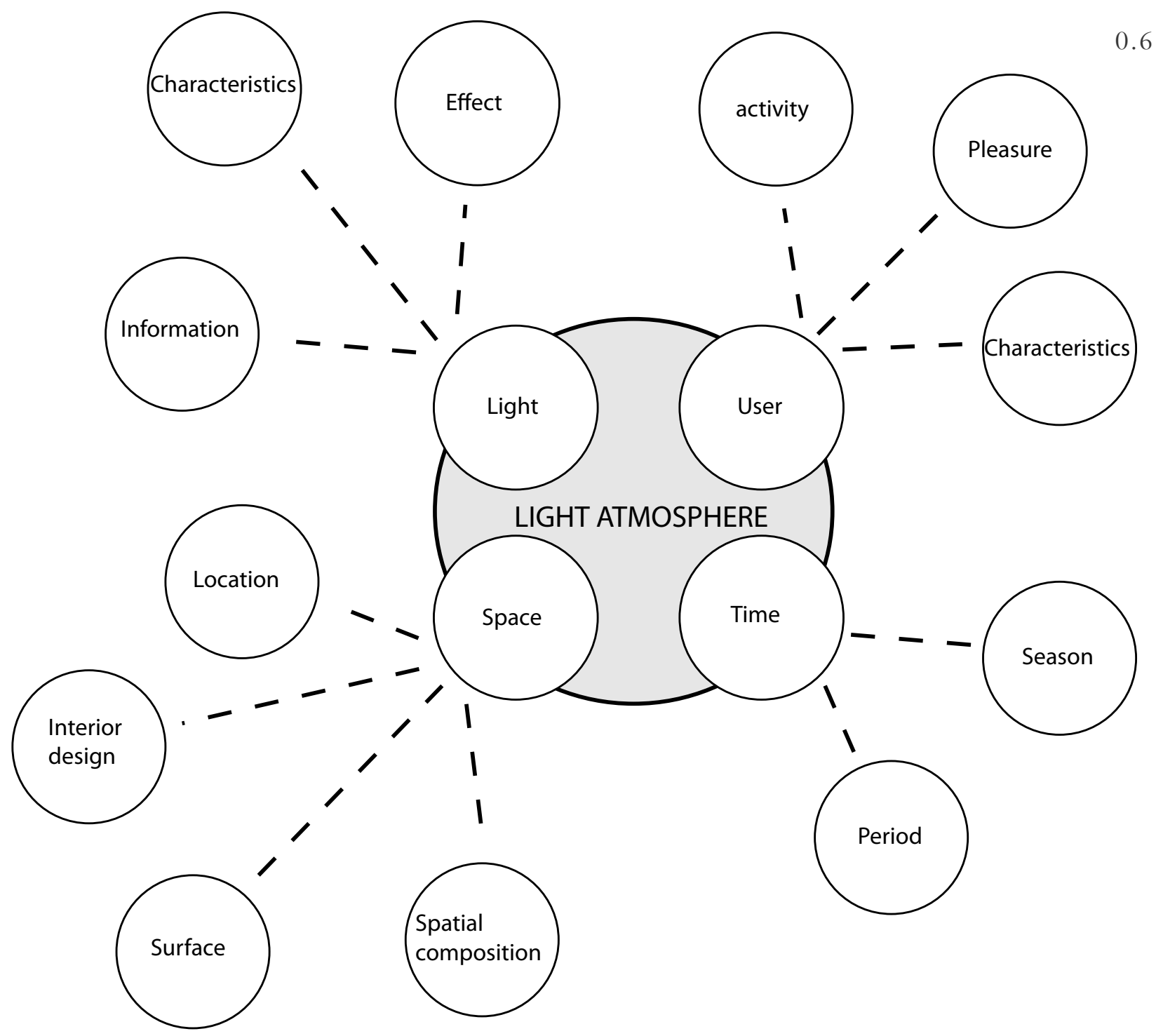

enough information to provide an illumination, which the patient can experience as homely and pleasant?

This project seeks to highlight the design process of lighting a hospital ward and articulate visual as well as written what a homely and pleasant light atmosphere could be in a Danish context. Therefore, the study investigates the socio-cultural understanding and the geographical impact of the understanding of light atmosphere. 'Model of Light Atmosphere' (fig 0.6) describes four key aspects of light atmosphere and displays what is important when a light atmosphere is qualified. The four key aspects are: 'Light', 'Space', 'Users' and 'Time'. 
The 'Light' aspect describes, as shown in (Fig 0.6), the character of the light, light information and light effect i.e. function, aesthetics or symbolism. The 'Space' aspect looks into the dimension of the space, geographical orientation, interior design, composition of the space, materials, surfaces and objects. The parameter 'Time' elaborates on the time one is present in the space, the season and time of day. The 'Users' aspect is split up into categories such as characteristics exploring the user group's preferences and needs. The user group has quite diverse needs and preferences, while the staff needs task lighting and the patient a space experienced as homely and pleasant.

Categories such as 'pleasure' and 'activities' are also a part of the user aspect. The space is divided into subcategories as 'location of the space' and 'geographical orientation'. The interior design, surface and spatial composition of the space are also parameters of importance.

The 'Model of Light Atmosphere' is the focal point of the project through iterative process and also developed through the study. First the model frames the study and later serves as a design tool for creating light atmosphere in hospital wards.

The project is performed through four cycles of iterations. The first cycle elaborates on atmosphere. Here the study find its theoretical foundation based on Gernot Böhmes' concept of atmosphere. It also finds its visual understanding by studying the architects' way to design atmosphere. The second cycle explores the users' preferences and trends of light atmosphere in four exploratory studies. First presented is an observation of ward atmosphere. Hereafter a study of light preferences in Danish homes. Then, the trends of light atmosphere in Denmark are lastly an investigation on light zones at the hospital ward defined in order to optimize the illumination.

The third cycle of iteration is an experimental study testing a lighting concept developed and grounded in the knowledge gained through the first and second cycle. The fourth cycle evaluates the effect of the light atmosphere at the ward. Here the patients are admitted to two similar wards not including the artificial illumination. The evaluation uses Semantic Environmental Description developed by environmental psychiatrist Rikard Küller, in order to evaluate the light atmosphere. 
SUMMARY DANISH/
SAMMENFATNING DANSK 
I Danmark arbejdes der lige nu med at skabe fremtidens hospitaler. De nye hospitaler har et øget fokus på brugere af hospitalet, og de fysiske omgivelsers sansemæssige betydning undersøges og forbedres, så de bedre understøtter brugernes behov. Bøger som 'Sansernes Hospital' og 'Helende Arkitektu' er danske bud på hvordan forskning kan tages med ind i designprocessen og emner som 'Evidence Based Design' efterspørges for at sikre et forskningsbaseret og dermed fremtidssikre hospitalsbyggeri. Ph.d.-projektet udbygger den eksisterende viden omkring lysets sansemæssige betydning for oplevelsen af rum og arbejder med en model, der beskriver vigtige faktorer i evalueringen af belysning. Derudover udvikles der gennem eksplorative studier, samt en teoretisk og visuelt koncept for belysning af sengestuer, der herefter installeres som eksperimentielt "real world study" på en sengestue, hvor der også evalueres af patienterne selv.

Forståelsen af begrebet 'atmosfære', sanselig erfaring og oplevelse af omgivelserne eksisterer og behandles som en slags tavs viden mellem arkitekter og designere. De skaber atmosfære og snakker om sansemæssige faktorer, som var det en selvfølgelighed og at alle andre har samme forståelse. Denne tavse viden om emnet og forståelsen af den generelle designproces bliver ofte misforstået som en hokus pokus metode til udvikling af æstetisk formgivning. Projektet tager udgangspunkt i Dansk Standards Retningslinjer for kunstig belysning i sygehuse (DS703) der er et supplement til Kunstig belysning i arbejdslokaler (DS700).

I DS703 står der i stk. 2 om Almene krav til belysningen s. 2.: "For den øvrige belysning må lysfarven valges ud fra patienternes behov for en tiltalende "hjemlig" belysning, hvilket i de fleste tilfalde vil betyde en farvetemperatur, der ikke er hojere end $3000 \mathrm{~K}$ og en rimelig god farvegengivelse med Ra>80. (Dansk Standardiserings råd nov 1983)

Generelt er de målbare kvalitetsparametre som lux, Raværdi og kelvingrader beskrevet tilfredsstillende, så det som designer er til at overholde. Men hvad betyder "hjemlig" og "tiltalende" i denne sammenhæng? Er det nok at henvise til lysfarve og farvegengivelse, når lyset skal være tiltalende og give patienten den følelse af hjemlighed ? Dette projekt tilstræber derfor at synliggøre designprocessen for belysningen til en hospitalssengestue, samt 


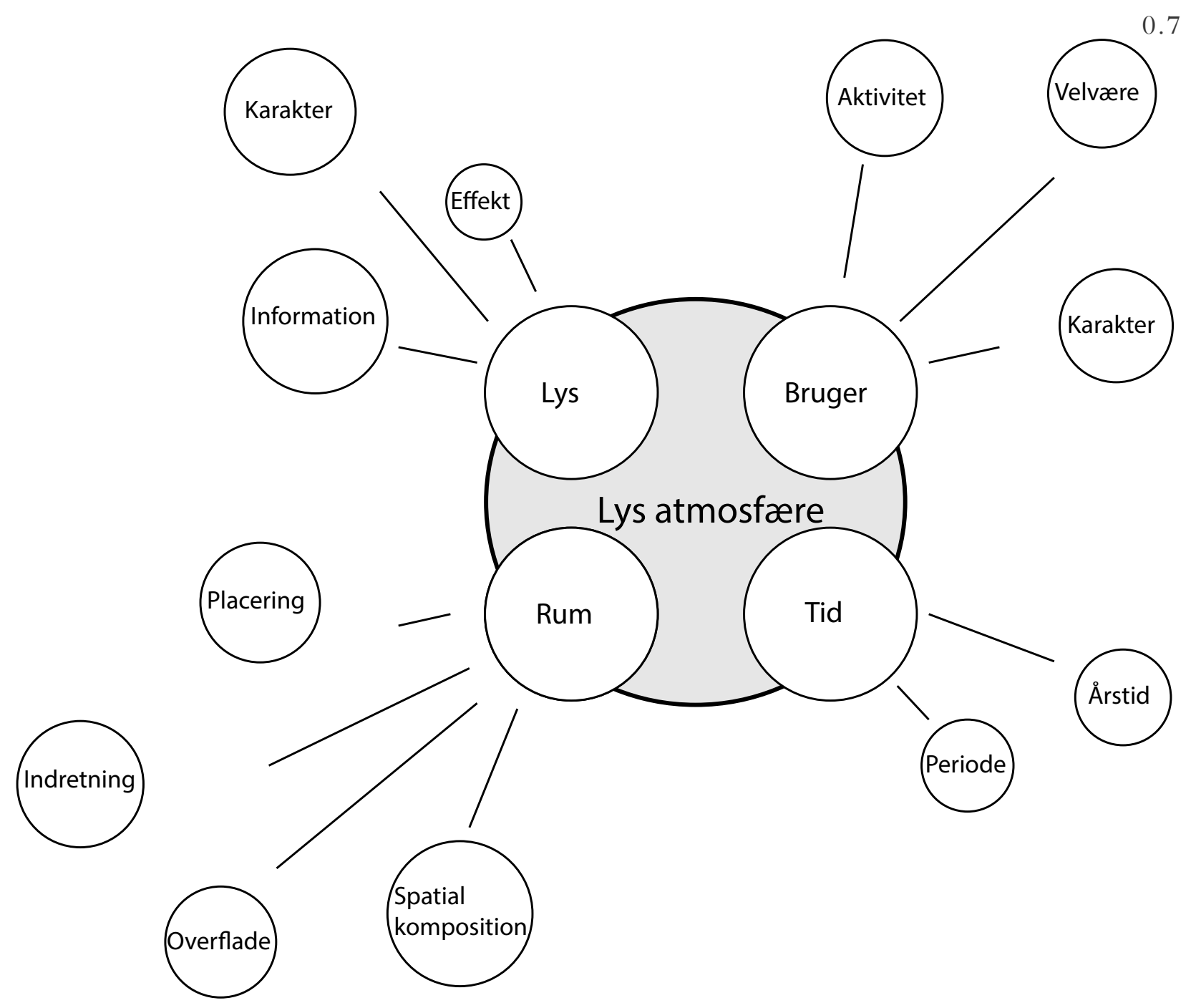

sætte ord på nogle af de parametre, der har betydning når en lysatmosfære bedømmes, eller som DS 703 skriver som tiltalende 'hjemlig' belysning. Jeg vil påstå, at de færreste sengestuers belysning kan betegnes som 'tiltalende' og 'hjemlig'. Lysatmosfæren er måske nærmere institutionaliseret med tydelig reference til belysningen i det offentlige miljø. Derfor arbejder projektet ud fra en hypotese om, at Ra-værdi og Kelvingrader ikke er nok til at definere en 'tiltalende hjemlig' belysning. Parametre som socio-kulturelle forståelse, den geografiske placering, lysets placering i rummet (horisontalt såvel som vertikalt) også har en betydning for hvordan belysningen opleves. Derfor stiller vi spørgsmål som: Hvad er hjemlig belysning? Hvilke præferencer har vi til belysning? Og kan man 
tale om en specifik måde hvorpå vi belyser vores hjemlige omgivelser?

Modellen 'Lysatmosfare' (fig 0.7 på forrige side) beskriver 4 kerneområder, der har betydning for kvalificeringen af en lys atmosfære, nemlig: 'Lyset', 'Rummet', 'Brugerne'og 'Tiden' Der skelnes mellem dagslys og kunstigt lys, lysets informationer og effekt som funktion, æstetik eller symbolik. Rumdimensioner, rummets placering materialer, overflader og genstande i rummet har også betydning for oplevelsen. Tiden og tidspunktet for ophold i rummet er også et parameter, man skal forholde sig til. Brugerne kan deles op i kategorier som 'Patienter', 'Personale' og 'Pårørende'. De har forskellige præferencer og behov. Rummet fungerer som arbejdsrum for personale, og patienter og pårørende er det et soveværelse, en dagligstue, en spisestue og nogle gange endda et toilet. Lyset må derfor kunne understøtte funktioner som læsning, samtaler med personalet eller pårørende, se TV eller måske at man går til hvile før den anden patient på sengestuen.

Modellen 'Lysatmosfare' er omdrejningspunktet i projektet hvorigennem den udvikles gennem en iterative proces. Først fungerende som en afgrænsning og brainstorm på feltet og senere som et designværktøj til at skabe lysatmosfære.

Herefter udføres eksplorative studier af præferencer for lys, lystrends gennem tiden, et studie af hvordan sengestuen kan optimeres ved zoneinddeling samt beskrivelse af personlig oplevelse af en indlæggelse. Derefter omsættes den opnåede viden til et eksperimentel 'RealWorld' studie hvor lyskonceptet installeres på en sengestue og evalueres med en Semantisk Miljøbeskrivelse.

Gennem projektet udføres 4 iterationsrunder. 1. runde beskriver "State of the art" og præsenterer teoretiske og visuelle aspekter af 'Atmosfare'. Studiets funderes teoretisk ved brug af Gernot Böhmes' atmosfærekoncept samt studier af arkitekters måde at designe atmosfære. Runde 2 udforsker brugernes præferencer og tendenser for lysatmosfære i fire eksplorative studier; først et studie præsentere observation af lysatmosfære på sengestuen. Derefter en undersøgelse af lyspræferencer i hjemmet samt lystrends gennem tiden og til sidst en zoneinddeling af sengestuen i et forsøg på at optimere lyset til bru- 
gerne. 3. runde er et experimentielt design studie, hvor en mock-up model af lysdesignet bliver installeret på en sengestue. I 4. runde undersøger måder til at evaluere en lysoplevelse. Sengestuens belysning bliver evalueret af patienter og sammenlignet med oplevelsen af belysningen på en referencestue. Til at evaluere patienternes oplevelse af sengestuen bruges en valideret metode "Semantisk Miljø Beskrivning" udviklet af Rikard Küller, der siden 1970' erne oversat til flere sprog. 



\section{JOURNAL PUBLICATIONS}

Mapping Light Atmosphere - Seen through the Danish interior Design magazine BO BEDRE.

Lone Stidsen, Niels Thuesen, Poul Henning Kirkegaard

Submitted to Nordic Journal of Architecture, 2012.

On Lighting Hospital wards - a cultural approach using light preferences as inspiration for the design concept.

Lone Stidsen, Henriette Bjerrum, Poul Henning Kirkegaard.

Submitted to Journal of Interior Design, 2012.

Experiencing Hospital Ward Lighting

- using Semantic Environment Description (SMB-Method). Lone Stidsen, Thorbjörn Laike, Poul Henning Kirkegaard, Submitted to Journal of Interior Design, 2012.

\section{CONFERENCE ARTICLES AND POSTERS}

Optimizing Lighting Design for Hospital Wards by Defining User Zones.

Niels Thuesen, Lone Stidsen, Poul Henning Kirkegaard, Henrik Harder, Valinka Suenson, Proceedings of first International Conference on Light 2011. Wessex Institute of Technology, UK,

Patients Light Preferences in Hospital Wards: related to light atmosphere in Danish homes.

Lone Stidsen, Henriette Bjerrum, Poul Henning Kirkegaard, Niels Thuesen, Anna Marie Fisker. Proceedings of first International Conference on Light 2011. Wessex Institute of Technology, UK, 2011.

Design Proposal for Pleasurable Light Atmosphere in Hospital Wards.

Lone Stidsen, Poul Henning Kirkegaard, Anna Marie Fisker, Jakob Sabra,

Colour \& Light in Architecture: international conference, Venice, 11-12 November 2010. red. / Pietro Zennaro. Venice: Luav University of Venice, Faculty of Architecture, 2010. s. 366-371.

Design Parameters for Evaluating Light Settings and Light Atmosphere in Hospital Wards.

Lone Stidsen, Poul Henning Kirkegaard, Anna Marie Fisker 2nd CIE Expert Symposium on Appearance - When appearance meets lighting... : Book of Abstracts 
The Design Parameters of Pleasurable Light Atmosphere in Wards.

Lone Stidsen, Poul Henning Kirkegaard, Anna Marie Fisker, Rasmus Lund Jensen,

2010. Abstract from 4th International Conference on Design Principles and practices, Chicago, USA.

Lighting Quality in Wards, Design Parameters for a Pleasurable Light Atmosphere.

Lone Stidsen, Poul Henning Kirkegaard, Rasmus Lund Jensen, Anna Marie Fisker.

Experiencing Light 2009: International Conference on the Effects of Light on Wellbeing : Adjunct Proceedings. Extended abstracts of interactive posters. Red. / Yvonne de Kort ; Wijnand IJsselsteijn ; Karin Smolders ; Ingrid Vogels ; Mariëlle Aarts ; Ariadne Tenner. Technische Universiteit Eindhoven, 2009.

\section{MAGAZINES AND OTHER PUBLICA- TIONS}

Lighting quality in hospital wards - State of the art : Design parameters for a pleasurable light atmosphere.

Lone Stidsen, Poul Henning Kirkegaard, Anna Marie Fisker. Aalborg: Aalborg University. Department of Civil Engineering, 2009. 37 s. (DCE Technical Reports; 63)

Lysatmosfære på fremtidens sengestue

Lone Mandrup Stidsen

CEEBELs nyhetsbrev Vol 3 nr 5

Lone Mandrup Stidsen writes the paper

Designmanual til venteværelset - afsnit om lys

Lone Mandrup Stidsen

2012, Region Syddanmark, Sundheds Innovation INVIA

Lys i psykiatrien

Lone Mandrup Stidsen

2012, Region Syddanmark, Sundheds Innovation 

TABLE OF CONTENT 


\section{SUMMARY DANISH}

SAMMENFATNING DANSK 23

\section{LIST OF PUBLICATIONS 29}

\section{TABLE OF CONTENT 33}

1 INTRODUCTION 39

$1.1 \quad$ Lighting design in Danish hosptials 41

1.2 Environmental aesthetics in healthcare environments $\quad 45$

1.3 Guidelines for hospital design 47

1.4 Design as therapeutic resource 50

1.5 Light in Danish context 52

1.6 Dynamic light 56

1.7 Research question and aims 63

\section{METHODOLOGY 67}

2.1 System of inquiry 70

$\begin{array}{lll}2.2 & \text { Strategies } & 74\end{array}$

Inductive and deductive approach $\quad 74$ Qualitative and quantitative methods 76 Real world studies $\quad 77$

$\begin{array}{lll}2.3 & \text { Tactics } & 80\end{array}$

$\begin{array}{lll}2.4 & \text { Summary } & 83\end{array}$ 
3. ON LIGHT ATMOSPHERE

3.1 Atmosphere and experience of architecture

3.2 Model of Light Atmosphere 96

3.3 Light Atmosphere 102

User 104

Space 116

Light 131

Time $\quad 139$

$\begin{array}{lll}3.4 & \text { Summary } & 140\end{array}$

4. EXPLORATIVE STUDIES

4.1 Admission to the hospital 145

Ward description $\quad 147$

4.2. Light preferences in Danish homes 152

Methods 152

Analysis $\quad 154$

Summary of preference study 158

4.3 Trends of light atmosphere in homes 162

Method 166

Categories evaluated 167

Analysis $\quad 173$

Summary of trend study 181

4.4 User zones at the ward 183

Method 185

Analysis of workflow 188

Summery of ward zoning 192

4.5 Summary of explorative studies 192

5. EXPERIMENTAL STUDY 195

5.1. Stages in lighting profession 197

5.2 Light atmosphere in hospital wards 199

The User 200

The Space 203

The Time 209

The Light 210

5.3 Visual presentation of the new lighting concept 214

High Lighting Scenario 218

Centre Lighting Scenario 218 
Low Lighting Scenario $\quad 219$

Lighting control 222

Summery of the lighting concept 223

5.4 Evaluating light atmosphere in hospital wards 224

Light Atmosphere Evaluation 226

5.5 The Semantic Environment Description 229

Data collection 232

Results 235

Summary 242

6. CLOSING 245

6.1 Summary 246

6.2. Conclusion 254

6.3 Discussion and future research 258

7. BIBLIOGRAPHY 263

8. APPENDIX 283

8.1 Appendix 283

$\begin{array}{ll} & \text { Letter to informants (in danish) } \\ \text { 8.2 Appendix } & 287\end{array}$

BO BEDRE analysis chart with illustrations
8.3 Appendix

Questionnaire: Light atmosphere

Evaluation (in Danish)

8.4 Appendix 309

Questionnaire: Semantisk Environmental

Description (in Danish)

8.5 Appendix

Selected files from Dialux documentation (in Danish)

8.6 Appendix

Room Categorisation in Sansernes hospital

(in Danish) 

1. INTRODUCTION<smiles>[CH]</smiles> 
"Art should not be explained at all, it must be felt and one must experience it to understand it. But through words and explanations, it can help others to experience art and that is what I will try to do”. (Rasmussen 1957)

An illumination in an architectural setting cannot be explained fully; not in words, pictures or illustrations. The experience of an illumination is based on more than the sum of the apparent details. Even though the task of describing light atmosphere seems impossible, this dissertation will attempt to explain important aspects of light atmosphere. The study introduces existing knowledge in the field of lighting design in hospitals, as well as provides new knowledge of sociocultural aspects of lighting design in a Danish context. To be able to introduce the area of light atmosphere and hospital, it is important to look at the context and question whether or not it is relevant to study light atmosphere in healthcare environments. In which context should the dissertation be red and what new knowledge does the study seek to provide? To answer these questions, the introduction will present the context of the study and underpin the relevance of the PhD study.

1.1

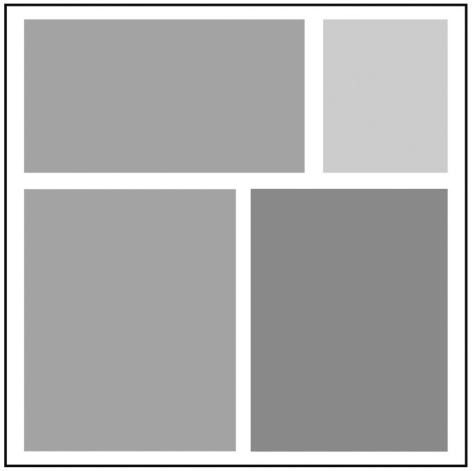

1.2

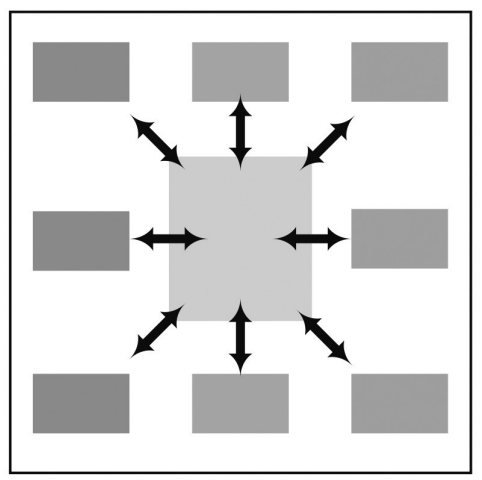

1.3

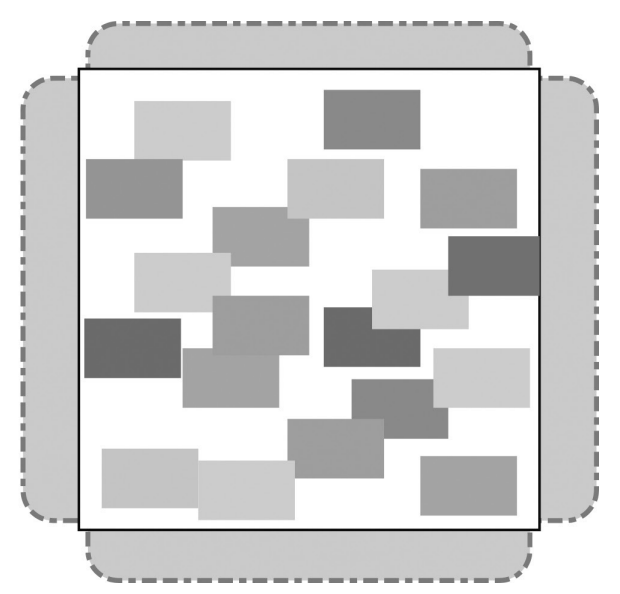


Fig. 1.1, 1.2, 1.3

Displays the arrangement of units through the hospital history. From 1.1 easy arranged plan, 1.2 show a hospital with attached specialities and 1.3 hospitals with many specialities, and with less space for each unit. The illustration is inspired by Heslets figure in Sansernes Hospital.

\subsection{LIGHTING DESIGN IN DANISH HOSPITALS}

Today the Danish government and the Danish Regions are investing around 41 billion Danish kroner in building 16 new hospitals in Denmark. According to the Danish Regions, the patients, staff and visitors are focal points and with the goal of sharing knowledge of hospital design, they have launched the homepage "Godt sygehusbyggeri" (Region Syddanmark). Some of the focus areas in the development of new hospitals are the patient's needs and preferences. With the aim of future-proofing the hospitals, the modernization of the hospitals and the new buildings has to support patient's needs in a way so the patient experiences a coherent procedure of an admission to a hospital (Danske Regioner).

The hospital has gone through a significant paradigm shift in the last 250 years. According to (Dirckinck-Holmfeld, Hornung et al. 2007), there have been different epochs of hospital designs throughout the history. First, the "Aesthetic hospital' which had fantastic aesthetic design but many hygienic problems and, second, the 1970s 'Machinery hospitals' which focused on function. To illustrate the epochs (Dirckinck-Holmfeld, Hornung et al. 2007) used the Danish national hospital 'Rigshospitalet' as an example. The first 'Rigs hospital' was called 'Frederik's Hospital' in the beginning. The hospital, belonging to the group of aesthetic hospitals, was characterised by only a few medical specialties as medicine, surgery and women's diseases and had a maternity unit. The different functional spaces were easy to arrange as seen in (Fig1.1). Later the hygienic hospital was built. Here, the design of the hospitals was divided into specialties, and the layout of the hospitals was pavilions including units as surgery and skin, child, and women's diseases (Fig 1.2). The patients were hospitalized in the pavilions and the doctors with the different specialties came to the patients in the pavilions. The third appearance of the national hospital is the one we know today. The main character of the hospital is technology. It represents a hospital epoch with many medical specialties and therefor a lot of different units, operations rooms and rooms for treatments (Fig 1.3). This kind of hospital is characterized by the lack of space and ungraceful interior design, but functional for the staff. 
Lighting design in Danish hospitals has not changed dramatically throughout history. Most hospitals in the last five years have been characterised by lighting techniques known from the "Machinery hospital". At machinery hospitals, the patient's needs and preferences are not at the top of important factors in the construction process. The illumination is designed to provide work lighting that supports the staff's needs. (Fig 1.4) Perhaps the design or the arrangement of light was "only" meant as something to provide light all over the space, and their thoughts of a pleasurable light atmosphere and preferences for light were not questions asked. The illumination provides sufficient light for the staff to see, but there is no apparent interest for the experience of the light and the ability of the light to stimulate the vision. Still, there was an exception at the old hospital in Nakskov where a luminaire was placed over a table arrangement for the visitors. The setting included table and chairs in a light zone; defining a "visitor space" and providing a welcoming place for visitors. But mainly the lighting design in machinery hospitals is designed to support the staff and not the patient. This machinery design has been distinctive for Danish hospitals over the years, however with some interesting lighting designs included.

In the $1960 \mathrm{~s}$, more experimental hospital designs were created. Herlev hospital (fig 1.5) is an example of interior experimentation. The artist Poul Gernes coloured the hos-

1.4

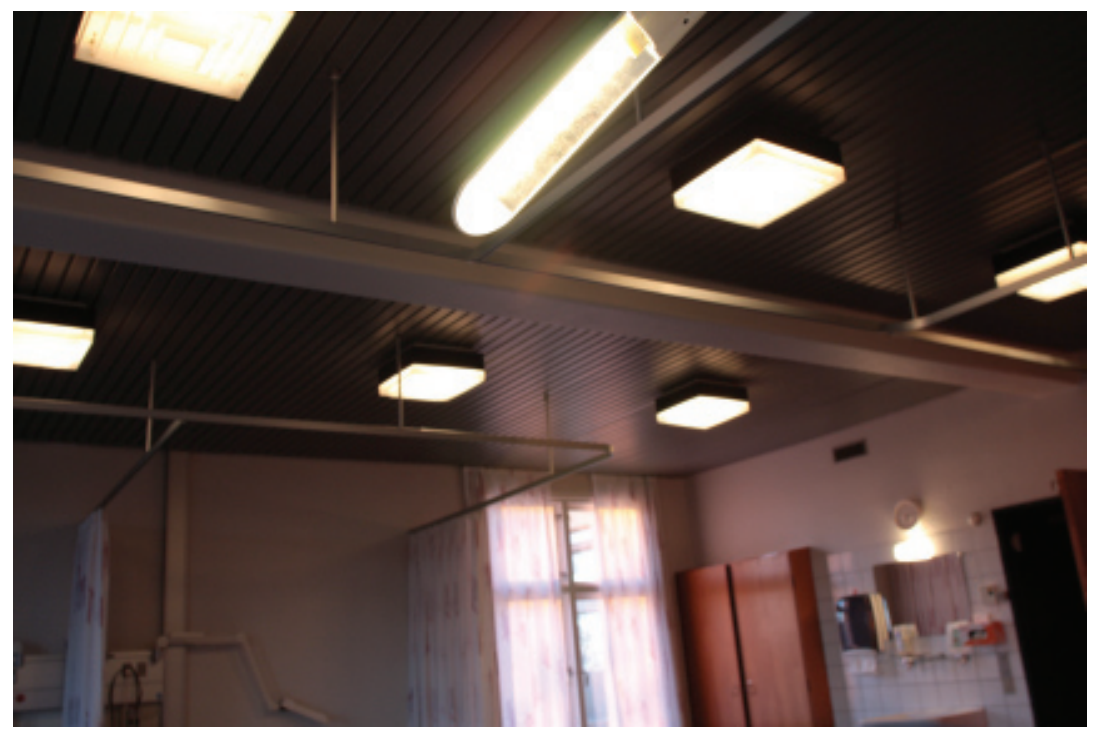

1.4

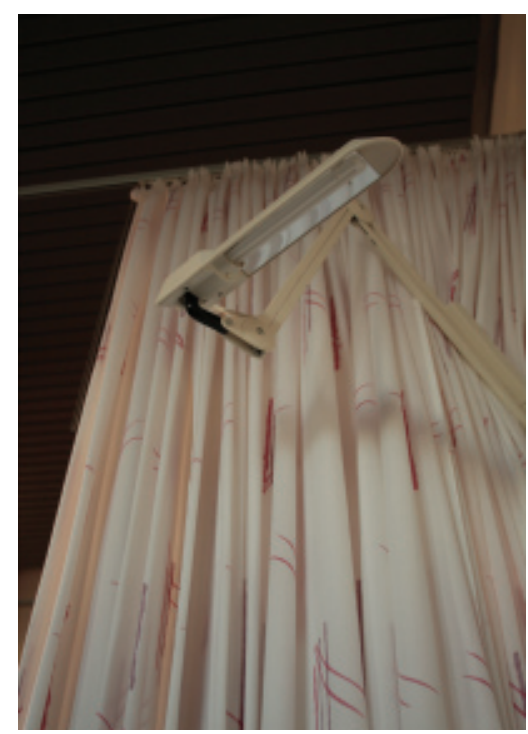


pital, and the aesthetic or artistic element was added to the machinery hospital. Here the artificial lighting design at the wards cared for patient needs and glaring problems were avoided by placing an up light luminaires over the headboard of the hospital bed and the patient's head. In this way, the patient was not laying down and looking directly into the light as in the example from Nakskov Hospital.

A few years ago in Kolding Hospital, the lighting designer Rune Tønnes(Sygehus lillebælt, Ingeniøren ) installed a lighting design in the intensive care unit. Here Tønnes, among many things, created a lighting control where the nurse could adjust the lighting according to the situation. The design is visionary and an innovative concept although I will claim that Tønnes design is too creative and the colourful illumination promise too much and the quality of lighting design can be discussed. At a lecture by Tønnes he presented the design as taking the best from the theatre lighting into real world settings. This can of course innovate the way of designing light, but it can also be problematic while it is not a scene, it is a reality and patients maybe need to stay in that reality. But the fact that nurses can provide an atmosphere suitable for several situations and the light can support activities is the right way to go, and the discussion on what light can do is going on.

Previously, the effects of physical environment in hospitals have been paradigmatically categorized in general research

Fig. 1.4

Traditional illumination of a hospital ward in Nakskov, Denmark. Ceiling mounted down light luminaires.

Fig. 1.5

Traditional illumination at Herlev hospital. The general illumination is an up light above the headboard, supported by a private bed luminaire.

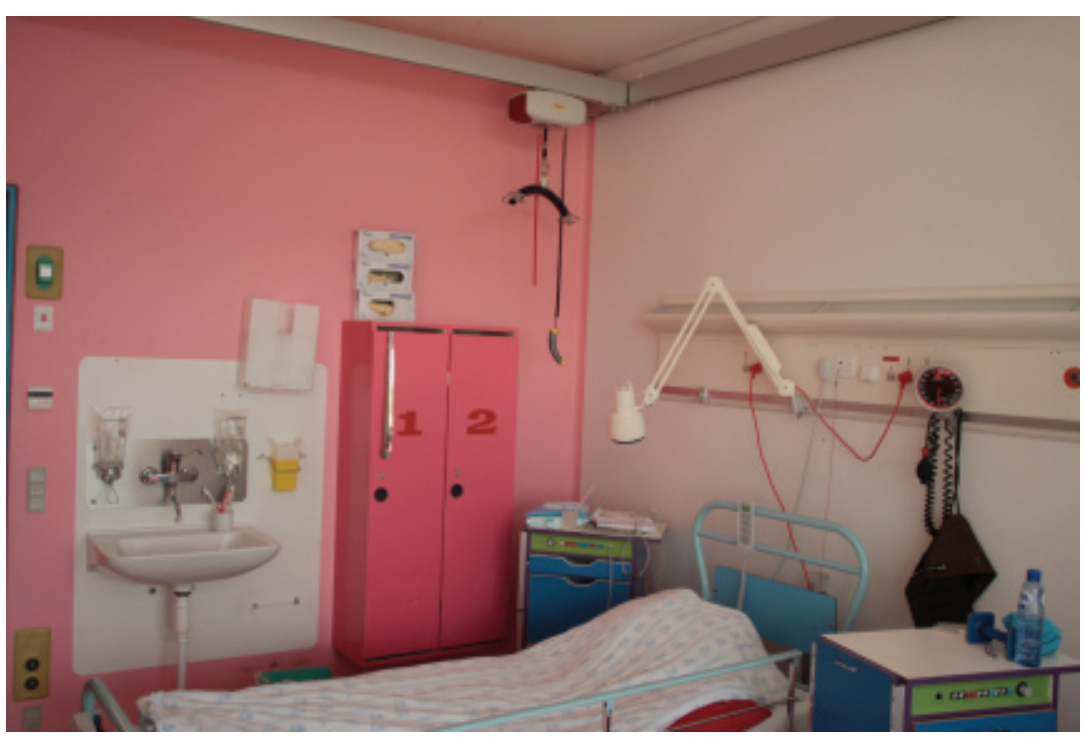


areas: stress reducing, improved outcomes, patients' safety and improved overall health quality of the hospital environment. Now, the physical environment seems to be asking for knowledge of the user's experience of space, sensory qualities of the architecture and human centred development included in the design of hospitals.

Looking into the regulations for illumination healthcare environment, the 'Directions of lighting in hospitals'was written in a third version in 1983. Dealing with designing light in Danish hospital wards a lighting designer has to comply the Danish regulation for light in hospitals DS703 (Dansk Standardiserings råd nov 1983) as well as the regulation in working environments DS700 (Dansk Standardiserings råd 2005). Visibility and visual comfort are clearly exposed as important in the text, but also the "message" of light is clearly defined in this way:

"For the general requirements of lighting that deals with glare, luminance distribution, light geometry, light colour, flicker and illumination refer to DS 700. The light should support patient needs and be shielded and arranged in a way so it doesn't create glare for patients in a supine position... For the remaining illumination the light colour must be selected to support patient needs for a pleasant and homely illumination, which in most cases means a colour temperature not higher than $3000 \mathrm{~K}$ and a relative good colour rendering Ra $>$ 80"(Dansk Standardiserings råd nov 1983).

The requirement makes sense as far as the patient needs to relax, and a glaring light can obstruct this activity. But what if a doctor or a nurse needs a brighter light for an examination? Then I am quite sure most patients will accept it for the time being when the doctor needs it. It would of course be unpleasant to have a light causing glare when the patients are by themselves in the ward. The quality of lighting design is mostly measured and evaluated in levels and horizontal light distribution. Specific measurable parameters as colour temperature and colour rendering seem to be relatively easy to define and to fulfil. But the question is whether it is enough to describe the light colour as the only parameter supporting the patient's needs for a pleasant and homely illumination. Is this definition sufficient for describing what a patient experiences as a pleasurable and homely illumination or could other parameters as direction, light zones, user experience etc. 
contribute to the definition?

While everything changes quickly in the lighting industry as well as in the knowledge of the impact of light, the direction may be ready for an update and benefit from knowledge of sensory qualities of light, user preferences and other aspects important for experiencing a pleasurable light atmosphere at the hospital.

\subsection{ENVIRONMENTAL AESTHETICS IN HEALTHCARE ENVIRONMENTS}

The idea of a healing environment is not new. Over 200 years ago, Florence Nightingale suggested patients would recover more quickly from illness if they were cared for in an environment that had natural light, ventilation, basic sanitation and cleanliness (Altimier 2004). Since then researchers have studied the sensory qualities hospital design in several ways. Some of the newer studies claim that the incorporation of a healing environment in a healthcare setting will not only optimize clinical care and outcomes, it will also optimize staff satisfaction, morale and foster repeat business (Altimier 2004). Altimier also points out that certain design choices and strategies work for or against the wellbeing of patients and staff, and that healthcare environments can lower stress and support wellness if they are designed to foster calming physical surroundings and promote access to social supports.

(Veitch 2008) points out the effect of lighting as important in a study of how a building affects health. Veitch accentuates results with lower mortality rates among cardiac patients, where the patients stayed in a sunny hospital room. Veitch also claims that parameters such as light exposures, annoyance of noise or light and the availability of a window view and at last overall housing quality influence human health. Regarding restorative environments, natural settings are particularly associated with restoration from stressful conditions (Kaplan, Kaplan 2003, Kaplan, Kaplan 2009). (Ulrich 1983) found that hospital patients in a room with nature view recovered faster from surgery than patients with a view to a brick wall. (Rashid, Zimring 2008) emphasise the fact that there is a great need to share knowledge among researchers on the studies concerning indoor environment with individual and/or workplace needs in healthcare and office settings. (Foqué, Lammineur 
et al. 1995) introduce a strategy bringing in a human scale in hospital design and focus on the patients, by claiming that a clear design strategy is needed to create a better end product introducing human scale within a high-tech environment. (Foqué, Lammineur et al. 1995) also notes that it is a complex and challenging process to design an attractive, stimulating recreational environment. It is important to have a holistic approach and consider the importance of age, mental and physical conditions, the stressful and burdensome working environment for the staff, the high-tech conditions of the medical profession versus the atmosphere of a family home, functional yet handicap friendly facilities and so on. Tackling the design problems with a set of defined conditions and a focused strategy, (Glind, Roode et al. 2007) sum up the history of patient-centred care and healing environment and claims that lately the impact on patients' physical and psychological comfort concerning healing and satisfaction have been emphasised. They provide examples of studies dealing with light, sound, ambiance, (fresh) air, green and nature, ergonomics and nourishment.

The role of light, the view and natural settings and bringing human scale into the hospital seem to be important factors for the experience of restorative environments, but still Veitch points out that more research is needed in this field (Veitch 2008, Veitch, Gifford 1996). (Boyce 2004) calls for more research to fully understand the impacts lighting has on health, wealth and safety of people, but no more of the same research. (Boyce 2004) claims that future lighting research in interior settings lies beyond visibility and visual discomfort in areas where lighting operates on mood behaviour through the "message" it sends and on the health and task performances through the circadian system. 


\subsection{GUIDELINES FOR HOSPITAL DE- SIGN}

The interest in hospital construction in Denmark is huge which induces discussions on several aspects relevant for the development process and the specifications of qualities to include in the buildings. Discussions as: Can architectural quality be valid knowledge? What to believe and what to forget, what is fact and what is not? In 2007, (Dirckinck-Holmfeld, Hornung et al. 2007) presented the book "Hospitals of the senses" (Danish translation: Sansernes Hospital). The book shared knowledge on the importance of sensory information in hospital buildings, and it was written in order to inspire architects and decision makers in future work as well as knowledge of healthcare architecture and stimulating environments. (Dirckinck-Holmfeld, Hornung et al. 2007) points out the fact that stimulating environments promote the recovery process in a way so the number of infections received in the hospitals as well as medication errors decrease. The hospital stay is shortened and the experience of a hospital stay is improved. Users such as the staff benefit from lesser stress, complaints from patients decrease and finally there are economic benefits of building hospitals in a new way. (Dirckinck-Holmfeld, Hornung et al. 2007) emphasizes the importance of a more holistic and stimulating approach to hospital design. A stimulating environment combined with the technology and staff knowledge will assist a healing process for the patients and provide better working conditions for employees.

Two years later, (Frandsen, Mullins et al. 2009) introduced 'Healing Architecture' into a Danish context. The aim of the study was to provide proper evidence to include in the design of the new hospitals so architects and designers would have easy access to evidence concerning hospital design. Frandsen presents a model, which summarizes the present challenges for the Danish healthcare system and the design of new hospitals. The model categorizes three primary parameters: 'Physical Environment', 'Factors', 'Consequences', The 'Physical Environment' is seen as the location, disposition, plan, interior design, materials and equipment. The parameter 'Factors' is defined as body (light, art, sound, air and movements), relationships (personal space, social space, outdoor) and safety (hygiene, damage and defects). Lastly, the 'Consequences' parameter is understood as physi- 
ology (healing, pain, immune response, infection, sleep, circadian rhythm, appetite, exercise, length of hospitalization, re-hospitalization, medication errors, accident / decrease, mortality) and as Psychology (comfort, stress, anxiety, calmness, distractions, trust, confidence, depression, seclusion, mourning, control, access, satisfaction, communication, concentration, motivation, mood / happiness, orientation) and financial (sick days, economic, work-related injury, resignation).

Before the Danish interest in healthcare environments started to increase, other researchers were showing interest in the subject. The Norwegian professor in architecture (Cold, kolstad et al. 1998) collected abstracts on theoretical and empirical research within environmental aesthetics. Cold found that the roots to aesthetic preferences originate from surviving nature, meaning preferences originate in our common sensory perception, which has been developed for thousands of years of surviving in natural environments. (Cold, kolstad et al. 1998) also found that preferences are shaped by cultural norms and influenced by the social and the built environment and the knowledge structure and emotional experience of each people.

Nature and natural elements and even simulations and symbolic images of nature appear to have a positive impact on people's wellbeing and health. Daylight is of course one of the natural factors which appears to be crucial for wellbeing and health and even better if the daylight is combined with a pleasant nature view.

'Environmental coherence' is essential for understanding the environment. Therefore, it is important that the user of the environment is able to 'read' the environment and to feel secure in it. Coherence is perceived when things are in order and 'fit together' somehow. It is also important that the room has an appropriate richness and complexity producing positive stimulation. A pleasant, exciting and calm environment makes us feel well. People do not prefer one specific style of architecture, but feel attracted to qualities such as high degrees of coherence, low contrast, medium complexity and high order. Familiarity and novelty must be balanced. There should be enough novelty to evoke curiosity, but an appropriate amount of familiarity to prevent overstimulation or overload of 
new information. Generally, certain qualities in the built environment appear to be preferred independently from people's knowledge structure, emotional experience and interest.

Lastly, (Cold, kolstad et al. 1998) claims that there is a need for "real life" studies and more research is needed because there are many unanswered questions on the effect of environmental aesthetics. 'Light and health' (translated from Swedish 'Belysning och Hälse') published by Work and Health provides a summary of the importance on modulation of light, spectral distribution and the chromobiological impact. (Sandström, Bergquist et al. 2002)

In UK, a report on light and colour for Hospital design concludes:

"A properly designed visual environment, with the appropriate use of colour and lighting, will have important benefits in hospitals. A relatively small investment in good, thoughtful colour and lighting design may reap major dividends over many years for patients, staff and visitors" (Dalke, Littlefair et al. 2004, Dalke, Little et al. 2006, Loe, Perry 2000).

Looking into Healthcare design in US' (Ulrich, Zimring 2008, Zimring, Bosch 2008), presented a review of research literature on 'Evidence-Based Healthcare Design'. Zimring explains 'vidence Based Design' as a design modelled on evidence-based medicine, where clinical protocols are based on systematic reviews of the research literature that evaluate the quality and quantity of research supporting the efficacy of specific clinical decisions. Ulrich found a growing body of rigorous studies to guide healthcare design specifically with respect to reducing the frequency of hospital-acquired infections. Ulrich concludes that the state of knowledge of evidence-based healthcare design has grown rapidly, and that evidence indicates that welldesigned physical settings play an important role in making hospitals safer and more healing for patients and a better work place for the staff. Regarding the effect of light (Ulrich, Zimring 2004) studied the role of the physical environment in the hospital of the 21 th century and found studies that linked the environment to patient and staff outcomes as a part of the design process. The effect of bright light - both natural and artificial - can improve health outcomes in cases of depression, agitation, and quality of sleep, circadian rest-activity rhythm as well as the length of admission for patients suffering from de- 
mentia or seasonal affective disorders (SAD).

\subsection{DESIGN AS THERAPEUTIC RE- SOURCE}

As the presented research shows, design can be used as therapeutic research. Vijk, nurse and researcher in colour and light support this. (Vijk 2012) points out that design could be regarded as a therapeutic resource to promote wellbeing and functionality among patients. She also points out one specific problem. The problem of people falling is increasing and $49 \%$ of 80 -years- olds have one or more falls per year, $2 \%$ having ending in hip fractures and $60 \%$ fall again within one year. Therefore, she points out that light and colour in the environment can help a patient's navigation in the environment and enhance visibility. In her presentation at the Ph.D. course 'Nordic light and colour', she also refers to daylight effects and what a higher degree of exposure to daylight implies: it reduces depression, length of stay as well as perceived pain and need of analgise. It increases the quality of sleep, wellbeing, job satisfaction and attention, and further more decreases staff stress. She also refers to research on adapted illumination, which has been shown to decrease errors in medication, and concludes that being exposed in variation to light intensity during night shifts promotes attention, adaption and quality of sleep.

(Malkin 2008) presents a visual reference for Evidence Based Design and points out important parameters to consider when designing restorative environment. He mentions connection to nature, the possibility to choose between privacy and socialization, and seating options. Positive distraction is also significant as well as social support like access to team members in an informal setting. Elimination of environmental stressors is also crucial and he recommends use of indirect lighting, the ability to dim lights in specific areas of the room and use of acoustic ceiling to absorb sound. Malkin also presents examples of several healthcare interior designs showing best practice referring to Evidence Based Design.

The book includes important parameters in interior design and the overall impression of the book that it is useful reading for interior designers working in healthcare settings. It must be mentioned, however, that the book presents a specific American aesthetics. The choice of co- 
lour combination and material used in the designs will not been found familiar in a Danish context. In Danish hospital interior design tradition, several design choices differ from the picture Malkin presents. To illustrate the differences, representative pictures were chosen, see fig. 1.6 Cleveland Clinic, US and fig. 1.7 Medicinerhuset, Aalborg, Denmark.

Fig 1.6 The first picture illustrates an American style of interior design and fig 1.7 illustrates the interior design from a relatively new hospital in Denmark. Some of the

Fig. 1.6

Cleveland Clinic, Naples U.S., FL. Marxhall Erdman \& Associates (architecture and interior design) Picture taken from 'Visual Reference for Evidence Based Design', page 7.42

Fig. 1.7

Medicinerhuset, Aalborg, DK. Friis \& Moltke (architecture and interior design).
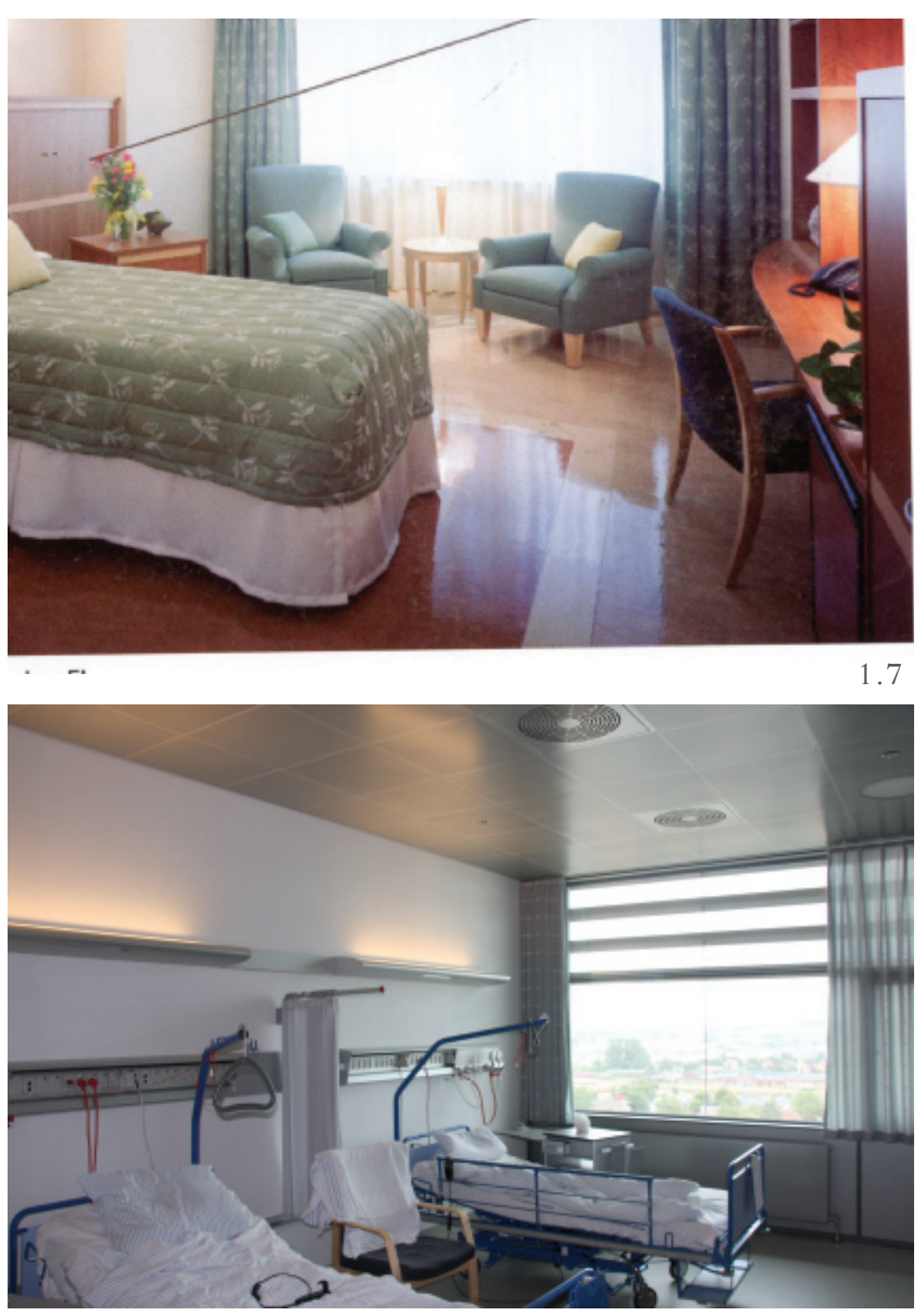
differences clearly represented in these pictures are the choice of materials and colours. The American design choice seems to be wood and a special greenish colour palette various kinds of textures and shapes of the objects, voluminous and rounded. In contrast to a Danish tradition of straight lines, greyish colour palette, minimized textures represented and steel and linoleum flooring. I would claim that many Danes' first impression of the American design would be of a hotel room with visual reference to a hotel interior design and not a hospital. Designing a patient room using the visual reference for Evidence Based Design in a Danish context could be problematic, because the reference to a hotel can also lead to ideas of the patient's room being less hygienic than the traditional Danish design choice and even be anxious about the treatment procedure. So the visual reference to Evidence Based Design seems to be an interpretation of Evidence Based Design in an American context. That poses two questions: Do we have a cultural understanding of design? What is the impact on expectations for quality and what would it mean to design an illumination in a Danish context?

The example of American interior style shows that it can be problematic to use concepts or metaphors as models for hospital design, because the design has to fill specific needs unique to the situation. The interior design indicates a code of conduct, and designing a hospital ward with too many references to hospital design can also induce other expectations for a hospital stay. In a hospital ward, the patient can basically expect a public atmosphere where he/ she is taken care of, and it is less private as for instance staying at a hotel. No matter what kind of interior design is chosen for the hospital wards, it can have consequences for the experience of staying at the hospital.

\subsection{LIGHT IN DANISH CONTEXT}

After a visit in Denmark, V. S. Neipaul, the west Indian Nobel prize winner in literature, said:

"For me the word Scandinavia evokes no other things than fear and the word Scandinavia is a word of ice, death and grumpy intercourse".

In a letter to Neipaul's friend and author Paul Theroux, he explained his view and experience of being in Denmark. 
Fig. 1.8.

Sketch and drawings of refelctions in the luminaire design Septima by Poul Henningsen
"If you have an interest for horrible places, I can recommend Denmark as a place to visit. Every one lives in small beautiful houses, but no one is rich and no one has the opportunity to live in luxury and every one is correspondingly depressed. Every one lives in their tiny cells with Danish furnishing and wonderful luminaires without which they would be insane. (Sørensen, own translation)

V. S. Neipaul's statement of his impression of Denmark is quite clear and he was obviously not impressed with seeing Denmark and the Danes. The only thing impressive enough to be mentioned was the beautiful luminaires. Perhaps because of a boring context, the lamps stood out and became more beautiful. In general, however, Denmark has a notable tradition in lighting design, and has introduced an aesthetic parameter and hygienic light as a term and is especially excellent in reflecting light in a luminaire. (Hansen, Jørgensen et al. 1994). As shown in fig 1.8, designer Poul Henningsen, 1894-1967, designed artificial light and created luminaires with a special interest for the reflection of the shades. His interest was to design a perfect luminaire without creating glare. The next fig shows a collection of comparable pictures displaying different illumination techniques and the effect of different luminaire designs. The pictures give an idea of how light can manipulate the experience of a space and how the placement of light and shadow has an impact on the visual impression of objects in the space. At these pictures, it is easy to see how differently the chairs appear in the space.

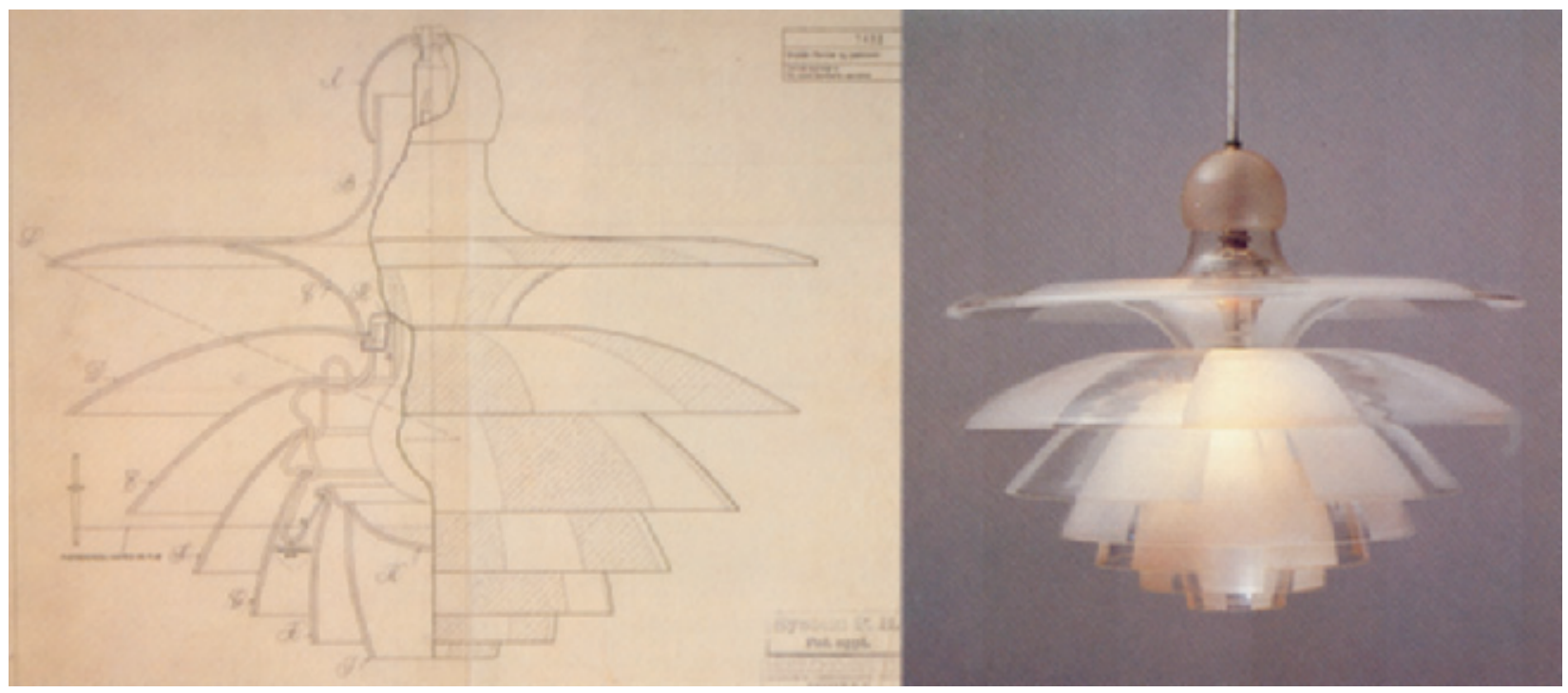



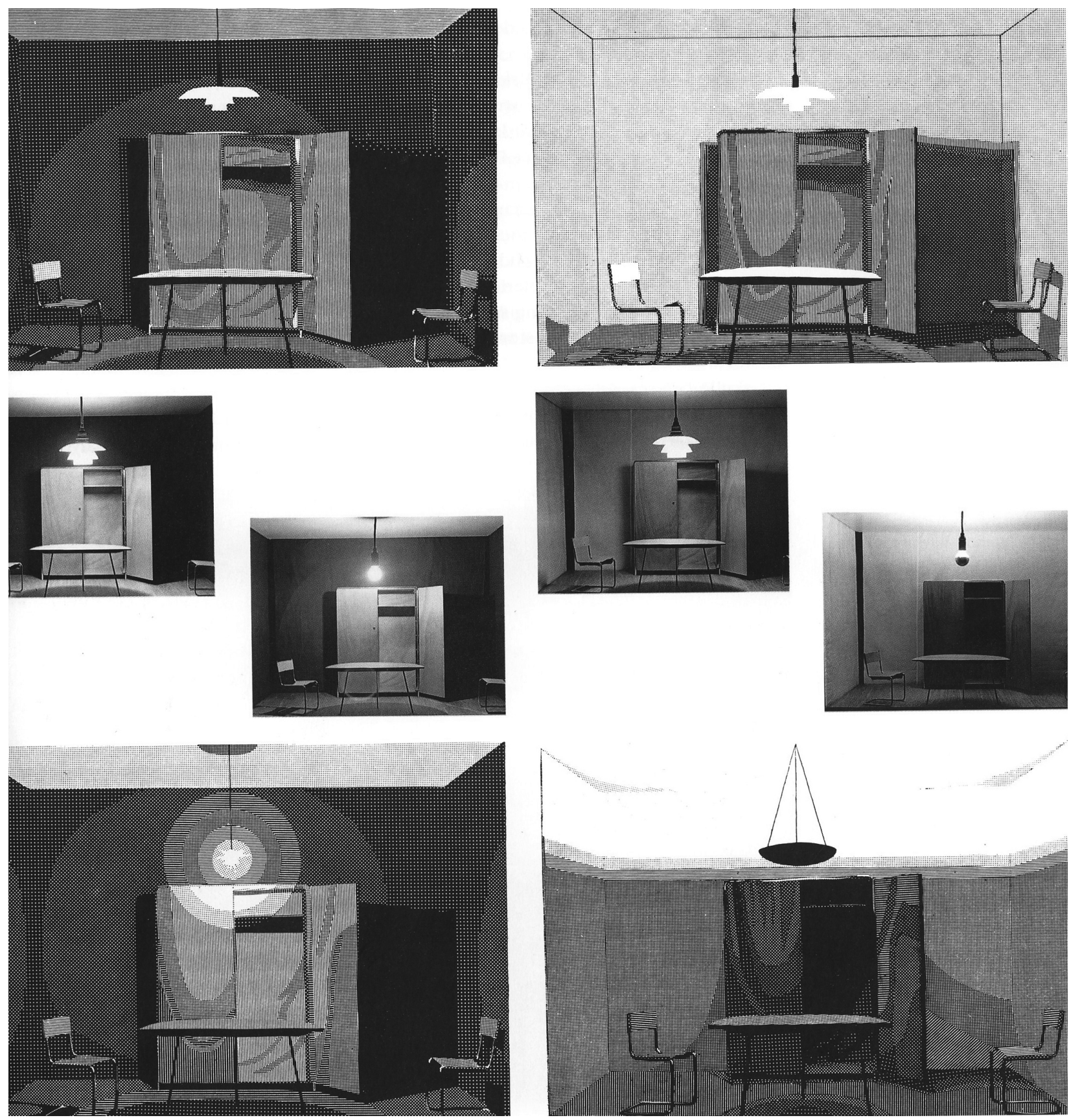
Poul Henningsen also draw light schemes displaying the effect of different lighting techniqes and showed the light effect in the spatiality of the space (Fig. 1.9).

Looking into Danish tradition of using light as an essential element in architecture, the school "Skolen ved sundet" is an important and essential piece of architecture focussing on daylight. The school is an example of functionalistic architecture where light, air and hygiene are important elements in the design. Kaj Gottlob designed the school in 1935-1938 and was one of the first in this tradition. And the design sent out a social political message by providing light and fresh air to the working class children. Everybody going to school deserves a welcoming architecture. (Coninck-Smith 1989)

Fig 1.9.

The spatiality of space is displayed in different types of illumination. Sketch by Poul Henningsen (Hansen, Jørgensen et al. 1994)

Fig 1.10

Skolen Ved Sundet, Kaj Gottlob 1945-1939

Picture: Royal Library, Copenhagen

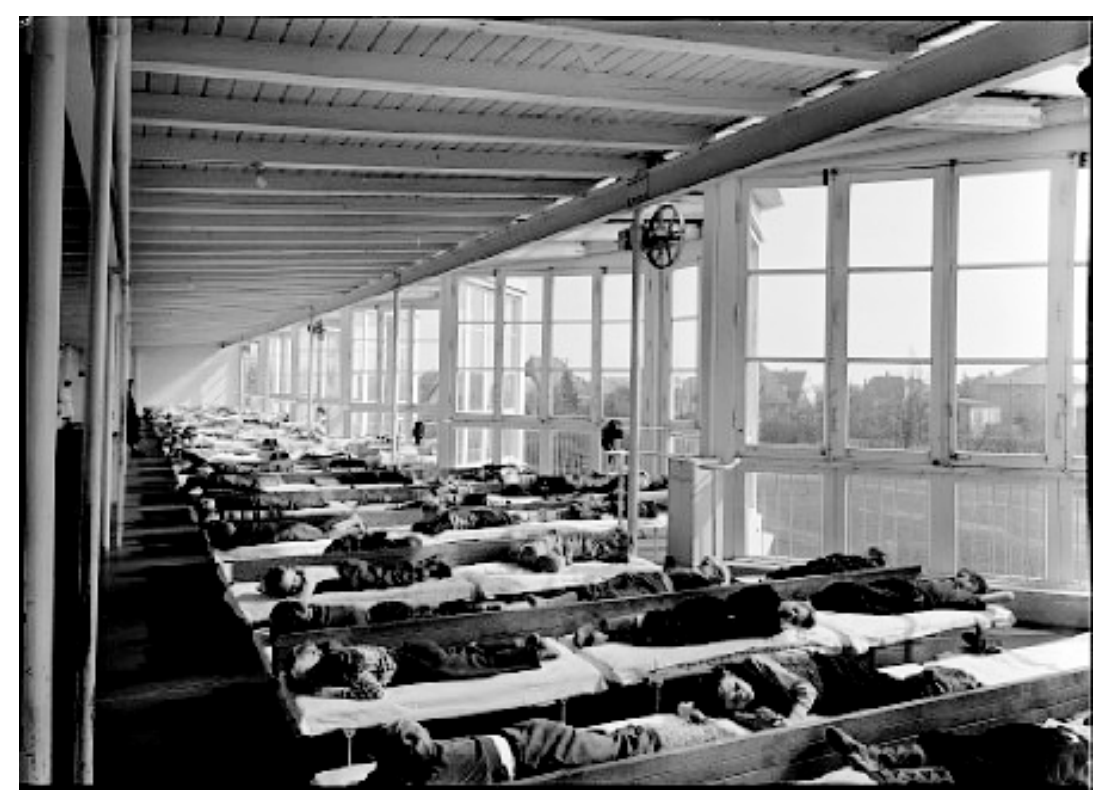


The interest for light and light's impact on the environment as well as the users of the light was established many years ago and is not a new phenomenon. But what is a typical Danish light situation? And what characterises the Danish daylight? Here are some of the central qualities daylight pose and qualities interesting to include in an artificial lighting design:

- The dynamics of daylight and the way daylight play a role for the peripheral vision. Light changes in intensity when clouds pass by or when surfaces reflect the light. It creates diverse experiences of texture in a space changing from glittering, reflecting, absorbing or mat.

- The direction and movement of daylight on its the route from sunrise to sunset. Shadows change throughout the day and are thereby also a parameter in the experience of the space.

In a visual study of daylight (Fig 1.11), the focus was on the shadow effect and how shadows can change according to the lighting situation. The study was only guided by daylight effect and the object was a branch in a floor vase just next to a wall. The picture shows how the shadow pattern on the wall changes in a period of three minutes. (18.marts 2008)

\subsection{DYNAMIC LIGHT}

Danish daylight is unpredictable and unstable all year round. Danes always talk about the weather. How has the weather been the last couple of days? What do we expected for the coming days? The weather is interesting because Danes cannot take the weather for granted, because it is so unpredictable. Living in a place where the sun always shines from a clear sky in summer time and maybe few days with overcast during wintertime makes the subject unnecessary. Another reason for 'dynamic light' being a popular topic is the finding that light has an effect on the circadian rhythm and that variation of light can reduce energy assumptions. The term "dynamic light" has been used in many ways, but the topic has many facets and is interpreted in several ways.

Dynamic light is highly recommended for office lighting. A lot of research points have gone into the fact that light
Fig 1.11

Shadow pattern on a wall in a period of three minutes on a cloudy day in march 2008. Copenhagen 

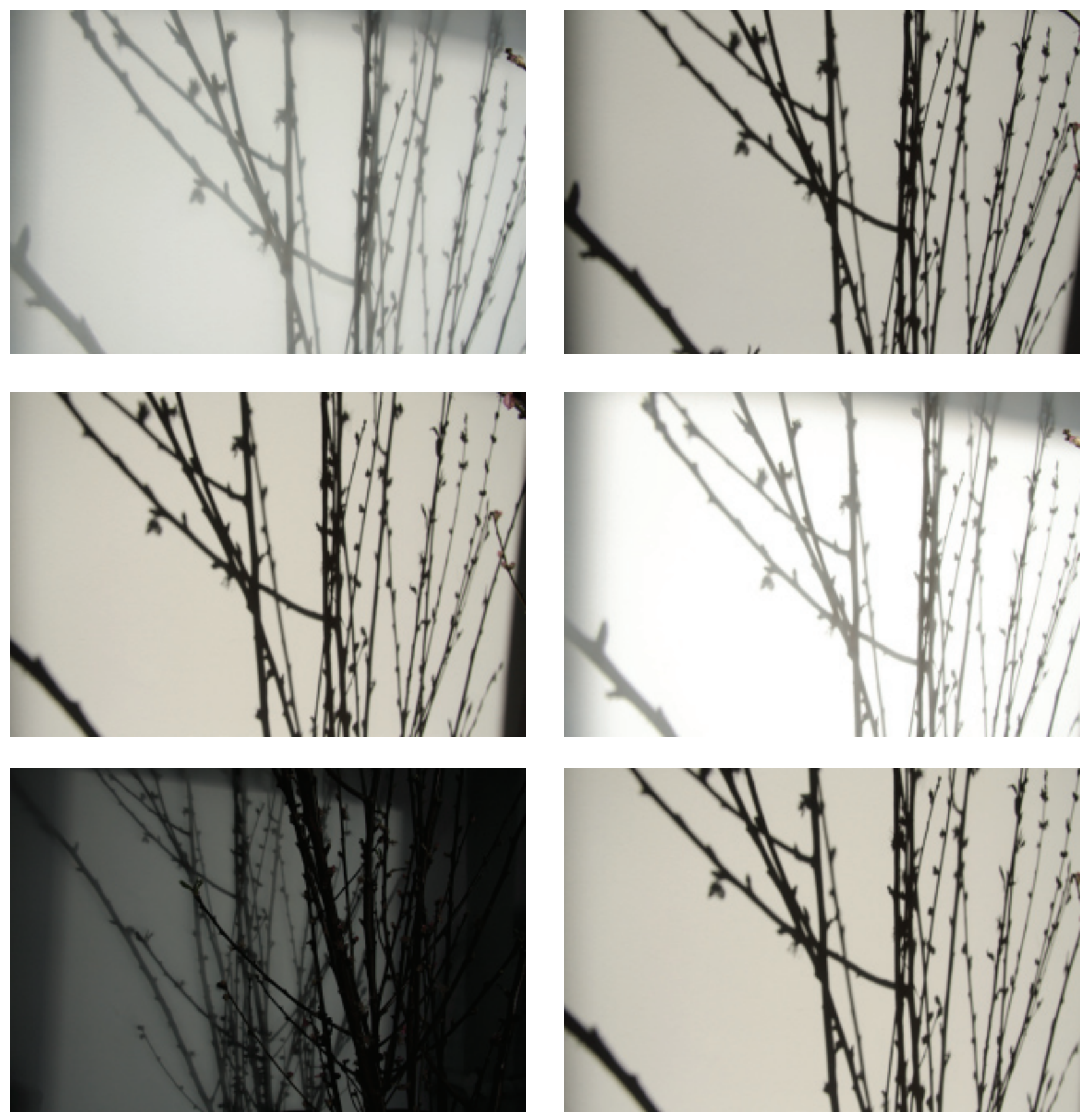
can have an effect on people's mood (Knez, Enmarker 1998, Adeniji 2006, Knez 2001, Quartier, Van Cleempoel 2008, McClughan, Aspinall et al. 1999). Studies have also been made in dynamic lighting (Boyce, Veitch et al. 2006, Abildgaard 2009, Butler, Biner 1987, Madsen 2008, Møller 2006, Nielsen , Rothstain ). The selected studies point at different qualities of dynamic light and the term "dynamic" is a flexible character. First of all, a dynamic light can be said in the sense of the change in light temperature or intensity of the light distributed in the space. Secondly, a 'dynamic light' as individual control and individual preference and dynamic in the way it can be used. Companies like Philips Lighting selling dynamic lighting solutions defines 'dynamic light' both individual and dynamic as:

"Dynamic Lighting brings the dynamics of daylight indoors. With seamless changes in brightness and warmth it creates a stimulating 'natural' light that enhances our sense of well-being. A flexible solution that can be adapted to different needs and moods, enhancing lives with light."(Philips Lighting)

On the same page, they says,

"Our bodies are affected by the rhythm of night and day. The dynamics of daylight set our body clock and influences well-being”. (Philips Lighting)

This statement is backed up by (Rea, Rea 2006, Veitch, Gifford 1996, Christoffersen 2006, Boyce 2003) among others. Philips also presents and tests lighting design in healthcare environment. One example is the "Heal well" project, which is a total lighting concept for patient rooms. It is developed specifically to address people's visual, emotional and biological response to light. The concept is tested in a hospital in Maastricht, and has created a unique healing environment designed to support patient recovery and improve the hospital experience. A video is available at Philips homepage where the daily rhythm of light is displayed. (Philips Lighting)

Another Philips project is the "Adaptive Healing Room" (AHR). The room concept is for patients recovering from a stroke or other brain injuries. The room concept helps them to orientate and it provides sense of time as well as 'dosing' a suitable level of sensory stimulus. (Philips Lighting). 


\subsection{2}

Light show "Fire at Kolding Hus" orchestrad by Lighting Designer Jesper Kongshaug.
"A patient doesn't experience each component of a room in isolation, and in the AHR we wanted to ensure every ingredient in the space worked in harmony with each other and was tailored to the needs of the patient," says Behere (Philips Lighting).

Philips also claims that there is a large body of evidence that suggests that the more a patient stays connected to the natural rhythms of time and nature, the better the chances of a speedy recovery.

The software used in the room concept is programmed with a 24-hour cycle. The cycle dictates how each element of the room works and thereby how it creates an "adaptive daily rhythm" among other things with the light level.

Looking to other disciplines than lighting designers in the built environment, stage lighting is one of the places we experience a dynamic light. The professional stage lighting designers are known for being very talented in changing atmosphere by adjusting the colour of light, intensity and direction in a way, so the scene change atmosphere from

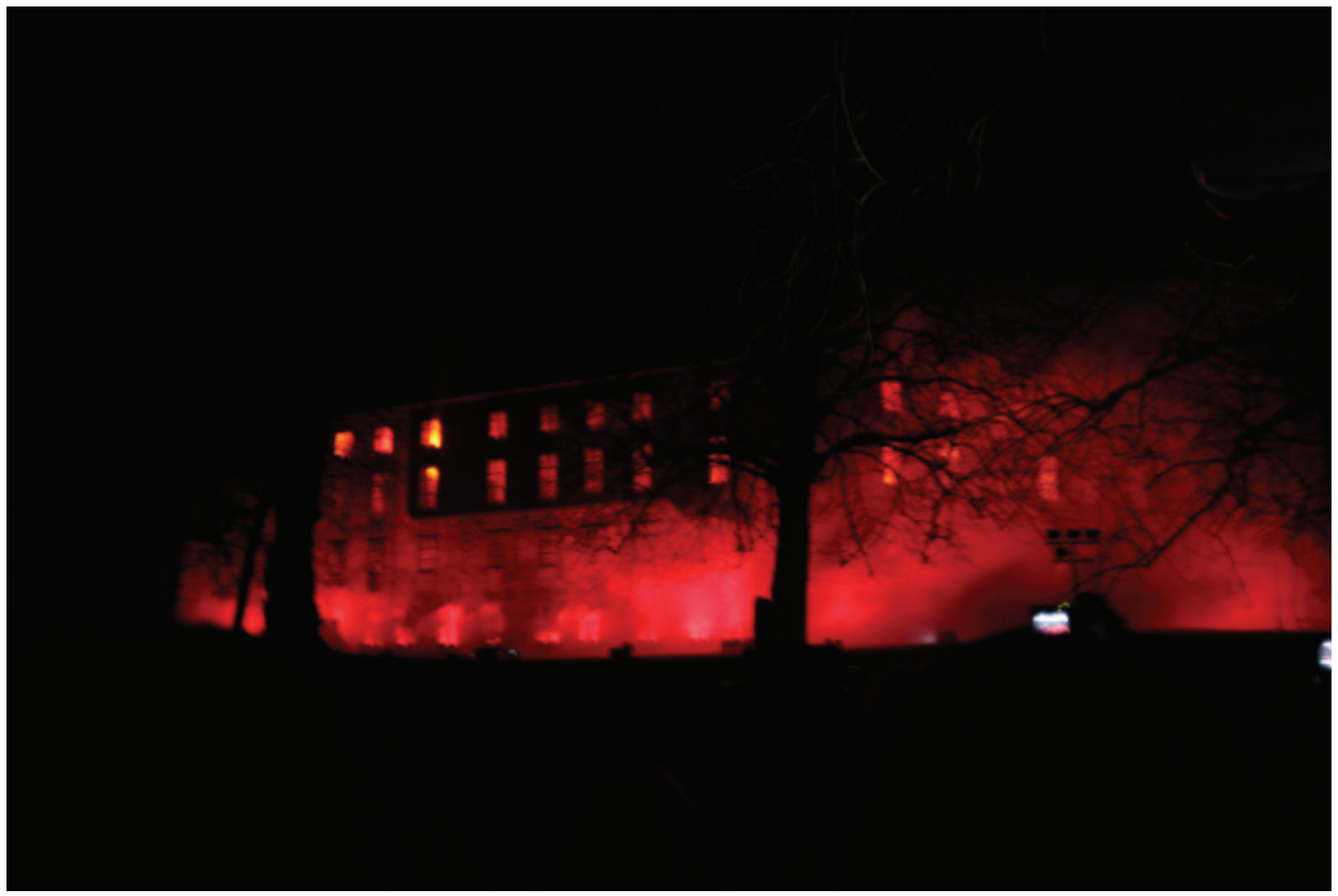


minute to minute. Lighting designer Jesper Kongshaug demonstrated in a show at Kolding Hus, Denmark, how it would feel if a castle were on fire. I participated in the show, and it was amazing how realistic the fire looked and created a very dramatic scene. Except from the heat effect, it felt quite authentic and was a somewhat scary experience.

The theatre lighting is often dramatic and overplayed in order to create a certain atmosphere and to provoke a certain mood. In a less dramatic way, the illumination of hospital ward could be inspired by stage lighting and the technics used for creating atmospheres and dynamic qualities. It is important to be aware of the user perspective and the differences in being hospitalised or being a visitor in a theatre.

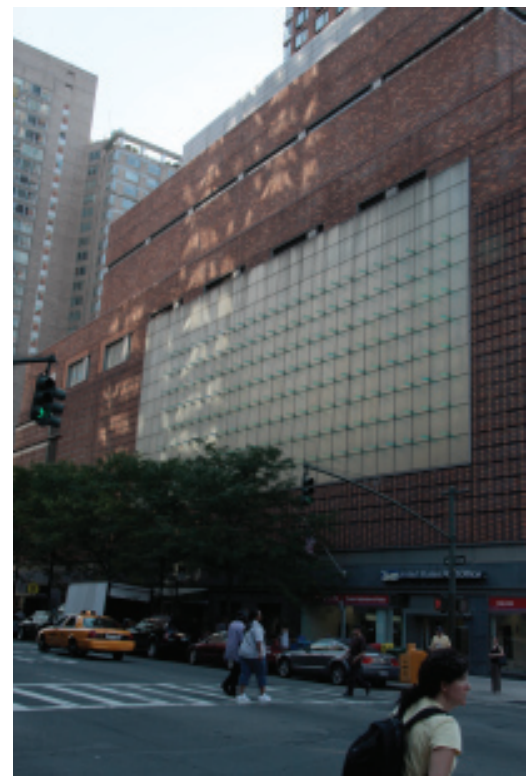

1.14

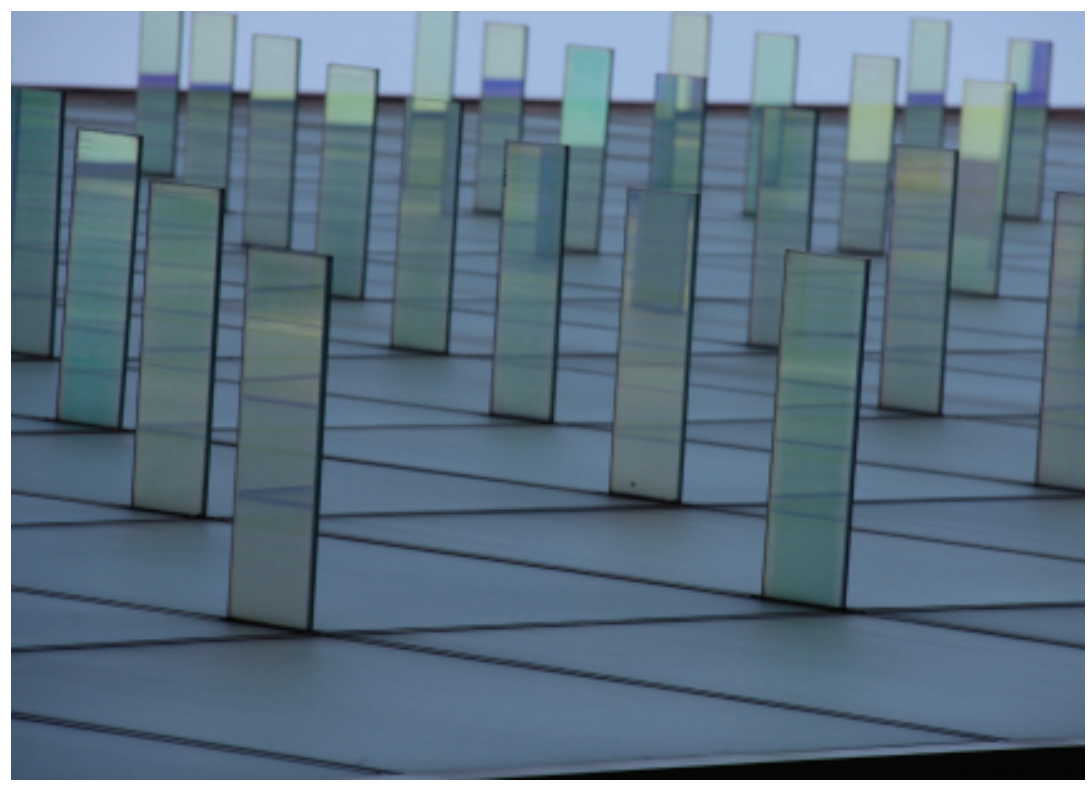


Fig. 1.13

Art installation by James Carpenter, New York

Fig 1.14

Detal of diachronic filterArt installation by James Carpenter, New York

Fig 1.15

Drawings of view.

Art installation by James Carpenter, New York.
Architect and lighting designer James Carpenter presents dynamic light in the environment in his work. (Fig 1.13, 1.14, 1.15)(Marpillero 2006). Carpenter points out two levels of information of light telling us about our world; a'Conscious Observation' that becomes the framework for our memory and 'Uunacknowledged Visual Information' that becomes the substance of our dreams. According to Carpenter, light can provide unacknowledged visual information and be the substance of our dreams. The art piece presented in (Fig 1.13,1.14,1.15) is installed at a north faced wall, on a building in a street in New York. The diachronic filters in the glass reflect and direct the daylight in a way so the light is distributed to the other side of the road and at the wall creating delicate light patches and beautifully decorating the wall.
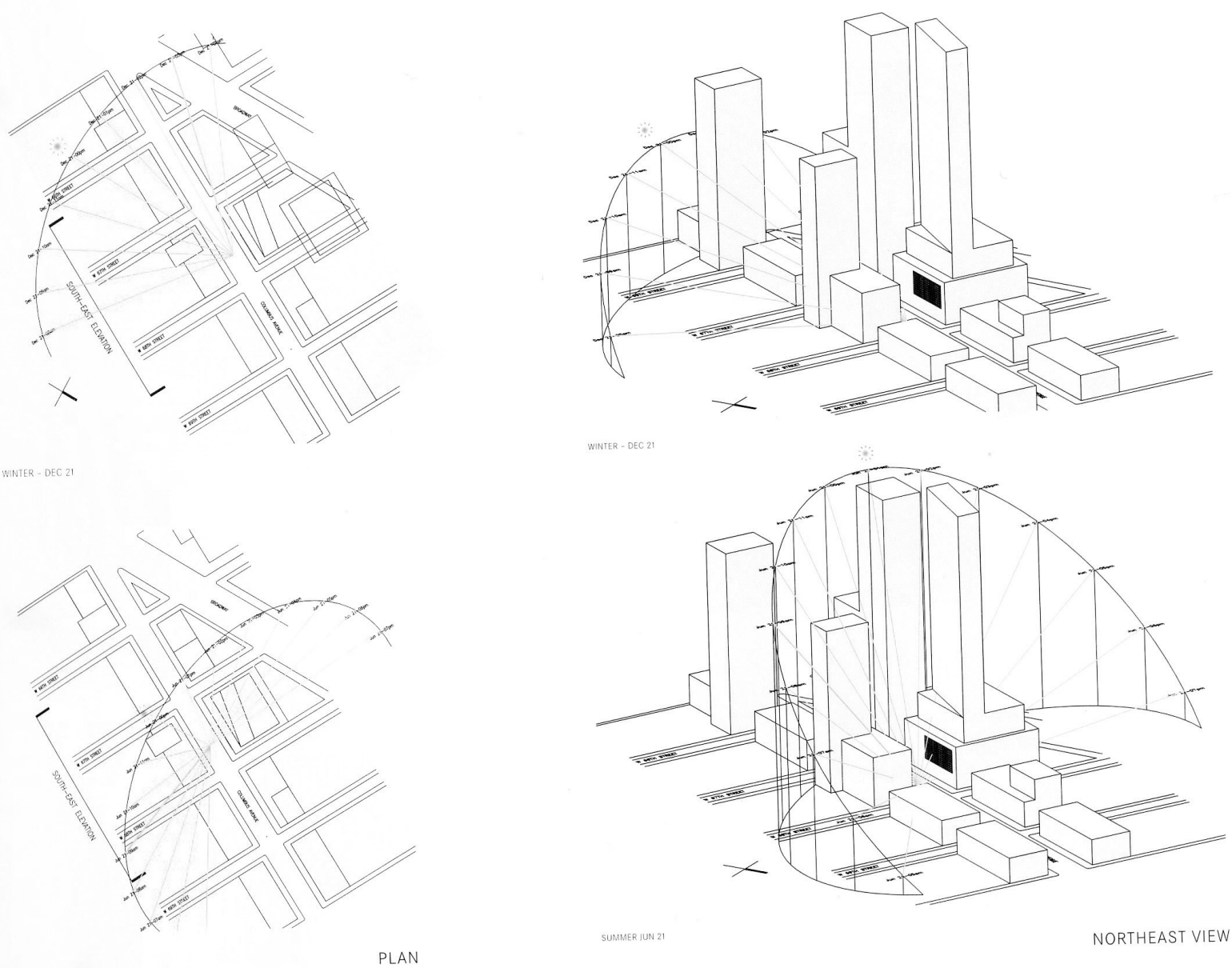

NORTHEAST VIEW 
Another effect of the dynamic of light is the acceptance that light is different from time to time. One day we might prefer dim light and other day's bright light. In 2008, I participated in an exhibition at the library in Kolding, and the design group (Line Dalby Gundersen, Britta Børsting, Christina Augustesen and Lone Mandrup Stidsen) contributed to the exhibition with a collection of objects in the category 'Spring - with a taste of cress'.

The aim of the contribution was to provide a piece of springtime into the exhibition, and one of the installations was a chair and a projected window (fig 1.16). Here, the visitors could sit and enjoy a one of the first "sunrays" created by artificial light. The idea behind the piece was to

\subsection{6}

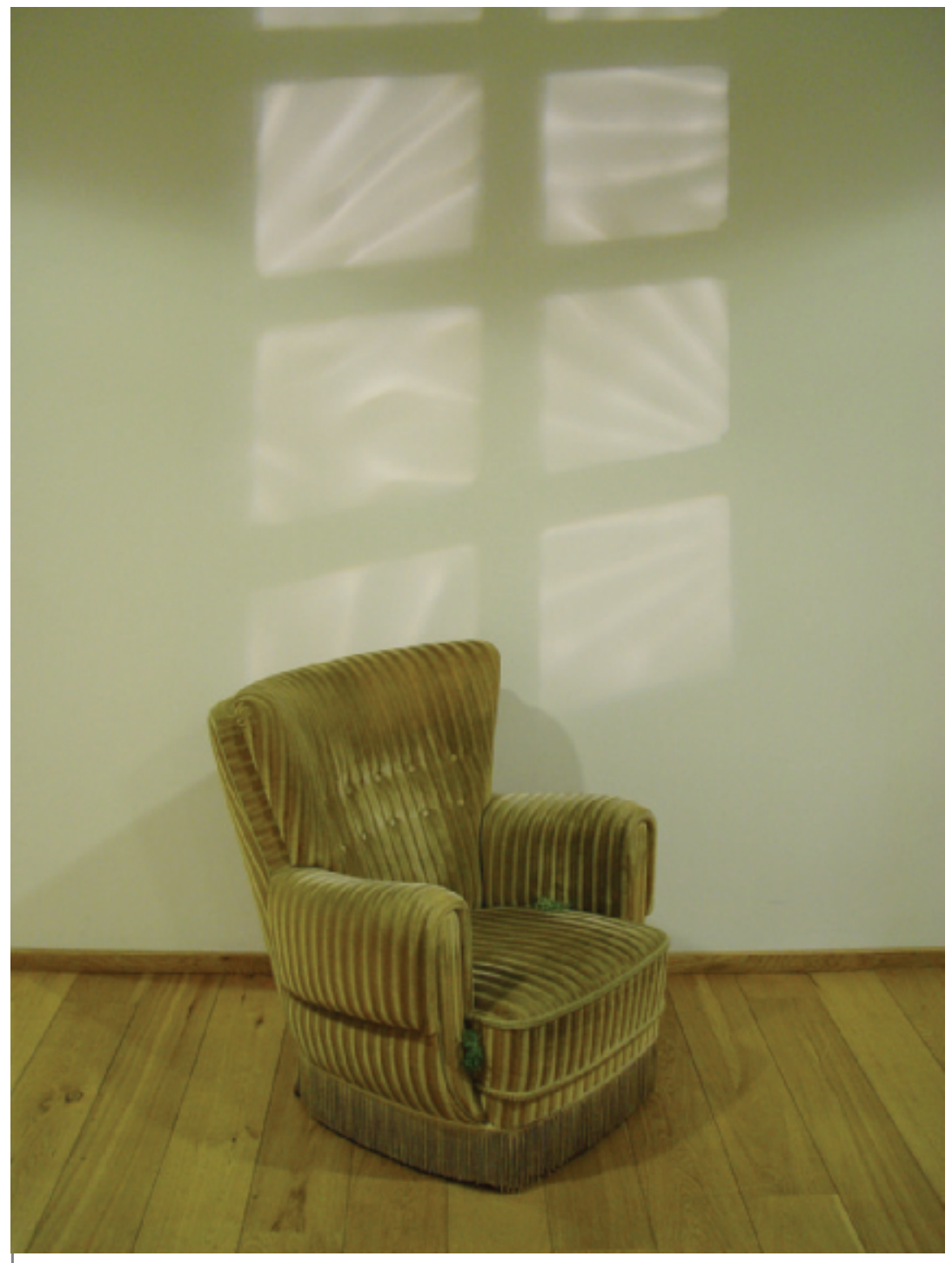

Fig. 1.16

An art installation from the exhibition 'Spring - with a taste of cress', Kolding, Denmark 2008 
provide an experience of springtime. In springtime, many Danes crave sitting in the sun, even enjoying the glare from the sun and feeling the heat of the sun. This desire of being blinded by the sun is perhaps logical due to the lack of sun we have through the wintertime. Later in the summertime, we are not that interested in the sunrays or being blinded by the light. Our acceptance and preference for the light and the sun seems to be seasonal, and in this way also dynamic in a seasonal way.

The examples of dynamic light in this discussion have different understandings of the term 'dynamic' In this study, dynamic lighting has contributed with knowledge to the fact that the variation of light can be an important parameter in a lighting concept, but also that dynamic light has many facets. I will not question the fact that dynamic light can have an effect on performance, biological impacts etc. I will, however, challenge the idea of a direct transition from the dynamic of daylight to a programmed sequence of artificial light changes in intensity and colour. I would dispute the idea that artificial daylight rhythm is experienced as daylight. One argument is that the body knows that we are inside a space and therefore familiar with the fact that daylight comes from a window. It could indicate a need for studying the effect of the placement of luminaires and the impact of light direction. So, in this study, dynamic light is used as a term for how the light creates shadows and how the shadows can support the daylight rhythm by being dynamic where the light patches and shadows are. The dynamic of the artificial light thereby creates an illusion of a daylight situation.

\subsection{RESEARCH QUESTIONS AND AIMS}

The history of hospital design is moving away from the machinery hospitals to now focusing on the patient's needs and preferences. The illumination of the wards seems to be similar throughout history with small adjustments, although lately there have been innovative examples of the lighting design, e.g. The Intensive Care Unit in Kolding. (Ingeniøren 2011) Maybe the similarity of lighting design is a natural consequence of the time with regard to energy and economic considerations. Perhaps the design of ward lighting needs to be studied more if the light should support the activities in this multi complex space. The Danish interest for light, luminaires and light's impact on health 
seems to be grounded in the Danish culture. But still we do not know much about preferences for light or not enough. The preferences for light have not been documented yet. Therefore, it seems beneficial to create explorative studies of light preferences so as to gain knowledge on a unspoken subject and to get answers to questions you did not ask and in this way become more informed on the subject and be better suited to ask new questions.

The concept of 'dynamic light' seems to be undefined. We need more research on how we experience 'dynamic light' and whether it is enough to interpret 'dynamic light' as "a luminaire providing a simulation of daylight rhythm in intensity and colour temperature" or "dynamic lighting supporting the daylight and thereby creates a more stable illumination in a space". It seems reasonable to explore these interpretations of dynamic and study the phenomenon in a Danish context by looking at shadow patterns.

Even though the guidelines provided have created more interest for research based design or Evidence Based Design in healthcare environments, there seems to be other factors not included in these studies that explain how the built environment has an impact on health and wellbeing. The architects now have a possibility to base the design on evidence, but more research is still needed.

There seems to be an agreement on the complexity in designing healthy and recreational environments, and a holistic and patient-centred approach is needed. Real world studies are required where users are able to read and feel secure in the environment. Patients must be able to recognise that things somehow "fit together" and that the surroundings have an appropriate richness and complexity, which cause positive stimulation. A balance between familiarity and novelty must be achieved in a way so there is sufficient novelty to evoke curiosity and an appropriate amount of familiarity to prevent overstimulation or overload of new information. The question must be what we find familiar. What is a high degree of coherence, low contrast, medium complexity and high order in a Danish context?

The contention of a pre-understanding or a cultural and familiar understanding affects our assessment of the environment and needs to be studied more closely. If the 
assessment of the surroundings is affected by an illumination, it seems logical to create a lighting design with coherence and balance between novelty and familiarity, so the user experiences an illuminated space where everything 'fits together'.

Therefore, the main interest of this study is to elaborate on a sociocultural aspect of light and to point out neglected or unnoticed parameters of a Danish cultural understanding of light atmosphere. In this way, the study contributes the knowledge of sensory qualities of lighting design. The goal is therefore to create knowledge about light atmosphere and to develop a model of light atmosphere to use as design tool as well as a structure for the PhD study. The research questions and the aim of the study are:

To identify the important criteria for the experience light atmosphere in hospital wards presented by a 'Model of Light Atmosphere'. How can a 'Model of Light Atmosphere' work as a design tool and how can it be described systematically?

To explore preferences for light atmosphere in a Danish context. What kinds of illumination do the users of a hospital ward need? What kind of light preferences do Danes have in their private sphere and what kind of illumination are we familiar with in relaxing environments? What is homely illumination seen in a Danish historical perspective and what are the trends of illumination through the years?

To design and test illumination for hospital wards and create a 'RealWorld Study'. How can the illumination provide a pleasurable light atmosphere in which way do the patients experience the wards? 

2. Methodology $\bigcirc$ 
"Optics, developing in us through study, teach us to see".

The study on light atmopshere will seek to be trustworthy in the approach and will be a designer doing research. As a designer being aware of one's own skills, I am also aware of the importance of gaining knowledge from other experts. The designer collects the right materials and combines it in new ways. They are not experts in all disciplines they handle in a study, but orchestra the information from experts in a way that make sense.

The definition of experts in this project is not 'academic people', but person who has expertise in one specific practice as well as theoretical or academic skills. It is not a question of educational training, but a question of experience, and this knowledge can be gained through practical as well as theoretical experience. The study always seeks to link information in substantial combinations and keeping an eye on the whole as a facilitator of combining information from different fields of knowledge.

(Groat, Wang 2002) introduce methodology in architectural research and display the design research process described as'Systems of inquiry', 'Strategies' and 'Tactics'. Groat and Wang claim that a research design is framed by a researcher's assumption about the nature of reality and thoughts about how it can be achieved These kinds of assumptions are called 'Systems of inquiry' in this dissertation also known as what Kühns called paradigm (Rasmussen, Østergaard 2009, p. 21). Both terms convey the notion of a worldview and an ultimate truthfulness that cannot be established. The system of inquiry frames both 'Strategies' and 'Tactics'. 'Strategies' and 'Tactics'. clarify the relationship between midrange of methodology and the more specific level of techniques; we distinguish between the 'Strategies' (method) and the 'Tactics'.(techniques).

The term 'Strategy' is defined as 'Skilful management and planning of anything”. 'Strategy' is also seen as the research design and defined as "an action plan for getting from here to there". "Here" describes the research questions and "there" describes the knowledge derived from the research. Between "here" and "there" there are some steps and procedures that may emerge along the research proceeds and these will be described subsequently.

The term 'Tactics'. is in contrast to 'Strategy'; a more de- 


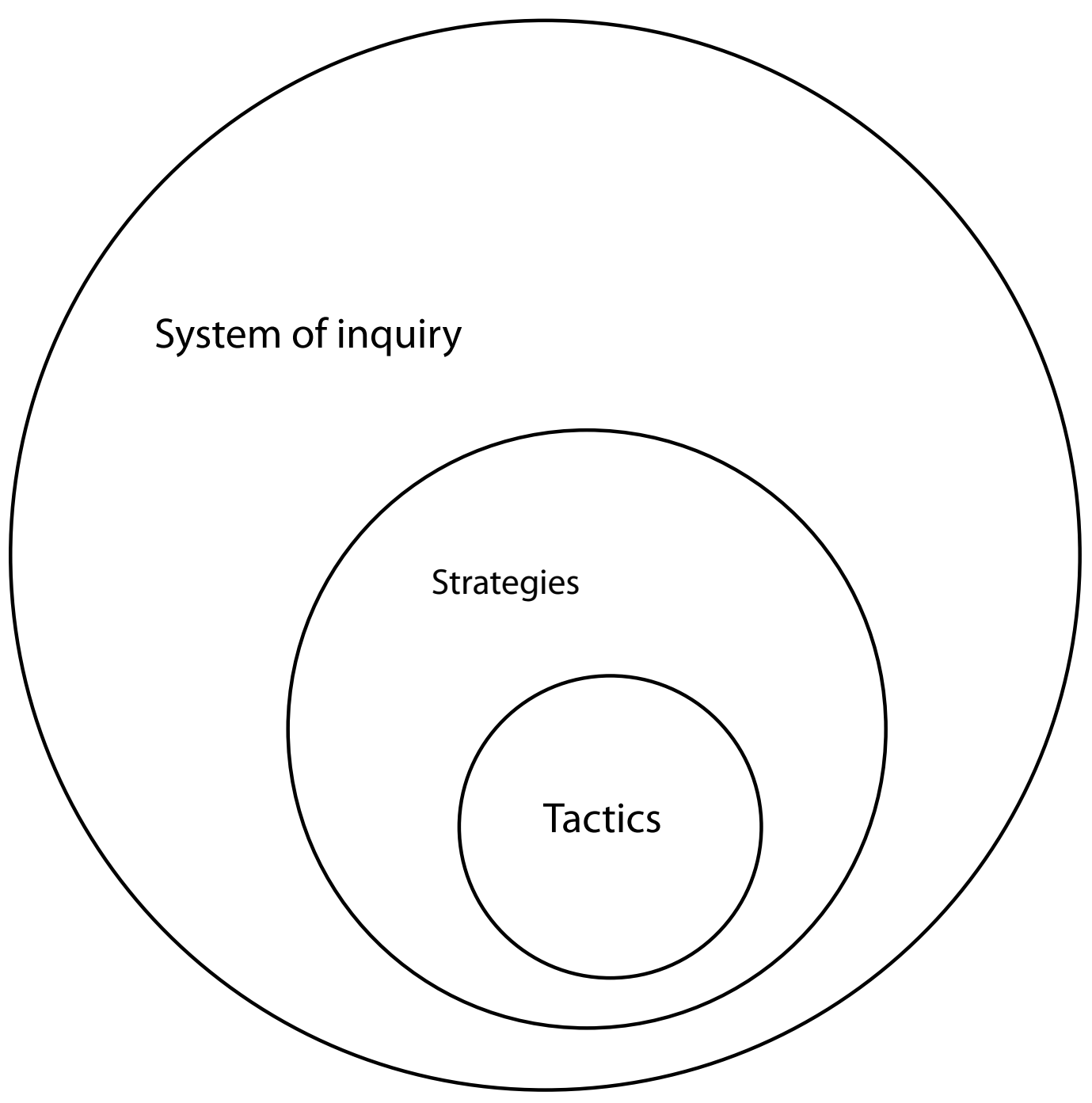

Fig. 2.1

System of inquiry, strategies and tactics. Model after (Groat, Wang 2002) tailed level defined as "any skilful move". That means that the 'Strategy' is the overall structure of the research study and "Tactics" are the specific techniques used, e.g. data collection devices, response formats, archival treatment and analytical procedure. The methodology used in the present study uses Groat and Wangs terminology: 'Systems of inquiry', 'Strategies' and 'Tactics'. to describe the approach of project and methods used to investigate light atmosphere in hospital wards. 


\subsection{SYSTEM OF INQUIRY}

A design practice requires knowledge of a vast array of phenomena ranging from physical properties of materials to principles of visual perception. It is therefore not surprising that the research within design requests a broad range of methods through the process; from creating a design to evaluation of a design. While the main interest of this study is to elaborate on a sociocultural aspect of light and to point out important parameters of a Danish cultural understanding of light atmosphere, there is also a pre-understanding of the subject and a cultural approach to the term quality. The'Systems of inquiry'will set the scene in which the study is carried out.

A design process should never be a linear process or a direct progress of solutions. The process is iterative, going from "here" to "there", making loops of intuitively creative periods as well as analysing and systematic periods. therefore the design process is the complete presented study and not only the experimental study presented in chapter 5. The experimental study is seen as a loop and all the loops create different directions, investigating details to prove a whole. In this way, an abstract idea of a design gets more specific and improved by studying details. Following a hermeneutic tradition, identifying the subjective life world and making interpretations of subtopics contributing to the whole process in general characterize the PhD study.

Figure 2.2 displays the iterative process starting out with a pre-understanding of the phenomena and building up an abstract model, followed by examples of real world phenomenon leading to a new understanding of the phenomenon. While the process does not go from 'here' (pre-understanding) to 'there' (result) in a linear process, this figure displays a process from 'here' to 'there' through explorative and experimental studies making $1+2+3 \ldots 4 \ldots 5 \ldots$ cycles of iterations. In this way, the design study consists of cycles and continues through the process, going from an abstract model to a specific and concrete design solution.

Theoretically, the iterative process can be described as the hermeneutic circle. A visual illustration of the process is often shown as a spiral or a circle. It is commonly used in connection with analysing texts, but is also used in many other contexts. The hermeneutic circle describes 
Fig. 2.2

Real World Phenomenon studies and cycle of itterations in the study. the process of understanding communication hermeneutically. It refers to the idea that one's understanding of communication as a whole is established by a reference to the individual parts and one's understanding of each individual part by a reference to the whole. That means that neither the whole communication nor any individual parts of the communication can be understood without the reference to one another; hence, it is a circle. However, this circular character of interpretation does not make it impossible to interpret communication; rather, it stresses that the meaning of communication or any data set must be found within its cultural, historical and literary context.

The German philosopher Martin Heidegger (1889-1976) developed the concept of the Hermeneutic Circle in 1927. This was to envision a whole in terms of a reality that was situated in the detailed experience of everyday existence by an individual (the parts). In that way, an understanding of a subject was developed on the basis of "fore-structures" of understanding that allow external phenomena to be interpreted in a preliminary way (Lambert 2003, Wikipe-

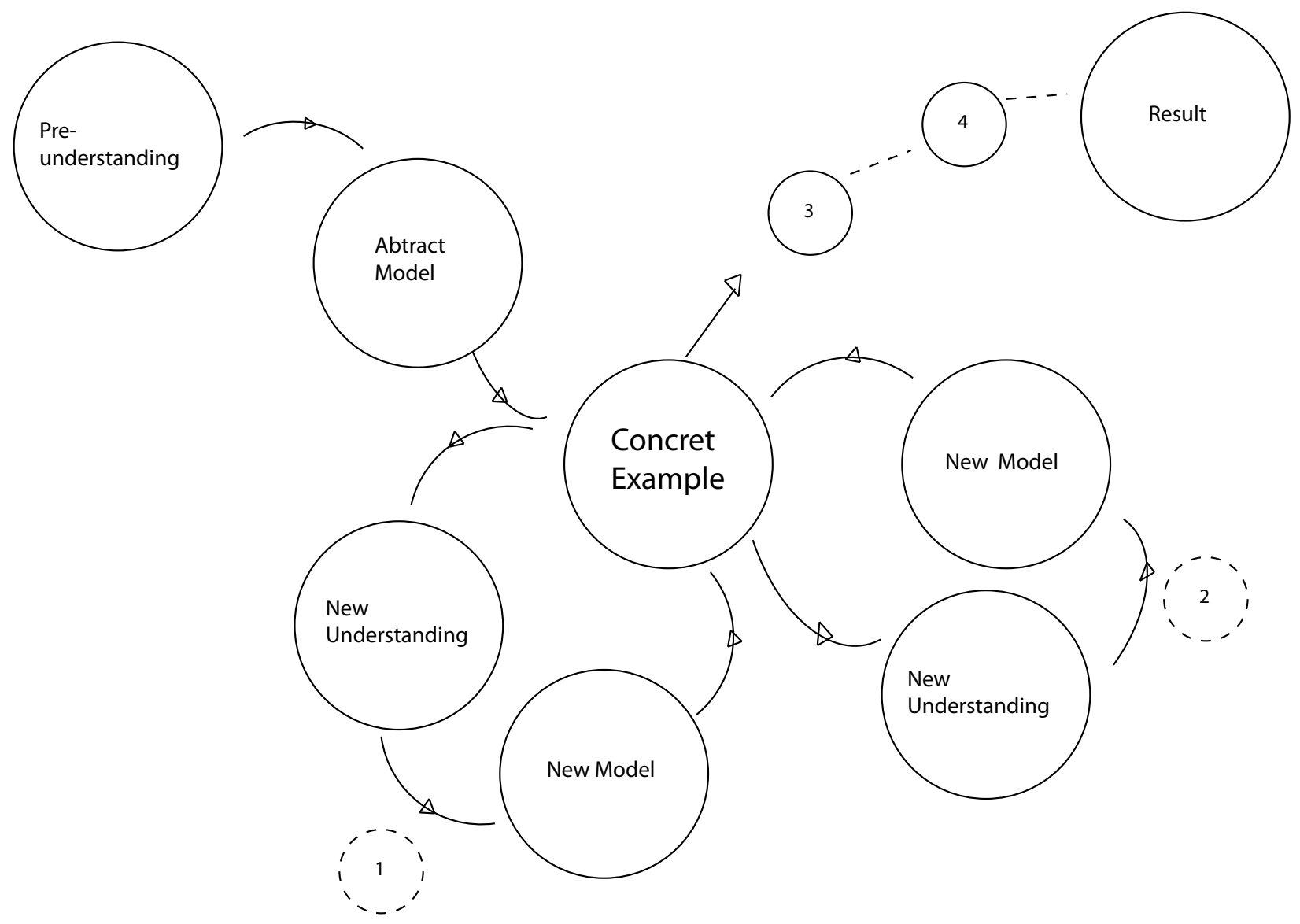


dia.). Gadamer contextualised the hermeneutic circle as an iterative process through which a new understanding of the whole reality is developed by the means of exploring the detail of the existence.

In the present study, the hermeneutic circle is used in two ways. Firstly, it is employed in the process of building up the 'Model of Light Atmosphere'. The function of the model is to be a contextual frame of the project, whereby an understanding of the different parameters of light atmosphere benefits from the improved understanding of the whole understanding of light atmosphere. Secondly, the function of the model is to be used as a design tool. In this way, the model is refined through the process and elaborated and improved by studies of theoretical, explorative or experimental characters. An understanding of the theoretical, explorative and experimental studies will likewise develop through understanding of the whole.

(Schön 2009) characterizes design as a hermeneutic circle that is developed by means of "a conversation with the situation." Being a design practitioner, the hermeneutic circle feels as a natural process. In the design process at Kolding School of design, we learned a similar approach i.e. on other designer practitioners' processes and not on research based teaching or a theoretical approach. But as student and later as a trained professional, the iterative process was used as design method; starting with an abstract model/idea of a problem first, then the product etc. refined through explorative and experimental loops, lastly all information was compiled and the design was shaped. The design is flexible and open to new ideas or for gaining new knowledge in the development of the design proofing the quality of the design.

In this way, a design project is based on both explorative studies expanding an existing understanding of a subject as well as reasonable assumptions of a generated theory. It is not a designer owned idea pushed through a refined process.

When Schön explains how professionals think in action, he uses the term 'reflection in action'. Schön claims that when a one deals with spontaneous and intuitive everyday actions, one possesses knowledge about the action in particular way. Sometimes the action is not easy or even possible to describe in words, and the words one use are obviously not enough or sufficient. In this way, knowledge 
can be built in our way of acting and in our sensation of a material with which we deal. Therefore, Schön claims that our knowledge is built in our actions: 'knowledge in action', and the design of a professional designer depends on this 'knowledge in action'.

A practitioner as a designer constructs a 'repertoire' of examples, pictures, understandings and actions. The 'repertoire'includes all of the practitioner's experience in the extent of what is available to him/her as an underlying basis for understanding and actions.

When a designer is going to make sense in a situation, the situation has to be considered as unique. Then the designer sees it as "something" already existing in the 'repertoire'. To see the situation as something is not about adapting it to an already known category or system. It is more likely to see the unknown and unique situation as similar and, at the same time, different from a known situation, in the beginning often without being able to express the differences. (Schön 2009)

A designer should be aware of the fact that it is not always possible in the middle of a design process to fully argue for precise and adequate criteria of the project. They have to trust 'knowledge in action' and use their intuition to solve a problem, while the intuition often is built on experience-based learning. Maybe it is not possible to argue for choices in middle of the process, but trusting 'knowledge in action' and use the intuition, things can be developed. Michael Polanyi (Schön 2009) describes this action as a 'Tacit Knowledge'. A 'Tacit Knowledge' is also explained by this example. When we learn to use a tool as for an example a pen, the awareness is enhanced from the way the tool is sensed by the hand to how it can transmit to a paper and therefore how a pen can be used. This process becomes the basis for understanding the process of acquiring skills. It becomes a feeling or a sense, which is first, noticed when it is internalised in our 'Tacit Knowledge'.

For this study, I will use my design skills of "see something" through the process and go for it, trusting the repertoire I possess. Being reflective through the actions does not mean being able to explain everything in the moment in which the action is going on. It means trusting the experience gained through several studies; that 
in the end this "seeing something" was important for the development of the study and thereby be able to explain why it was important.

\section{STRATEGIES}

While design in some situations can be understood as being a hocus pocus process and "just" a matter of good taste or consequence of impulsive actions, it is important to me to display the design process as transparent as possible. The studies of details challenge the hypothesis and use both inductivity and deductive research strategies in the project as well as and qualitative and quantitative methods. Therefore, cycles of iteration always seek to validate the studies by suitable methods by using traditional methods from the disciplines used to explore the details. In this way, the studies of details produce knowledge of different characters, clarifying important parameters of the 'Model of Light Atmosphere'.

\subsubsection{Inductive and deductive approach}

There are generally two ways to create or apply knowledge(Fig 2.3); induction and deduction (Rasmussen, Østergaard 2009). Deductive process is characterised by having a starting point in the theory, a generalization of reality. The aim is to explain and test logical assumptions and hypothesis and specific situations where the conclusion follows the terms. If the terms are correct, the conclusion must also be correct. If a term is assumed to be valid and it is not, the conclusion must also be false or misleading. Deduction as a method applies a generalization to a special case. In practice, it means that the process takes a theory, a framework or generalizes a theme and tests it on something real.

Inductivism is a scientific research strategy generally used when the coherence between logical relations and premises are insufficient. Inductivism has experienced or empirical knowledge, and the inductive method generate theory from evidence by observations. That means that inductivism has a starting point in a specific situation and moves to an abstract theory, instead of evaluating already existing theory (deduction). Induction begins with empirical data from a specific situation and then makes a generalization and finds patterns and coherence. It is often used in qualitative studies such as anthropological or literature studies and discourse analysis, and it is a question of a certain probability, but you cannot be $100 \%$ sure. 


\section{Fig 2.3}

Model of Induction and Deduction. After (Rasmussen, Østergaard 2009, p. 41)
In the present study, both inductive and deductive strategies are going to be used. Inductive methods are used to explore and create new knowledge of something unknown and to create generalisations from studies of details. Deductive methods seek to go from generalisations as for example light atmosphere and investigate the subject by testing logical assumptions. This strategy implies a open process while it is important to seek information from detail studies. In this way, the project can be said to have a flexible character.

\section{THEORY}

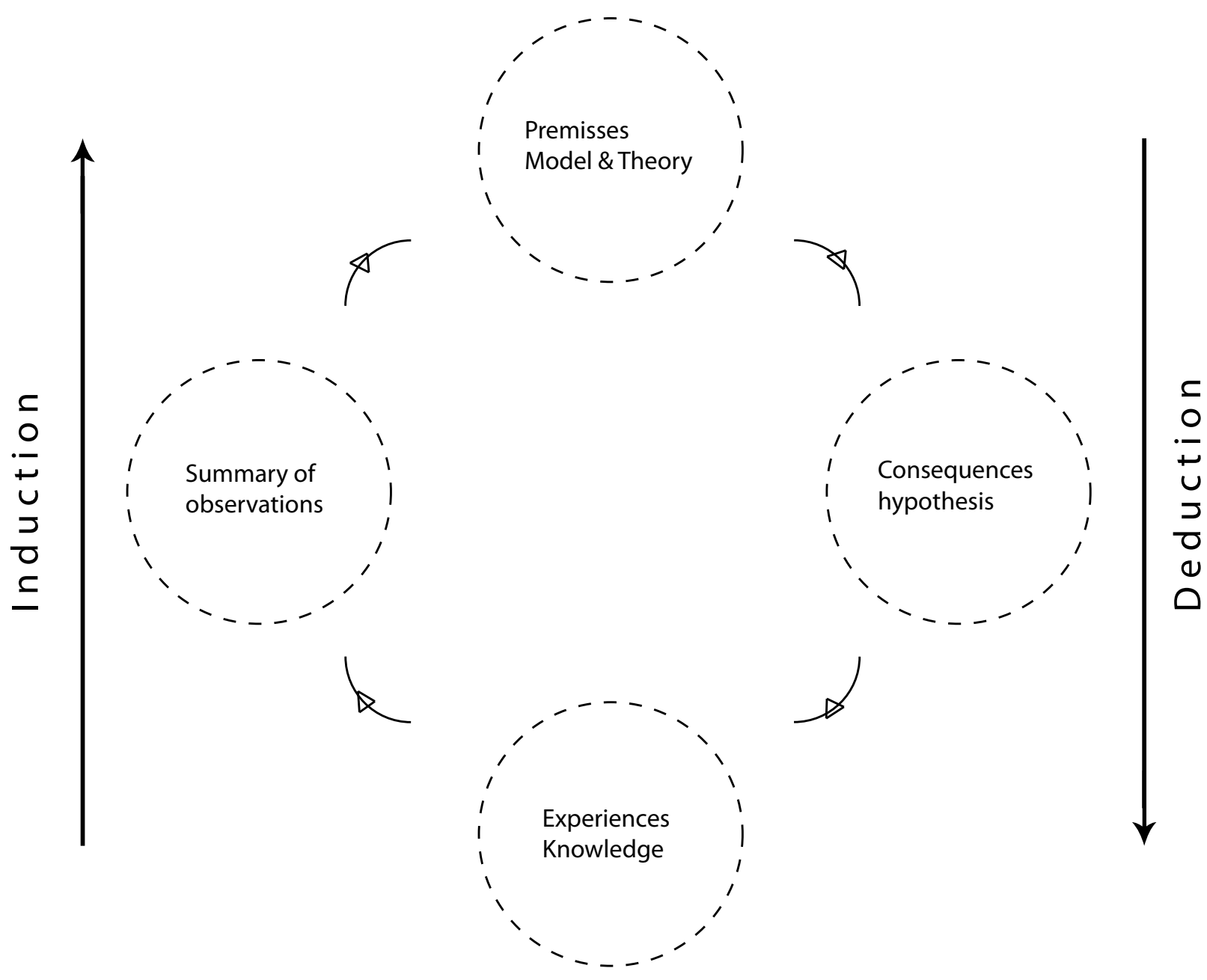




\subsubsection{Qualitative and quantitative methods}

To explain the method used in this study, an explanation of qualitative and quantitative studies is needed.

Methodology in architectural research can be performed in many ways and with different approaches. According to (Groat, Wang 2002), there are two systems of inquiry. While this study is a design study, the terminology of using qualitative and quantitative methods may not be that clear. Both strategies are used during the process of developing a design or evaluating design proposals. But at the most basic level, the terminology of qualitative and quantitative methods assumes that quantitative research depends on the manipulation of phenomena that can be measured by numbers. In the same way, it can be said that qualitative research depends on nonnumeric evidence and can be verbal (oral, written), experimental (film, notes of people in action) or artefacts (objects, buildings etc.).

In a qualitative descriptive method, the analysis of a content pattern or a phenomenon is investigated and described. Qualitative method is based on knowledge produced inductively. A phenomenon always appears in a context and the role of the researcher is therefore to study the natural environment by being placed on the site without manipulating the situation. The researcher's task is to observe and understand the phenomenon. In this way, the goal is to gain knowledge or explore new phenomena and be able to describe the situation. There must be flexibility in the research design and a researcher needs to presuppose an understanding of the language to be able to study the phenomenon. The transmissibility of the observations is conducted through an understanding of complexity, diversity and a depth of the phenomenon and the understanding of the specific context can be applied in another context.

A quantitative system that refers to a scientific explanation typically contains a mathematical description made up of linked fragments. Looking at research fields such as technology, engineering or behavioural issues in an architectural context, they represent such a system of inquiry or scientific paradigm. The quantitative system of inquiry can be seen as a fixed design. The reliability in fixed design is associated with the use of standardized research instruments as formal tests, scales and standardized human observations. These tools can be problematic and hard to deal with in the process of validating qualitative 
research when something is missing. On the other hand, research with flexible design can look like a messy affair filled with a lot of words and no results, delivering loads of new questions and not having a clear and visible result to verify. Traditionally, the qualitative and quantitative methods have been used separately and seen as incompatible. However, the two methodologies seem to be compatible and credible, because a statistical analysis is only as credible as the background assumptions and arguments, and these are not manageable to mechanistic demonstration. (Robson 2011, p.165)

Dealing with a real world study, the reality is complex and cannot be simplified as a matter of qualitative argumentation. Therefore, quantitative methods are used to circumscribe the variables of interest and measure them in prescribed ways in order to specify the relationships among the details studied. The qualitative methods are used to explore and interpret an unknown field of interest in order to generate concepts and to make sense of the situation being analysed in quantitative ways. In this way, the study is what (Robson 2011, p. 161) calls a multi strategy design using mixed methods.

\subsubsection{Real World Studies}

Lighting design is a multi-disciplinary field to navigate in and the field of knowledge has different approaches to the research. Robson defines mixed method as including: - Quantitative and qualitative methods within the same research program,

- A research design that clearly specifies the sequencing and priority that is given to the quantitative and qualitative elements of data collection and analyses,

- An explicit account of the manner in which the quantitative and qualitative aspects of the research relate to each other; and

- Pragmatism as the philosophical underpinning for the research (Robson 2011, based on Denscombe, 2008, p. 164).

Robson finds mixed methods and multi-strategy design as usable strategies for real world studies. A real world study with flexible design is characterised by being a project small in scale. It is often carried out in an educational or health related setting by professionals and practitioners (including practitioners-researchers). The focus carried 


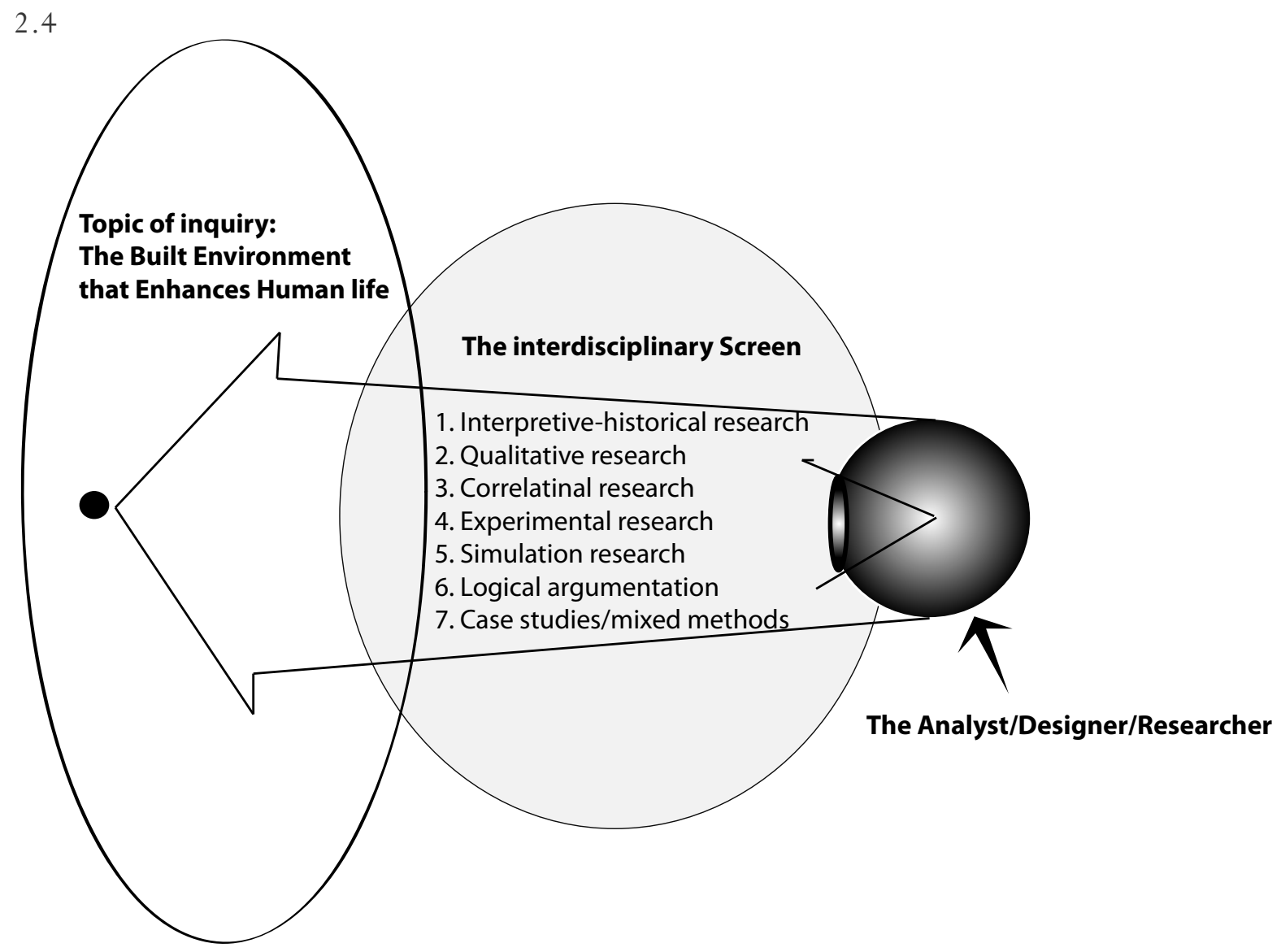

out by a practitioner doing research differs from traditional academics by not having so many concerns of extending an academic discipline, but merely to focus on problems and issues of direct relevance to people's lives. In this way, a real world study seeks to help finding ways of dealing with a problem in order to provide a better understanding the situation. (Robson 2011, p. 4)

The real world study triangulates and corroborates between quantitative and qualitative data. Thereby it enhances the validity of findings of details and its whole. At the same time, a triangulation produces a more complete picture of the research topic. By using this method, it is possible to answer a wider range of research questions. In this way a multi-strategy method has the ability to deal with complex phenomena and situations and is thereby valuable for real world settings.

When a complex phenomenon is going to be communicated, it also seems to be beneficial to display illustraFig 2.4

The designers position in the interdisciplinary reality. Model after . figure after Groat and Wang.

Fig 2.5, 2.6, 2.7

The interaction between the different fields of knowledge. After Rasmussen, Østergaard 2009. 
explanations discussing the data and thereby paint a better picture of the situation.

To illustrate the designer's position in the interdisciplinary reality, figure 2.4 can be used. The figure display different disciplines to handle when a designer deals with real world studies. Firstly, the field of social science can contribute with knowledge of a group of people's feelings, their experiences or the way they are organized. Explorative studies could provide new knowledge of preferences or behaviour. It could be relevant for this study to explore aspects as preferences for light in a given situation, interviews finding needs or behavioural character. The field of natural science will also be a natural part of a multistrategy design. Methods known from social science can create reasonable situations for study or can contribute to the study with new knowledge. Methods known from the natural science is an appropriate way to evaluate the given hypothesis from the given situation.

In this study, the method known from natural science is used to evaluate the design concept and to evaluate light atmosphere in a quantitative data set. Methods from humanistic research can contribute to the view of the tradition and history of a situation or the interpretation of a given situation. Methods picked up from design research can contribute with innovation in the field and collate important information in new ways.

The different fields of knowledge are normally presented as Natural Science, Humaniora, and Social Science (Fig. 2.5, 2.6, 2.7)(Rasmussen, Østergaard 2009, p. 35). Work-
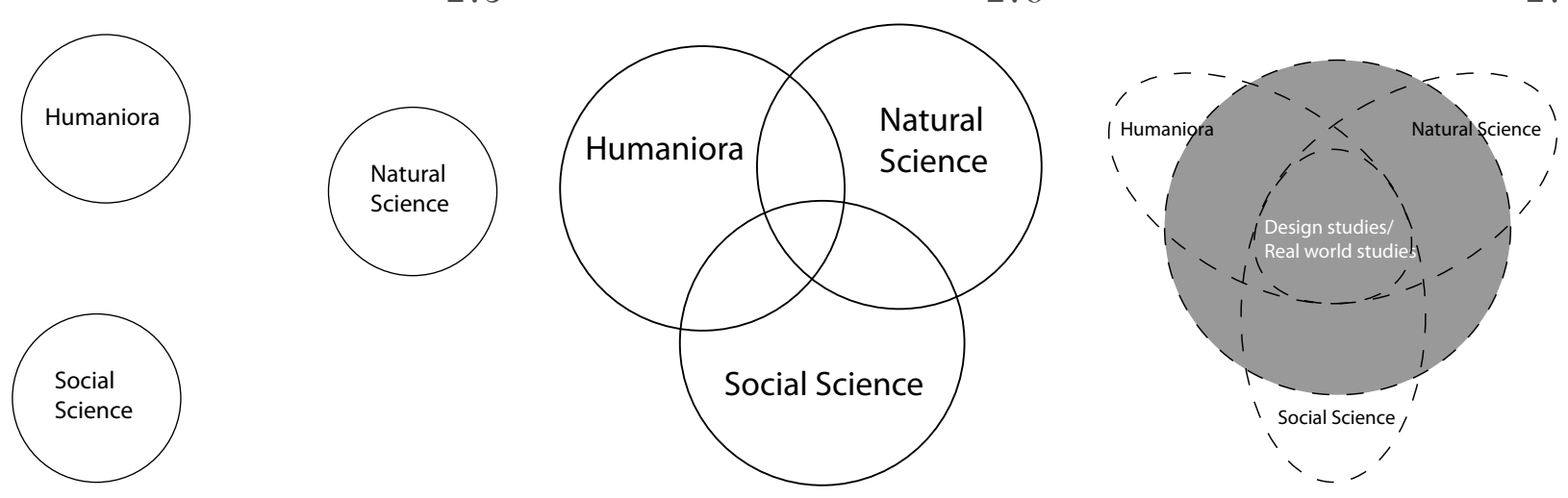
ing with research in lighting design, however, something is missing in the traditional fields. The lighting design research can be illustrated as a circle in the middle containing a part of the three main approaches. The tradition of research is shown in fig 2.5, 2.6 and 2.7 is the future of research projects, where research is connected by design or real world studies.

So being a designer carrying out a real world study of flexible character and using mixed method and multi strategy design, the project seek to follow fig 2.8 the real world study/design study mixing research approaches and use qualitative and quantitative methods where it is appropriate. The next section displays the tactics used to explore the phenomenon 'Light Atmosphere' as well as how this kind of phenomenon can be evaluated.

\subsection{TACTICS}

The tactics of the phenomenon light atmosphere in the context of hospital wards could benefit from various studies. In this study, tactic can be seen in two ways. First, tactic can be interpreted as the origin of the "Model of Light Atmosphere' and the iterative processes as the "whole story". Another way of using the term is as doing explorative, experimental and theoretical studies of details. In this way, the "detail studies" provide a substantial credibility to the model and thereby the eligibility. For convenience, the tactic of the whole story is presented and hereafter the tactic of the studies of details.

Fig 2.8 presents the process of building the 'Model of Light Atmosphere'. The structure of the process is similar to the structure of the dissertation, going from a start-up phase through brainstorm and the first abstract 'Model of Light Atmosphere'. Hereafter, the first cycle of iteration is carried out as literature and visual studies displayed in chapter 3: On atmosphere. This chapter presents the origin of Model of Light Atmosphere' as well as displaying the state of the art on the field. The information presented here has different characters as literature studies and visual studies of different aspects. While the Model of Light Atmosphere' has the function of being a design tool in the project as well as structuring the study, the following cycles of iterations are presented in the next chapters. Chapter 4: Explorative studies elaborate on the phenomenon 


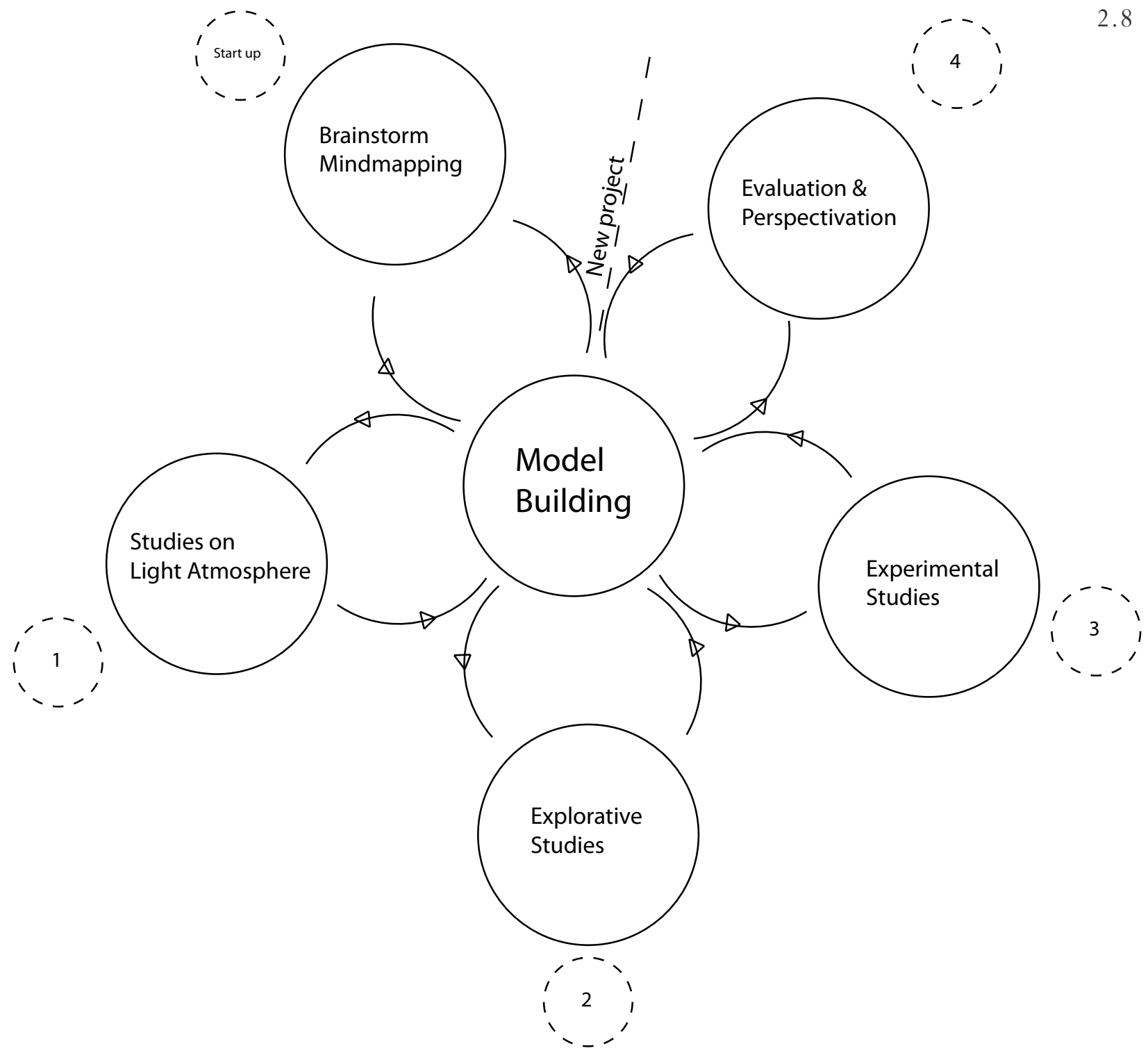

Fig. 2.8

Model presenting the cycles of itterative of the study 'light atmosphere' in explorative way. Cycle 3 and thereby Chapter 5: Experimental studies deals with adaptation of the gained knowledge from chapters 1 and 2 in a real world study of light atmosphere. The design experiments are then evaluated and presented in chapter 6: Findings, discussions, conclustion the study as well as future perspectives. 
In that way this dissertation present:

\section{Chapter 3: On Light Atmosphere}

The chapter has two main interests. First, to present the visual identity of 'Model of Light Atmosphere' through the study and, second, to display the important parameters included in the final 'Model of Light Atmosphere'. To create a 'Model of Light Atmosphere', tactics as brainstorming structured by mind mapping are going to frame the study and be the preliminary guide for literature studies and collection on visual data.

\section{Chapter 4: Explorative studies}

The tactics chosen for explorative studies of course depends on the character of the explorative studies. The studies presented in this chapter will all be a part of expanding the understanding of light atmosphere by studying details as preferences for light, looking into the history of light atmosphere and lastly to display what it means to experience a light atmosphere when you are a patient in a hospital. Tactics suitable for these kinds of study are multifaceted using both qualitative and quantitative strategies. Tactics as semi-structured interviews, photo album, analysing pictures, RFID tracking, semantic differential scaling and Likert scaling are some of the tactics used to explore light atmosphere.

\section{Chapter 5: Experimental studies}

The knowledge gained from the state of the art studies and explorative studies form the basis of the design concept presented in chapter 3 . First the concept is presented, the experimental scene displayed and hereafter the process of developing the concept to an application, which will be ready to be installed in a hospital ward. Design choices substantiated and a visual presentation of the ward lighting concept is shown in the chapter.

\section{Chapter 6: Evaluation and perspectives}

The tactics of evaluating the experience of a light atmosphere in a hospital ward are displayed in chapter 4 . The evaluation is based on quantitative strategies and first the development of the questionnaire Light Atmosphere Evaluation is presented. The questionnaire seeks to evaluate the experienced light atmosphere in the ward based on known 
tactics as Semantic Differential Scaling and Likert Scaling. While the questionnaire did not agree with the expectation in a satisfactory way and, in the end, had problems of understanding unclear questions, the validated questionnaire Semantic Miljö Beskrivning or Semantic Environmental description (SMB) is used to evaluate the experience in the ward with the application and a reference ward.

\subsection{SUMMARY}

To describe the methodology in design research, (Groat, Wang 2002) divide the process into three categories: 'Systems of inquiry', 'Strategies' and 'Tactics', 'Systems of inquiry' describes the researcher's pre-understanding or assumptions of the nature and thoughts of how it can be addressed. 'Systems of inquiry' frames both "Strategies" and "Tactics", where "'Strategies' clarifies the relationship between midrange of methodology, the "Tactics" is a more specific level of information described.

To display the 'Systems of inquiry', Schöns uses the terms 'reflection in action' and 'knowledge in action' to define the designer's position of doing research, and to set the frame of the project. The designer's 'repertoire' is the foundation of the process and underlying basis for understanding and actions, and one of the main goals of this study is to display some of the 'tacit knowledge' of experiencing light atmosphere.

'Strategies' is presented in a hermeneutic tradition using cycles of iterations. The research design uses mixed methods and multi-strategy design, which Robson defines as a method using both quantitative and qualitative strategies within the same research program. 'Tactics'presented in this chapter are literature studies and visual studies to create a foundation for the 'Model of Light Atmosphere' in the first cycle of iteration. Hereafter, methods like interviews, RFID tracking and visual analysis of pictures and observations represent methods in the second cycle of explorative studies. Experimental studies are built on knowledge gained from the first two cycles and display the real world study. Lastly, the fourth cycle of iteration evaluates the experimental set-up. 

3. ON LIGHT ATMOSPHERE 
"Atmosphere can not be seen - It must be experienced through other senses and an atmosphere rarely occurs through one sense alone, but in an interaction between several senses. Atmosphere affects people emotionally.” (Albertsen 1999)

Right now, 'Atmosphere' is a quite trendy subject in architectural discussions. In many cases, it seems to be used as synonym for "an excellent experience of something" or maybe the view of a "beautiful architectural place". But what is an atmosphere, why discuss atmosphere and is atmosphere always beautiful?

As Albertsen defines, atmosphere is something that cannot be seen. It is to be experienced by using all senses, not only what is displayed in front of your eyes. Atmosphere is an experience based on the interaction between several senses. The Oxford Advanced Learner's Dictionary defines Atmosphere as:

"The feeling or mood that you have in a particular place or situation; a feeling between two people or in a group of people" (Hornby, Turnbull et al. 2010)

That means that atmosphere is a both a feeling of a place or situation, or the mood between two or a group of people. So, two types of atmosphere are pointed out i.e. the atmosphere of a space and the atmosphere between people. Wikipedia refers to the term atmosphere as the sensorial qualities that a space emits:

Atmosphere is an immediate form of physical perception and is recognised through emotional sensibility. Architects and designers use the notion of atmosphere to argue that architecture and space is designed and built for people to use and experience. (Wikipedia)

The way Wikipedia and Oxford Advanced Learner's Dictionary present the term, Atmosphere can be understood in different ways. The term can be understood as the atmosphere between people or the emotional experience of a situation or space. Atmosphere can be interpreted in different ways and it has many faces. Philosopher Gernot Böhme points out that it is uncertain whether we should attribute atmosphere to the environment or to the subject experiencing them: 
Fig. 3.1

Yellow atmopshere. Image of a restaurant in Lagos Nigeria.

Fig. 3.2

Green atmosphere. Image of a studyroom at NTNU, Trondheim, Norway. Photo:

Fig. 3.3

Relaxing atmosphere in a living room. Denmark.
"Atmosphere is indeterminate above all as regards their ontological status. We are not sure whether we should attribute them to the objects or environments from which they proceed or to the subjects who experience them. We are also unsure where they are. They seem to fill the space with a certain tone of feeling like a haze" (Böhme 1993, p. 114)

Böhme also characterizes atmosphere and claims that it can appear in different ways and can be serene, melancholic, oppressive, uplifting, commanding, inviting, erotic etc. Böhme presents atmosphere as something concerning the relation between environmental qualities and human state, and points out that the atmosphere must be this "and" and the in-between, while it are means of which environmental qualities and states are related. (Böhme 1993, Böhme 2012)

This means that atmosphere is not an endorsement of good taste or the right choice, but can be scary, attractive, impressive, entertaining or maybe repulsive, uplifting or inviting. The content of an atmosphere includes both objective and subjective parameters important to evaluate.

Figure 3.1, 3.2 and 3.3 display three kinds of atmosphere. First a "yellowish" atmosphere from a hotel restaurant Lagos in Nigeria where a yellow filter was mounted to the window. Secondly, a "bright light" atmosphere is displayed of a green study room at Trondheim University. Third picture illustrates a' homely' atmosphere in a Danish living room. All of the examples have a specific atmosphere. Often atmosphere is connected to something beautiful and a term for an extraordinary experience, but atmosphere can be discussed in many ways. To be able to understand what an atmosphere is and what is important, an introduction to experiencing architecture is presented.
3.1

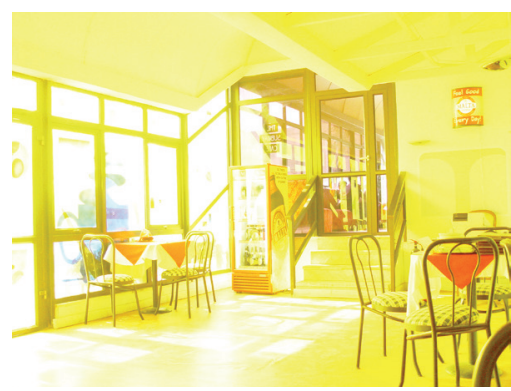

3.2

3.3
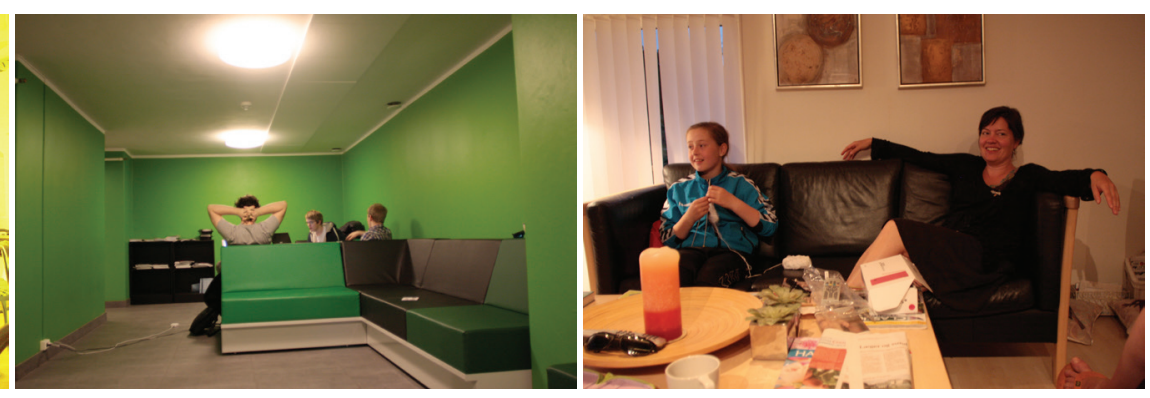
Space is genuinely experienced by being in it, through physical presence (Böhme ). You have to be present to feel the atmosphere, but this does not mean that you cannot talk or write about it.

To present a polyphonic analysis of light atmosphere and trying to divide the experience of light atmosphere in smaller parts can be problematic. Describing each part as an independent category provides some problems while as Böhme highlighted

"An experience of atmosphere consists of more than the separate parts and is an experience of totality" (Böhme 2012).

Maybe part of the experience can be described in words, other aspects can be displayed in pictures or figures, but you can never display pictures or describing situations fully, as the bodily experience of the space is a part of the experience. Even though this statement is a core value, the model of light atmosphere is still useful and eligible, and seeks to present some of the aspects important for understanding light atmosphere. In this way, the model serves as guideline for creating lighting design and points at aspects to consider. While it has not been possible to find other models of light atmosphere, this model attempts to be a part of the assessment of these kinds of models. At any rate, this model attempts to present important aspects in the discussion of what a light atmosphere is and what is important to analyse and evaluate in the design process of an illumination.

Therefore, this chapter of the dissertation attempts to present a way of discussing atmosphere and has references to different methods of displaying atmosphere as personal experiences and examples from architecture. Later, model light atmosphere is introduced and elaborated on as an attempt to create a model as a design tool, framing important aspects of the experience of a light atmosphere. The' Model of Light Atmosphere' contains the following subcategories 'User', 'Space', 'Light' and 'Time'.

\subsection{ATMOSPHERE AND EXPERIENCE OF ARCHITECTURE}

The conference "Understanding Atmosphere - Culture, materiality and the texture of the in-between" in Aarhus 2012 was a brilliant example of displaying research in 
atmosphere as a multi disciplinary and complex area to study. At the conference, atmosphere was discussed in areas as anthropology, architecture, museology, archaeology and philosophy. The conference contributed with knowledge on the fact that atmosphere is a multifaced term while it has to be defined for each project.

Other researchers has found interesting aspects of atmopshere. (Jörgensen, Römma et al. 2009) studied the associations between ward atmosphere and patient satisfaction, and the result showed that differences in the healthcare environment had an effect on the patient satisfaction. (Vogels ) presented a tool to quantify perceived atmosphere. (Boyce 2009) noticed that there is still much to learn about the impact of light on human health. (Liu, Jang 2009) studied the effect of dining atmospheres, (Alfredsdottir 2002) investigated the atmosphere in the ward environment and characterised atmosphere as a vulnerable dynamic phenomenon. (Quartier, Vanrie et al. 2010) provided an experimental set-up and studied how a light setting alone can be used to elicit a particular atmosphere. (Fernandez, Giboreu et al. 2010) researched atmosphere in connection with hotel rooms, and they studied the light in the hospitality industry from light perception to lighting conception. (Fernandez, Giboreu et al. 2010) looked into the control of the illumination as one of the parameters important to experience comfort. Although there are many interesting ways of exploring atmosphere, this study concentrates on describing atmosphere connected to architecture and design and specifically on working on the light atmosphere of hospital wards.

Famous architects as Peter Zumthor and Johanni Pallasma have both created architectural spaces with a special interest for the sensorial qualities of the design. Both architects are also successful authors of architectural theory dealing with atmosphere in architecture. In 2006, Zumthor presented the'Atmosphere' (Zumthor 2006) and 'Thinking Architecture'(Zumthor 2006). In these works, Zumthor claims that the roots of architectural understanding lie in our architectural experience. His definition of architectural experience is the experience of our room, our house, our street, our village, our town and our landscape. We have an early experience of these spaces, and unconsciously we compare them with later experiences of towns, houses and countryside. And so, our architectural 
understanding lies in our childhood, in our youth. It could be said that they lie in our biography. Zumthor presents the expression: 'The magic of the real'. The definition of the term is the 'alchemy' of transforming real substances into human sensations. Creating that special moment when matter, substance and form of architectural space can truly be emotionally appropriated or assimilated.

"We perceive atmosphere through our emotional sensibility - a form of perception that works incredibly quickly, and which we humans evidently need to help us survive. The big question is "What is the magic of the Real"? The Body of Architecture, Material Compatibility, The Sound of a Space, The Temperature of a Space, Surrounding objects, Between Composure and Seduction, Tension between Interior and Exterior, Levels of Intimacy, The Light on Things."(Zumthor 2006)

Almost at the same time as the book was published,
Fig. 3.4

Gallery of images from Term Vals, Switzerland. Photo: Héléne Binet.

\section{4}
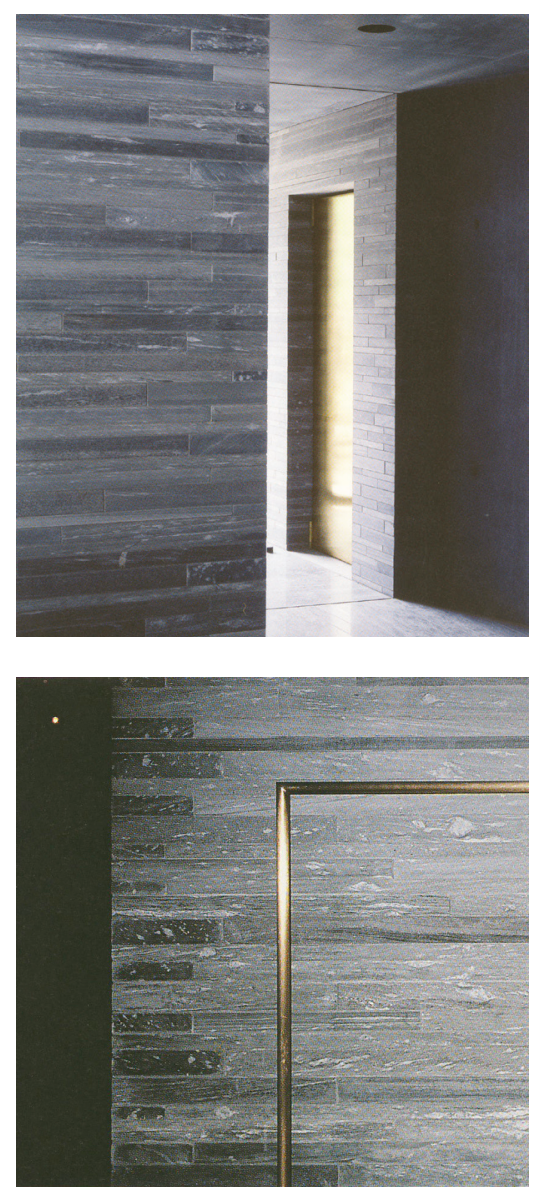
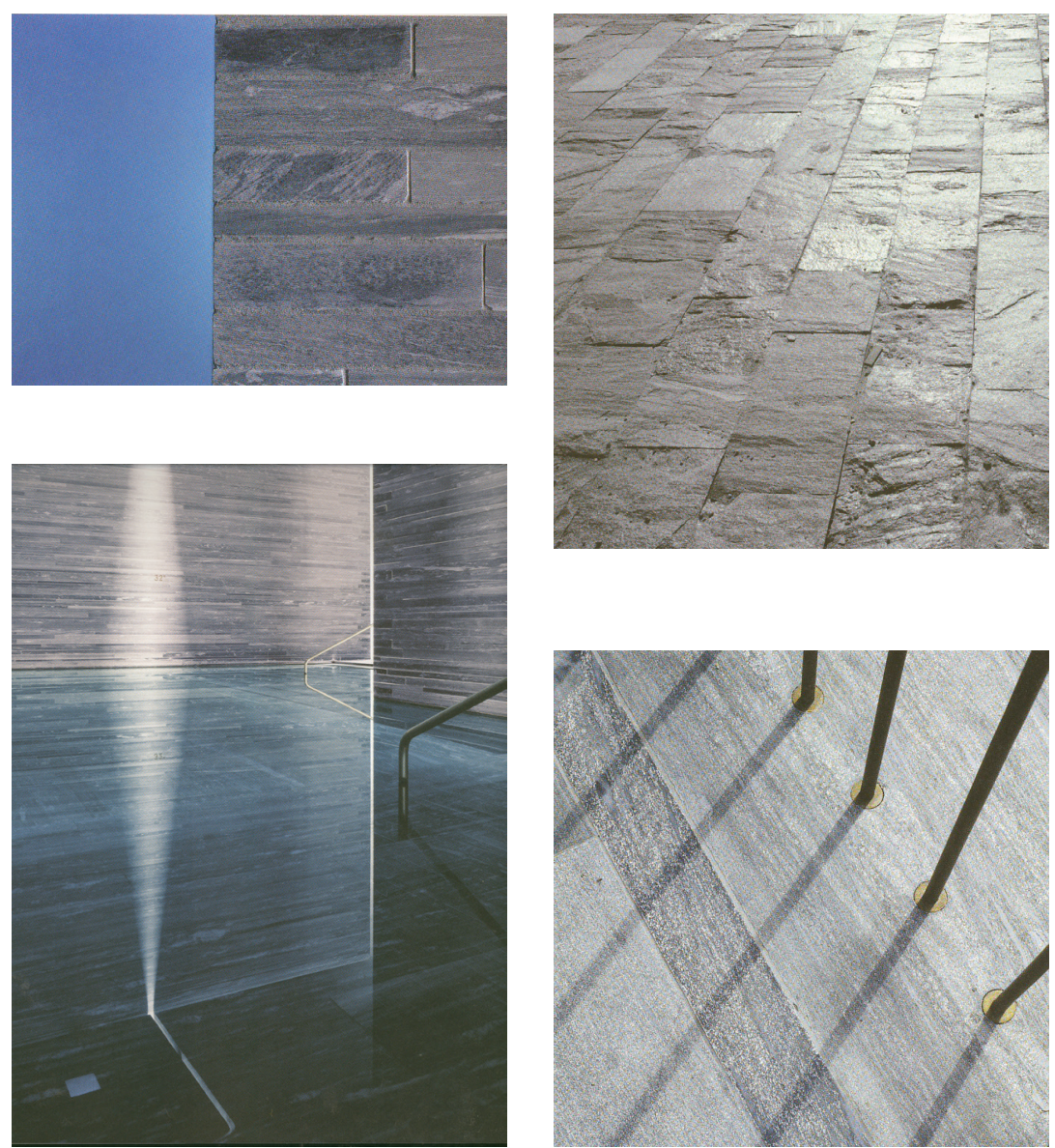
Zumthor created the thermal baths Term Vals, see fig 3.4. The pictures present the thermal bath in Switzerland and is often referred to as "this is atmosphere" by architects. The appellation is correct in the way that Term Val provides several different experiences of interesting atmospheres. Personally, I was fascinated by how simply using materials as water, bricks from the local stone quarry, gold and light created different atmospheres (Zumthor 2008, p. 142-143). In this way, the separate baths were experienced as open or closed and one of them was even a little scary because the flowers were floating in the water, illuminated from the bottom of the bath creating small black shadows. My immediately thought was that there were fish in the water, but it was a 'flower bath'(Zumthor 2008, p. 103). Some baths seemed a little scary to enter, and other baths almost dragged me into the water. The overall impression of the baths was impressive and they contained an interesting and fascinating atmosphere. It was a really beautiful experience of how the combination of materials, spatial composition and light can provide different experiences of atmosphere.

The architect Juhanni Pallasma presents his theoretical concept of sensory experiences in the book "The eye of the skin" (Pallasma 2005). Pallasma's theoretical approach is built upon the work of (Rasmussen 1957) who wrote the book 'Experiencing architecture'. Pallasma claims that a sensory experience becomes integrated through the body, or rather, in the very constitution of the body and the human mode of being (Pallasma 2005, p. 40). Pallasma presented a psychoanalytic theory and introduced the notion of body image or body schema as the center of integration. The essence of the theory is that our bodies and movements are in constant interaction with the environment. In this way, the interaction process between the world and the self is constantly redefined, and the perception of the body and the world turn into one single continuous existential experience. The body cannot be separated from the space and the experience of a space include a image of perceiving oneself as a part of the experience.

One of the important issues of Pallasma's work is that he points out the flatness of today's standard constructions is moving in a direction of providing a weakened sense of materiality. He claims that natural materials as stone, brick and wood allow the vision to penetrate their surfaces 
and enable us to become convinced of the truthfulness of matter. The category of natural materials has a history, expresses an age and tells the story of their origins and the way in which they have been used. The natural materials have patina and our body recognizes the materials, even if they are put in a new context. We use all our senses at the same time when we experience and enter a space, and we try to connect the information given by our senses. Merleau Ponty claims that we try to create a line of sensory information. The body does not only rely to the senses, but it attempts to form links between the senses - a sensory integration. Consciously or unconsciously we decide whether we like being in a room and thus relax, or whether we have to adapt to the surroundings and the idea of wellbeing, and a sense of safety. (Rasmussen 1996)

Philosopher Gernot Böhme presented Atmosphere as a following concept originated from ideas of 'concept of spirit'(Böhme 2012). In 1968, atmosphere is mentioned in psychiatry for the first time. Böhme introduced atmosphere as something more than the total of architectural quality and notes that it is present whenever a situation is staged. At the the conference Understanding Atmosphere Böhme emphasised that atmospheres are the totalities and a unifying thing - it is the 'tone' in a room. Atmosphere floats in the 'in-between' and is the generator in a stage set. Böhme distincts the 'Concept of atmosphere' from being sighs as in the Semiotic tradition, and states that atmosphere is the art of stage set, not things or objects. Thereby, there are different kinds of aesthetics; the perceptual aestheticsand the product aesthetics. (Böhme 2012)

Böhme introduces the 'bodily presence' and the 'bodily sphere' in an aesthetic theory of atmosphere (Böhme 2007, Böhme 2007). He says that the 'Concept of atmosphere' is a momentary and difficult distinguishable concept, and it is difficult to separate from other concepts as sensory design, emotional design, designs ability to affect mood, creating of ambience etc.

Pallasma and Zumthor also emphasise the relation between the body and the space, but Böhme's theory goes deeper into the understanding of atmosphere. Böhme contributes to the 'Concept of atmosphere' by noting that the subject basically relates to the environment by a bodily presence. The bodily presence has an emotional dimension, and a
Fig. 3.5

'Concept of Atmosphere' by Gernot Böhme. Model afterDalsgaard and Kortbek's

Fig. 3.6

'Concept of Atmosphere' by Gernot Böhme. Aspects as Others and Technology added by Dalsgaard and Kortbek.

Fig. 3.7

'Concept of Atmosphere' by Gernot Böhme. Aspects as Socio Cultural understanding is added by Stidsen, Kinck. Model after Dalsgaard and Kortbek. 

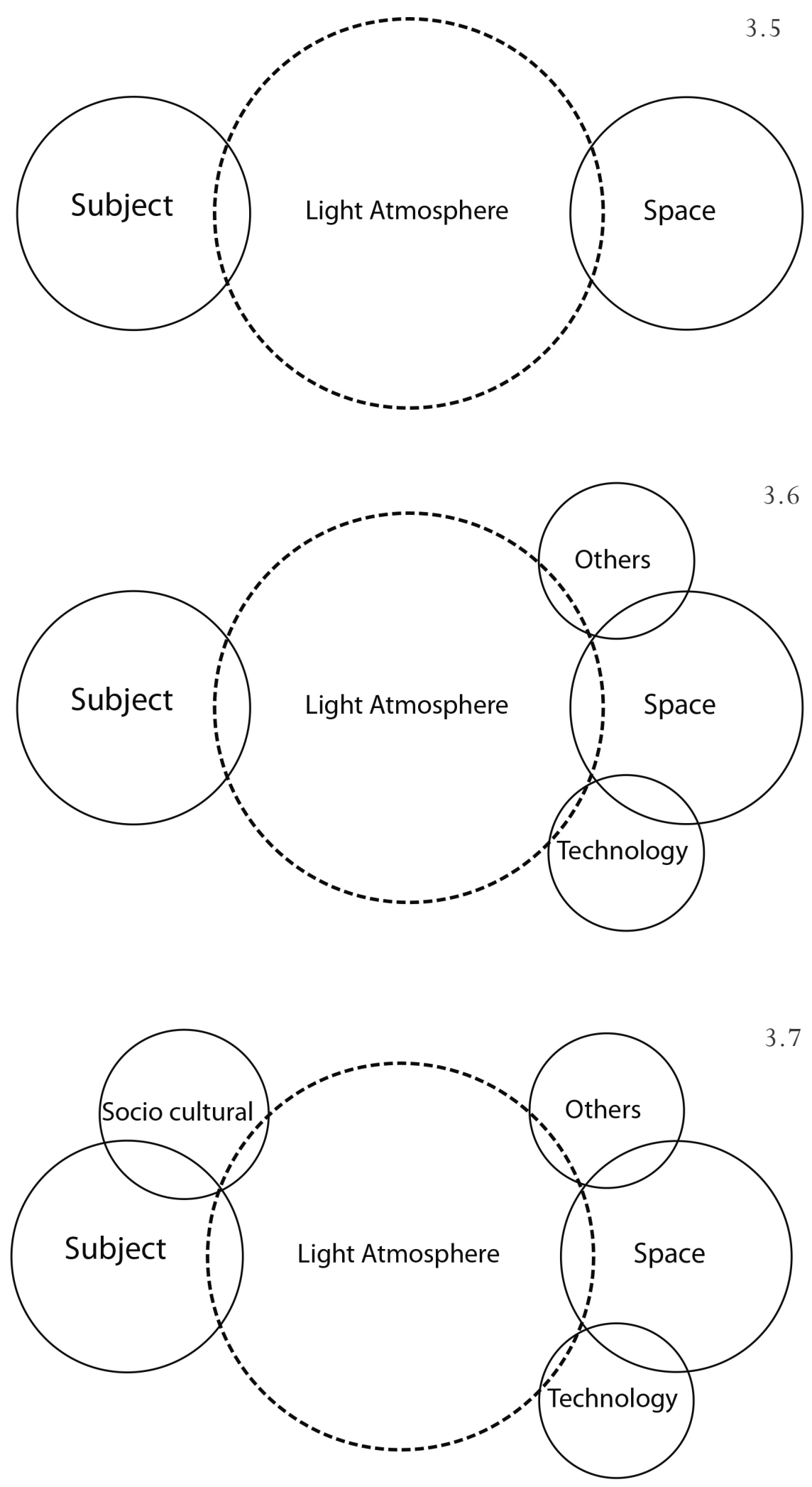
bodily experience is extensive and never emotionally neutral, it always has an impact on our state of mind. Bodily presence is based on how we find ourselves situated in the space that we sense and is affected by the characteristics of the environment we live in and by the way we perceive it. Therefore, Böhme claims that because of the emotionally effect of atmosphere, an absolute 'here' appears and since architecture is an instrument of creating 'true' experiences it also affects people emotionally. The goal must be to create a bodily feeling or experience of "where" you are, and the architectural design of space to influence the 'how' you are in the space. The'how', according to Böhme, appears in precisely the concept of atmosphere where it opens new perspectives in architecture - both from a perspective of understanding the way it is practiced. There should be an understanding of the spatial structures of the building for people experiencing 'something'.

Dalsgaard and Kortbek tackle the difficult concept in a context of interaction design. First, they visualise a model displaying Böhme's 'Concept of atmosphere' and thereby show a connection between subject and space, (fig 3.5) (Dalsgaard, Kortbek 2008). Dalsgaard and Kortbek claim that to understand 'Concept of atmosphere' in interaction design, the model must be expanded further while other categories are important. Therefore, Dalsgaard and Kortbek add the parameters 'Others' and 'Technology' to the figure (fig 3.6) and point out that time also is an essential parameter, because atmosphere is a procedural phenomenon and not constantly the same.

Based in the initial observations studying the theory of Böhme and Dalsgaard \& Kortbek addition in the context of interaction design, the model is put into the context of lighting design and needs a further expanding. Therefore, a 'Sociocultural' parameter is added to the model (fig 3.7) close to the subject and the atmosphere as we have different expectations and pre-experiences influencing the experience of an atmosphere as well as visualize the timeline Dalsgaard and Kortbek suggested. The 'Sociocultural'parameter is an important addition to the model, because of our different cultural understanding and expectations for the quality of the environment. The geographical experiences as well as subjective expectations are, as Zumthor claimed, that the roots of architectural understanding lie in our architectural experience established in the early years.
Fig. 3.8

Light atmosphere in a living room of a family with Danish cultural background.

Fig 3.9

Light atmosphere in a living room of a family with a Bosnian cultural background. Photo Anne Marie Raakjær Stidsen 
An example in lighting design here is to look into two living rooms. I asked two persons to turn on the light they preferred when they had guests. The first gallery of picture, (fig 3.8), displays the illumination in a family with Danish cultural choice of illumination. The light is hanging over the coffee table and a lamp on the bookcase. The gallery of pictures in (Fig 3.9) displays illumination in same situation, but in a family influenced by Bosnian traditions. Although the family has lived in Denmark for many years, it is obvious to locals that this kind of illumination is not familiar. Here, the preferred illumination is a 100 -watt light bulb in an uplight luminaire placed in the corner of the living room. The luminaire provided a brighter and uniform illumination than we often see in Danish homes.
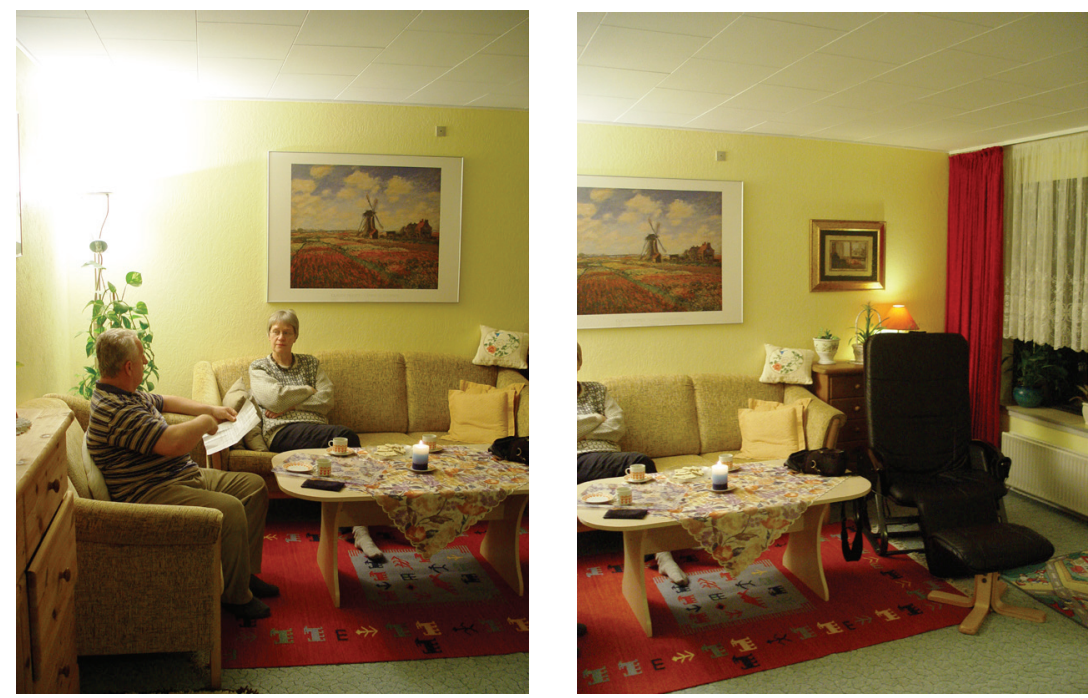

3.8
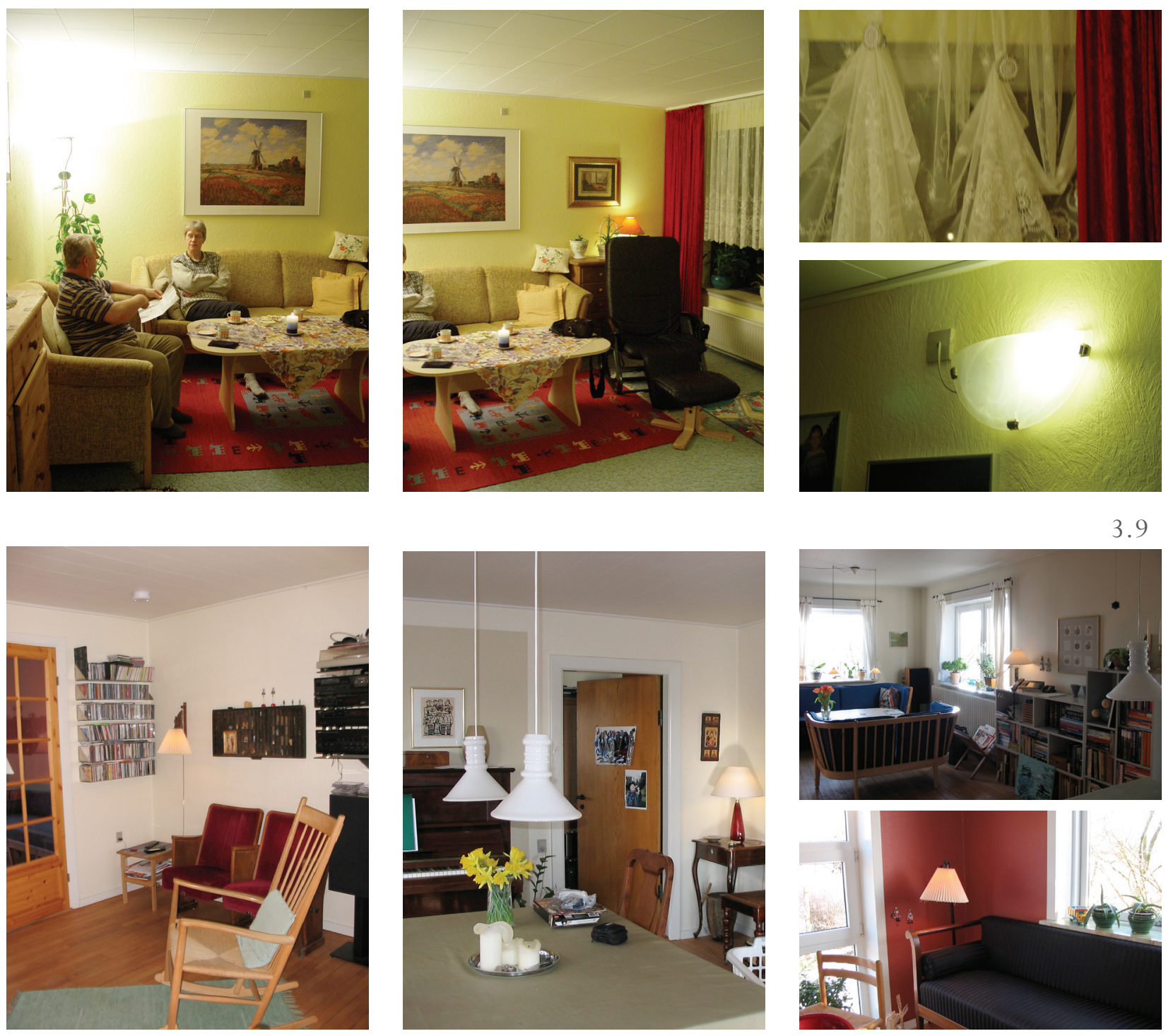

3.9
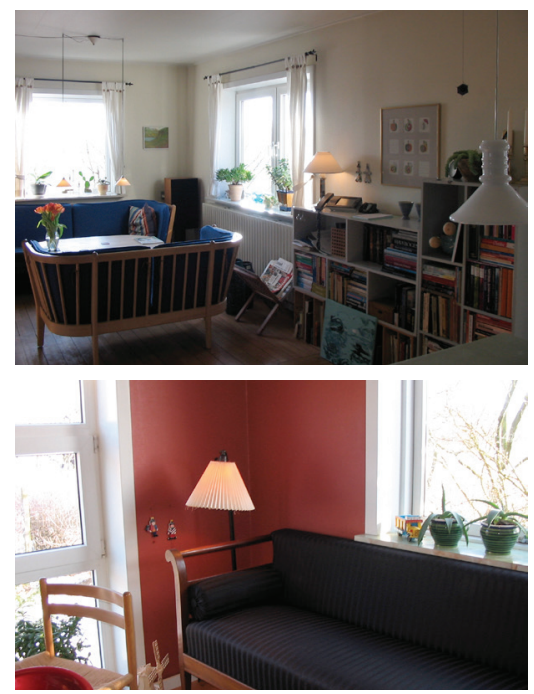
The timeline is important because the experience of atmosphere is momentary and not a stationary state.

The theories of Böhme, supplemented by Dalsgaard and Kortbek parameters 'Others' and 'Technology' and Kinch and Stidsen'Socioculture' parameters as well as a timeline place the project in a philosophical context as well as display a way to use it in the field of design. To be more specific and create a moe precisely discussion of light atmosphere a model is created. A Model displaying the aspects important for the experience of light atmosphere is therefore created. The next section presents the origin of the 'Model of Light Atmosphere' based in the Böhme's theory. The aim of the model is to provide an overview of important parameters to consider and handle in a design process as well as define the frame of this PhD study. A presentation of the final model is in the following section.

\subsection{MODEL OF LIGHT ATMOSPHERE}

"I am inclined to think that the majority of cheerful cases is to be found among those who are not confined to one room, whatever they are suffering, and that the majority of depressed cases will be seen among those subjected to a long monotony of objects around them. A nervous frame really suffers as much from this as the digestive organs suffer from long monotony of diet. The effect on sickness of beautiful objects, on variety of objects and especially brilliancy of colours, is hardly to appreciate. Such cravings are usually called the "fancies" of patients but these "fancies" are the most valuable indication of that which is necessary for their recovery. People say that the effect is only on the mind. It is no such thing. The effect is on the body too. Little as we know about the way in which we are affected by form and colour and light, we do know this: that they have an actual and physical effect. Variety of form and brilliance of colour in the objects presented to patients are an actual means of recovery" Florence Nightingale (Dalke, Littlefair et al. 2004)

It is not new that the environment has an impact on patients. As Florence Nightingale said the patients need a stimulating environment and light as one of the important factors in a supporting environment. (Millet 1996) said that the luminous effect depends firstly on the source of its intensity, secondly on the geometry or relationship between the source and receiving surface, thirdly on the reflective surfaces that receive and modify light and 


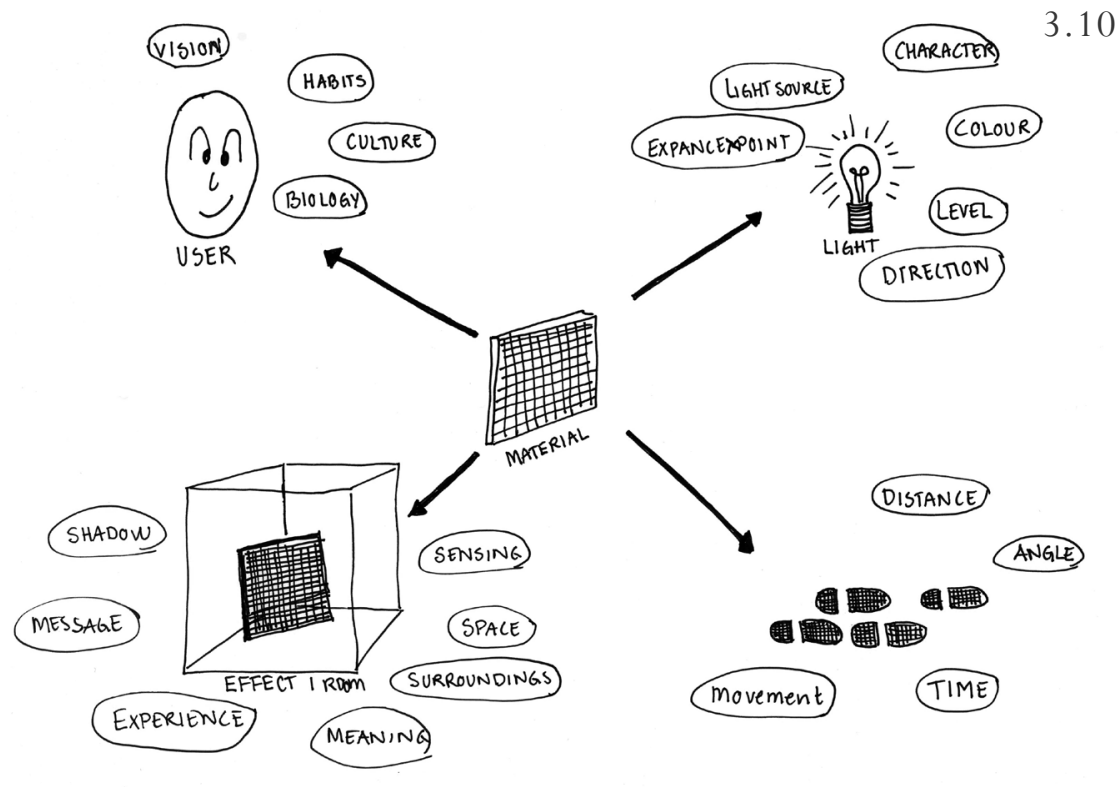

fourthly on the person who views both the source and the illuminated surface. As the section of Atmosphere and the experience of architecture explains, there are many "faces" of atmosphere relevant for study with regard to hospital design. As the different faces of atmosphere are all important for clarifying what kind of atmosphere that is being discussed. To avoid a mix of the understandings discussed and clarify the picture of what is discussed, this section deals with 'light atmosphere'and the content of 'light atmosphere' An abstract model was created to establish the framework for studying light atmosphere. The first model, (fig 3.10), is made quite intuitively and hereafter clarified through literature studies, visual experiences, explorative studies as well as experimental studies. First, the model seeks to pave the way for the study and later clarify and structure the $\mathrm{PhD}$ project, and lastly function as design tool to help sort out the important parameters. The presentation of the model development in this dissertation is based on the different visual identities, which the model have been presented to through the PhD study.

First version of 'Model of Light Atmosphere' was, as previously mentioned, developed using brainstorming based on

Fig 3.10. First version of 'Model of Light Atmosphere' called. Based on intuitively assumptions and brainstorm. a pre-understanding of the field and the gained knowledge from being a professional designer using this method to open up a new project. The technics exercised in the development process is mind mapping, visual analyses, notes from personal experiences, sketching and photographing. 
The model has 'material' as the center for the observation. In the upper left corner of figure 3.10 the user illustrated in a way looking at a material influenced by'light', 'time' and 'space'. Basically, the model has the same form in the following variations, however the models will change in the visual presentation focussing on different categories. The goal of producing the model is to create a temporary model functioning as a guide to literature and visual studies. Through cycles of iterations, the model is refined and elaborated by explorative and experimental studies corresponding with the model. In this way, the model is central to the PhD project. Thereby, the model is a useful tool for structuring the project as well as the design process.

Second version of the model, fig 3.11, is called 'pleasurable light atmosphere'. Here, the model puts 'a pleasurable experience of light atmosphere' as the center of the work. The question is: What is a functional lighting design and what does it take to evaluate a pleasurable light atmosphere? The main categories in the second model are 'Surfaces', 'Light source', 'Users', 'Space', 'Energy' and 'Time and distance'. Although all aspects are relevant to answer in a design process, the question is how important energy is in the experience of light atmosphere? Therefore, the third version of 'Model of Light Atmosphere', (Fig 3.12), excludes energy as a category.

The visual presentation of the third model is displayed in two illustrations. Both are circular and include subcategories as 'Light source', 'Time', 'User' and 'Space', and 'Light atmosphere' in the outer circle. The composition of the circles displays an interrelationship between the subcategories and light atmosphere. In this way the model seeks to visualize a more circular approach and put the user in the center of the experience of light atmosphere. This third version of the model seeks to understand the hierarchies in a model, but it is not applicable because the 'User', 'Time', 'Space' and 'light source' categories are not only a part of the 'light atmosphere' cycle, it is also "something else" out of the "light atmosphere'circle. Therefore, once more the model was reconsidered, rephrased and redrawn in order to display a better understanding of the field.

Fourth version of 'Model of Light Atmosphere',(Fig 3.13), displays the same main categories as the previous models. This time the hierarchy of the model is displayed as a
Fig 3.11

Second version of 'Model of Light Atmosphere' called 'pleasurable light atmosphere"'

Fig. 3.12

Third version of 'Model of Light Atmosphere' displays a circle with the user aspect in the center. The model appears in two similar examples with a little adjustment. 

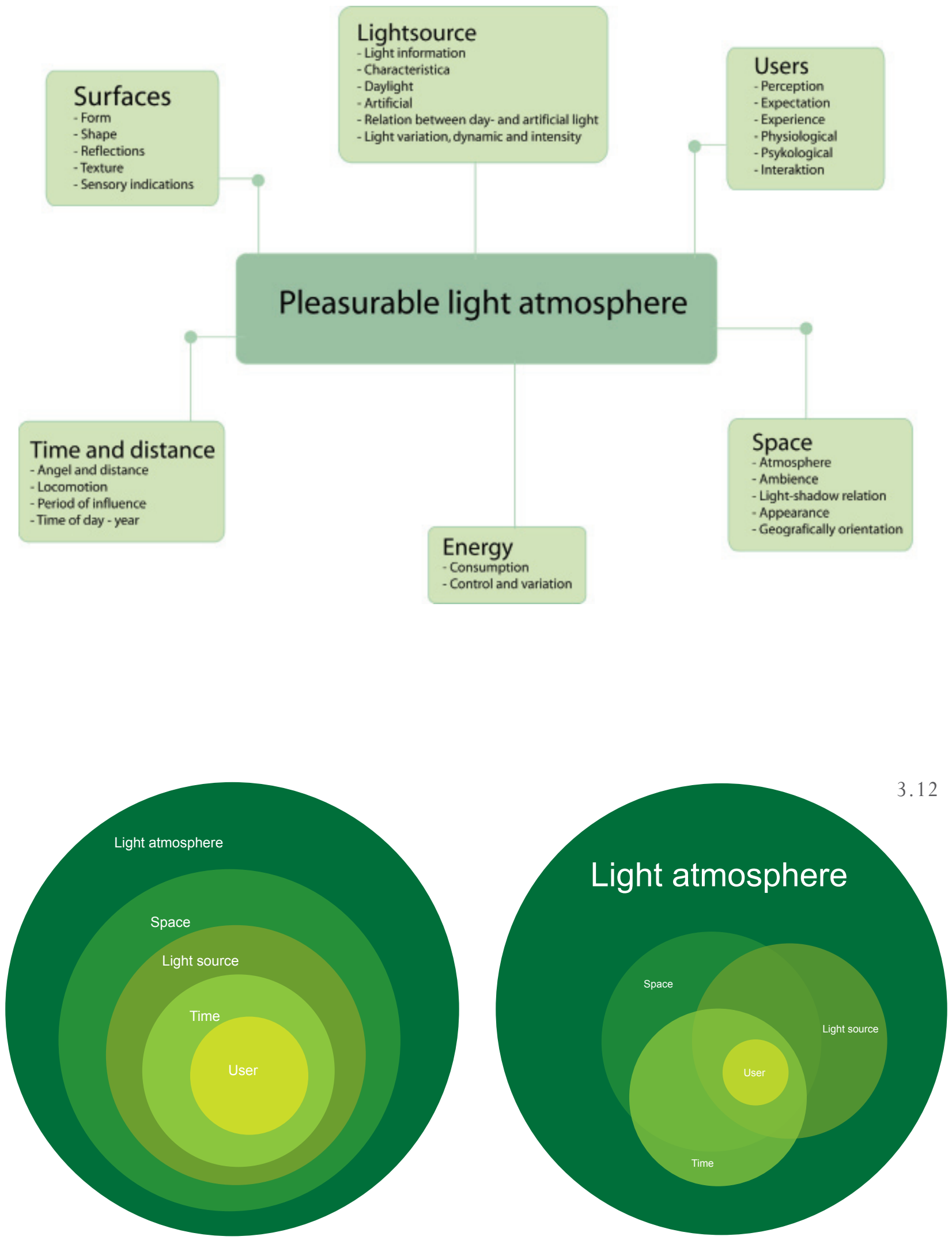


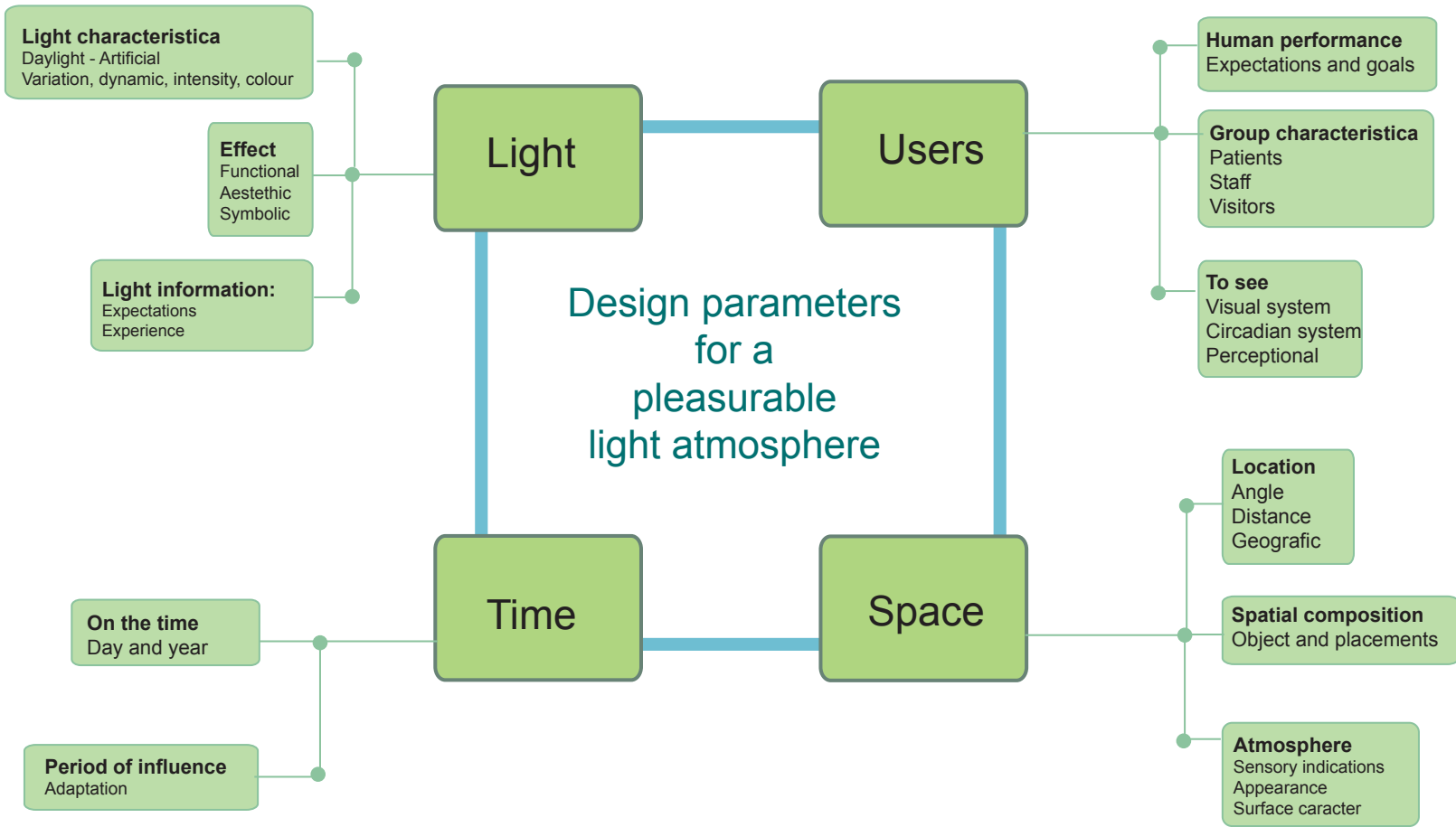

3.14

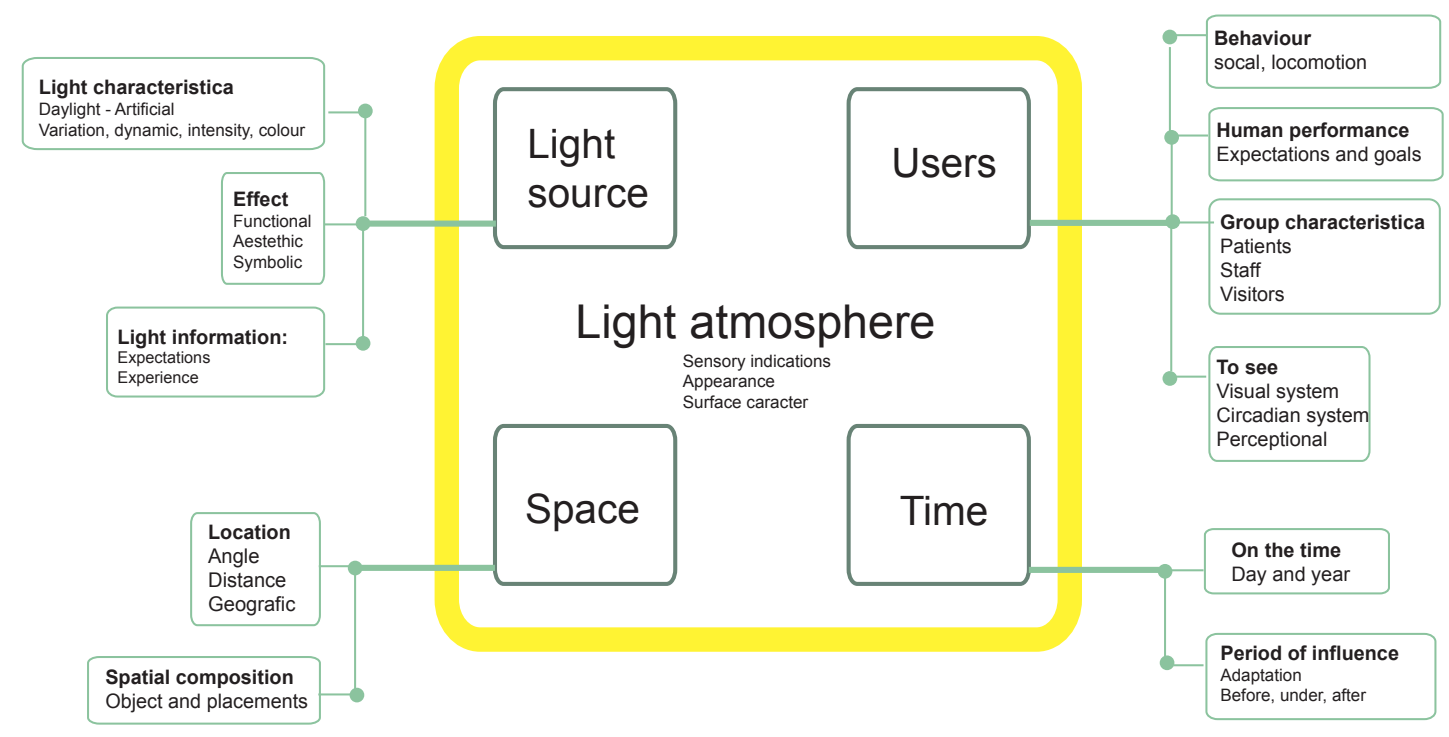

Design parameters for a pleasurable light atmosphere 
Fig. 3.13

Fourth version of "Model of Light Atmosphere". More detailed than previous model and the atmosphere in the centre of the model.

Fig. 3.14

Fifth version of 'Model of Light Atmosphere'. rounded square 'Design parameters for a pleasurable light atmosphere'. Sub categories 'Light', 'User', 'Time' and 'Space' are placed at the edge of the circle in a way to include a part of the light atmosphere as well as "something outside".

The subcategories are specified and explained outside the circle. This version still has some problems of confusion in communication. One of the subcategories placed in the main category 'Space' is 'Atmosphere' defined as sensory indicators, appearance and surface character, and this is conflicting with the center of the model where atmosphere is also represented. Therefore, yet another model, the fifth 'Model of Light Atmosphere', was created. The fifth model (fig. 3.14) is refined into a new form for the project, useable as framework for literature search and visual studies as well as a tool for the design process. The fifth model keeps light atmosphere as the central part of the model as well as the four subcategories 'Light sources', 'User', 'Time' and 'Space' as the important parts for the study. This time, the subcategories are included in the circle of light atmosphere in order to point out that the interesting part of the subcategories is what relates to this model. The model still has some layout problems while the very clear yellow bar defining the light atmosphere almost excludes the explanations of the subcategories.

The fifth version of 'Model of Light Atmosphere', (fig 3.14), was presented as a poster at the Experiencing light 2009 conference (Stidsen, Kirkegaard et al. 2009). The model is now finding a usable visual form supporting the aim of providing a model for framework on light atmosphere, as well as a design tool to test. This time, colours were excluded and the main categories arranged on the edge of the atmosphere circle so it shares space with light atmosphere as well as being outside the circle. The visual expression of the model is again more circular and the dashed lines display that they are not fixed terms or the route to light atmosphere can be interrupted by other important aspects.

While the background for developing a 'Model of Light Atmosphere' was to create an overview on this subject working as a framework on the thesis, the model is as well used as a design tool in the process of creating a lighting design for hospital wards. This means that the model is the beginning of the project, defining the field of light atmosphere and then used as a design tool when the lighting concept 
for hospital wards was created. Because the aim of the thesis is to describe important aspects for the experiencing light atmosphere and not what it needs to create a well-designed illumination, the energy aspects and maintenances of light installation are left out. That does not mean that energy and maintenance of an illumination are unimportant parameters in a well-designed, long lasting illumination, but with the aim of describing parameters important for the experience of light atmosphere, they are not the most central parameters. They do not directly influence the experience of a light atmosphere and are therefore omitted. Still, it has to be mentioned that the chosen luminaires in the project always seek to be the most efficient light sources, not conflicting with the need for light and suitable light source for a specific purpose.

The sixth versiton of 'Model of Light Atmosphere', (fig 3.15), goes back to black and white. To understand the content of the 'Model of Light Atmosphere' and to deepen the term in connection to light, four aspects are presented in the following section. The four subcategories 'User', 'Space', 'Light' and 'Time' are presented in a arbitrary order. While all categories have an impact on the others, it can be discussed whether they can appear in a single category or it is better to display the connection and interrelation between the categories. In this thesis, the content of the subcategories is explained and discussed separately in the category most central to the discussion.

\subsection{LIGHT ATMOSPHERE}

As we introduced section "Atmosphere and the experience of architecture", Böhme and Albertsen said that atmosphere is not a proof of "good taste" or a question of having access to "right" architectural understanding. Merleau Ponty claims that we use all our senses to experience and enter an environment (Rasmussen 1996). We use all our senses at the same time, and try to connect the information from the senses. We try to create a line of sensory information. The body does not only rely on the senses, but attempts to form links between the senses - a sensory integration. Consciously or unconsciously we decide whether we like being in a room and thus relax, or whether the body must adapt to the surroundings. This section will not go further into light atmosphere, as the atmosphere described in the former section and the idea of specifying
Fig. 3.15

Sixth version displaying 'Model of Light Atmosphere'. The model used throughout the rest of the thesis. 

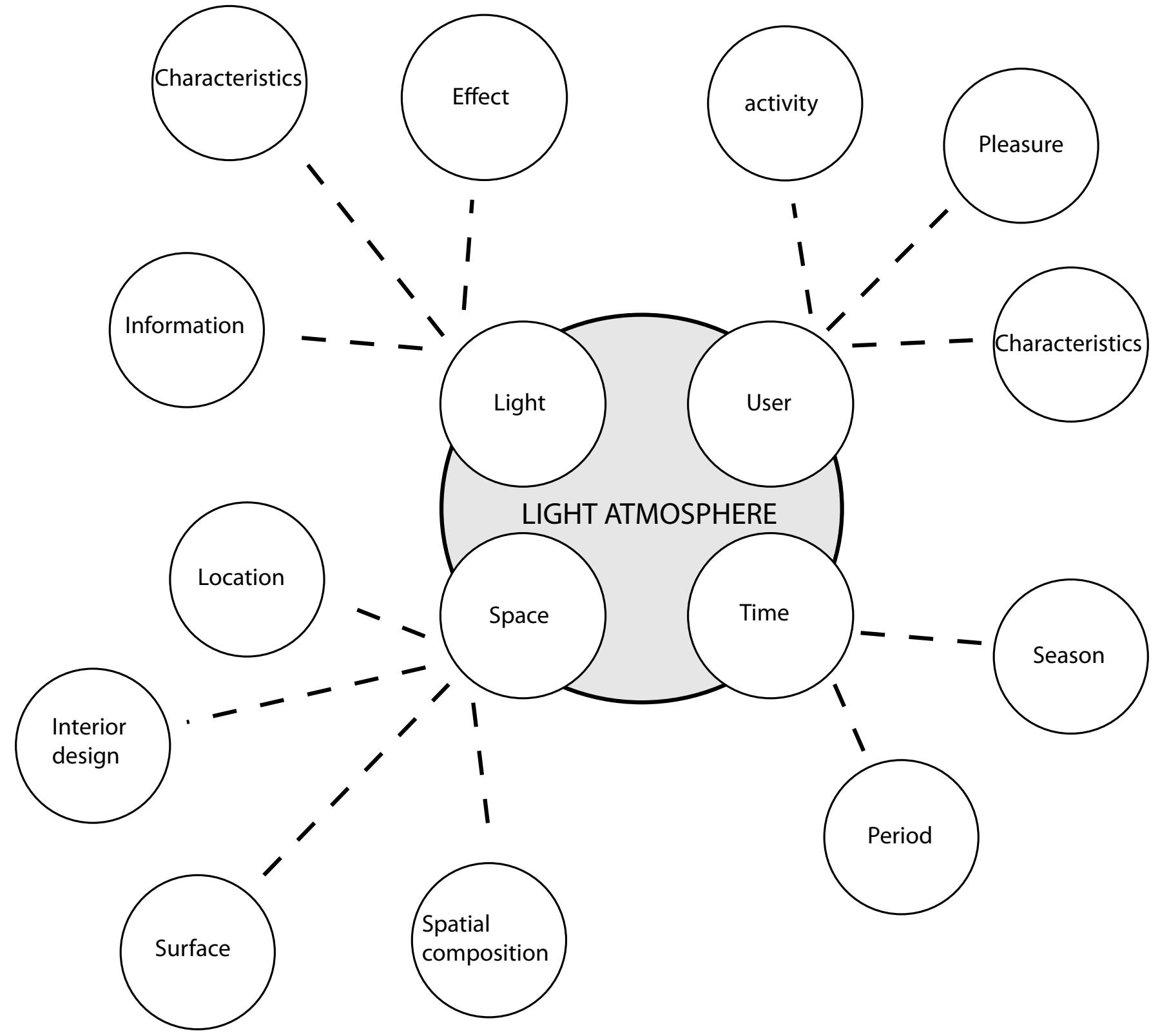

1

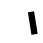

1

light and atmosphere is relatively new. Philips presented the book "Light and atmosphere - discover the secret of Home lighting" (Philips Lighting) and (Clausen 2009) presented the book "Light and communication-nature as reference in lighting design", and both contributed with information on something 'more' is going on and enhance the sensorial qualities of light as important. Light communicates something and provides a message based on the natural phenomenon of light. And light has an effect on 
the mood of persons in the space.

In this way, the thesis seeks to present some of the things going on, the'more' and 'in between' of the light's impact on the experience of a space. The thesis describes and displays light atmosphere in the four subcategories User', 'Space', 'Light' and 'Time'.

\subsubsection{USER}

Our experience with light and the dream of the light we wish to see is important for our perception and appraisal of the quality of light. The artist James Turrell created light installations providing a gestalt theoretical explanation of the experience of light in space. Turrell claims that:

"There is a light that has a clarity as great or greater than the daylight vision, and a lucidity of colour that is beyond how we see colour now. It has a fully formed vision, with characters involved and everything else - this is a seeing that is totally present and it is with the eyes closed. I'm interested in the point where this imaginative vision meets the seeing that comes from what we want to think of as outside physical reality - how we function. And a lot of the places I do will at times be on the edge of how we think about reality. (Turrell 1999)

Turrell explains the experience with light as if there is a connection between our 'inner light' and 'external light'. We accept the scenario or maybe we do not notice light as an important factor of the experience. If the connection between the 'inner light' and the 'external light' does not exist, we notice the light and the light experience is recognised consciously or unconsciously. So, the 'inner light' and the 'external light' have an effect on the experience of the luminous environment, but what the effect is and what our 'inner light' is, we do not know much about. To answer the question, we need studies dealing with the experience of light and elaborate on the user perspective. It is the user's eyes that see, the body of the user that feels the atmosphere. According to (Cuttle 2008), a lot about the visual system remains a mystery. But it is clear that it involves both the eyes and brain working together. The luminous environment is transformed into a retinal image. The retinal image is the stimulus for the visual process that provides information to the perceptual process to recognize objects and surfaces. This perceptual process forms the visual basis for the perceived environment. We 
are all affected by the stimulus of the environment, and it is also the goal to provide a pleasurable light atmosphere to all users of the ward. First, a presentation of the user categories is given followed by a discussion on what pleasure means in connection to light atmosphere and lastly user activities at the ward.

\section{User characteristic}

(Küller 1991) claimed that a basic emotional process constitutes the very foundation of people's assessment of their environment. The user's expectations and appraisal of an environment is important for the experience because a lighting design is often designed for more than one user group. Users can have different tasks and expectations for the environment or even different experiences affecting the experience of a space. Therefore, the users must be defined as well as the activities meant for the space, so the light atmosphere can support all user needs. Looking into health care environment, there are three important user categories. A hospital ward has a working staff, a recovering patient and visitors/relatives to the patients. All three categories have common as well as diverse needs and preferences for light.

\section{Pleasure}

The common denominator could be that the light atmosphere should be pleasurable. It is not enough that the illumination is usable or just okay. It should support a pleasurable environment and what it takes to design "more" than usable product. Patrick Jordan presented a pleasurebased research introducing the human factor in product design and spliting the term pleasure into four categories of pleasure: 'Physio pleasure', 'Psycho pleasure', 'Socio pleasure' and 'Ideo pleasure'. (Jordan 2000, Jordan 2000) Even though the theory of the four pleasures is developed regarding product design, Jordan underlines that product is for professionals working on human factors, interaction design, industrial design, software design, marketing, market research, product management and engineering. In this way, the theory seems appropriate for use in the experience of a space while the illumination is a part of engineering as well as an architectural understanding.

The category 'Physio pleasure' is related to the body and the senses. It is associated with touch, smell, taste and other sensory input. It is the kind of pleasure experienced 
in connection with the physical capacity of a product. In which way can the product make you physically capable to manage or perform both biological and visual performance? (Newsham, Richardson et al. 2005) found that the effect of expectations had an impact on the evaluation on the illumination. (veitch 2006) presented lighting for well-being as a revolution in lighting and pointed at the problem of incorporating the new knowledge in the recommendations. (Boyce 2003) pointed at the fact that light is important for visual comfort and discomfort. Boyce defines visual comfort as the absence of visual discomfort and visual discomfort as something that can occur if there are gaps in the luminance distribution. It can also occur because of people's expectation and preferences change over time. He points out that there is no reason why lighting should be exempt from such shifting expectations. He also states that problem can occur when diverse user groups from same or different cultures have different experiences for the environment and hence different expectations for the illumination.

According to Peter Boyce, lighting conditions can affect human performance in three systems: the visual system, the circadian system and the perceptual system. The visual system is a system that operates over a wide range of luminances, and the vision can operate from sunlight to moonlight or starlight. The way the visual system operates depends on the available amount of light and has three operating stages. The photopicstage where the vision discriminates details aspects as colour, materials, size, form etc. The mesopic stage is used in intermediate stage lighting conditions. The last stage is the scotopic stage. Here, colour can no longer be seen and details are impossible to discriminate. The visual system uses most of its resources analysing the central area of the retina, particularly the fovea. This implies that peripheral vision is mainly devoted to identifying items that later can be examined in detail by turning the head and eyes against the object. The threshold of the perceptual system defines the limits of the visual system. Most of our life we look at things clearly visible and we perceive myriads of stimuli. Boyce claims that perception of the visual world is not solely determined by the physical stimuli presented to the visual system as the retinal image. It is also determined by the characteristics of the visual system described above. According to (Valberg 2012), many properties that we normally attribute 
to the external world as contrasts, movement and depth mainly rely on the perception. Valberg remarks that it is almost impossible to distinguish between neutral and cognitive levels of perceptual patterns, and despite his background in natural science, he points out that vision is neither entirely nature nor entirely consciousness. A visual experience of the world does not emanate from a series of static retinal images. The vision has access to a dynamic flow of continuously varying retinal information interplaying with complex information from all other senses, about spatial colour, light relations, movements and about our present position in space. By a philosophical approach with Merleau Ponty and Valberg's natural scientific points of view, the human experience derives its origin from multiple sources that are external as well as internal (Klaren 2012).

Boyce talks about the perceptual constancies in light and mentions four fundamental attributes of an object, which are maintained constant over a wide range of lighting conditions. Firstly, lightness related to a physical quantity is the reflectance. Secondly, constancy is colour and the stimulus a surface present to the visual system depending on the spectral content of the illumination. Thirdly, the size of the space or shape, and, fourthly, the shape of the object is constant. If the lighting conditions in a space provide a good quality of lighting, the space can be understood. The lightness, the colour, size and shape of objects in a space remain constant, no matter how they are viewed. Lighting can be used to reinforce or to undermine the perceptual constancies.

The circadian systemor the "body clock" is a basic part of life and can be found in all plants and animals, including humans. The role of the circadian system is to establish an internal replication of external night and day - a body clock. Lately, the circadian system has been the focus of lighting research due to its major impact on human performance. The new knowledge discovered in 2002 is the photo biological science discovery of the third receptor. In 2002, Berson et al discovered an unknown quality in the retinal ganglia cells and found that the light has an impact on the biological clock, the circadian rhythm. (Christoffersen 2006, Rea , Rea 2006). After these findings, the dynamic of the light was a new subject for research in lighting (Brennan 2007). Rea claims that light is the pri- 
mary stimulus for regulating the timing of a wide variety of biological functions. He also mentions important dimensions of light essential for the biological functions. Dimensions as the quantity of light, the duration of light exposure, the spectrum of light distributed, spatial distribution of light and lastly the timing of light explosion. Rea notes that daylight has an affect on the circadian system, but the artificial light may not be bright enough for a direct effect. But he also concludes that the artificial light is bright enough to extend our waking hours and reduce the time we sleep. Therefore, Rea points out that it is important to be aware of the effect of artificial light on sleep deprivation and deterioration of performance and thereby the health. (Christoffersen 2010) points at the light effect on wellbeing and highlights that lighting therapy can have an effect on people suffering from Seasonal Affective Disorder (SAD). (Stuhlmiller 1998) concluded that researchers studying the effect of seasonal change should be aware of cultural perception and adaptation. Perhaps the artificial light has a minor effect on the circadian rhythm, but the physical pleasure also includes the visual and the perceptual system. Here the artificial light has an impact on the understanding of the environment and the experience of the environment, and is therefore important.

The 'Psycho pleasure' pertains to people's cognitive and emotional reactions. Therefore, this category is to "see yourself seeing". The psycho pleasure is linked to the brain and is thereby the psychological aspect of light. What does the light do to you, how can it stimulate the experience of a space and what does light do to the senses.

(Goodman 2009) explored in which way light has an impact on humans and noted the shortcomings in our current measurement systems for light and lighting. Goodman thought that it was not sufficient or enough to discuss and talk about lighting in measurements as luminance at work plane or the colour rendering scales. It is a reduction of lighting quality and we have to broaden our measurement scales and instrumentation to allow for a more comprehensive description and analysis of our visual world. (Knez, Enmarker 1998, Knez 2001, Knez, Kers 2000) investigated the effects of the recommended office lighting on people's mood and cognitive 
What is Turrell's art about?

About light and perception, one feels tempted to answer. Perhaps it would be more correct to say: his art is light and perception. Turrell's works do not represent anything. They are themselves: Light and darkness, space and perception. His installations manipulate the conditions of our perception rather than present objects of aesthetic contemplation. This is art liberated from all objects. It is not about what is before, but rather what is behind our eyes - about the preconditions of seeing and the limit of perceptions..... Turrell's work is about the ability of light to fill up a space and saturate it with seeing. Thus, seeing itself becomes visible - you see yourself see. In Turrell's words "I am really interested in the qualities of one space sensing another. It is like looking at someone looking. Objectivity is gained by being once removed. As you plumb a space with vision, it is possible to "see yourself see". The seeing, this plumbing, imbues space with consciousness" (Birnbaum 1999)

performance. Knez also studied gender effect in lighting and found that the gender role for light perceiving is different. Knez found that light was considered more glaring, more intense, less dim and less soft by females than it was by males. Consistent with some previous results in emotional psychology, these data indicates that females are more expressive (in general terms) toward the indoor lighting (an affective source) than males are.

(Veitch, Gifford 1996) describes the development and accessed beliefs about the effect of common types of interior lighting on human health, work performance, mood and social behaviour. The study provided information allaying unwarranted fears and concerns about new lighting technology, while some scepticism was demonstrated. According to (Küller 1991), people seek to understand their surroundings, create meaning, make sense, search for positive and emotional experiences and enjoy challenging the brain. Kaplan introduces an information-processing model of environmental appraisal: 'Human Environment Interaction model' (HEI). (Küller 1991) claims that a 'Basic Emotional Process' (fig 3.16) constitutes the very foundation of people's assessment to the environment. As ill 3.15 displays, the 'Basic Emotional Process' is partly affected by 


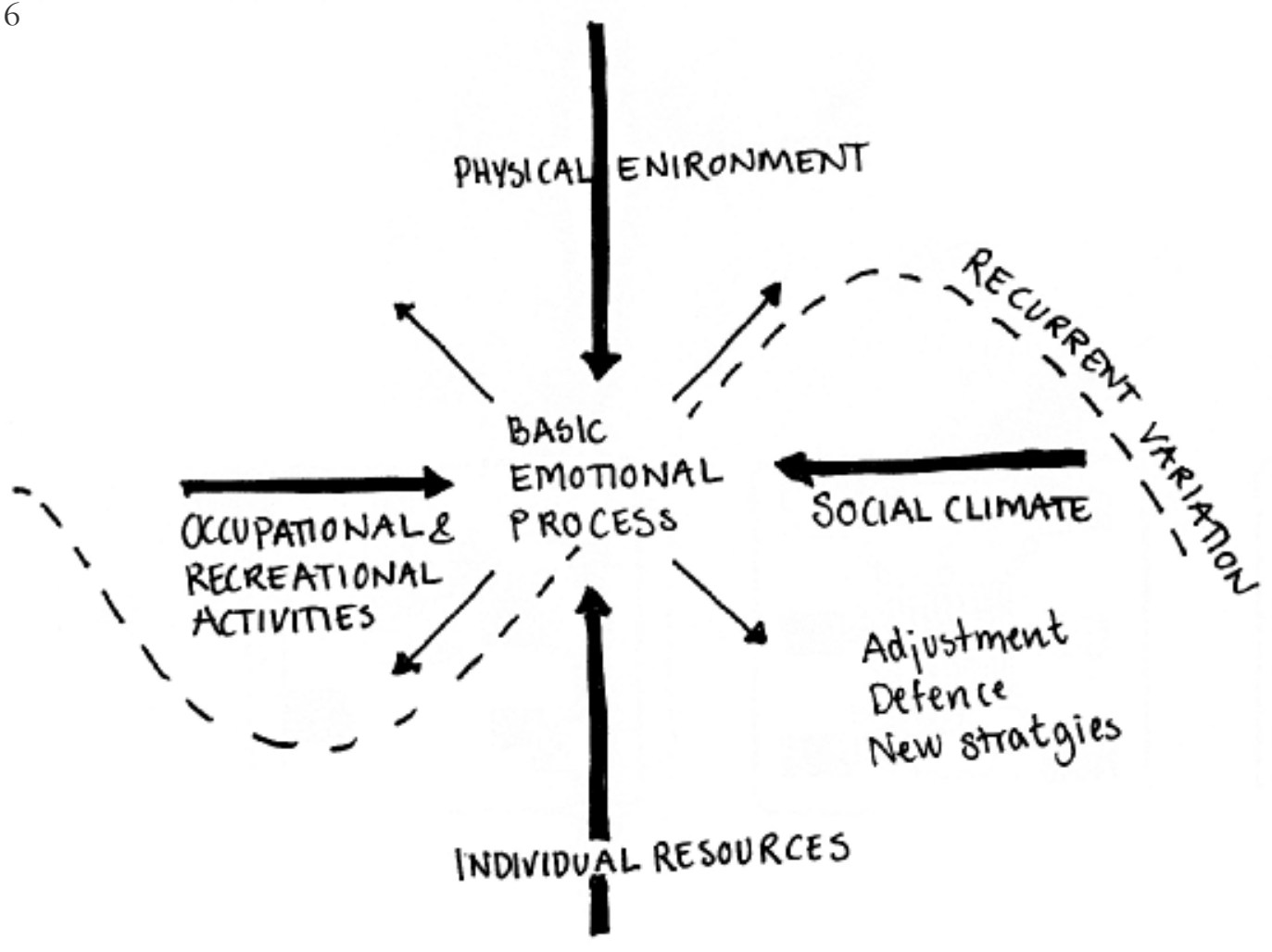

physical environment, the occupational and recreational activities, and the social climate. All aspects affect the 'Basic Emotional Process' and vary in extent over time. The individual resources will try to retain control over the situation and will lead to various strategies of adaptation, defence and coping. There is an interaction proceeding in four steps: activation, orientation, evaluation and control. If the physical environment, the social climate, the individual resources or the activity do not match the basic emotional process, the outer parameters must be adjusted in a way so they fit the basic emotional process or a new strategy must be planned. On the other hand, it may be the 'Basic Emotional Process' that must be adjusted.

Küllers interest was to find out to which extent the information available in a scene is central to our appraisal. Therefore, Kaplan notes that people need to make sense of what they see and to become involved. He introduces four dimensions important for the appraisal of an environment. He mentions coherence, legibility, mystery and finally the complexity and the need to be an active interpreter of the information. Küller described environmental assessment Fig 3.16

'Basic Emotional Process'

Modified after Küller, Basic neuropsychological concepts in environmental assessment. seen from a neuropsychological perspective. Here, Küller 
claimed that an emotion is not a state, but a process that evolves in stages and calls it 'Basic Emotional Process'. The process proceeds in four steps corresponding to the neurophysiological events of arousal/activation, attention/ orientation, reward/aversion (evaluation) and coping/ control. The 'Basic Emotional Process' entails that every impulse causes a brief, temporary arousal reaction. A result of repeating the impulses is that the arousal level may be altered to a higher or lower level. This kind of change in the emotional state results in a growing preparedness to react to an upcoming situation. That means that we have an experience that teaches us to react in a situation. Once control is established, the basic emotional process can be concluded. The process will be repeated over and over again, as a response to changes in the human environment relation. For the experience of light atmosphere, it means that the 'Basic Emotional Process' regarding light is affected by the sense of coherence. Does the light "fit into" the situation. (McClughan, Aspinall et al. 1999) pointed at light, having a long-term effect, involves complex interactions between gender, which is consist with Küller's proposal for short-term and long-tern lighting effects (Küller 1991).

(Galasiu, veitch 2006) studied preferences and satisfaction with daylight control systems. (Flynn, AIA/FIES. et al. 1977, Flynn 1979, Flynn 1988) studied the effect of light levels and the light source colour on user impression and satisfaction. (Butler, Biner 1987, Boyce, Veitch et al. 2006, Logadóttir, Christoffersen 2008, Quartier, Van Cleempoel 2008) studied preferred light levels for tasks and found that when participants believed the lighting conditions to be important to a situation, they wanted to be able to control the lighting. Similarly, Veitch (1996) predicted that beliefs about the effect of lighting would correlate with the desire to control features, including lighting. All the studies pointed out the importance of careful awareness of users being affected by what we expect to see and what we have learned through the developing process of the ' $\mathrm{Ba}$ sic Emotional Process'. The study also pays attention to the effect of being in control of the light situation and sense making. It requests going deeper with an understanding of the situation, to define the psychological needs for light and to give greater priority to the user needs, preferences and learn from the user's expectations and experience of light. (Hawkes, Loe et al. 1979) studied configura- 
tions with diffuse light and focused sources and found that the diffuse light sources were rated as uninteresting, and configurations with one or more focused source were on the interesting side of neutral. In 2008, (Rowland 2008) found that the overall conclusion is that people create an environment. Aspects as attitude, competence and helpfulness of the staff create the atmosphere of the hospital ward regardless of layout, furnishings, equipment and décor. Rowland notes that patients felt that the environment had an effect on their mood and wellbeing. These positive factors were discussed and Rowland pointed out that if a small friendly ward is wanted, factors such as the light, airy climate, clean environment are important as well as an outside view to nature.

The medical sociologist Aaron Antonovsky claims that it is important to find a 'sense of coherence' in a situation (Jensen 2009). He defines the "sense of coherence" in the following manner:

"The sense of coherence is a global attitude that expresses the extent to which one has a comprehensive and durable, yet dynamic - feelings of confidence to the stimuli that one gets from the inner and outer world through life, is structured, predictable and comprehensible, that the resources that are necessary for being able to meet the demands of these stimuli are available, and that these demands are challenges that are worth investing."

Antonovsky mentions three important aspects of establishing a 'sense of coherence'. The first aspect is 'Comprehensibility' which is the extent to which one experiences inner and outer stimuli as rationally comprehensible. Many things happen around us and appear to be clear and not a diffuse noise, chaotic random, unexpected or unexplained. A person possessing a strong sense of comprehensibility can feel future stimuli as predictable, and if the stimuli come as surprises, they are sorted out and explained later on. Secondly, 'Manageability' is an aspect concerning the extent to which one sees resources disposable for meeting the demands there are posed by the stimuli. These kind of resources can also include support and assistance from others. Usually this will be assistance by well-known and trusted people. People with a strong sense of manageability who do not see themselves as victims of circumstances, and they do not think that life treats them unfairly. Thirdly, 'Meaningfulness' is the extent to which one finds 
that life is worth investing energy in or worth engaging in. Here, problems are seen as challenges rather than burdens. People with a strong sense of meaningfulness see meaningfulness as the motivational components.

In connection with the illumination of an environment, we are not use to talk about comprehensibility, manageability or meaningfulness. But to be able to relax and recreate, it is important to feel a sense of coherence to generate energy for the recreational process. Therefore, it is important to discuss and study the comprehensibility, manageability and the meaningfullness of an illumination.

'Socio pleasure' refers to the relation to other people, both in a specific and an abstract understanding of the term. What kind of behavioural or social impact contains the product/space and what kind of influence does it have on society or other social groups. One of the scopes presented in the (Rashid, Zimring 2008) study is to underline that a proper lighting is very important for residents in assisted-living facilities. Proper lighting can allow the elderly to function more independently by improving social contact appetite, mood, self-confidence and anxiety levels. (Alfredsdottir 2002) described the atmosphere between staff and patients as a vulnerable dynamic phenomenon. (Jörgensen, Römma et al. 2009) studied the connection between ward atmosphere and patients' satisfaction. (Rossberg, Friis 2004) studied the patients and staff's perception of a psychiatric ward environment and found that staff members had significantly higher scores on the WAS scale (Moos 1974, Moos, Shelton et al. 1973). (Carr, Dabbs 1974)) found that dim lighting lessens eye contact and increases verbal latency in conversations. (Gifford 1988) found that light settings have an effect on communication and mood. He studied the effect of lighting level and room decor on interpersonal communication and showed that brighter lighting stimulates more general communication. He also showed that home-like decor would encourage more general and more intimate communication. Gifford points out that human activity level should generally increase in daytime or in bright light; as light dims, activity should slow.

The light seems to have an effect on the social situation. From lighting design practice, it is also known that it is possible to create visual distance in a space with lights, and to unify the space in light zones where people can 
gather. The light can have an impact on the behaviour of people. From the course of light and colour in Trondheim 2012, Assoc. Prof. Karin Søndergaard, The Royal Danish Academy of Fine Arts - School of Architecture in Copenhagen, had a lighting performance workshop where the participants experienced what it meant to be inside the light zone(fig 3.17), on the border of the light zone and outside the light zone. The body felt different from space to space, being exposed to the light or hidden by the shadow. The interesting part was to explore the interaction with other people inside or outside the light zones.

The term 'ideo pleasure' is according to (Jordan 2000) linked to the individual taste, values, desires and what we strive for when we use a product. The flavour we associate with colours, music or art. It may be values that arise from religious ethical, moral or cultural issues. It is the image in which we want to see ourselves. In Denmark, we are influenced by a Christian culture, although few would describe themselves as Christians. But the Danish society and the fundamental ideologies are based in a Christian mind-set. Therefore, the schools teach Christianity instead of religion, and most Danes grow up affected by a positive conception of light. In the following quote, it is obvious that light is interpreted as something positive and darkness associated with something negative.

"No one lights a lamp and puts it in a place where it will be hidden, or under a bowl. Instead they put it on its stand, so that those who come in may see the light.Your eye is the lamp of your body. When your eyes are healthy, your whole body also is full of light. But when they are unhealthy, your body also is full of darkness. See to it, then, that the light within you is not darkness. Therefore, if your whole body is full of light, and no part of it dark, it will be just as full of light as when a lamp shines its light on you." (Luc 11, 33-36)

Politically we also use light as a symbol of freedom. May 4 is the day when we celebrate the anniversary of the Danish liberation in 1945. On the day of liberation in 1945 when Danish people heard the news on the radio, they tore the blackouts of the window down and lit candles in the windows to lighten up the cities. Since then, the liberation day has been remembered and celebrated by putting candles in the windows as a symbol of regained freedom. (Danmarks Radio ) 


\section{Activities}

According to (Küller 1991), human activities can be divided into three categories. First, 'Sleep activities or related to sleep' is a predominant activity providing slow and subdued physiologic processes. It demands a quiet and stable environment, free from strong, sudden or irregular stimulation and a light providing a relaxing tone to the situation. The next category of activities is the 'Every day activities' which is marked by a medium arousal state where the human can handle varied stimulation of all kind. The kind of illumination supporting this kind of activity has to be split up in subcategories, because it depends on if you are sitting or standing or if it is visually demanding character or setting the "tone" in the space. The final category is 'Extremely difficult or dangerous activities'. These activities put a heavy demand on concentration at the expense of all irrelevant information. This state of so-called vigilance performance is accompanied by a high or very high state of tonic arousal, and the light must support the concentration aspect.

Fig. 3.17

Image from light workshop. A person experience the edge of light and what it means to be inside or outside the light zone.

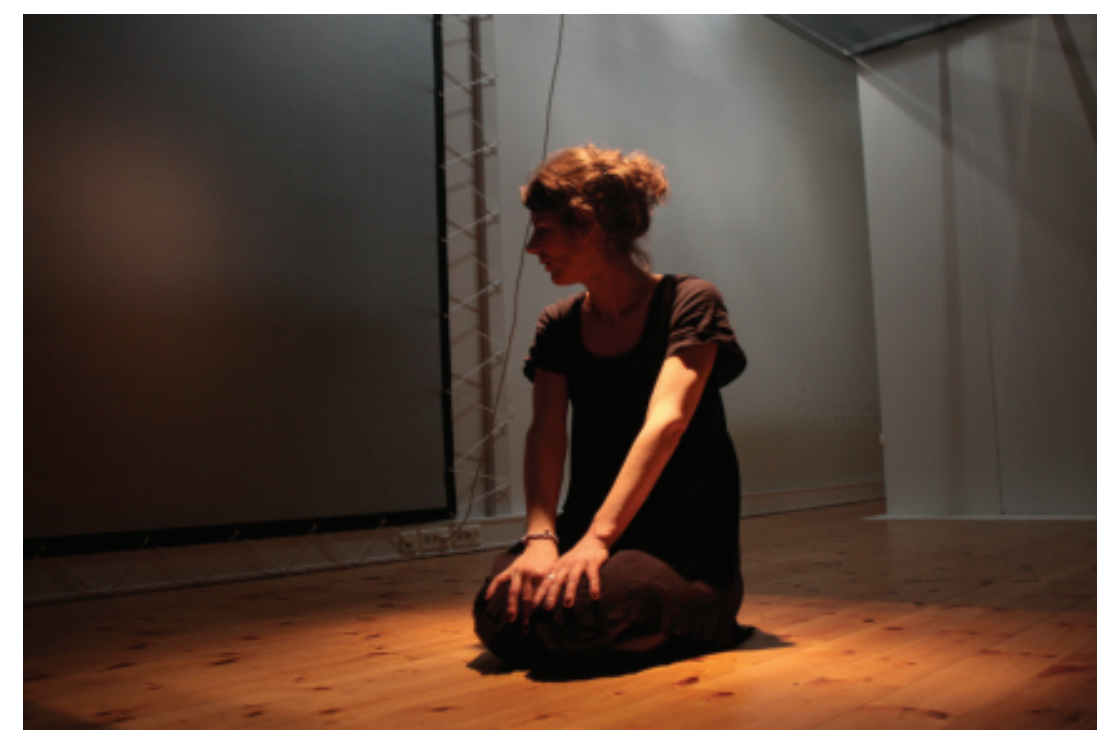




\subsubsection{SPACE}

Looking at the 'Model of Light Atmosphere', the third category is space. This category includes subcategories as location, spatial composition, interior design and surfaces. The location deals with the geographical orientation and placement of the light atmosphere evaluated. The spatial composition is the overall impression of the space as openclosed, complex etc. The interior design is the choice of furnishing, the shapes of the objects etc. and the surfaces deals with the microscale of colours, material qualities and texture etc.

\section{Location}

The geographical location and orientation of the space have an impact on the light situation in the space. Geographically there is a huge difference in daylight exposure. People living near the equator are familiar with a sun from Zenith. In Denmark, we have a long transition between day and evening. People living near equator have a very short period of sunset and a transition period around $15 \mathrm{~min}$ every day all year. Denmark has a dusk period of approximately 4-7 hours with large variations during the year (Volf 2010). That is a great difference in the experience of what daylight is and what kind of daylight experience is familiar to us.

The Danish weather situation moves from days with long periods of light in the summertime and short periods of light in wintertime. As ill displays, the sun moves from being low in wintertime to high in summertime. This has an impact on how the shadows are experienced throughout the year; from a winter sun creating long shadows around ustosummertime where shadows are shorter and nearer the body.

The table of the weather situation in Denmark provided by Danish Meteorological Institute (DMI)(Fig 3.18) also displays a variation of rain throughout the year. With rain follows cloudy weather and thereby a lack of direct sunrays, but sunrays filtered through the clouds. (Fig 3.19) display theIn that way, the shadows get more blurred and faint compared to daylight with direct sunrays creating shadows with sharp edges and forms. This could also have an impact of a local experience of daylight and our familiarity with the daylight. In this way, people near equator 
are perhaps more familiar with a vertical ecliptic of the sun, shadows falling quite near the body and an unfiltered, high light level compared to people in Denmark.

The location of the illuminated space has to be defined, since it also has an impact on how long the duration of daylight is available. In a south-facing space, the direct sunlight and heating can be essential to the experience of the space, as well as a north-facing space has to deal with indirect light. The illumination should be designed so as to supplement the orientation of the space and the environment located next to the space.

The extent to which the daylight experience has an impact on artificial illumination of the surroundings is an

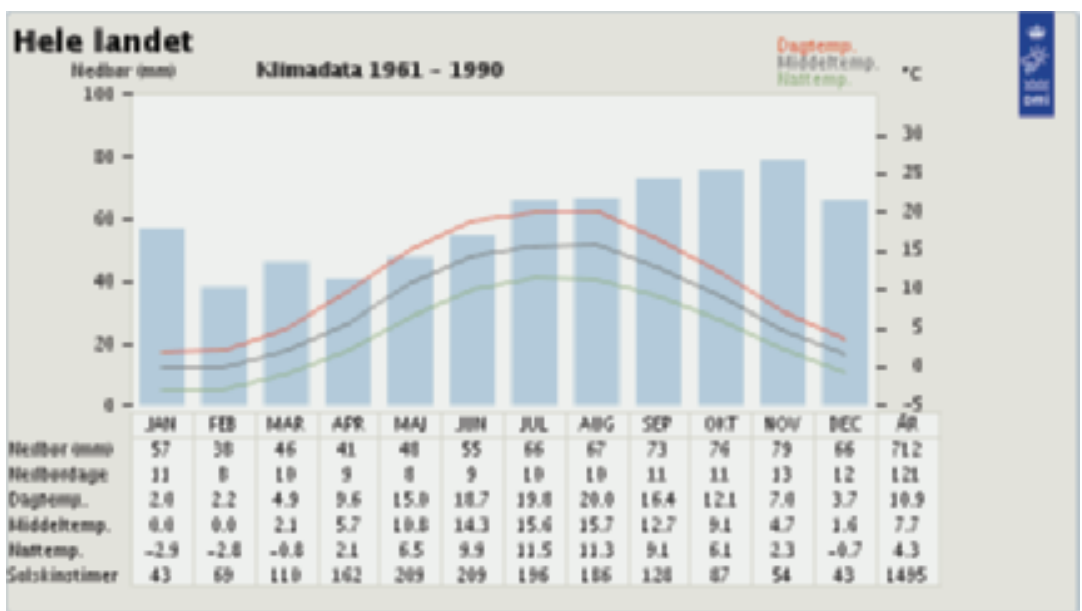

Fig 3.18

Danish Meteorological Institute. The Danish weather from 1961 1990

Fig 3.19

Summer and winther solstice. After DMI

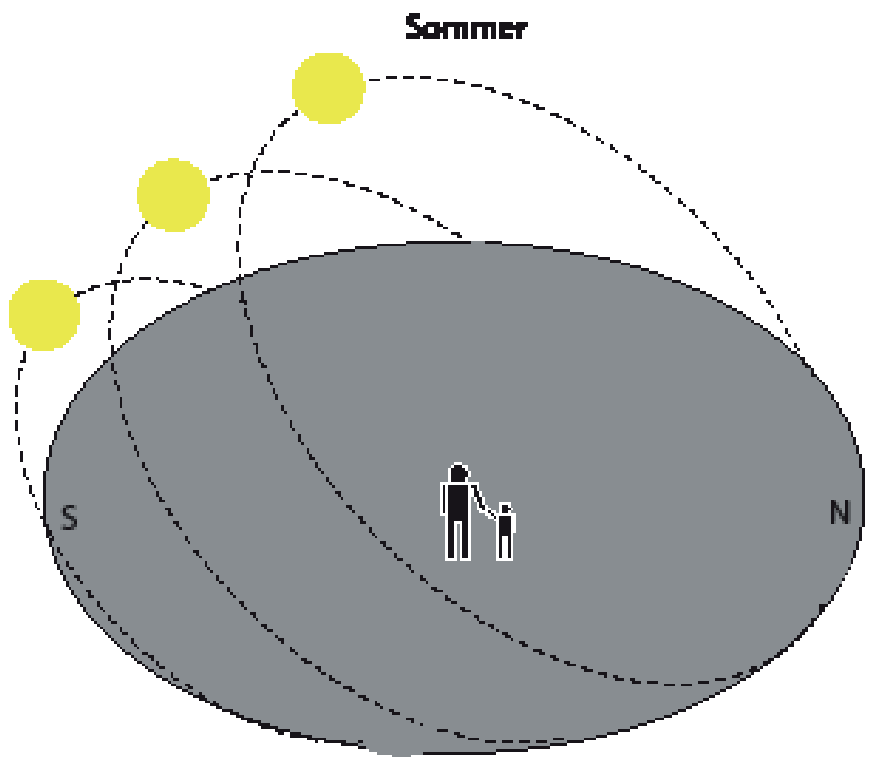


unanswered question. The way daylight is distributed; the appearance of light paterns and shadows can unconsciously have an effect on how we like to se the space around ourselves. Maybe we use our socio cultural experience of daylight to create a 'home like' artificial illumination. We do not know, but explorative studies as (Daniel 2012, Bille 2008) indicate that culture has a huge impact on the atmosphere. Right now, the Nordic countries are focussing on being 'Nordic'. Almost any kind of product at the moment has added the term "Nordic". Maybe the term is used as sales promotion. The Nordic people have a common understanding of light being important. Light is used with the purpose to create 'hygge' (create a cosy atmosphere), candlelights are used in extraordinary large amounts, people are in their private sphere surrounded by many luminaires so the light atmosphere can vary. Last year, the book 'Nordic Light' was published as a kind of sale promotion for the Nordic countries' approach to light. This is one of the signs showing that light is essential in a Danish space.

Inge Daniel from the Institute for Social and Cultural Anthropology at Oxford University presented in her talk "Kutsurogu - Feeling at Home" the Japanese approach to atmosphere and intimacy (Daniel 2012). In Japan, the coffee table is the center of the home. Daniel demonstrated how the Japanese created a homely atmosphere around the coffee table by placing a blanket over a coffee table covering legs. Thereby, it created a private space and kept the body warm at the same time. The table had the function of being an individual space where each member of the family had their own space for reading etc. At the same time, the table was used as a unifying and gathering space for the whole family. In this way, the feeling of being 'home' can differ from culture to culture.

Bille's study of light relates directly to aspects of Gernot Böhme's philosophy of aesthetics that argues that things are ecstatic, in the sense that they step out of themselves to display their presence to their surroundings (Bille 2008). To sense an atmosphere, whether cosy, scary, serious, powerful or pleasant, is to perceive how things and people are in relations in a location. Thus, 'atmosphere', as the manifestations of copresence of subject and object through the ecstasies between material and bodily presences, questions the classical ontology of things. Bille argues that light is
Fig. 3.20

The picture shows a contemporary Bedouin reception room in Jordan. Traditionally painted in two sections. A lower section painted in bright, light blue acrylic paint and a dull white colour in the upper part of the room. The light is a central, ceiling mounted unshielded luminaire. Photograph Mikkel Bille (Phd thesis chapt 7 : The luminosity of protection) 
used to reveal and conceal people, places and things in culturally specific ways. Light is cast for and not just on the material environment. Light is used in social life as a means of experiencing, reflecting and creating notions of identity, morality, security and spirituality. It does this by revealing, concealing or highlighting relations of things or particular aspects of social life.

Bille explains that many reception rooms in today's Bedouin homes often have the lower 1,5 meter of the wall painted with light blue acrylic paint, which could be to imitate traditional ways of protection against the evil eye by wearing light blue stones. The bright paint is practical because it cleans easily, but the acrylic paint also makes the texture of the wall appear even more luminous (fig. 3.20).

"Hence, colour, shininess and brightness are intrinsically linked to the light source and lightscapes in which they perform. The light bulb glows a yellow light, but within the last few years this has been replaced by fluorescent light, which is considered to have a clearer (blue) light. It is also considerably cheaper and

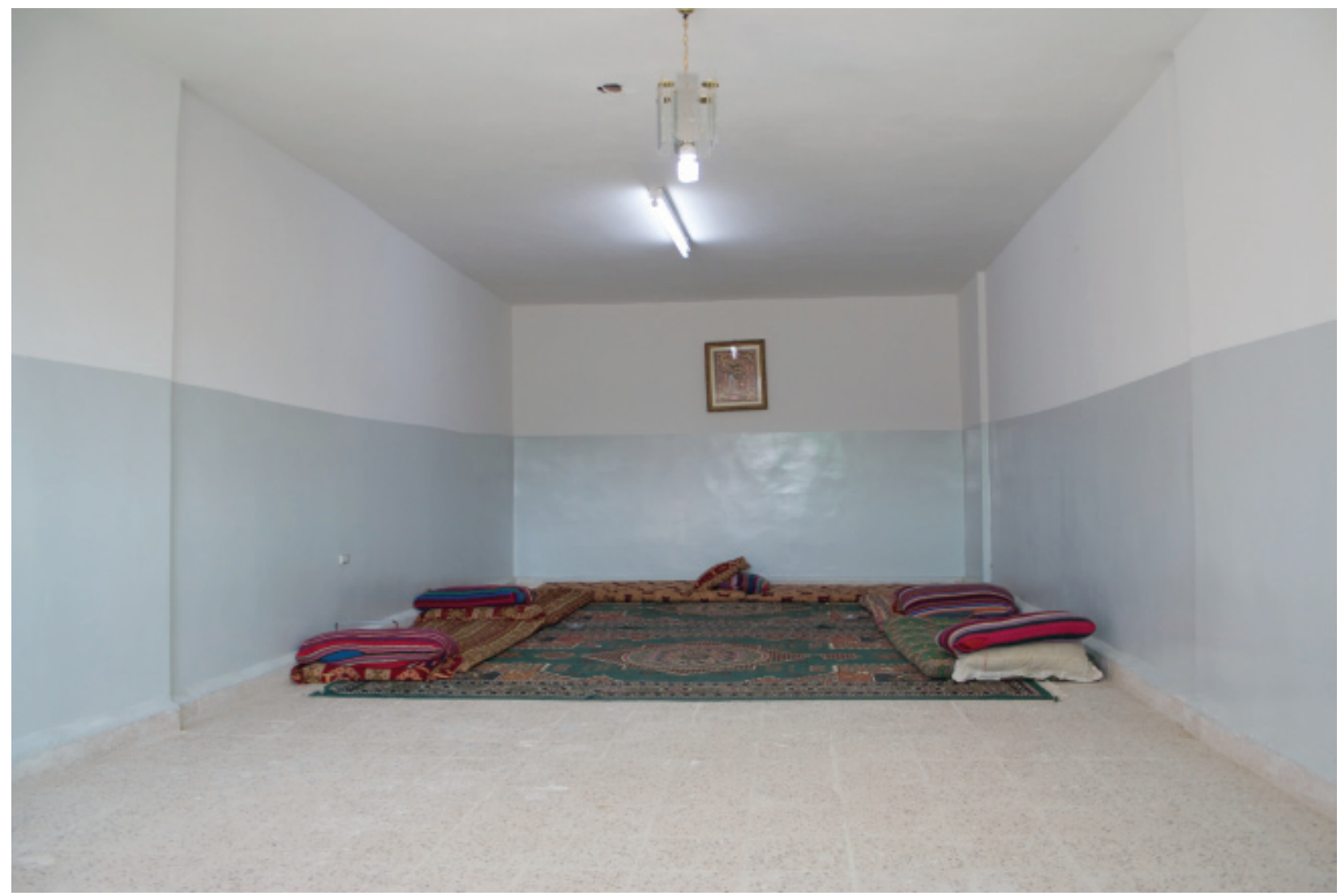


durable, but informants emphasized the clear blue colour. With the recent expansion of the reception rooms to cover larger areas, everyone uses several fluorescent lights in the ceiling. By using strong unshaded light, (if paint is used) white walls, brilliant acrylic paint, and empty interior spaces, rooms appear more spacious than they actually are. To relate this to the discussion of the developments in architecture, the room appears to be more spacious, allowing the family to appear more generous towards guests. Light exposes every corner of the expanded room, ensuring that nothing is hidden or concealed once within that domain. It also allows people to look each other in the eyes, thus shaping trust. Furthermore, shadows and dark areas are thought of as places where the jinn $d w e l l$, thus further suggesting the importance of illumination." Mikkel Bille thesis page 140.

When a family with a Danish cultural background has guest, there seem to be an opposite interest of using light as a gesture. Here, small light zones are surrounded by darkness. The light zones create an intimate or private sphere, and the "tone" of the space is more like a cave and embressant than an open space. From the study of light preferences in Danish homes presented in chapter 4 , Danish culture of illuminating in living rooms is presented. In Denmark, the living room can be compared to the reception room of a Jordan house in the way that, in both places, light plays a central role in the gesture of providing hospitality. But in contrast to the Jordan tradition of illuminating the space, the Danes use light to create small light zones around the space instead of having a central, ceiling mounted luminaire. In this way, the darkness is also a part of the space and the "tone" in the space is more like a cave illumination or a way to create an intimate/ private light space surrounding the people in the space. These differences in the way we illuminate homes could be influenced by the way we experience daylight. The socio cultural aspect of light is not a defined area and there are a lot of "maybes" and "what ifs" dealing with this area of lighting design. But through observations of chosen illumination techniques, it seems to be more than likely that the daylight experience has an impact on preferences for illumination. 


\section{Spatial composition}

The spatial composition of the space, the indoor air quality, the connections between the materials, acoustics and the thermal environment are all important for the perception of space and the experience of atmosphere (Rowlands, Noble 2008) to distinguish between spatial composition and interior design. In this thesis, the term spatial composition is defined as the architectural organisation of the space as the spatiality, enclosure, arrangement of doors, windows etc. Interior design is different from spatial composition as it concentrates on the design of objects in the space and shapes of the interior etc.

(Heslet and Dirckinck-Holmfeld, p. 263) present five categories of spaces in connection to hospital design (Appendix 6). First mentioned is the 'sublime' environment, which is a space where it is possible to disappear in the grandeur of the room. Second category is the 'qualified'environment where the space is experienced as stimulating and obliging. Thirdly, the 'indifferent' environment is a space found unimportant and trivial. Fourthly, a 'suppressive' environment that confuse the experience of the room, and lastly the 'unhealthy' environment that is experienced as unhygienic and makes the user field sick. The categorisation of a space can be used to get an idea of the quality of a space or to put a label on the quality of the environment. But to go into details, the interior design category takes over. (Lorenz 2007) studied the potential of the patient room and provided a review of research in the area. Among many results, Lorenz refers to studies showing that there is as relationship between the lighting in the room and patients' recovery rate. Patients admitted to sunny rooms recovered faster that patients admitted to dull rooms. (Wotton 1986) highlighted that windows in an intensive care unit can help prevent sensory deprivation, which can contribute to depression and delirium. (Ulrich 1983) highlights the fact that the assignment to a patient room with a view to nature instead of a view to a brick wall has an impact on the restorative influence.

\section{Interior design}

As mentioned, the 'sense of coherence' in the environment is important. We are influenced by our experiences throughout time, and we learn to navigate in the environment based on these experiences with the environment. The interior design is therefore an important aspect of the 
atmosphere while the shape; the amount and size of an objects, hard or soft impression, compact or open, organic or geometric etc. is a part of the experience. The environment affects our behaviour in a space. Our body stores sensory experience from previous meetings that effects sensing of new spaces.

An example of bodily storing of sensory experience from previous meetings with space is the sofa "Soft Wood" (fig 3.21 and 3.22) produced by Moroso and presented on Milan Furniture Fair, Italy 2009. Offhand I will claim that nobody would throw themselves onto this sofa without prior knowledge of the materials. The visual impression of the sofa is in the category of "wooden benches", and the body recognizes the material and form and has a behavioural reaction because it is a "hard material". This reaction is a bodily experience of wood and how the contact with wood is. In reality, this sofa consists of soft material and the wooden look is a printed fabric. If you dared throw yourself onto the sofa, it would have been okay, and a softer experience than expected. This example shows that the body's expectations of the appearance of an environment is consistent with previous experience and operates on a pre-understanding of the environment. The body perceives beyond its borders in order to "feel" or and recognize it.

From a study of psychological benefits of the view of nature, (Kaplan 2001) suggests that nature elements are

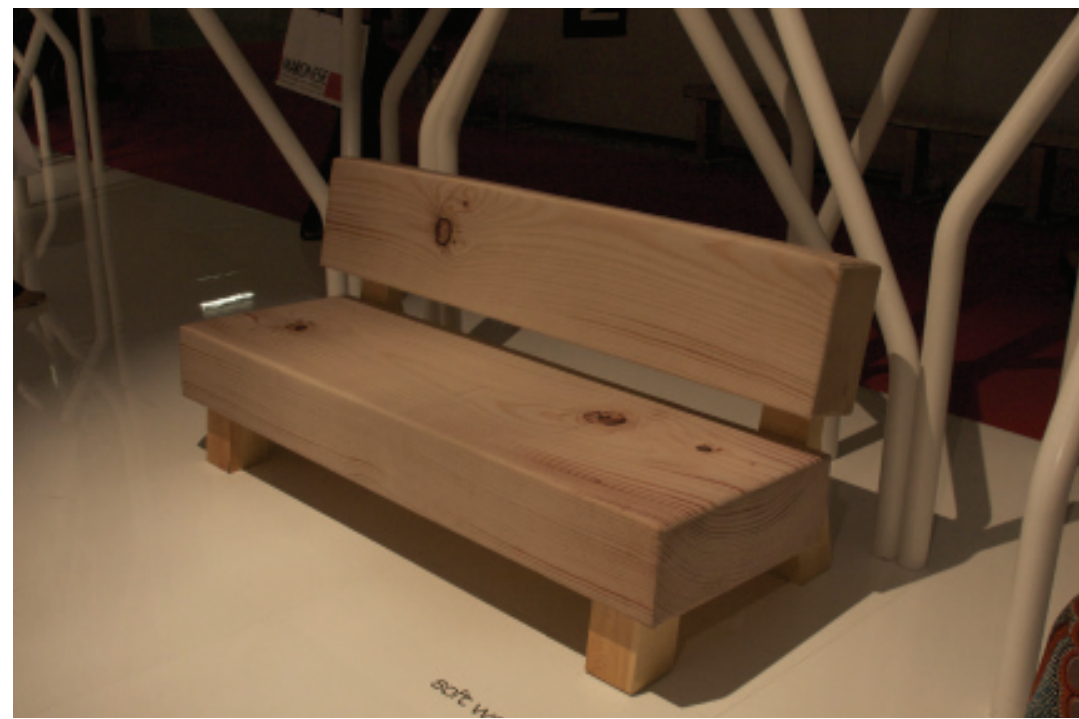

Fig 3.21

"Soft Wood" sofa, seen at Moroso Stand at the Furniture Fair 2009 in Milan.

Fig 3.22

Detail of "Soft Wood" sofa.

\section{Fig 3.23}

Gallery of pictures displaying light effect created by glass in windows.

Photo: Mathilde Botfeldt

\subsection{2}

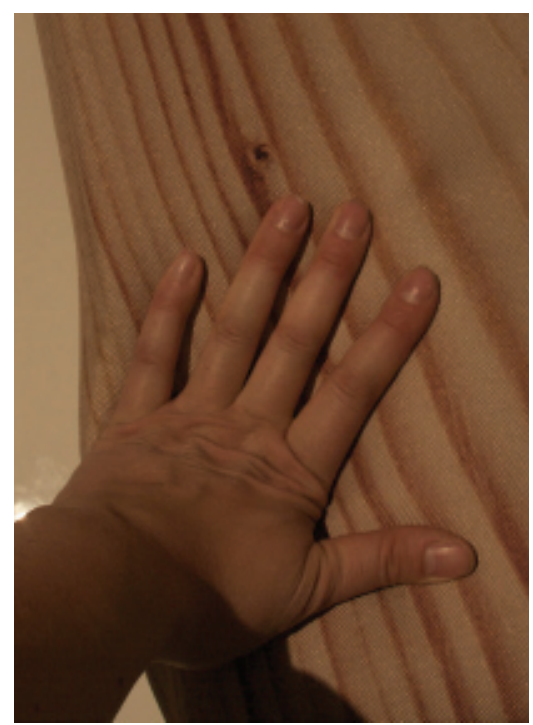


basic to provide satisfaction and wellbeing. The hospital must be a place which provides consistency between the goal of supporting user needs and an environment naturally supporting the user needs. It is a space where the 'sense of coherence' is essential and not a place to be playful or provide conflicting expressions of objects. Still, there is space for curiosity with light and shadow. The effect of shadows is also mentioned in this section of interior design, as light and shadow effects can create spatiality and accentuate the form of objects or zones in a space. But it can also be placed in the surface section or even in following category 'Light', as it is marking the light.

The shadows from objects and the light patterns created in a space can change the perception of the space (Fig 2.23). The reference to inspirational light or poetic light is often shown, by lighting designers, as sunlight passing through the crown of a tree creating myriads of light and shadow transitions. The variation in the light and the fanciful pattern of light contrasts are inspiring and something we find interesting. In everyday life, we can suddenly watch well-known surroundings in a new way because the light is creating a beautiful play of light and shadows or the sun is transmitted through materials creating reflections in the space.

To present light and shadow as a positive distraction the following study display how light can be used as inspiration

3.23
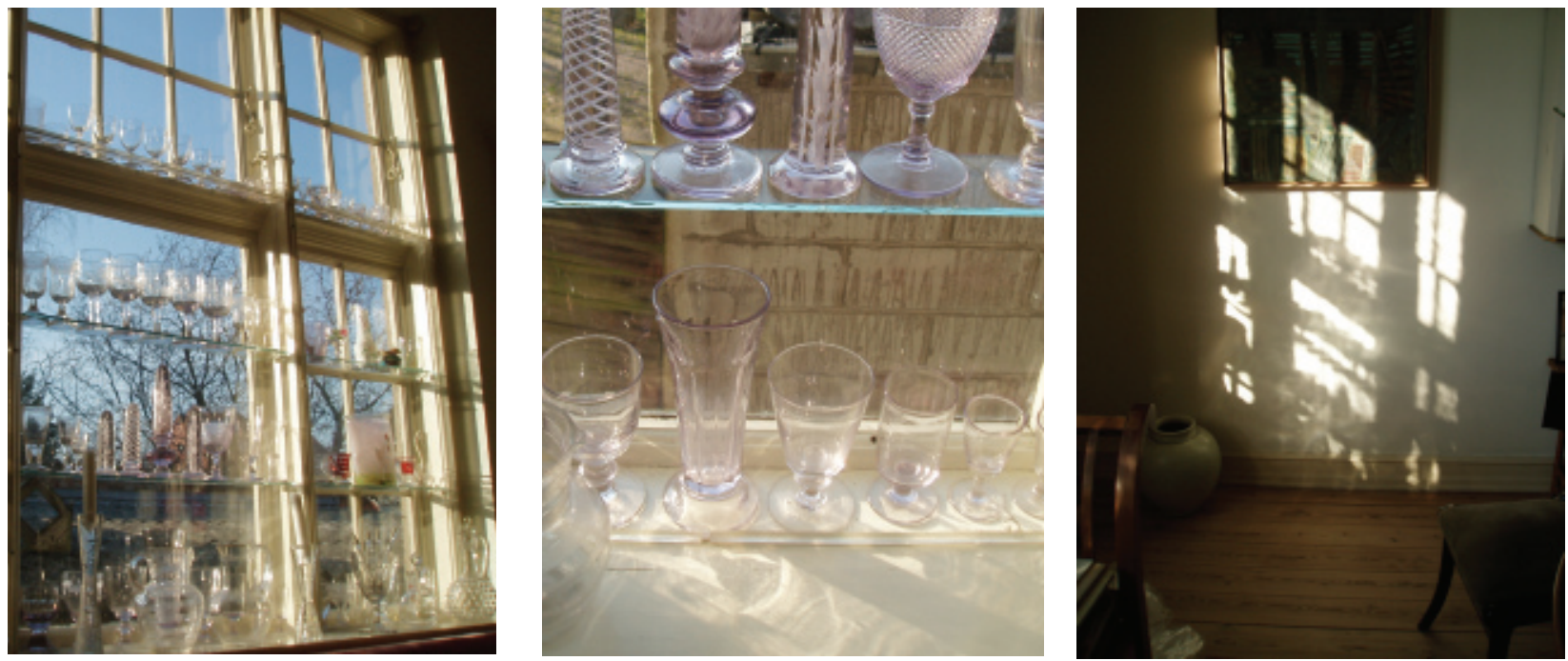
in fashion design. (Botfeldt 2005). Here, the effect of light is used as a material pictured as light transmitted through materials, reflected from materials or filtered by materials. The light-shadow effect can create impressive zones and in many ways change the appearance of the space and the light atmosphere. Botfeldt's trend book 'The shadow out of the shadow' has a playful approach to light and shadow and uses light as inspiration to her designs of cloth. The following collection of pictures(Fig 3.25) is from the project and tells stories of what is inside the shadow, the length of shadows, manipulation of the shadow and how a shadow can create new shapes and lastly the filtration of light as decoration.
Fig 3.25.

Photo collection from the study 'The shadow out of the shadow' by faosion designerMathilde Botfeldt. Photo: Mathilde Botfeldt
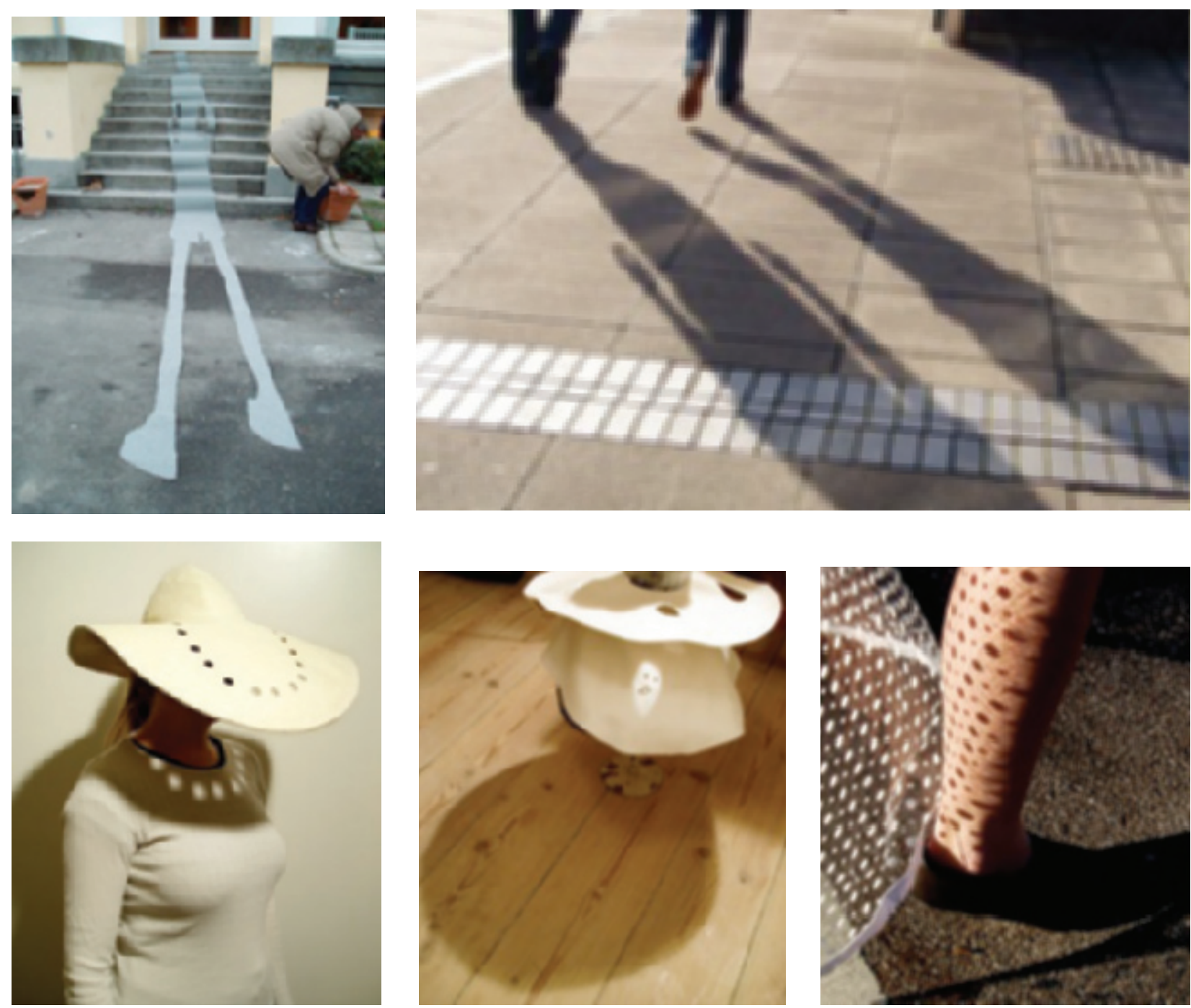
3.25
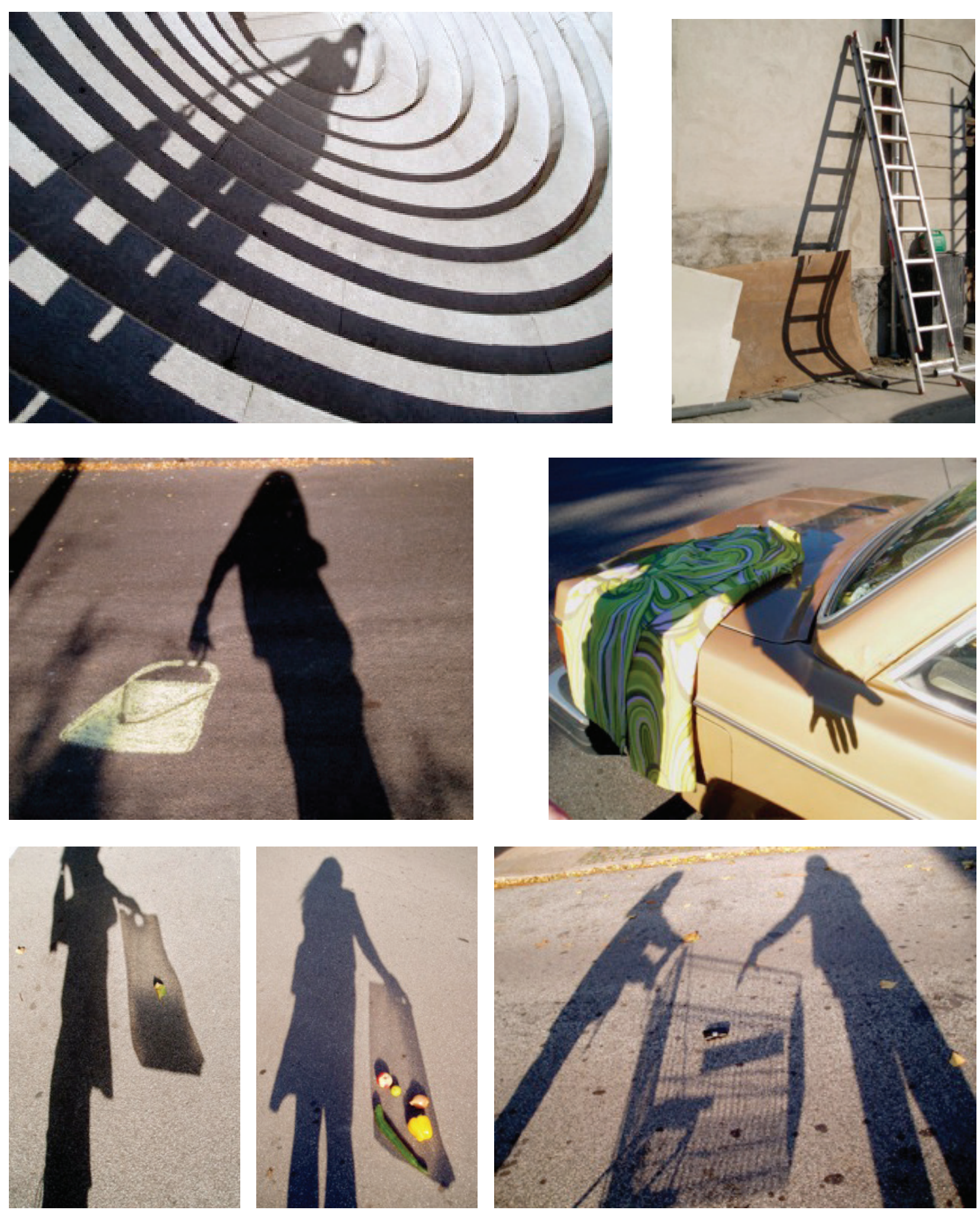


\section{Surfaces}

The surface of the elements in a space is important. (Malnar, Vodvarka 2004) point out that many of our most revered structures are clear tributes to light and colour. This implies that their expressive, sensory aspects are likely more important than their form. The choice of colour and texture is important for the experience of the light as it reflects or absorbs the distributed light and thereby make the light visible and has an impact on the sensory perception. (Boyce 2003) described the important categories of analysing materials as 'Brightness', 'Lightness', 'Hue', 'Saturation', 'Transparency' and 'Glossiness'. 'Brightness' is based on the extent to which an object is judged to be emitting more or less light. 'Lightness' is based on the extent to which an object is judged to be reflecting a greater or lesser fraction of the incident light. The 'Hue' is based on the classification of a colour as reddish, yellowish, greenish, bluish or their intermediaries or as having no colour. The 'Saturation' of the material is based on the extent to which a colour is different from a colour of the same brightness or lightness. 'Transparency' is based on the extent to which colours are seen behind or within an object, and lastly 'Glossiness' of a material is based on the extent to which a surface is different from a matte surface with the same lightness, hue, saturation and transparency.

(Liljefors 2004) points out contrast as essential for the way we navigate in a space. A variation in texture will stimulate the senses and be one of the aspects important for the time it takes to "read" the environment. Using the hospital as an example, there are hygienic conditions to consider and restrictions to respect. Therefore, most surfaces are easy to clean and the hygienic quality of materials in focus. The solution is often to use smooth, flat and glossy surfaces. In order to give the impression of a hygienic environment, the colour used in Danish hospital is white or light coloured, which in many cases gives the impression of a hygienic environment, but also provides a cold and unstimulating environment. It is too bright and glossy and thereby reflects the light in a uniform illumination. Looking into the private sphere, the surfaces consist of myriads of texture qualities and material combinations, which can take a while to sense. Sometimes it can be over stimulating, confusing and too much, but at other times it is an aspect of feeling relaxed and stimulated. 
While reflectivity is a directional property, surface character could be split into two categories; 'specula' and 'diffuse' surfaces. 'Specula'are glass, polished metal and the reflectivity will be nearly zero at all angles except from the reflected angle. For 'Diffuse' with for example a matte white paint, the reflectivity is uniform. The radiation is reflected in all angles equally or near-equally.

Colour researcher (Dalke, Little et al. 2006, Gurura, Mc Donal et al. 2004,Dalke, Littlefair et al. 2004) presented a report on lighting and colour design schemes, accessible to non-professionals with responsibility for refurbishment strategies. They drew a picture of the current practice in England and identified key issues where colour design could broadly enhance the environment for the users. Critical areas were outlined in this report and it displayed how light and colour can be utilized and applied. One example is colour contrast for the visually impaired. (Vijk 2006) worked on colour and lighting design among people suffering from dementia. Vijk notes the effect of strong light patterns on floors created by daylight or artificial light can be a problem, because it can be experienced as difference in levels at the floor plan and thereby cause falling problems. Vijk demonstrates how colour can help older people navigate in ward environments by using light as support to the experience of the space. Bille introduced the cultural approach to colour use in his thesis and notes that the colour green (both light and material colour) is associated with Islam in Jordan (Bille 2008, p. 137). Later, he also referred to a study on architecture in the United Arab Emirates and argued that colours were used to reduce the monotony of the dim interior of the tent, so as to enlighten and enliven it and make people feel happy and relaxed. Bille mentioned that the colour can appear both in light and in materials. While the reflected light from a colourful space can affect the objects and persons in the space, coloured light can change the appearance of a surface. It is important to use colour in light with awareness. An example from Elsinore Psychiatric Hospital is a green gym and exercise space as seen in nex page (Fig 3.26 and fig 3.27).

The green colour may appear fresh and meant as energysing and supporting of the activity in the space, but it also changes the way we see ourselves as well as the way we see others. Daylight dominates the space and illuminates the 


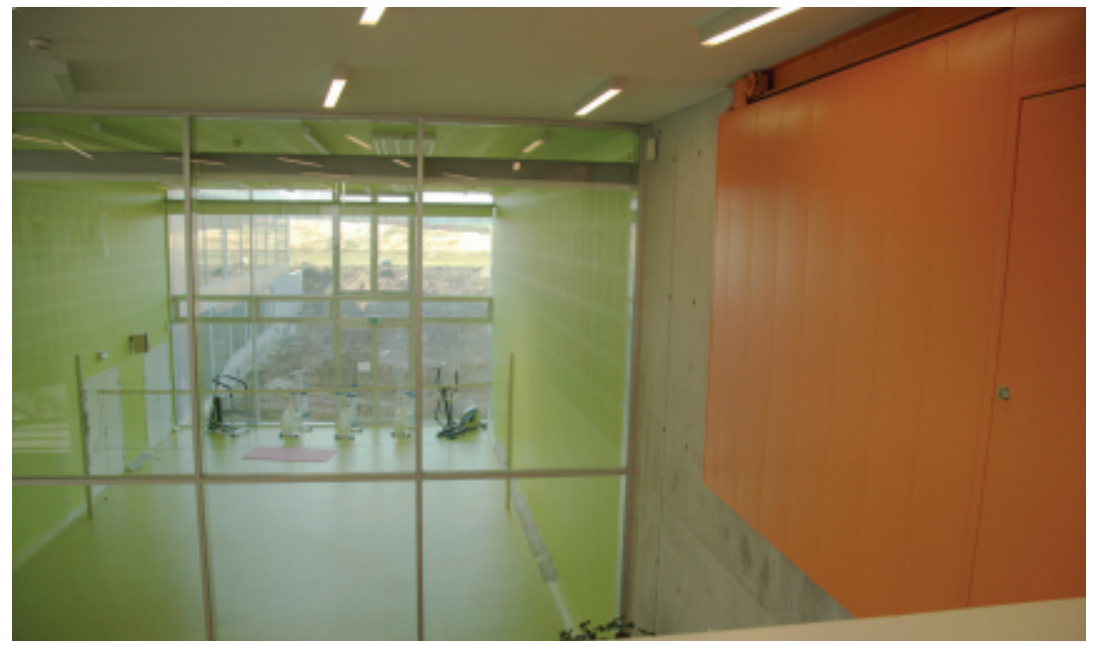

3.27

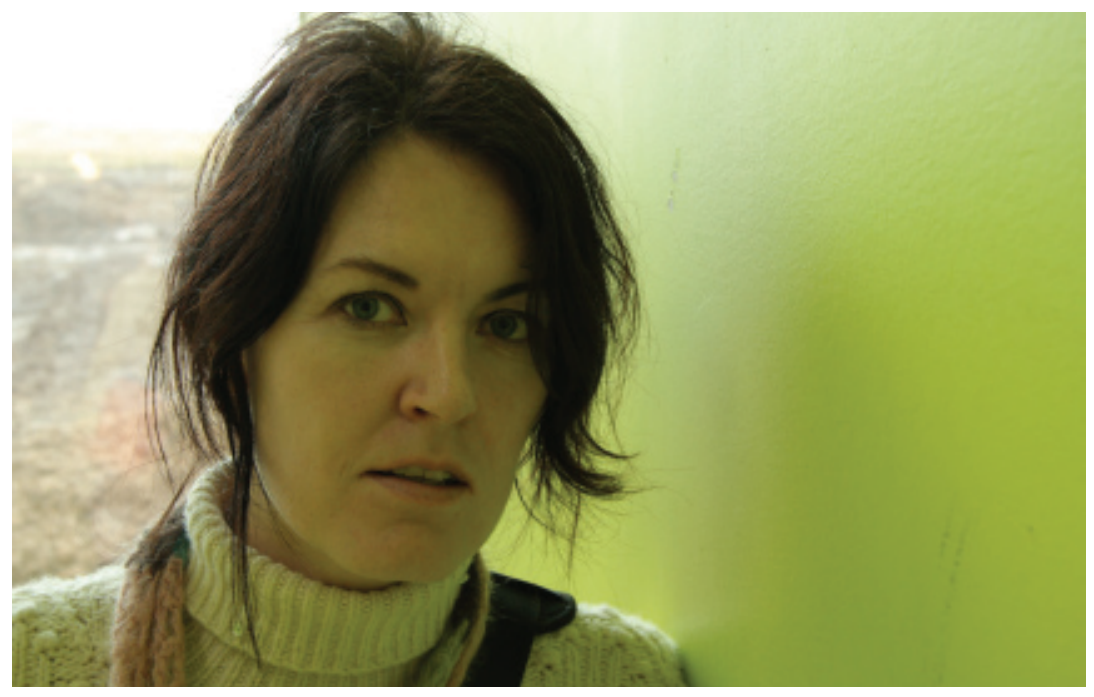

3.28

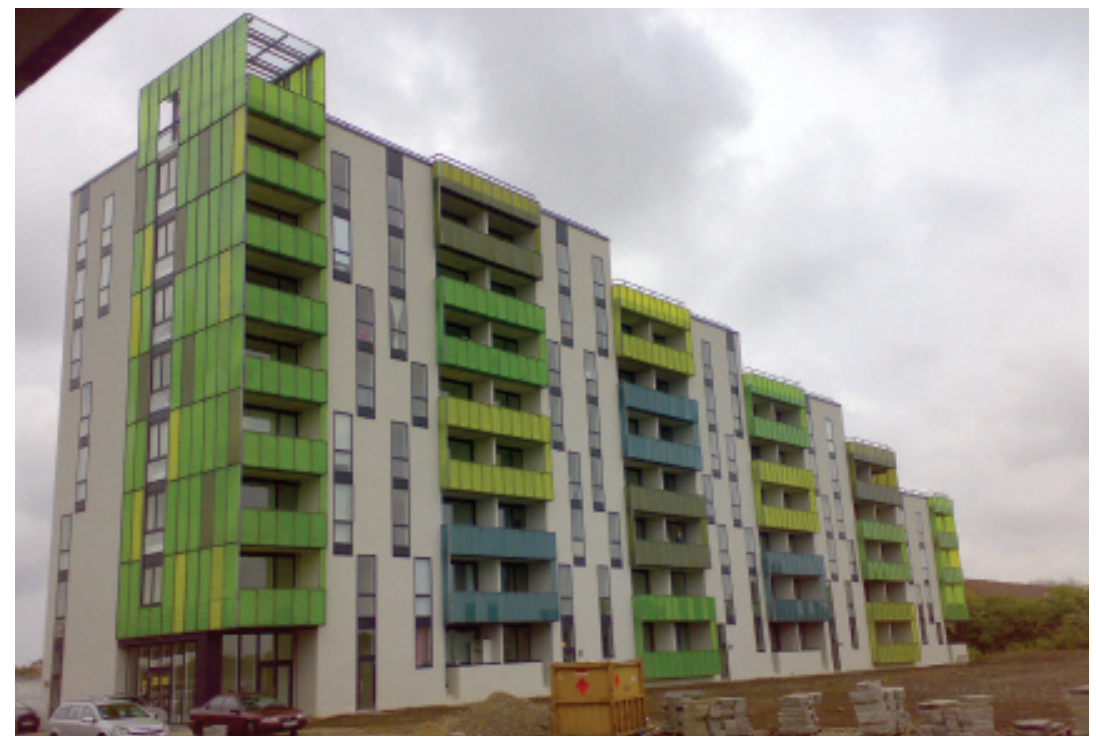

Fig 3.26

The green spors area at Elsinore Psychiatric Hospital.

Fig 3.27

The reflected daylight from the green walls has an effect on the colour of the skin.

Fig. 3.28

New trend of decorate buildings using coloured translucent materials colouring the light.

Fig. 3.29

Coloured cardboard placed behind a white cardboard to reflect the daylight.

Fig. 3.30

The refected light on white cardboards. 
green surface from wall, ceiling and floor paint. The green colour creates a greenish light. This green coloured light provides a light colouring of all objects including persons in the space and thereby their skin. In that way the skin turns more greenish and into a grey colour, which is the colour we have when we are not feeling good. This cannot be the intention of using the green colour, but it is a consequence of using coloured light and coloured surfaces.

During the last couple of years, a new phenomenon of light has happened in building design (fig 3.28). The poetic light from old church windows might inspire it with coloured glass creating a coloured play of shadows. The phenomenon is tainted glass or acrylic panels decorating buildings in colourful ways. A coloured ornament adding to a white building. After a period without use of colours and most architecture has been carried out in natural colours or "black and white" style, this colour play is refreshing, but it is important to be aware of the effect the colour is creating in the space. It is not only an outdoor element; the light penetrates the coloured surface and has an effect indoor.
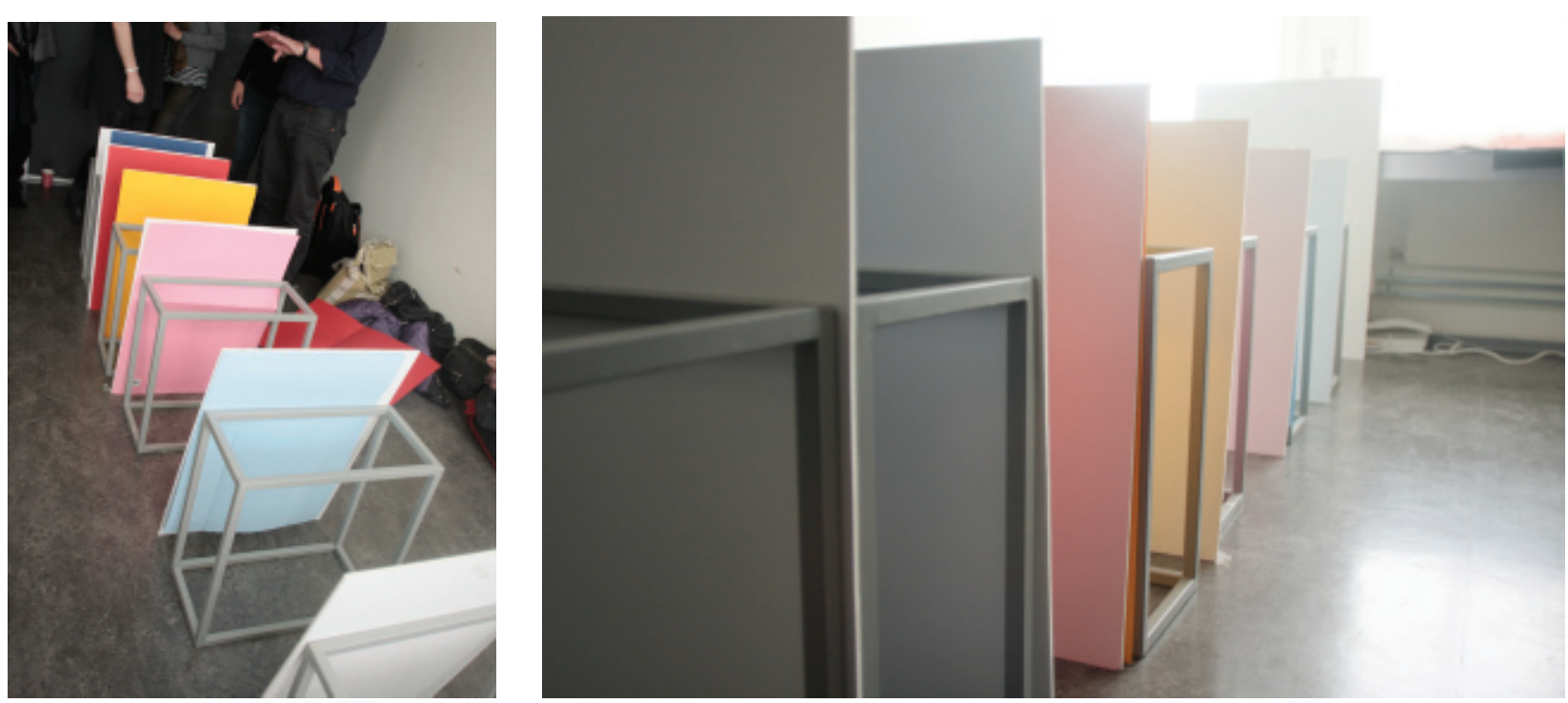
From an experiment on reflected light (fig 3.29 and 3.30) the effect of coloured refelctions impact on white surfaces. Olafur Eliasson designed "Your rainbow panorama" at the museum of art AROS in Aarhus 2011. Here, the visitors can experience themselves in the colours of the rainbow as well as have a look at a colourful city.

"Your rainbow panorama enters into a dialogue with the existing architecture and reinforces what is already given, namely views of the city. I have created a space, which virtually erases the boundaries between inside and outside - a space where people are a little unsure as to whether you have stepped into a work or into part of the museum. This uncertainty is important to me because it encourages people to think and sense beyond the dimensions, they are used to commit themselves in"(Eliasson 2011)

This way of changing the experience of a space is interesting as art, but questionable for use in a patient room. (Nickl-Weller, Nickl 2009, p. 183-187) presented the architecture of the Angelika-Lautenschläger-Clinic, Centre for Paediatrics, University Clinical Centre, in Heidelberg, Germany (fig 3.32). The presentation included a picture of a patient room taken in sunshine with sunrays falling into the space creating an interesting light pattern in the space. The space appears clean and in harmony, and the yellow acrylic window decoration provides an artistic element in the space. But as Olafur Eliasson emphasised, the colour also changes the view and reinforces what is already given, and the view and the light effect on the patient can also trigger an uncertainty of the situation.

3.31

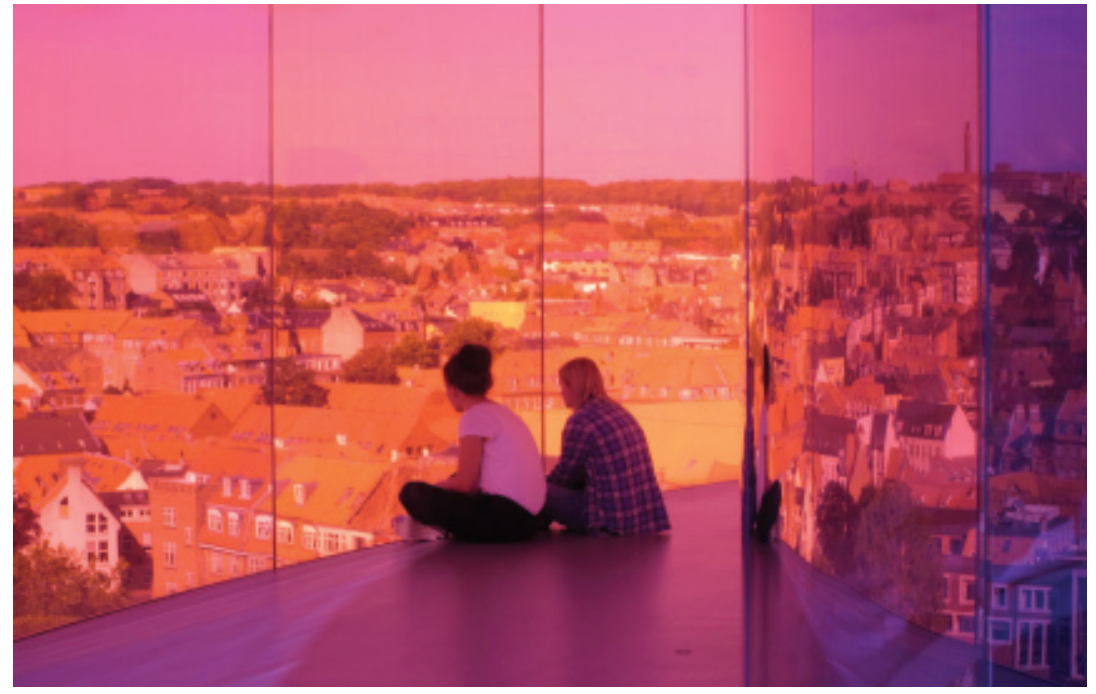

Fig 3.31

Art installation by Olafur Eliasson: 'Your Rainbow Panorama', Aros Aarhus, DK. image: Students at Blaakilde Efterskole

Fig 3.32

Picture of the Angelika-Lautenschläger-Clinic, Centre for Paediatrics, University Clinical Centre, in Heidelberg, Germany 


\subsubsection{LIGHT}

As displayed in this chapter On Light Atmosphere, the physical environment has an impact on how light is experienced and the light has an impact on how the environment is experienced. The subcategories in light are the 'Characteristics', 'Effect' and Information' of light. It is possible to discuss the quality of light, but the term quality is also defined in many ways. (Boyce 2003) refers to different definitions of lighting quality. First definition is a singlenumber, photometric index calibrated by subjective response. Another definition is holistic design process based on lighting patterns (Loe, Rowlands 1996). Third definition is that lighting conditions with desirable impacts on task performance, health and behaviour (Veitch, Newsham 1998). Last definition is lighting which enhances the ability to discriminate detail, colour, form, texture and surface finishes without discomfort. In this thesis lighting quality will be defined as

"Lighting, which enhances the ability to create an experience of a pleasurable light atmosphere supporting user needs and preferences".

Boyce separates quality lighting in three categories; bad, indifferent and good. 'Bad quality' lighting is the kind of lighting, which does not allow you to se what you need to see quickly and easily and/or causes visual discomfort. 'Indifferent quality' lighting does allow you to see what you

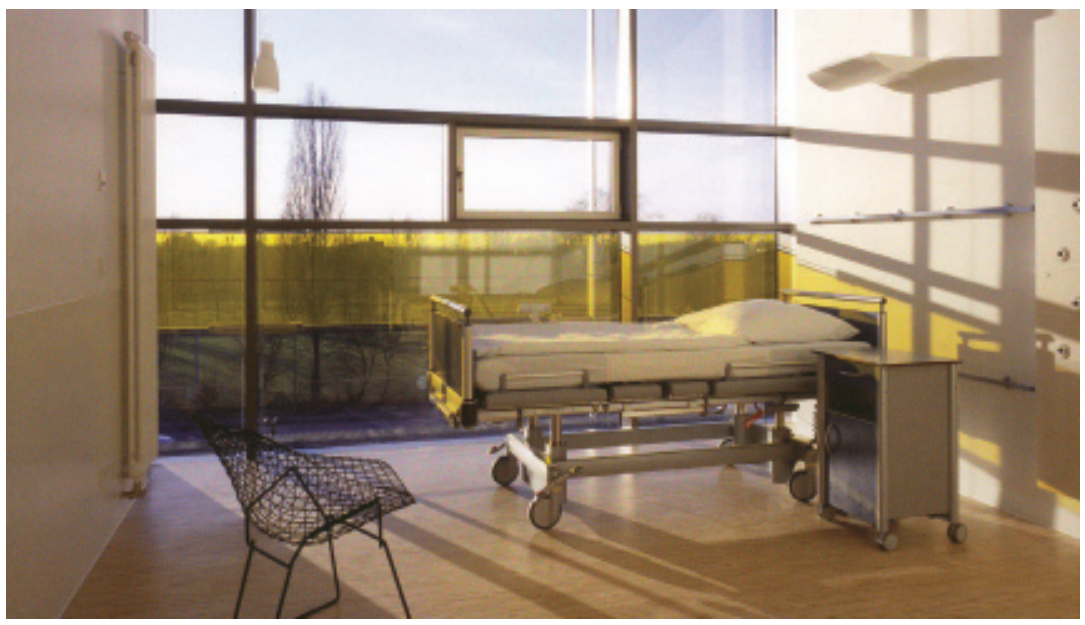


need to see quickly and easily and does not cause visual discomfort, but does nothing to lift the spirit or the effectuate the tone in the space. Lastly, "good quality" lighting is the kind of lighting that allows you to see what you need to see quickly and easily and does not cause visual discomfort, but does raise the human spirit (Boyce 2003).

\section{Characteristic}

When the characteristic of light is discussed, it is important to distinguish between two main light sources. The sun or daylight coming from outside a building and the artificial light inside a building. It can also be outside, but
Fig 3.33

Collection of sky images in Denmark. Variations of sky appearance, impressive, fascinating with diverse appearance.

\subsection{3}
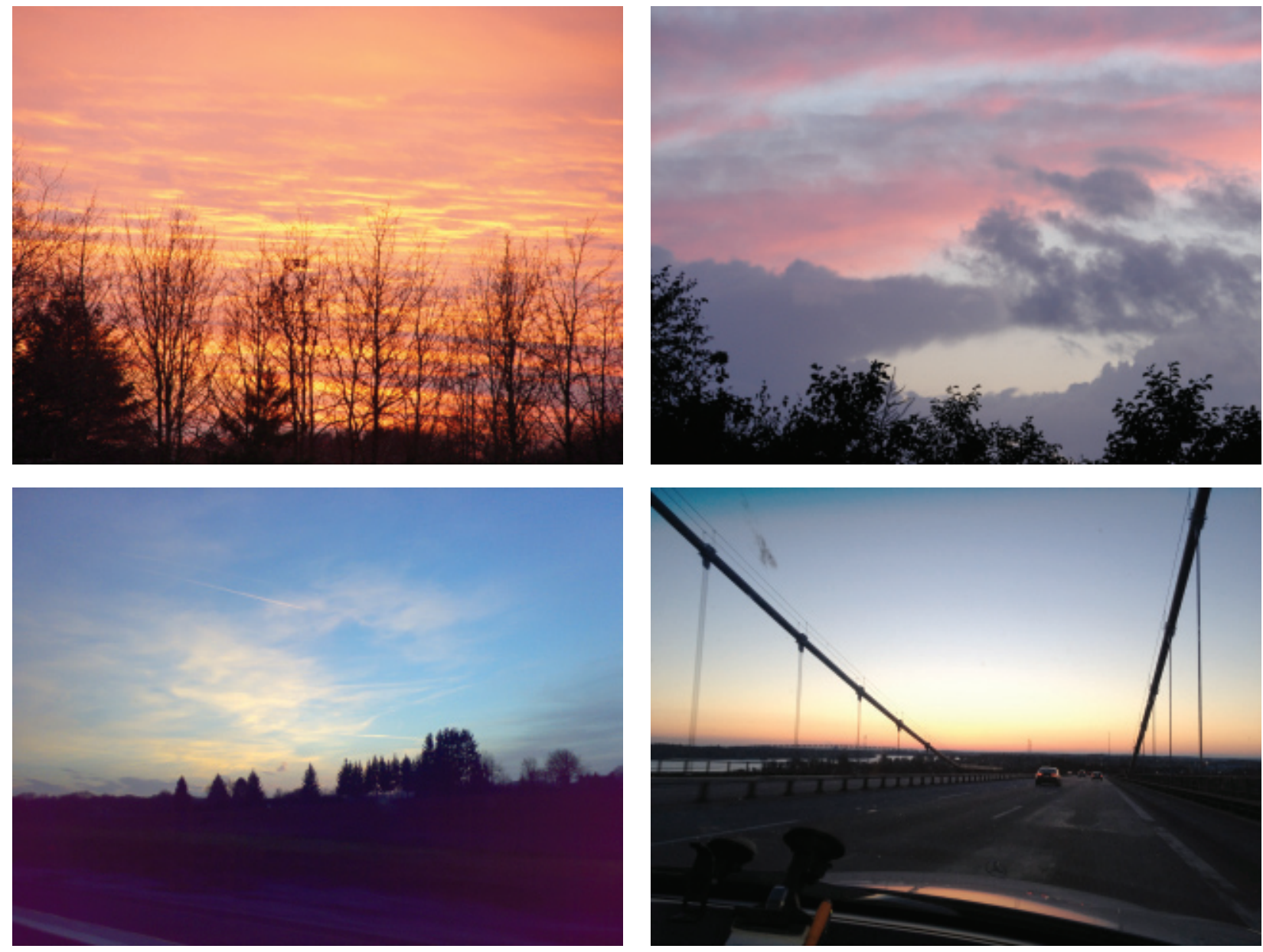
in this thesis indoor illumination is discussed. Taking daylight into a project of artificial lighting is appropriate and relevant. In day lighting, it is also important to distinguish between the light distributed as sunlight, reflected light or skylight (Madsen 2002), into the space and the look outside at the light from inside.

A daylight atmosphere can change the way of contemplating the view of nature while light can affect people emotionally. The collection of sky images (Fig 3.33)is collected and displayed to get an understanding on the difference in sky effect. Sometimes a view is so impressive
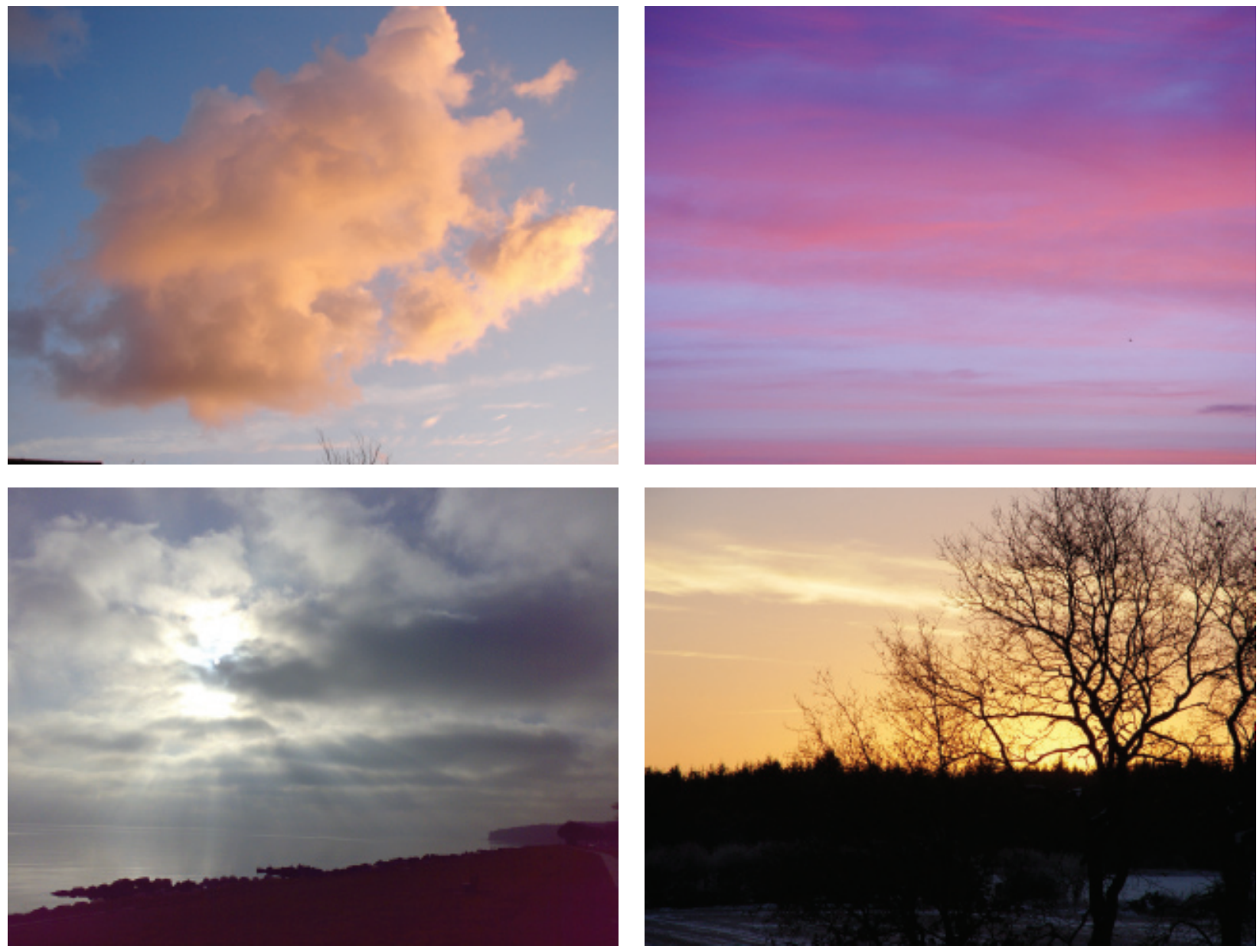
that we stand, take a picture, and just enjoy the view of the sunset for a moment. Sometimes the light can create breath-taking moments where we have to stop and look at the scenery. Other days we just pass by same place without noticing the scenery in the same way.

It is often fascinating to look into the sky and observe the clouds, the movements, the compositions and the colours of the sky, and it is fascinating how daylight can change the appearance of materials or filtered in a way creating beautiful compositions of light and shadows. Even a dishes can appear beautiful when It the light interacts with materials in a way creating creative compositions of delicate light colours. (fig 3.34)Daylight has an ability to bring life to the environment, because the light is constantly changing intensity and direction. This variation affects the way shadows fall on the floor, materials appear differently and the experience of objects changes during the day and throughout the year.

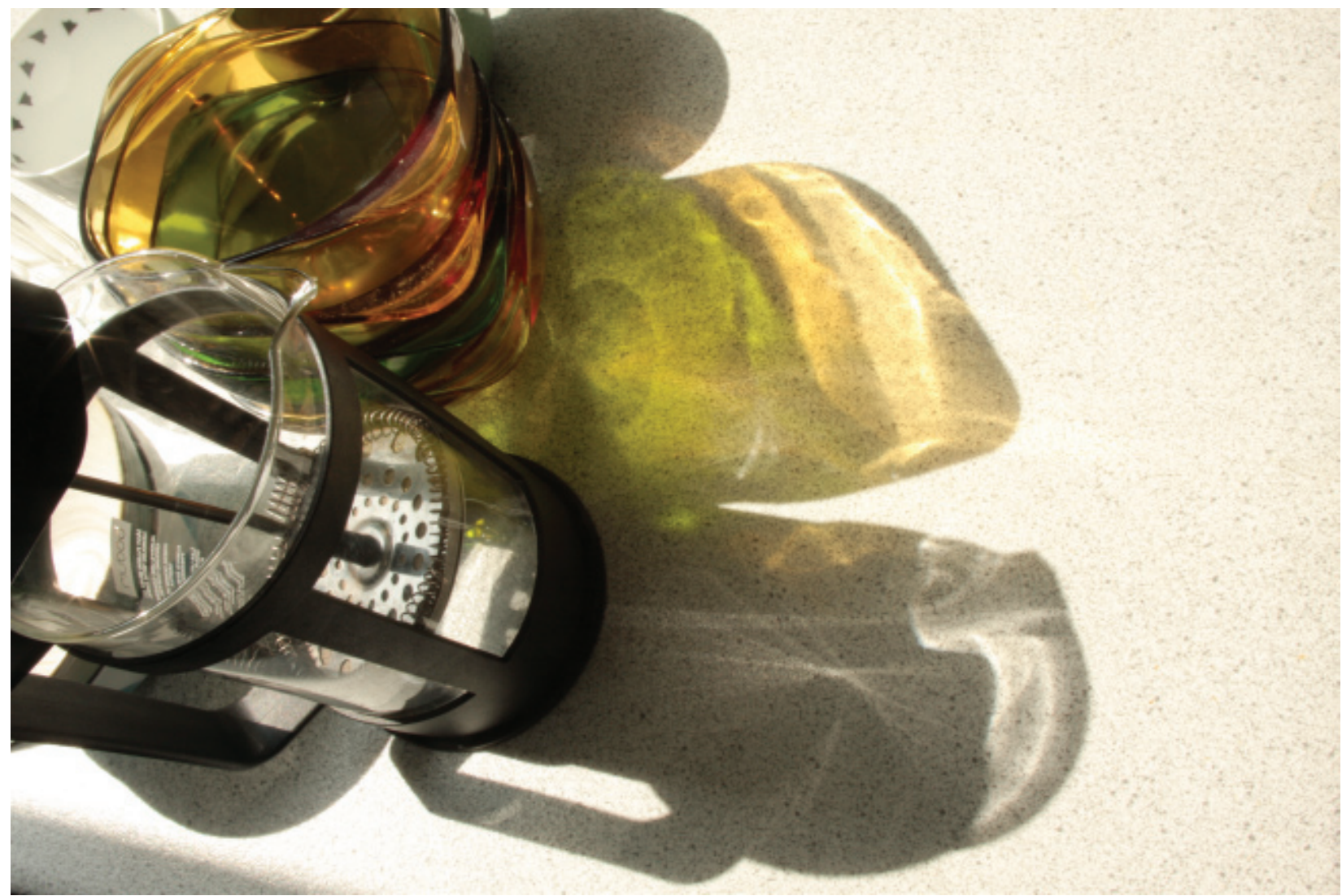


Fig. 3.34

Image of a glas in a sunny day where light play with the materials.
(Millet 1996) describes how light can reveal architecture and highlight Frank Lloyd Wright's residential design while it provides connection, both real and metaphorical, between inside and outside. Another example is as just presented the effect of coloured panels in windows. There is a connection between daylight and artificial light because there is a transition period between daylight and artificial light. A space can also be experienced in a varied and intense daylight, where sun rays are streaming in through the windows. At night, the experience of the space will be different, because it is dark outside and the window surfaces appear dark. (Madsen 2002) uses the term light zone as a special way to observe daylight in spaces. Regarding an architectural way of seeing light, it becomes a spatial composition of light zones, where the light is a kind of 'bubbles', 'spheres' or 'zones' of light that can be compared, squeezed, collected, raptured or disrupted no matter of character of the meeting between light zones and space.

Looking at the hospital ward, the daylight accesses the room from outside. Artificial light will mostly come from the ceiling, and the light source is located closer to us. The artificial light is a replacement for daylight and is more controllable than daylight. Both daylight and artificial light play a role together to the ward appearance and atmosphere, and it is not always possible to experience the two types separately. It should be seen as a whole lighting design. The two categories of light have different qualities and purposes. If the purpose for a better light atmosphere is to create a more natural artificial light setting, it is important to rethink the use of artificial light and work with the placements of the light fittings and the way the light creates shadows. (Veitch, Newsham 1998) demonstrates that people who rated the illumination as higher quality (regardless of the type of lighting they experienced) considered the space to be more attractive, they were happier, and they had better health and wellbeing, less discomfort and greater satisfaction with their environment and their work. The people in the study also generally preferred to be in a space with windows rather than one without windows, while this aspect is a matter of course in a Danish lighting tradition. But the preference for light implies daylight creating an interior which is more pleasant and satisfying than one illuminated only by electric light. Therefore, it is interesting to simulate 
daylight in spaces in order to make it more attractive and pleasant.

The artificial light takes over when the daylight cannot provide enough light to space. The lighting techniques for artificial light can be split into 'Down light', 'Mainly down light', 'Uniform light', 'Up-and down light', 'Mainly up light' and ' $U p$ light' according to (The Danish Illumination Engineering Society 2004).

The colour rendering index (CRI) is used to evaluate the light source's ability to represent colours in the environment and noted on a 100 RA scale where 100 is very high and 50 very low. The colour temperature is evaluated on a Kelvin scale. $2800 \mathrm{~K}$ coming from an incandescent light is the preferred light temperature in Danish homes. Fluorescent light is often used in public areas and as the figure hereunder shows, the spectral distribution of the light is not a smooth graph, but has spikes in the blue and green areas.

The choice of colour temperature and colour rendering as well as light level and type of luminaires should be a balance between providing a suitable light for the situation or activity as well as always keeping in mind that the energy use should be as effective as possible. That means that it is not always incandescent light that provides the best illumination of a space. A sustainable low energy solution can also be the best solution. While Danes have preferences for and experiences with the incandescent light, a lighting solution will always be compared with the pre-understood "quality" term, and the experience through this study is that fluorescent light tubes per definition is bad in Danes understanding of light. No matter what quality of fluorescent light tubes is being discussed, it is known as problematic, a low quality of light and mostly referred as "cold light".

\section{Effect}

According to Boyce, Peter. R. (2003), the effect of light can be divided into three categories: 'Functional', 'Aesthetic' and 'Symbolic'. 'Functional' effect is the need for light changes from activity to activity depending on the other aspects as space, time and users. 'Aesthetic' effect is where light can be an artwork or only decoration with light and/or illuminate the space in a certain way creating
Fig 3.35

Functional lighting

Desk luminaire "Proud Mary", Designed for Nordlux by Graabæk-Stidsen.

Fig 3.36

Aesthetic Lighting

Art installation "Flora" by designer Astrid Krogh, Kolding DK. 
an aesthetic experience. Lastly, the 'Symbolic' effect can be used as a signal of something.

'Functional' lighting (fig 3.35) can be to support different activities such as a football match, an oral presentation at a conference or a cosy evening with friends or family in the sofa corner. The light can be used to support the activity and the preference for light in a given situation by using appropriate lighting technics and appropriate luminaires providing the good quality lighting.

'Aesthetic' lighting (fig 3.36) can be artwork or light that does not belong to the functional light, or maybe have the function of being creating "hygge"/ a cosy atmosphere. During Christmas time, this kind of light is all over. Decoration lights such as Christmas lights, string lights, candle lights in decorations or illuminated stars in the windows. The neon wallpaper "Flora" created by textile designer Astrid Krogh is an example of an artificial illumination where the main focus is the aesthetic effect. The installation provides enough light to see and be seen at the parking area, but the light is a decoration of the space with a focus on the aesthetic effect.
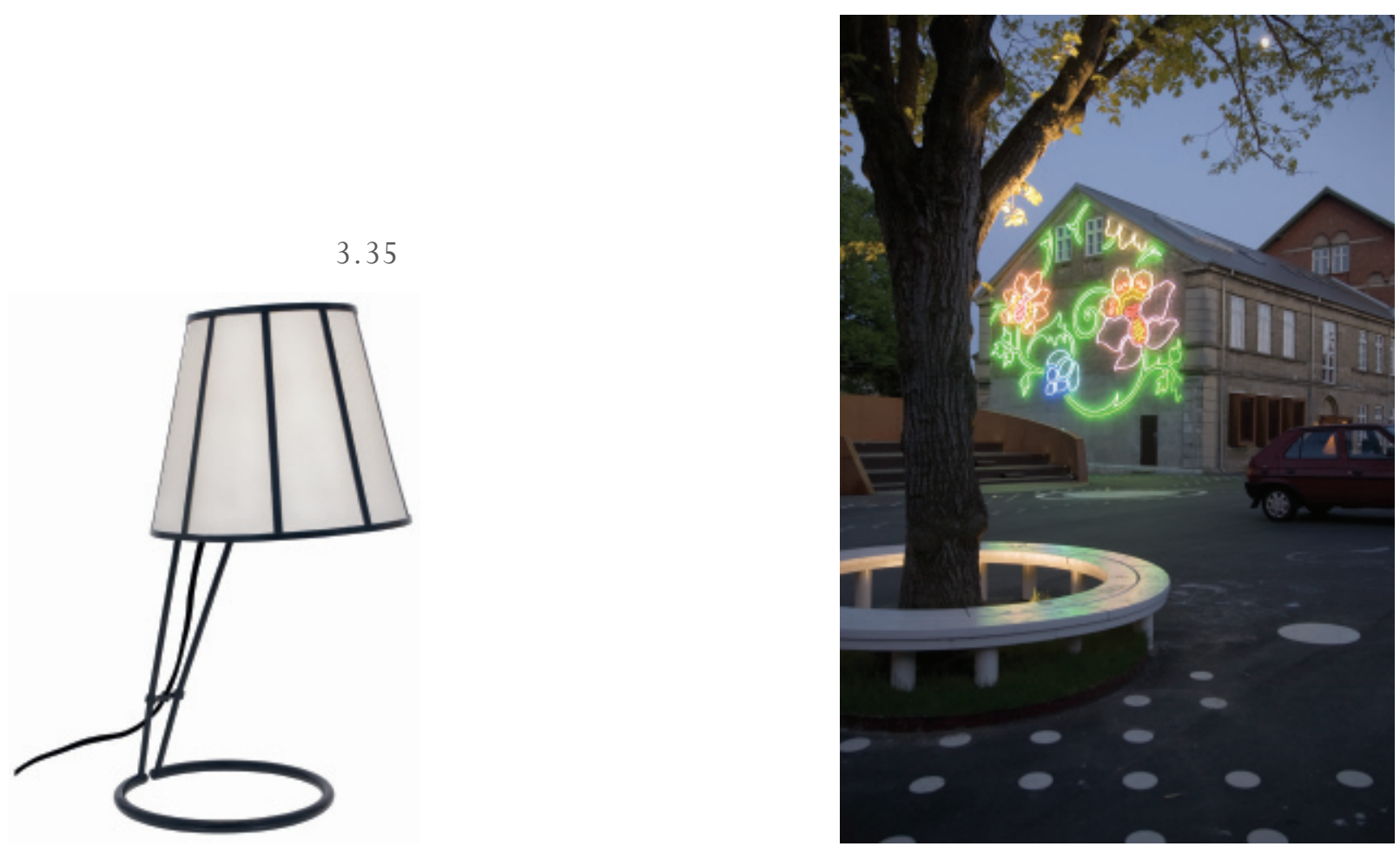
Light can also be used as a 'Symbolic'. Light is used to regulate traffic and users of the road have learned that red light means stop, yellow you have to be ready and by the green light you can cross the street. With roadwork you have to pay attention to the yellow flashing light as it means "men at work" or maybe another hindrance in the way. At the hospital, a red blinking light is a signal for the staff to go the patient close to the light, or it can be a signal of something not working in the right way and there might be danger.

We all have a common learning in light as 'Symbolic', but there are also diverse perceptions on light as symbols. From a conversation with a Danish colleague living in Italy for some years, I heard about an experience of having guests in their home. Candlelights were lit around the house as we normally do to create a cosy atmosphere in Danish homes. The guests entering the living room immediately paid their condolences, as they thought that somebody had died. In some countries, candlelight is lit as a religious action and a way of sending thoughts to people who died. In Denmark, it is a central part of creating "hygge" and used as a gesture of hospitality. In this way, light can be used as a signal and provide information.

\section{Information}

When leaving our home and traditions and go to other countries or settle down in other cultures, we are confronted with our cultural understanding of light quality. Maybe we are influenced by our experiences of daylight in a way that has an effect on the way artificial light is arranged. Our familiar understanding of light conditions and our culture of using the artificial light can be influenced by the experience of daylight and the way we "naturally" see the light throughout the day. To achieve attractive surroundings, we should obtain consistency between our expectations and our experience. There should be a sense of coherence in the experience of the connection between self-perception and the situation you actual experience. (Clausen 2009, Clausen 1999) claims that if we do not recognize ourselves, it leads to uncertainty, insecurity and it afffects the perceived situation. Our light culture is incorporated and adapts the understanding of ourselves in the surroundings. Our body, skin, hair and eye colour 
adapts to the amount of light we are expecting in the place we live. Our ancestors have lived in the same latitudes for thousands of years, and instinctively, we have a common reference and feel the same lighting moods.

In his research (Stamps 2007) estimated the strengths of the relationships between judgments of mystery and amount of light and depth of view. The experiments showed that light had a large effect on the judgement of mystery. In that way, the illumination can be used to put focus on some of the areas and hide others in the dark and by the lighting technic provide a certain amount of information.

\subsubsection{TIME}

Time has an impact on our experience of the environment in more than one way. Time can morning or evening time, but it can also be seasonal or the time used in the space. The daylight has a natural rhythm that could be an inspiration for the design of artificial light. Some artists work on creating an experience of daylight in spaces where there are no daylight access and thereby no light to show the rhythm of the day. Designer Daniel Rybakken is one of the artists working with the experience of daylight where daylight has no access. In his work/designs, he plays with the experience of light and shadows in a delicate and sophisticated way, and this work would be relevant in the discussion of dynamic daylight and what is important in the experience of the dynamic of light in space. In the picture

Fig. 3.37

Art installation by Daniel Rybakken. Artificial Daylight in a space where no daylight has access.

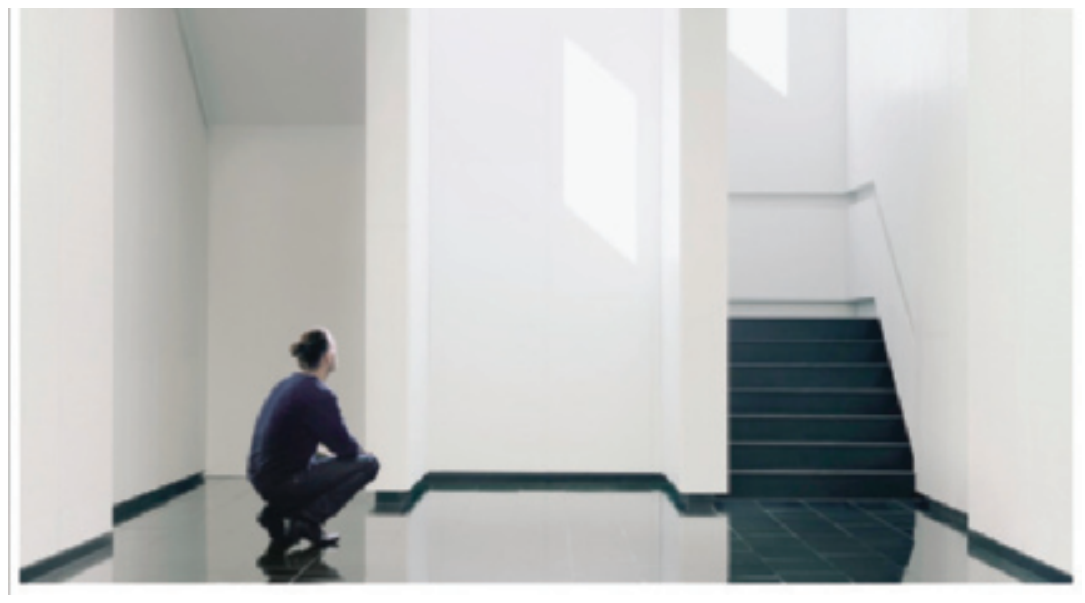


fig (3.37) of Rybakken's work, an illusion of daylight is shown in a room without daylight access. This work also displays the change between a space which is experienced in daylight and a space which is artificially lit. (Rybakken)

\section{Period}

The experience of light also depends on the period used in the light setting. When entering a very dark environment coming from a illuminated space, we sometimes need to blink several times to adjust the eye to the new environment. The eyes need time to adapt to changes in light intensities. That means that an experience of a light situation can differ depending on when the evaluation is made. It is important to note the period around an evaluation time in order to be sure that the evaluation not is influenced by adaptation problems.

\section{Season}

Denmark and parts of the countries far from the equator have larger change of light situation between seasons than countries close to equator. As we showed in the Space section, this implies different experiences of shadows and light throughout the year. At wintertime the sun has a lower position in the sky and thereby creates longer shadows. At summertime the sun's position is higher and the daylight period is longer. The season has an impact on the mood and in Denmark SAD (Seasonal affectional Disorders) is often discussed (Martiny, 2006, Stuhlmiller 1998).

\subsection{SUMMERY}

The state of the art in the field of light atmosphere started with an introduction to the vague term 'atmosphere'; in many cases used as a stamp of approval for beautiful architecture or as an exceptional experience. Architects as Zumthor and Pallasma are seriously dealing with the term in their designs and point out the senses and the sensorial experience of architecture as essential for creating building designs. Going deeper into the concept, the study from Böhme's 'Concept of Atmosphere' contributed with knowledge of the importance of the bodily presence in an experience of atmosphere, and the base for 'Model of Light Atmosphere' was grounded in Böhme's theories. The model seeks to qualify sensory qualities in an evaluation of light atmosphere and points out socio cultural aspects as essential for the evaluation. To get information on the socio 
cultural aspects on experiencing light atmosphere, explorative studies were made in order to elaborate on the term 'homely illumination' or a maybe a better word is familiar or pleasurable light atmosphere. The question of 'homely' is a positive or negative reference. The word 'familiar' refers to something recognizable and safe, but still 'familiar' can have a negative tone, therefore the translation of homely in this project is called a pleasurable light atmosphere.

The 'Model of Light Atmosphere' contains four subcategories in light atmosphere. The first subcategory is the 'User', which includes aspects as psychological, biological, activity and characteristic of user types. Second, the aspects of 'Space' are discussed and split into topics as location, spatial composition, interior design and surface character. Third, the 'Time' show how the season and period of time has an impact on light. Fourth, the 'Light' aspect is displayed and divided into subjects such as characteristic of the light, the effect of light and lastly the information light can provide. The state of the art requests more information on some of the socio cultural aspects important in a Danish context. While it is shown that light can be used in opposite ways in two different cultures in the situation of having guests, it is important to study in which way we use light in different situations in a Danish context. It is also interesting to see if the way we illuminate homes is a contemporary trend of illumination, or the trend history can display other traditions of illumination. Another problem found in the state of the art studies is the different user's use of the hospital ward. It is a working space for the staff and a relaxing place for the patient and visitors. Sometimes the staff lighting is the most important and when the staff is not present at the ward, the patient is the main user of the space. Therefore, a study of zoning the ward into user zones is found important, so the light can be optimized for the main users of the ward. 

4. eXPLORATIVE STUdies 
"A lot of the learning to work with light, since it doesn't form by working with the hands as clay does, is the working with the light through thoughts". James Turrell (Madsen)

The previous chapter introduced to a theoretical and visual studies of light atmosphere and different questions of user perspectives emerged. What is a Danish cultural approach to light and what are the preferences for lighting among elder people in Denmark? This question is relevant due to the few local research projects on the subject. And even though almost all Danes to whom I presented the project, agreed on the hypothesis that in Denmark we place as few luminaires as possible in the ceiling in the spaces where we relax. Instead luminaires are located lower in the space and often many luminaires around the space. But there is no research supporting this lighting culture, why these explorative studies are carried out.

The main goal of the phd study is to promote healthy environments and bridge or maybe point out light as one of the essential parameters in the feeling of wellbeing at a hospital ward. Therefore it is important to create knowledge about light atmosphere in a danish context and to find user preferences on light atmosphere in Denmark as a part of the design process. Therefore, some of the aspects from 'Model of Light atmosphere' are elaborated further in this chapter where four studies represent the explorative studies.

First off, it was important to get a personal experience being at a hospital and being present in the atmosphere in which the lighting design is installed. The section ' $A d$ mission to the hospital' presents the overall impression of ward. The second explorative study focuses on the 'patient preferences for light in a homely atmosphere' and therefore elaborates on the user perspective of the 'Model of Light Atmosphere. The third study elaborates on the time perspective and puts the light preferences into a historical context displaying 'illumination trends in Danish homes' through the last 50 years. The last explorative study presented in this chapter elaborates on the staff use of the ward, and here the focus is on zoning the ward in 'main user zones', so an illumination can be adjusted to the main user of the ward.

The four studies together are a part of elaborating and specifying important aspects of the 'Model of Light atmo- 
sphere' as well as relating the light atmosphere to a context of light atmosphere in Danish hospitals. They express an interest for the user aspect of the experience of the light and are seen as a way to future proof the hospital design by centering the user in the design. The explorative studies seek to expand the pre-understanding of what a light atmosphere in a hospital is. The studies point at aspects important for the experience of the atmosphere in a ward, and suggest reconsidering the tradition of ward illumination.

At the same time, the explorative studies are a part of the design process creating a ward lighting concept presented as the experimental study in chapter 5 . In this way, chapter 4 sets a frame for an explorative study while the lighting design tested in chapter 5 is based on the knowledge

gained through the explorative studies and the 'Model of Light atmosphere'. The explorative and experimental studies are, however, all seen as equal in the thesis, and the experimental study is a way of testing the concept created from the knowledge gained from the explorative studies and from the study of light atmosphere.

\subsection{ADMISSION TO THE HOSPITAL}

The admission took place on 22-23 September 2010 at Odense University Hospital, Department O3, and ward number three (model photosession p. 148-149). The ward is similar to the ward in the experimental study in chapter 5 . The goal of the admission was to get a personal experience of being in a hospital ward for more than the normal visiting time, and thereby to collect impressions over time. So, questions such as these were asked: How does it feel to be in a hospital ward overnight, from daylight to artificial light and reverse? What kind of daily activities happens in the ward? And lastly, what is the daily rhythm at a ward? During the admission, activities, physical dimensions of the ward and the use of material, ar tificial light solutions and colour choice were all noted. All activities were done with the aim of being more specific in asking relevant questions and to personally experience a ward design. 
The collection of 'physical data' as well as the impressions from the admission at the ward was interesting and fruitful in many ways. First of all, analyses and obersevations were med while experiencing a ward atmosphere making observations being present in the space.

The experience being at a ward can quickly become boring. Perhaps it would have felt different being an actual patient.

To be more specific in the methods of collecting information, we used video recording to document the transition from daylight to artificial light. Photo registration of different central situations was taken to get material for sketching and to have explainable pictures for central activities. A Dictaphone was used to record conversations on sensory impact as well as analysis of the ward atmosphere. In this way, it was easier to have a continuous conversation and express all thoughts uninterrupted by using time to write them down. After the admission, the recordings in real time were transcribed. Some of the discussions were on idea generation; what we found inspiring, what we needed, problems in the existing light installation and ideas for new concepts. Lastly, digital equipment was used to measure the physical frame and elements as light, objects, colours and spatial composition was described. In chapter 5 'Experimental study', the 'Model of Light Atmosphere' is examined in order to evaluate the light atmosphere in the existing ward and to be able to design the new lighting concept for testing. Some of the registrations that moved our existing understanding of the challenges of creating a ward lighting concept are described in following section.

Being confined to a hospital bed results in a horizontal positioning of the body, where it is difficult to avoid glare from the private luminaire next to the bed or from the light used by the other patient in the ward. Another problem is adjusting the luminaire, because it entails a twisting motion of the body harmful to a patient suffering from hip fracture; where a twist in the hips is to be avoided after operation. Spending hours looking at the ceiling provided an idea of projecting light, pictures or interactive games on the ceiling as a positive distraction.

A walk down the corridor gave an impression of the light- 
Fig. 4.1

Floorplan of hospital ward, OUH O3

Fig 4.2 (Next page)

Collection of Images from $\mathrm{OUH}$

$\mathrm{O} 3$, ward number 3

(Arranged photosession with model setup)

ing scenarios at the ward. Most patients arrange the light atmosphere by turning on the bed lamp and turning the luminaire into the wall and thereby creating indirect light. The switch controlling the recessed luminaires is placed beside the entrance to the ward. That means if you want to change light atmosphere, you have to go to the door to switch the light on and off. Being a patient with knee or hipster fractures, it would be easier to stay in bed and a reason for not changing light situation. Therefore, there could be improvements in the access to control the lighting.

\subsubsection{WARD DESCRIPTION}

Entering the ward (fig 4.1), the yellow colour of the closet catched your eye and is the most conspicuous part of the space. A washbasin is arranged with a yellow background is situated to the right. A mirror is placed over the washbasin, illuminated by an integrated luminaire. Next to the washbasin, there are plastic gloves, napkins and disinfectant soap. The hospital bed is placed $1 \frac{1}{2}$ meter inside the room with the headboard directed to the right wall. A second bed is placed in similar direction next to the window. Moveable tables on wheels are placed next to the

4.1

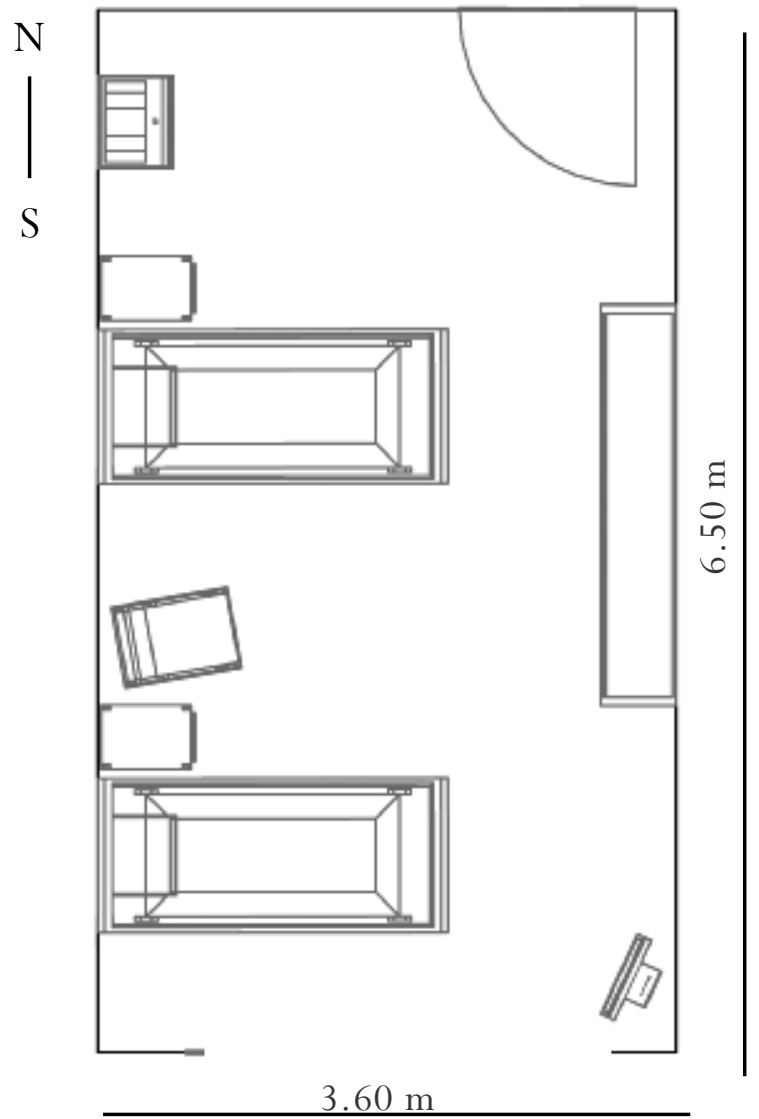



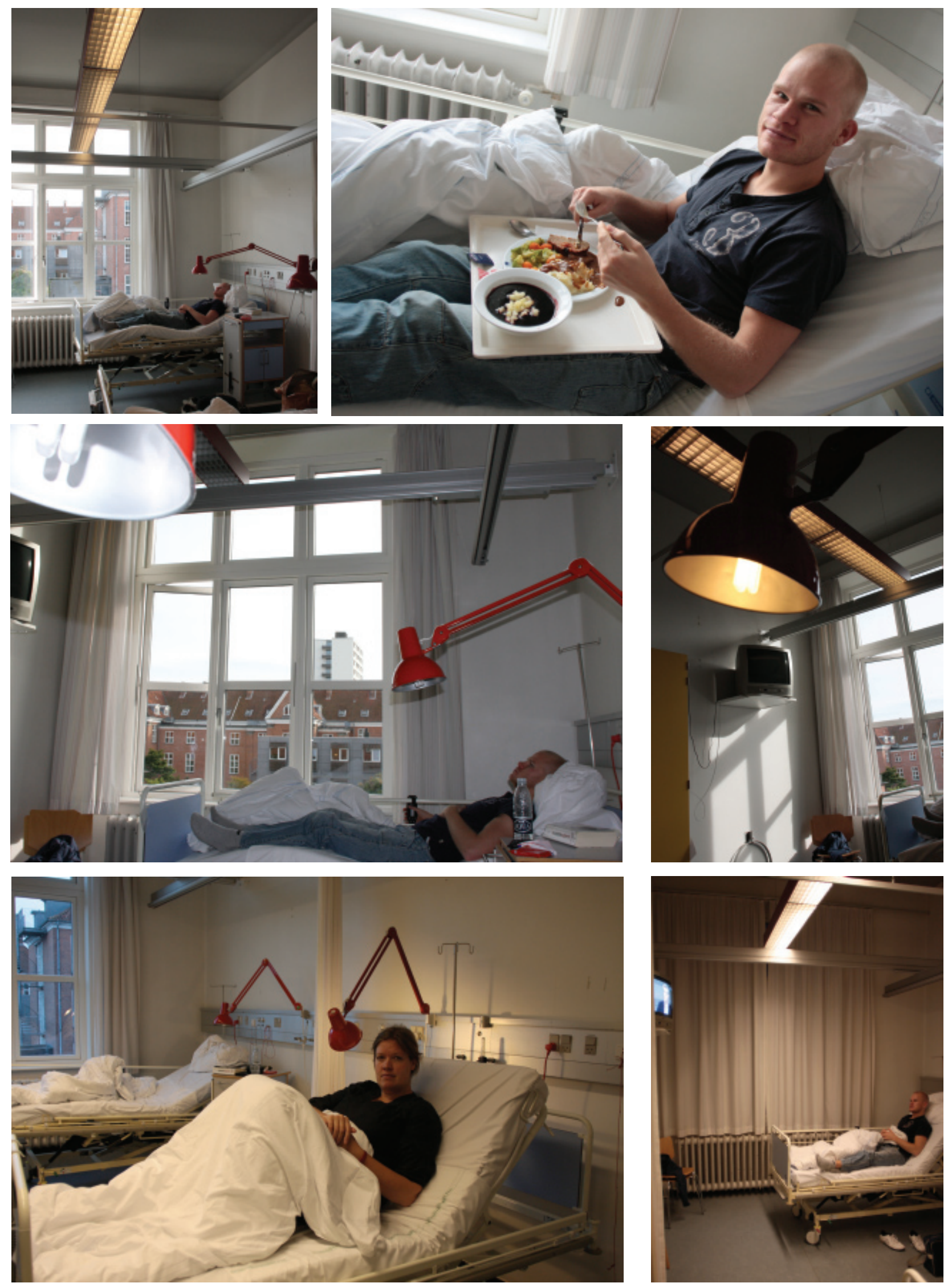

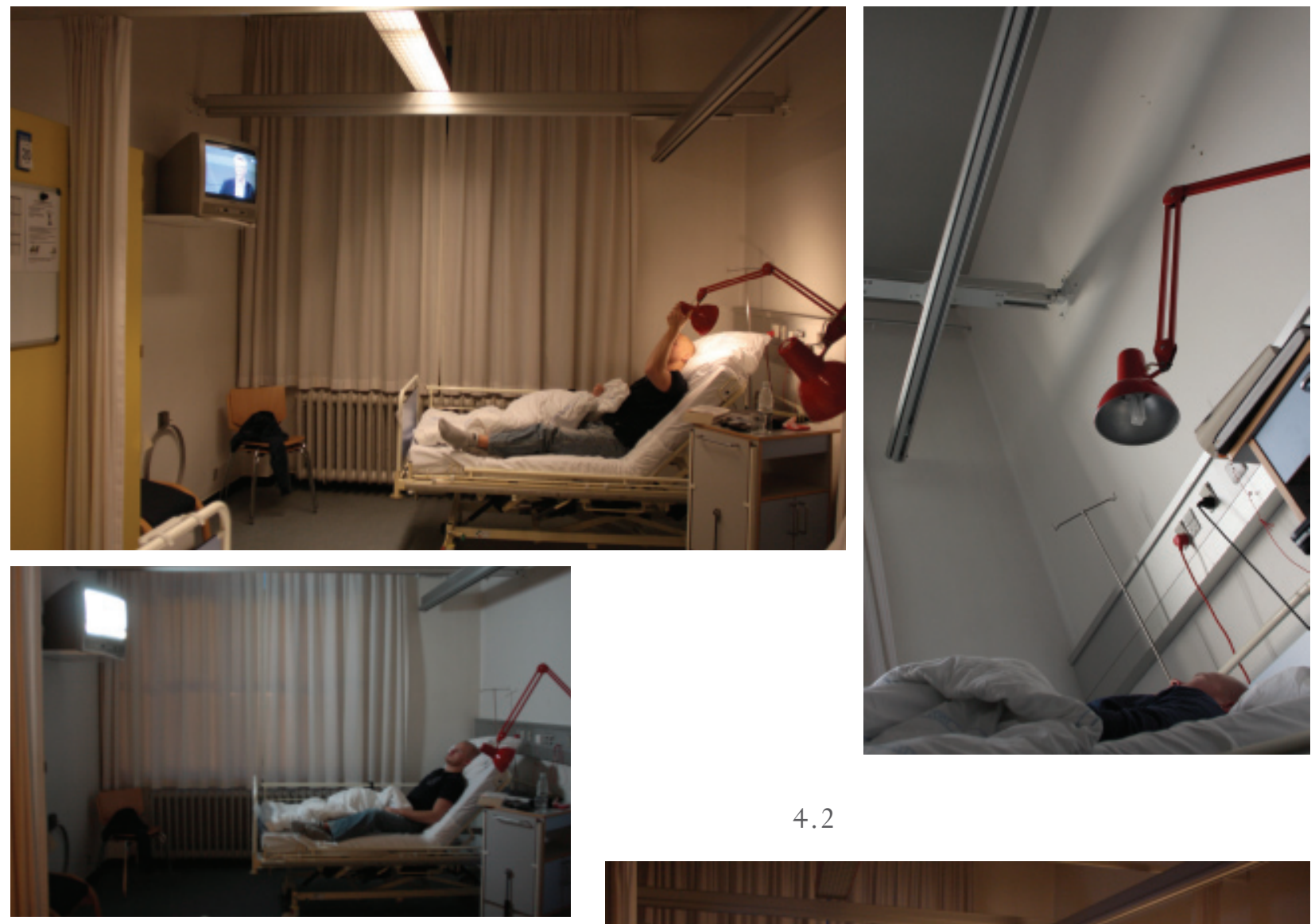

4.2
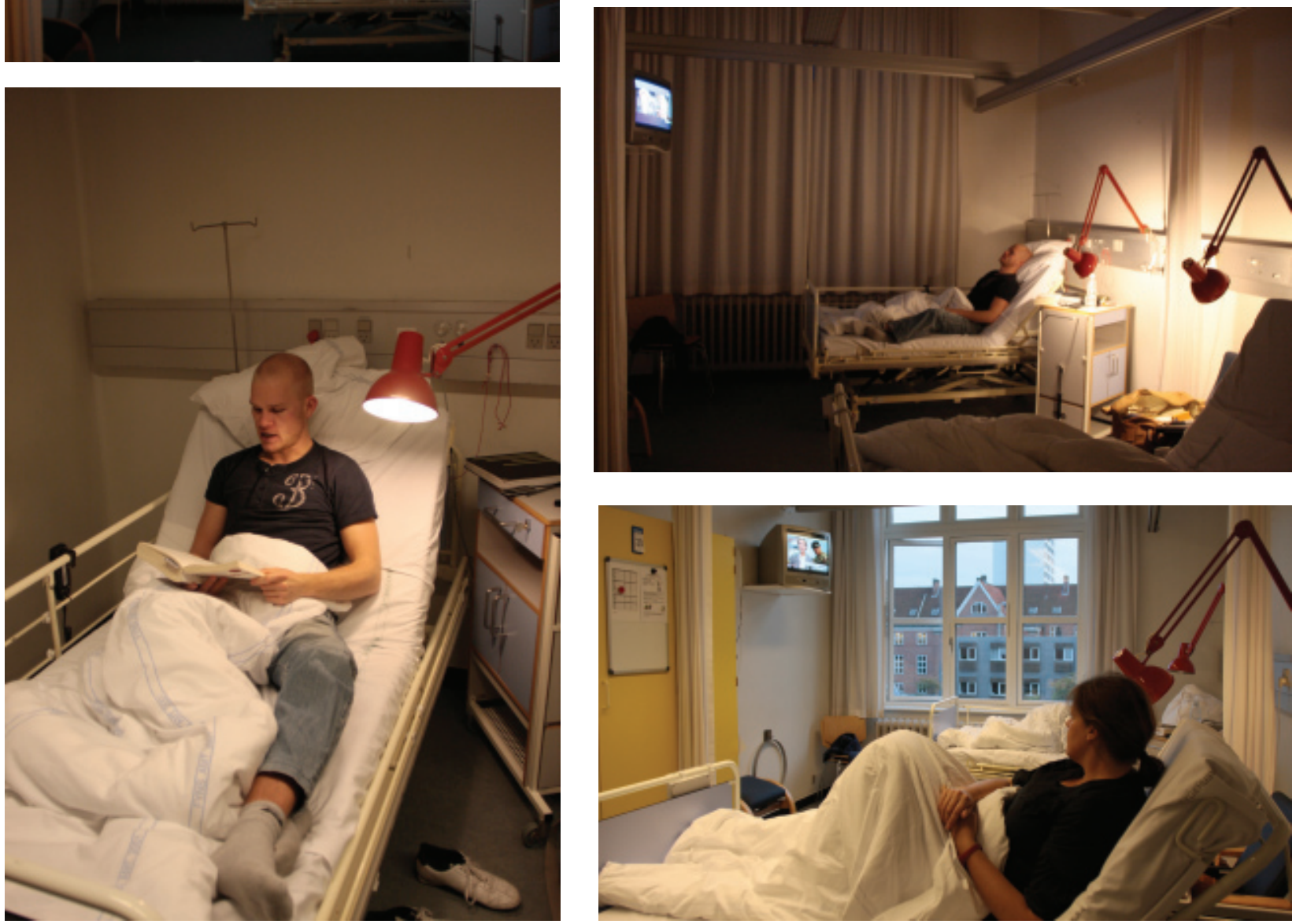

EXPLORATIVE STUDIES 
bed. A chair is placed on the opposite side of the bed. A private bed luminaire is placed behind the bed.(Fig 4.2) The big yellow closet is placed at the wall in front of the beds. A picture is placed on the left side of the closet and on the right, near the window, a TV is placed around 1.60 $\mathrm{m}$ above floor level.

A couple of chairs are placed right under the TV. A calendar and recommendations for the admission are hanging on the closet. Around one meter below the ceiling, there is a "second ceiling" consisting of cables for curtains, suspended luminaires and the lift helping the nurses move patients. All the lines created by the panels to the lift and curtains created a feeling of a lower, secondary ceiling confusing the overall impression of the space.

The colours used in the space were intense and powerful. Yellow was the most dominant colour, and I find it interesting and like the yellow colour approach, but research shows that yellow is one of the colours chosen last in a preference test (Jan Jansen, 2006). So maybe I will be the only one finding it uplifting and nice. Yellow in interior design has for me a reference to Verner Panton's installations and the especially the zinc area seemed as an endto-end solution in harmony.

The ceiling is painted in a light grey tone, and there are white walls and bedcovers. White curtains with thin rainbow coloured stripes are hanging in front of the windows. The ends of the beds are in a light lavender blue colour. Only the colours of the closet and washbasin appear in a clear yellow colour. The suspended luminaires have a dark red colour with somebrownish tone, and the room has black skirting. The bed luminaires are a clear red colour, matching the red coloured wires behind in the technic panel over the aluminium coloured headboard. The floor has a bluish grey tone.

The brick walls are covered with painted felt and the ceiling is also painted, both with a glossy colour. The floor is made of linoleum, the closet is laminated wood and the door to the corridor is painted wood. A large window fitting the wall size is in the other end of the ward. There is a lot of steel in the ward. The steel is seen in the construction materials in the hospital beds, the electronic panels behind the bed, chair legs and heater. Between the 
beds, curtains of synthetic and natural materials are hanging in front of the window, and curtains made of cotton are hanging to separate the bed area from the washbasin.

In the ward, there were a lot of power sockets and electronic panels. First of all, a red button is placed right next to the door. The button is connected to the lift hanging beside the beds. Next to the red button, the staff button connected to the alarm system is placed, so the nurses quickly can turn off the sound and light of the alarm. Beside the door, four power sockets are placed to control the light in the ward, and it is not easy to guess which one turns on the light, and which light is controlled by which contact.

The huge window distributes daylight to the ward. The window is facing south, so the daylight is present during most of the day and in the summertime there could be problems of overheating. The staff told that overheating was a problem for the patient nearest the window. Being in the ward for a day in September, it felt good to feel the sunrays. It was obvious that design choices in the interior were made in the 1980s. The red suspended luminaires, the textile design of the curtains, the chose of powerful colours likes red and yellow had references to the period. During the evaluation of the light atmosphere, the issue of light for communication was discussed. Because there is a big window providing a high light level from one side, it is important having the doctor stand on the door side of the bed in a communication situation. Standing on the window side, too much light could disturb the communication with the staff, because the contrast is too big and therefore the faces of the staff and their facial expressionsare too hard to see. We also noticed humming luminaires when turned on, the wall clock ticking noticeably, voices coming from the corridor, ventilation growling, and the sound of metal scratching even with closed doors. The last note is that a suspect yellow light came into the ward from the corridor and a bluish light from the window side and so mixes of colour temperatures were mixing in the ward. 


\subsection{LIGHT PREFERENCES IN DANISH HOMES}

Being a designer studying user perspective, it is of course a matter of finding the right experts to interview. The right experts in connection with light preferences in Danish homes are both professional designers as well as the everyday user, Danish families with a Danish cultural reference to light. In chapter 3 (On Light Atmosphere), theoretical experts as well as visual examples are discussed. In this section the main goal is to explore in which way the artificial illumination is used to support everyday activities in Danish homes.

The method used to study preferences for illumination is inspired by the study 'hjemlighed' (Winther 2007) and (Højlund 2008). Both studied 'home like' as a concept. Winter made use of techniques such as a photo album as an interview guide of semi-structured interviews of kids and what they linked to the term 'home like' Højlund studied home like in connection with institutions for children in care.

\subsubsection{METHOD}

This study seeks to discover unknown approaches for light atmosphere with the purpose of expanding our own frame set and pushing our pre-understanding of the Danish traditions of light atmosphere. We used qualitative methods rather than more quantitative approaches (Seeberg 2009, Selmer 1998) to describe the difference in the subject field so as to distinguish between the stable versus the reflexive object. Regarding the reflexive objects, it is fitting to use methods where the understanding of the contextual and constructed everyday life is embedded in the method.

Qualitative methods are thus particularly suited for scientific studies dealing with content and profundity, in exploring new ways of looking at themes. In this context, anthropological methods are particularly interesting with the emic approach to the study. As (Hastrup 2010) writes:

"The empirical claim implies that anthropology deals with (specific, known and named) people's actions and the perception of their own lives and activities (...)". 
The anthropological methods focus on the informant's own world and experience and are therefore interesting for this study. The technics used to gain the information are a combination of semi-structured interviews and photo documentation. As a result of the admission to the hospital, daily activities were defined as 'Dining', 'Watching TV', 'Going to bed', 'Sedentary Activities' (Reading, knitting, sewing, solving crossword), 'Upstanding Activities' (walking, playing music instruments, cooking, etc.) and at last 'Communication / social interaction' (having guests, having conversations with staff etc.). These activities were of special interest in the interviews.

Semi-structured interviews were chosen as the main method for this study, a method that is ideal for what (Rubow 2010) calls a 'multi-site field work'. On top of the challenge of working in a multi-sited field, working with light is often filled with tacit knowledge. Many people have trouble describing their own perception of light because light is primarily a phenomenon that we relate to intuitively and experientially. Therefore, we have combined our interviews with a visual approach to fieldwork using photo albums (Winther 2006). Both the albums and the interview guide focus on keeping the interview concrete and descriptive. As (Kvale 2009) writes:

"In the interview itself the main questions should be of descriptive character "What happened and how did it happen? How did you feel then? What was your experience?"

It was essential to find a method supporting the informant's experience of being the experts on the illumination in their own homes, even when a lighting designer/ researcher is visiting the home. The generation of knowledge in qualitative methodology is an interaction between informant and researcher. This means that there may be a bias in interactions when the researcher appears as an expert in the area, on which the informant has previously reflected tacitly rather than explicitly. In that case, the researcher may have a disproportionately large influence on the informant's statements. The specificity of this study is to verbalize what few have articulated exactly, to minimize this bias effect and to ensure, as far as possible, that the informants would be experts on the illumination in their own homes, by using so-called photo documentation. The purpose is to get a spontaneous and emic description of 
the informant's everyday use of light as possible.

Firstly, the informants took pictures with disposable cameras of their use of light in everyday life in relation to the different activity categories previously described. The informants sent the disposable cameras to us, and the pictures were developed and put into a photo album. Afterwards, the informants were interviewed in their homes and the photo album functioned as basis for the interview. Lastly, the interviews were transcribed and analysed. To optimize the method of the study, we undertook a pilot study. This was primarily to ensure that the participants' task of working alone was easy to understand and to test the idea of structuring the interview with photo albums. (Letter to informants in appendix 1)

\subsubsection{ANALYSIS}

The collected data was analysed in the before-mentioned categories and revealed a varied use of everyday light in relations to the different activities.

\section{Dining}

Dinner activity can be divided into two different situations; 'Dinner for the household' and 'Dinner for guests'. The everyday dinner for the household was mostly eaten in the kitchen or sometimes in the dining room. During weekends, the dinner experience should be different and the dinner was served in the dining room or at a dinner table in the living room. Across aesthetic choices and interests for interior design, almost all informants chose an illumination type where a pendant was hanging over the table creating a light zone that covered table, chairs and the persons around the table (fig 4.4 and fig 4.5). The pendant was often flexible and could be moved up or down and from side to side.

The other situation was when the informants had guests for dinner. Then the illumination was changed to a cosier atmosphere. A cosier atmosphere meant, in most interviews, the informants turning on several luminaires in the room and arranging candlelights on the table and around the room. If they had the option, they dimmed the light in the pendant. To compliment the desired atmosphere, most of the informants preferred having a light zone where the guest were sitting, and a light zone in the other end of the room, emphasizing the character of the room.
Fig. 4.3

TV illumination in the living room

Fig. 4.4

Dining table with a luminaire hanging central located over the table.

Fig. 4.5

Dining table with a luminaire hanging central located over the table.

candlelights used as illumination when having guests.

Fig. 4.6

Illumination for TV or Sedentary activities 


\section{Watching TV}

When it came to watching TV (fig 4.3, 4.6), the light atmosphere was very important. The most important thing was to avoid the reflecting light from luminaires in the TV screen. Almost all of the informants placed one luminaire beside or behind the TV, one near the TV observer and one luminaire away from the observer's location to give a
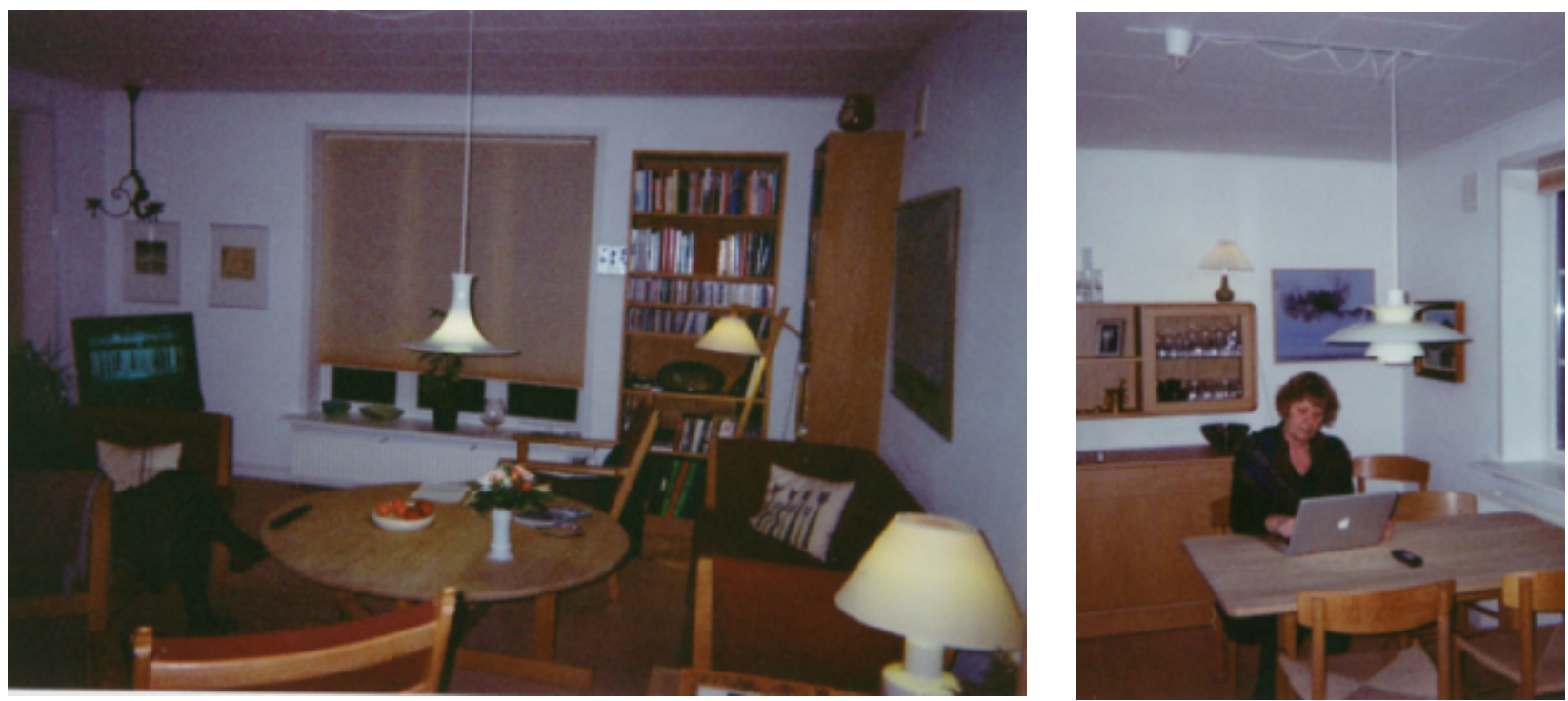

4.5
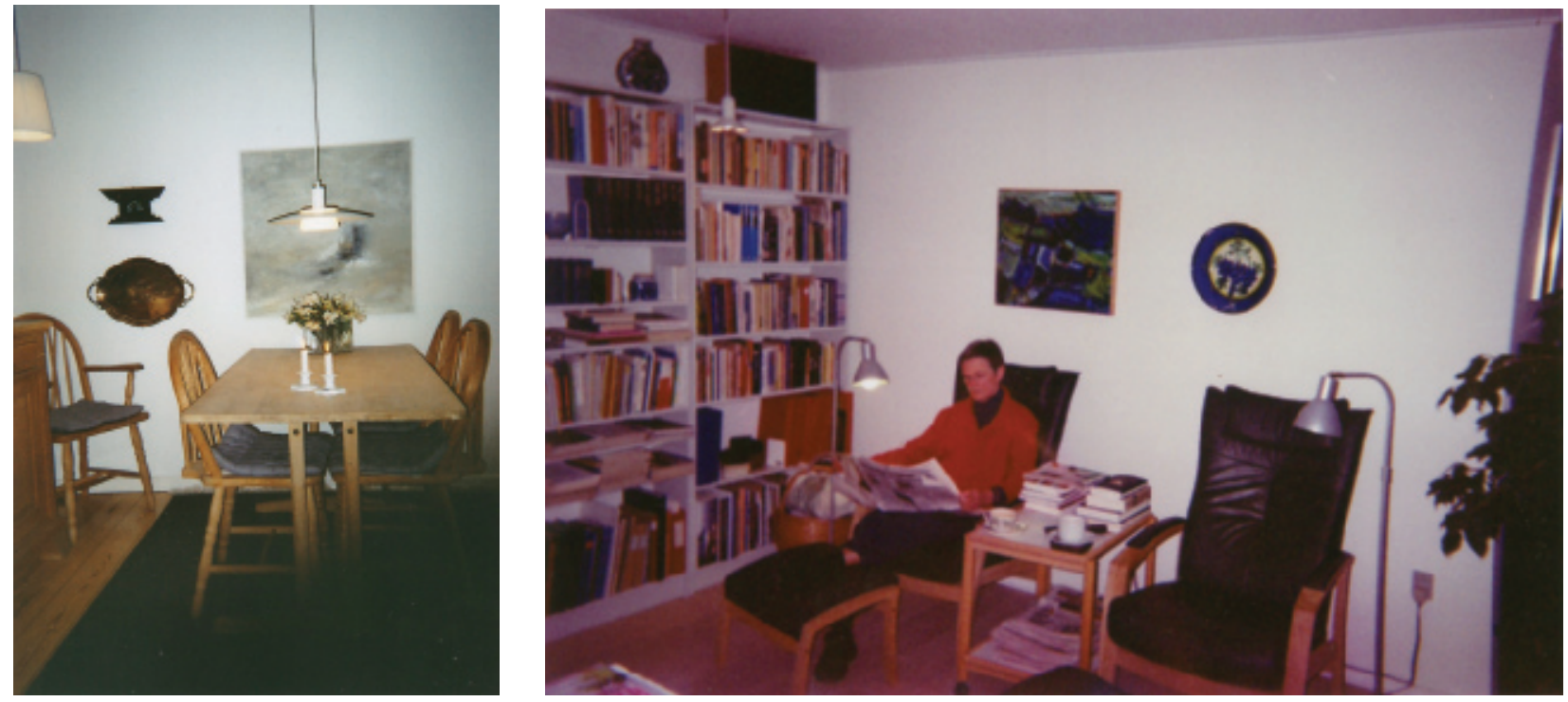
feeling of seeing the room. All luminaires were dimmed, shielded or adjusted to direct the light downward and arranged so as to create small light zones around the room.

\section{Going to bed}

In general, the lighting design for bedrooms was not a focus area for the informants. Many were apologizing for the illumination of this room, and it seemed to be illuminated by chance with "leftover" luminaires. The analysis showed that the activity of "going to bed" or "having a rest" could be split into two different categories i.e. those who read in the bed and those who do not read in bed (Fig 4.7).

Most of the informants had ceiling mounted luminaires centrally placed in their bedroom. The use of the light was to "switch on" when entering the room, and then "switch off" as soon as possible when they had turned on the bedside luminaires. The informants who were reading in the bed, sitting or lying, were conscious of using the light and knew exactly how they liked the light distributed and how to avoid conflicts with a partner if only one was enjoying reading in bed. Most liked the light coming next to the shoulder (fig. 4.12), directed precisely at the book. In some cases, the informants had trouble seeing the contents of the closet and desired to have direct light focused on it.

\section{Sedentary Activities}

Analysing the sedentary activity as reading, knitting, sewing, solving crossword etc. also produced several interesting answers to light preferences (Fig 4.8, 4.9, 4.10, 4.11). The informants had a pronounced opinion about the light atmosphere for this activity. The usability of the lamps was important, and many informants had floor lamps or lamps mounted on the wall right above and behind the chair or sofa to create the perfect light for the activity. Almost all informants used a primary luminaire for visual task lighting in this situation and then secondary luminaires around the space for lighting the peripheral vision, creating a pleasurable light atmosphere. Most of the informants placed the luminaires near the walls and in a horizontal tripartition of the central zone. Almost all of the participants were conscious about the fact that they needed more light now than when they were younger.

\section{Upstanding Activities}

Fig. 4.7

Bed illumination

Fig. 4.8

Light for sedentary activities as working on computer.

Fig. 4.9

Light for sedentary activities as working on computer.

Fig. 4.10

Light for sedentary activities as working on computer.

Fig. 4.11

Light for sedentary activities as working on computer.

Fig 4.12

Bed illumination with adjustable luminaire 

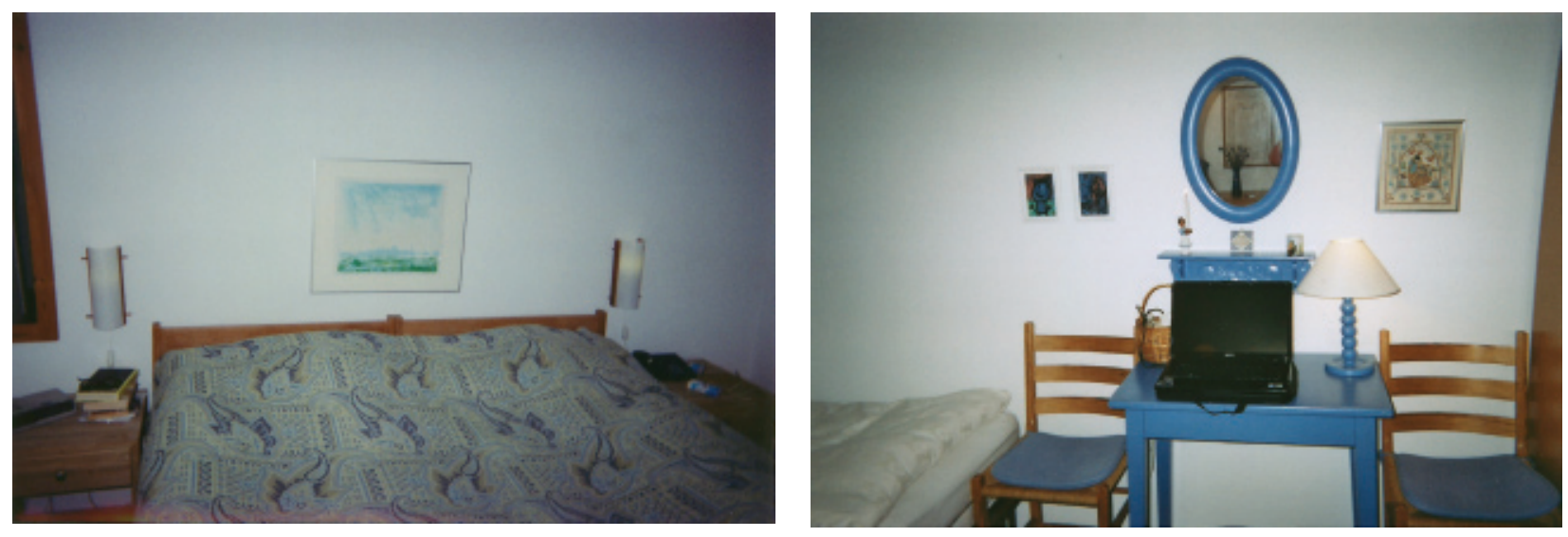

4.9

4.10
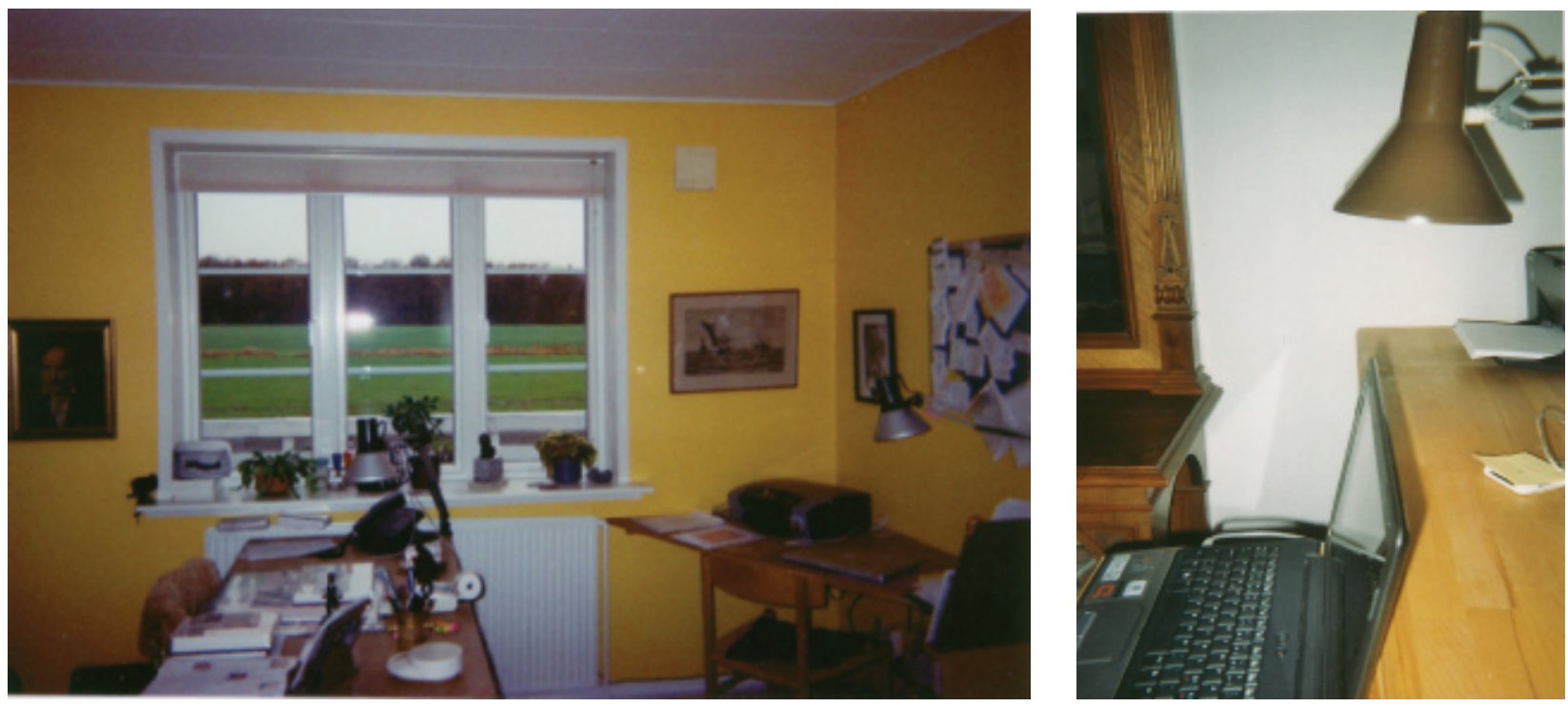

4.11

4.12
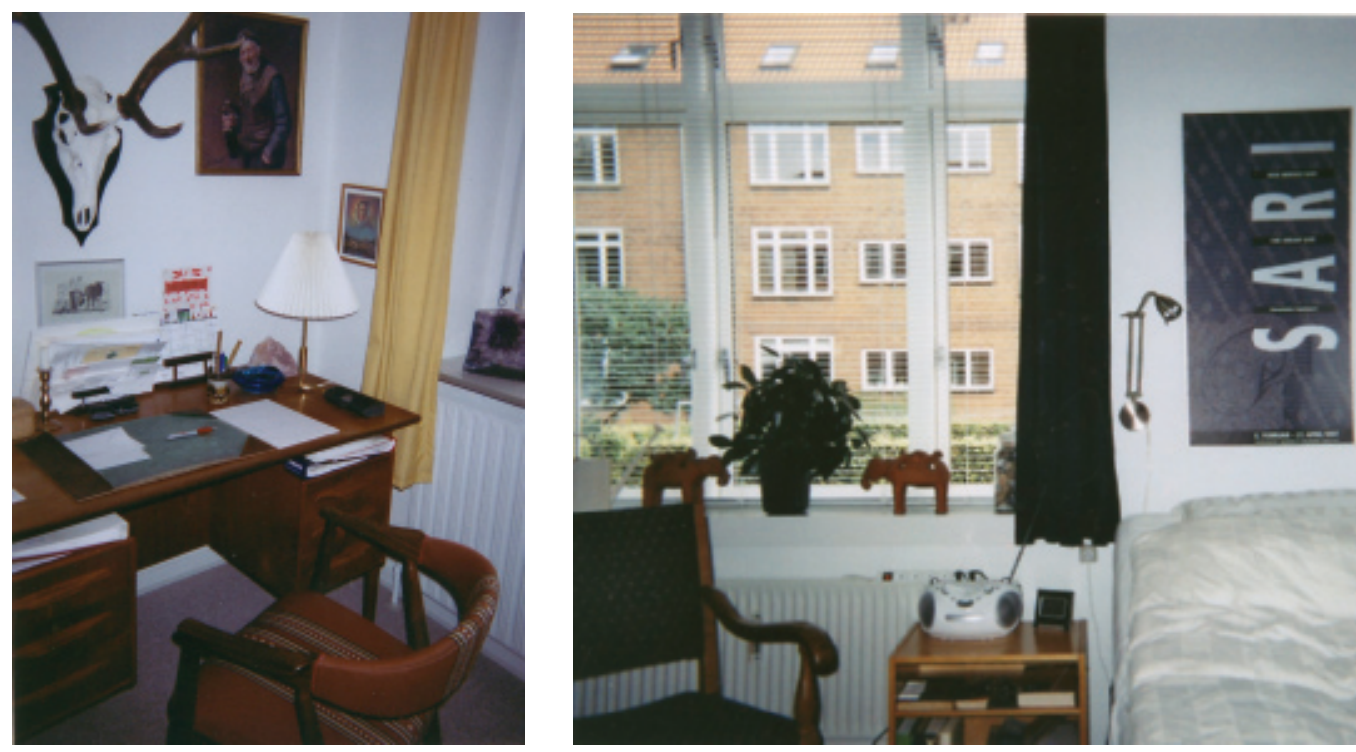
When it came to upstanding activities like walking in the hallway(fig 4.13), using the bathroom or cooking( fig 4.16), it seemed to be important to have a general illumination supported by specific task lighting when necessary. The general light preferences for standing activities were to have a primary, uniform light distribution so every part of a room appeared bright. The illumination was mostly ceiling mounted and supported with specific task lighting right where the light was needed. If the space was used as walking area like in a hallway or when entering the bedroom, the light should just distribute enough light to see where you were walking and prevent accidents, and then there could be a specific task light near the mirror etc.

\section{Communication / social interaction (having guests, conversations)}

In situations where the informants were having social interactions such as having guests in their home, they presented their homes in the best light. They turned on almost every luminaires in the 'guest area' as a gesture of welcoming visitors (fig. 4.14 and 4.15). Almost every informant mentioned that they lit more candles and illuminated their living room with many luminaires so the room was filled with a warm, light atmosphere and myriads of light zones. The luminaires were mostly located near the walls in varying heights and often supplemented by luminaires highlighting the tables. All luminaires were placed so they emphasized the appearance of the room in different light settings. When the communication was in connection with a work situation, it was different. Here, the informers preferred a more uniform light atmosphere. One informant, who works in a workshop for physically and mentally disabled persons, had a problem using pendants and having dark areas in a classroom because it could prevent contact with users. She preferred a light distribution with fluorescent light tubes. With those she felt a good connection with the workshop users, and pointed out that it was very necessary to have good light.

\subsubsection{SUMMARY OF PREFERENCE STUDY}

The analysis of everyday use of light in Danish homes among people in the age group of $60-85$ established a clear picture of light atmosphere preferences for different activities, and the interviews contributed with new subjects important to the informants. Homes are illuminated
Fig. 4.13

Light in a corridor, upstanding activity

Fig. 4.14

Communication and social interaction

Fig. 4.15

Communication and social interaction

Fig 4.16

Upstanding activities as kitchen illumination 
more or less consciously, but no matter of preferences for interior design or level of considerations for illumination of our homes, all Danes use similar techniques to create a homely atmosphere. Both daylight and artificial light can transform the atmosphere in the spaces.

In general, the study showed that with activities like walking and standing, the light was distributed from the ceil-
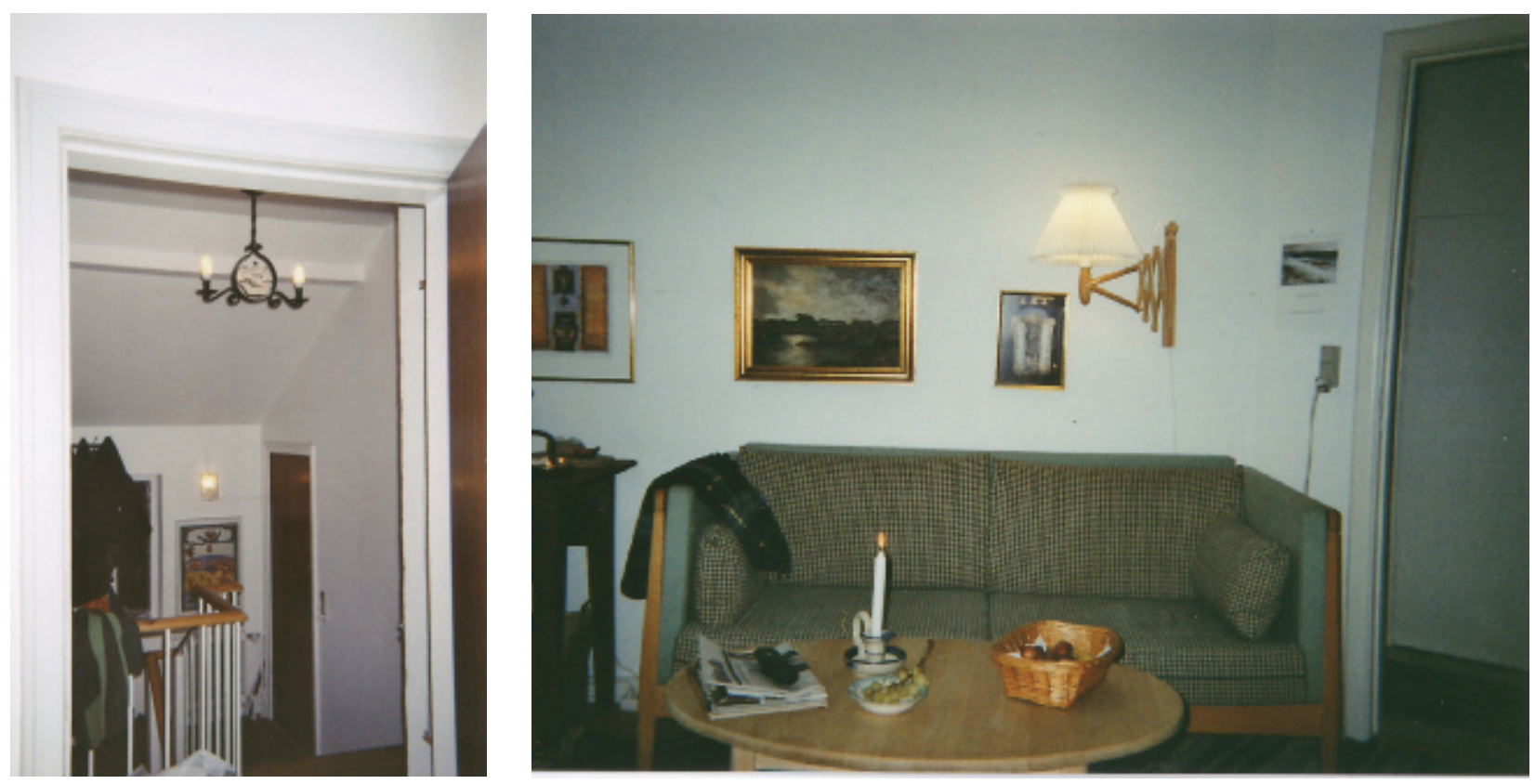

4.15

4.16
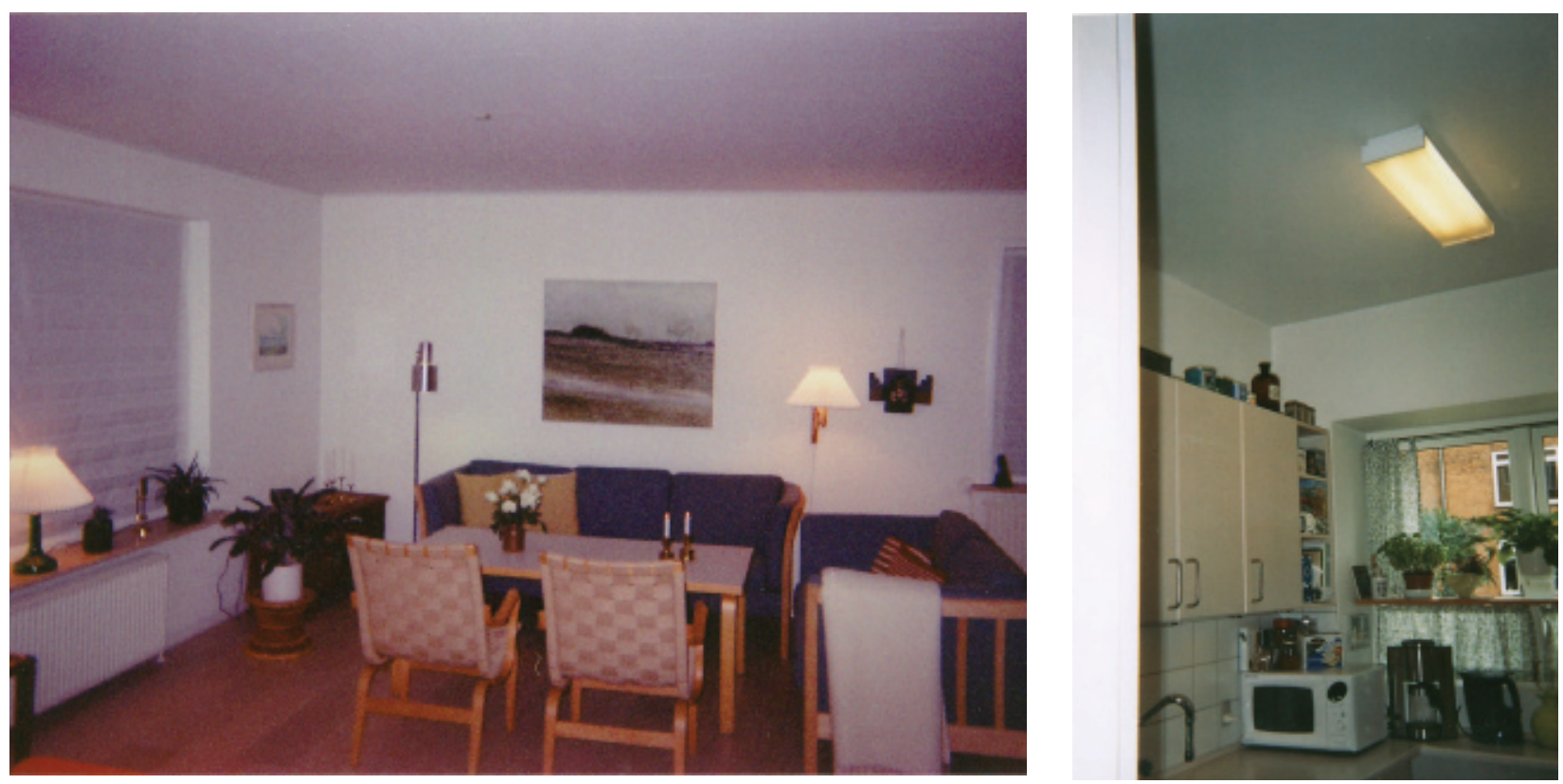
ing. With sitting activities like working by a table, reading in a chair, watching TV, having guests etc., the light was distributed in a way so light zones appeared surrounded by darkness. Rooms for standing activities such as walking in a hallway or working in the kitchen showed a preference for a more uniform illumination where the light was mostly distributed from the ceiling and often with opal luminaire or a shielded down light.

When it came to questions on unpleasant light, few informants claimed that the illumination of southern European houses was unpleasant. They did not find it comfortable or cosy to be in a light atmosphere with fluorescent tubes or light bulbs mounted to the center of the ceiling in a room where they were supposed to relax and feel at home. Even though we did not ask directly about hospital light, some of the informants mentioned the subject and talked about light in hospital environment as being cold and too white. Attention was also drawn to issues such as sleeping problems because of the light during nighttime.

Going back to the pleasant light atmosphere, all informants were specific about preferences for the relaxing place, and lights were intentionally adjusted to support the need for relaxation. In the living room, the study showed, among other things, that in order to achieve a relaxing light atmosphere, the main part of the luminaires were shielded and placed near the walls in a way so they created a dark zone in the center of the room and illuminated light zones around the walls. The number of light zones and the amount of luminaires were also issues in the home illumination. Up to 14 luminaires were counted in living rooms, without including lights from Christmas decoration. Informants preferred flexibility in the light atmosphere, so they had the ability to change light atmosphere if needed. All had a favourite place in their living room. They had different ways of creating a private sphere around the place or ways of illuminating the area, but they all had their "own" place where they liked to relax.

Another matter was the dining situation. Lights from pendants created a small light zone including tables and chairs so the persons around the table were sitting inside the light zone or in the transition zone between light and dark. The lamp shadings were either reflecting the light from a metal lampshade or light transmitted through textile-covered 
lampshades. The use of candlelight is enormous and seems to be synonymous with the Danish concept "hygge" (translated to "cosiness") in illumination in Danish homes.

The study contributed to the design study by pointing at the horizontal and vertical placement of the luminaires as essential to the light atmosphere. It seems that in horizontal tripartition of the space in a 'High Light Scenario', 'Centre Light Scenario' and 'Low Light Scenario' could be beneficial in the design process. The space for relaxation has most light in the 'Centre Light Scenario' and the 'Low Light Scenario'. Walking activities have the most light distributed from the 'High Light Scenario'. In connection with going to sleep, the preferences were for 'Low Light Scenario'. A vertical twopartion of the space in a 'near the wall' or in 'centre' of the space also showed that most light was distributed from the zone near the walls and lesser light in the centre of the space.

Since this tripartition is a new concept, it has not been possible to find backup from other researchers with same approach. Therefore, another study was made in order to find backup for the idea of the tripartition. While this study is based on anthropological descriptive methods, the next study is based on a quantitative character using scaling methods to map the trends of light atmosphere in Danish homes for the last 50 years. In this way, it could be displayed whether the tripartition is representative for a short period or a longer tradition of illuminating Danish homes in same way. 


\subsection{TRENDS OF LIGHT ATMOSPHERE IN HOMES}

The study of preferences for light atmosphere in homes pointed at a separation of illumination in lighting scenarios based on horizontal zones. In this way the light was separated into a 'High Light Scenario' a 'Centre Light Scenario' and a 'Low Light Scenario' (Stidsen, Kirkegaard et al. 2012_b). It was shown that the illumination in Danish homes was distributed in a decentred manner, but it did not tell if this trend is old or new. To find the period of different light atmosphere trends, the Danish trend magazine 'BO BEDRE' (Better Living) was used as reference. The study was made in the winter 2011-2012. The aim of the study is to discuss how the appearance of light and space have an impact on each other.

A descriptive knowledge of the tradition of using light is helpful in understanding a modern way of using light as well as the impact of the technology on the use of light. Seeing the hearth fire as the archetype of the living room light not only explains the persistence of an open light source but also says a great deal about the perception of light in the nineteenth century.

Studies like (Schivelbusch 1995) explained how technology and light had an impact on living conditions and the industrialisation of the light in the nineteenth century. The book pointed out what it meant for a family losing the hearth fire, which was the center of the family household and focus of life until lamps were invented. Schivelbusch also writes:

"Some autobiographical senses of communal evening life confirm that the light played a central part. "At supper time", reads the autobiography of one peasant, "a small tin oil-lamp was placed on a upturned pot in the middle of the table. Gradually, all the members of the household would quietly gather around it". The situation was the similar in the bourgeois (or rather, the petty bourgeois) home. "In the evening, our parents and the older children would sit around the round table in the living-room. Mother worked as usual, but the rest of us would rad."'The evenings when the lamp was burning above the round table and the family was gathered around it, chatting, reading or working, were always a special time". (Schivelbusch 1995 p. 166) 
Historically before the electric light became a part of the homely sphere, a Swedish study showed that people were using light sticks, oil lamps, petroleum lamps or gas light to illuminate their homes in a way so they were able to work after dark (Garnet 1993). In the beginning, the lights were carried around the people who needed the light, or centrally placed among the main users of the light. Later, when light was cheaper and something everyone could afford, the light became a part of the decoration in a space and used as fixed elements in interior design.

"The dusk of the North consists of a liminal zone, a border zone, of light and darkness. Those who were able to use to enjoy a moment of relaxation in a "twilight sit"; the Swedish (kure skymning) is one of the several expressions for the habit of pausing in one's duty when it had become too murky to see, for a quit talk, for relaxation in silence, or quite simply for meditative tranquillity“.(Garnet 2011)

In Denmark, the same tradition was called 'morkning' and, as in Sweden, the habit was influenced by the technological development of light, because light was extremely expensive and therefore only used when needed. In those days, light was needed and used differently than today. At that time, it supported the need for seeing where today it is a more light is also seen as providing visual wellbeing as well as physical and emotional.

The evaluation of light has gone through different stages. First stage evaluated the lighting quality as the measured the light level uniformly distributated on horizontal plane. Second stage of lighting quality had a focus on human needs and preferences mostly based on studies of visual performance, effectiveness or physical impacts. (Cuttle 2010) argues that the second stage failed to achieve its objective and there is a need for third stage. The need for third stage is based on a reality where the illumination beside apply the illumination according to the standards, also has to meet the user expectations and respect the users experience of the space appears adequately lit. In that way the essential difference from stage one to three is a switch from assessing light incident on planes to assessing light arriving at the eye. In that way the third stage evaluates the reflected light arriving to the eye from the surrounding room and be aware of expectations and pre 
understandings of quality of light.

As earlier presented in the chapters 'Introduction' and ' $O n$ Lihgt Atmosphere', Denmark is known for lighting and luminaire design focusing on the "good light" and well being (Coninck-Smith 1989, Hansen, Jørgensen et al. 1994, The Danish Illumination Engineering Society 2004, Volf 2010, Lund 2008, Sørensen, Haug 2011). Danes brag about having a special Nordic light and being skilled in illuminating our surroundings. There almost seems to be a common knowledge of "good lighting" and a certain way of illuminating homes in a good way. While these studies tell something about the past, the daylight, the luminaire design and provide some information on illumination on homes, it seems to be something of Danes using light in a certain way when they illuminate their homes. (Bille, Sørensen 2007) introduce anthropology of luminosity as an examination of how light is used socially to illuminate places, people and things, and hence affect the experience of materiality of these. The Finnish architect Juhanni Pallasma notes the phenomenology of a home distinguishing between architecture and home. He notes that home is an individualized dwelling and it is not always easy to see in the architecture of today. Home is an expression of personality and family and their very unique pattern of life.

Being a designer myself, I seek visual information on what is going on in the field. Normally, I use trend magazines as inspiration and as the task is to find the trends of light atmosphere in Danish homes, the old Danish Interior design magazine 'BO BEDRE' is found applicable for the study. (Stidsen, Kirkegaard et al. 2012_a)

\section{Trend magazine BO BEDRE}

When studying light atmosphere and the sensory qualities of light in Danish settings, it is interesting to look back through history and analyse lighting trends in private homes. A way to find this information is to analyse a representative collection of the Danish interior design magazine BO BEDRE. The interesting thing when analysing BO BEDRE is giving a historical overview of the trends in interior lighting, focusing on lighting in Danish homes.

The magazine has a target group with quite mainstream thinking in proportion to interior design. It could also be people who are interested in home décor trends, but 
without being avantgarde. It is a well-respected magazine showing current trends, and it has been published since 1961 and still on the newsagent's shelves.

The magazine has been published every month. Some years, special issues as Kitchen or Christmas have been issued in addition. Through second-hand stores, private transactions over 'Gul og Gratis' and 'Den Blå avis' (internetshop providing used items from private to private user). 491 magazines from the period January 1961 - December 2007 was collected. 103 from the 1960 s, 113 magazines from the 1970s, 101 from the $1980 \mathrm{~s}, 86$ from the $1990 \mathrm{~s}$ and 88 magazines from the 2000th. (Benjamin Media)

\section{Photography}

Even though it was desirable to be present in the space being analysed for a study of light atmosphere, it was not an option for us to personally be in homes representing the period of 50 years. It is also hard to believe that it would be possible to find original interior design representing the period. Therefore, the magazine was seen as a possible way to get the information. (Newsham, Richardson et al. 2005) concluded that images can be a reasonable surrogate for the real space particularly on ratings related to aesthetics. (Newsham, Richardson et al. 2005) note that you can look for general trends, but you cannot find the optimal scene. This means that the method seems appropriate for this study of identifying general trends. So, it seems appropriate to use images as representative material, at least when it is not possible to recreate real world studies of the environment.

It is also a discussion of whether the method of using images from a interior design magazine during a period is representative for the actual trend in the period or rather a question of representing fashion in photography and ways of illustrating interior design. Photographers are able to manipulate light in pictures and a set-up can be supported by light not visible in the scene photographed. The expression in the images can also vary as the technology in photography has gone from an analogue to a digital process, which can have an impact on the images. This can of course be a problem, but while a magazine hires the photographers, they must follow the guidelines of the magazine and the visual identity of the magazine. So, the 
way of representing an interior design is seen as an approach from the magazine and not as a photographic style or approach. Still, it is important to be aware of the dilemma throughout the study and note if remarkable changes happen. Therefore, focus is on the location, shapes, size and numbers of luminaires in the images and not on the light represented in the pictures; bright picture or dark picture, and luminaires without light were included in the study. In this way, the imagination of the light situation is a part of the study, while the analysis requests knowledge on how luminaires are distributing light in a space. So, it is possible to see if the photographer has added extra light in the set-up or not. The light level is, for example, defined by the way the luminaires distribute light and not by the reflected light from surfaces in the space.

But while images are analysed with knowledge on how light is distributed, it should be possible to evaluate the light level in the pictures and not if the picture is more or less bright. The materiality and space appearance request the same kind of knowledge since the analysis is based on knowledge of how it will reflect or absorb light, and the characteristics of materials.

\subsubsection{Method}

The analysis chart is developed based on studies of lighting design books. The methods used to structure and classify light and lighting was compared and translated into a study of images. Since the study is made on Danish magazines, the language used developing the analysis chart is written in Danish.

The light pattern book for homes (Leslie, Conway 1996) presents lighting technics in seven categories: Day lighting, ambient lighting, indirect lighting technique, wall washing, accent lighting, task lighting and finally special purpose lighting. 'Day lighting' is defined as direct sun, the sky that diffuses the light. Daylight luminaires are the windows and skylights that admit daylight into the building. In this way, the analysis of daylight is separated from the analysis of artificial light. 'Ambient lighting' provides the general illumination for a space and enables people to move around the home. 'Indirect lighting technique' uses one or more luminaires to direct light onto the ceiling and upper walls of a room and use the upper walls and ceiling as reflectors. The technique is also referred to as "up-light'. 'Wall wash- 
ing' illuminates vertical surface to an acceptable uniform brightness and draws attention to the wall.

'Accent lighting' also called highlighting, emphasizes objects by focusing light directly on them and it point a visual interest for the illuminated area.' Task lighting' increases light for specific tasks in a room that may already have some ambient light. Finally, the lighting technique 'Special purpose' is lighting as artwork, light for plants, the light television, mirrors or light for security.

\subsubsection{CATEGORIES EVALUATED}

(Leslie, Conway 1996) also presented eight categories of luminaires. 'Ceiling mounted' as the luminaire diffusers or track/adjustable heads. 'Suspended luminaires' as down lights, up lights, up lights/down lights, chandelier or ceiling fans.' Recessed luminaires'as troffers and luminous ceilings, down lights, wall washers or accent light. 'Architectural luminaires' as coves, soffits or valance.' Wall-mounted' as diffusers or vanity lights. Then, 'Furniture or cabinet integrated luminaires' as can be experienced in medicine cabinet, shelf or display cabinet, under cabinet, artwork or stove appliance. Lastly, the 'Plug-in luminaires' as table lamps, desk lamps, floor lamps or night lights.

Leslie's categorisation is not directly translated into this study, which is why this study needed to support the study of preferences. As the categorisation for this analysis also has to match the character of images in Bo Bedre, it was chosen to use the luminaire categorisation from (The Danish Illumination Engineering Society 2004). Here, the luminaire categories are: a'Downwards directed', a 'Partially downwards directed', an 'Evenly lighting' an 'Up and downwards directed', a 'Partly upwards directed' and lastly a 'Directly upwards directed' luminaire. This type of categorisation is found useable to this study as combines a type of light with work or relaxation etc. The technique is in focus and not what the light does to the space.

Inspired by the study of preferences, we are aware of the different ways of using light when having standing activities as well as sedentary activities. In order to be compatible to the type of pictures presented in the magazines and to be able to compare the light results, we chose the following categorisation of type of spaces:'Living room', 'Dining room', 'Standing activities', 'Bath, Multifunctional 
room', 'Corridor', 'Sitting activities' and 'Bedroom'.

(Liljenfors 1999) introduces lighting theory and basic lighting knowledge combining both visually and physically factors in lighting design, and highlights seven basic terms describing the visual experience of light. What he finds essential in the analysis of an illumination is first 'the level of lightness' and how light or dark is present in the space. Secondly, the evaluation of Spatial distribution of brightness' and how the composition of light and dark is present in the space, and here questions as where is it lighter and darker are asked. Thirdly, an evaluation of 'Shadows' in the space and of where the shadows fall and what the character of the shadow is. Fourthly, the 'Reflections' of light in the space and where the reflections occur and what the character of the reflection is. Fifthly, the issue of 'Glare' is evaluated; where does glare occur and how noticeable is it? The 'Colour of light' or maybe the colour experience of the light is noted; is the experience of light cold, warm, reddish, greenish etc. Lastly, the 'Colours' are evaluated and the question is: do the colour looks natural or distorted?

(Boyce 2003, p. 212) found it important to evaluate the experience of the illumination in a bipolar scale and point out five essential factors: First, the 'overall evaluation' of whether the spaces are friendly-hostile, pleasant-unpleasant, like-dislike, harmony-disorder, satisfying- frustrating, beautiful-ugly, sociable-unsociable, relaxed-tense and interesting-monotonous. Then, the 'Perceptual clarity' as clear-hazy, bright-dim, faces clear-faces obscure, distinctvague, focused-unfocused and radiant-dull. Thirdly, the 'Spatial complexity' is evaluated as simple-complex and uncluttered-cluttered. Fourthly, 'Spaciousness'as largesmall, long-short and spacious-cramped. Lastly, 'Formality' is defined as rounded-angular and informal-formal. Boyce also points out analysing the lighting and the perception of spaces and includes 'Lightness', 'Brightness', 'Luminance intensity', 'Distribution', 'Brightness', 'Light spectrum', 'Visual clarity' and lastly the 'Colour appearance'.

Both Boyce and Liljenfors agree on many of the central focal areas of evaluating an illumination. The both introduce important factors in analysing the experience and the appearance of light in a space and provide a picture of how light can be analysed. Liljenfors talks more about descriptive tradition, while Boyce talks about using bipolar 
scaling methods. For the study of illumination trends by using images, the study of Boyce and Liljenfor's methods contributed with the awareness of evaluating both the overall impression of the space as well as the importance of the different detail for the overall impression. In the study of pictures of light atmosphere in a space, some of the factors are more or less relevant. An example could be perceptual clarity, which is important in analysing a space, but a picture presented in a magazine will have clarity and be shiny and glossy as well as colour appearance is adjusted.

So, in the end what we used was the bipolar scaling in five steps, which Boyce presented as important. The categories found important for the analysis chart are presented in fig 4.17 on next page. First a general registrations as magazin number, year and page number. Then 'Light appearance' (light level, light distribution and daylight contribution) and 'Space appearance'(visual temperature and spatial composition). Data on 'Luminaire Effect' (shadow effect, and design focus) is noted, 'Lighting Technique' (Down light, mainly down light, unifor light, up- and down light, mainly uplight and uplight) was noted as numbers of luminaires in the different categories. 'Room Definition' (living room, dining room, Standing activities, bath, multi functional, corridor, sitting activities and bedroom) data seperates the information in different everyday activities.

The analysis chart included also data on 'Horisontal Zone' (High Lighting Zone, Centre Lighting Zone and Low Lighting Zone) and 'Vertical Zone' (Near walls and Centre of space) and lastly if the image is taken in daytime or night time and the focus of the article. Is it a report or 'do it your self' focus of the article. 


\section{DATA COLLECTION}

General:

Year

Magazine Number

1) No article 2) No magazine

Page number

Light Appearance: Light level

Light distribution

Space Appearance: Visual temperature

Spatial composition

Luminaire Effect: Shadow effect

Design focus

Lighting Technique: Down light

Mainly down light

Uniform light

Up- and down light

Mainly up light

Up light

Room Definition: Living room

Dining room

Standing activities

Bath

Multi Functional

Corridor

Sitting activities

Bed room

Horisontal Zone: High Light Zone

Centre Light Zone

Low Light Zone

Vertical Zone: Near walls

Centre of the space

Horisontal Zone Numb: High Light Zone

Centre Light Zone

Low Light Zone

Vertical Zone Numb: Near walls

Centre of the space

Photo:

Article Focus

Night

Day

Report

Do it yourself
Fig. 4.17

"Short" version of the analysis chart. The full described analysis chart is in appendix 3

Fig. 4.18

Table displaying numbers of registrations in each room category.

Fig. 4.19

Distribution of registrations in room category. 


\begin{tabular}{|lc|}
\hline Room Category & Registrations \\
\hline Living room & 937 \\
Dining room & 704 \\
Standing activities & 555 \\
Bath & 287 \\
Multifunctional room & 202 \\
Corridor & 221 \\
Sitting activities & 217 \\
Bedroom & 360 \\
Total & $\mathbf{3 4 8 3}$ \\
\hline
\end{tabular}

4.19

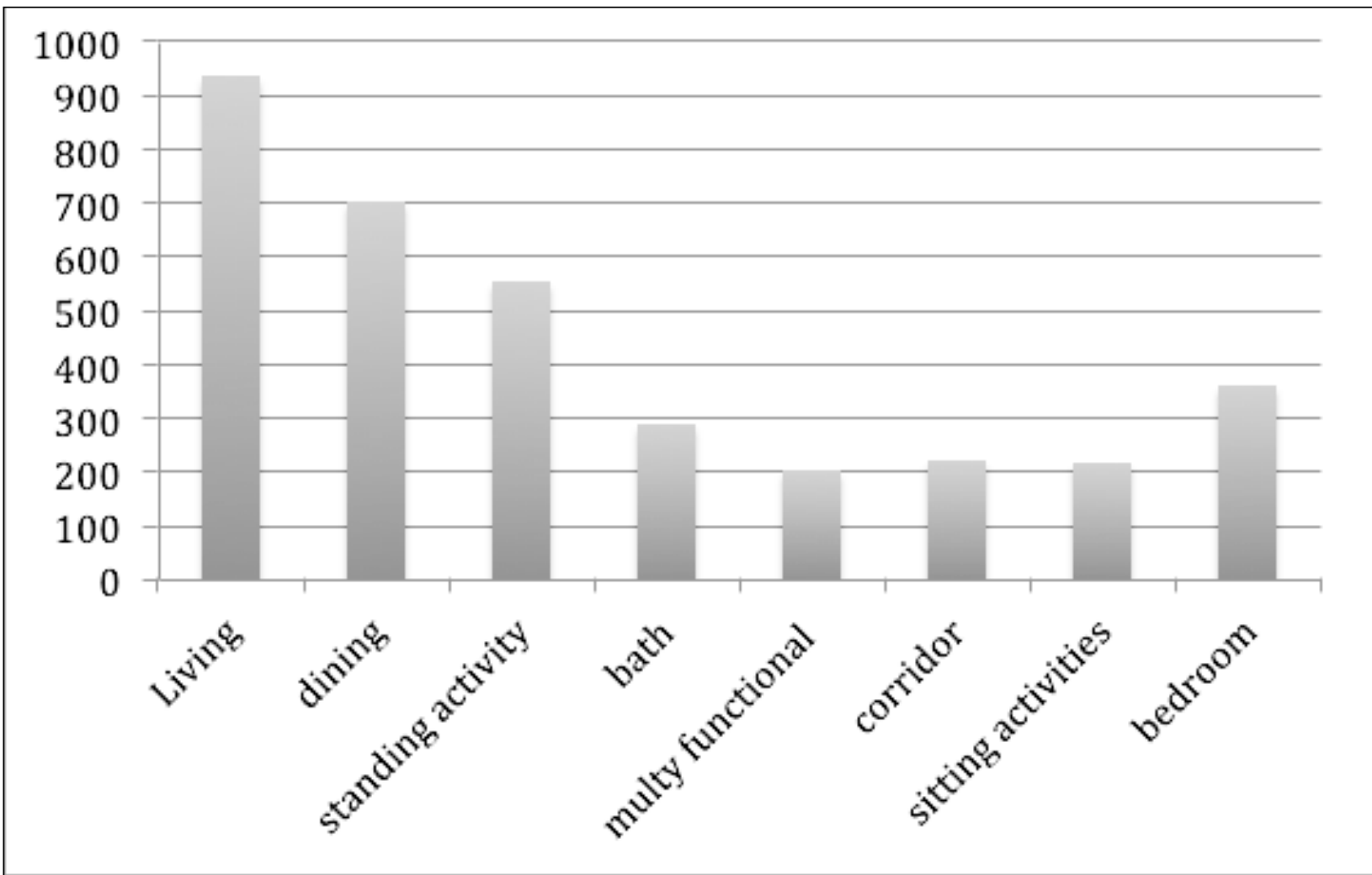




\section{Validation}

It is perhaps a risky endeavour to measure subjective impression of a picture with the purpose of evaluating atmosphere, and likewise there can be problems putting numbers on sensory impression because these kinds of scales require a pre-understanding of terms and content. In order to minimize different understandings of subjects and to validate the rating tool, the content of the table was tested in five issues of BO BEDRE and revised two times in order to get the final table. Adjustment of the rating scale from a 7 -scale to 5 -scale was done because the interval between the numbers was found insignificant. Hereafter, five volumes of BO BEDRE were simultaneous analysed by two persons sitting next to each other over a period of three weeks. Likewise, we modified the text so the scale went from "nothing- full of" to "only little- full of". An example could be light level. Bo Bedre does not show pictures without light, because then it would only be black and boring to the reader. But pictures with low light level appeared many times. (The criteria is displayed in appendix 2)

\section{Selection criteria}

The categories are representative for rooms appearing in Danish homes in the period, with only a few exceptions with issues presenting'lofts' and 'studio flats' where all activities take place in the same room. In those cases, we chose the category 'multi functional'. The study included only pictures from interviews or presentations of Danish homes, while holiday homes and houses from abroad were excluded. The study presents an evaluation of light atmosphere in pictures of interior design and indicates traditions of home lighting. It is based on a total of 3,483 registrations distributed in categories as 'Living room' 'Dining room', 'Standing activities', 'Bath', 'Multifunctional room', 'Corridor', 'Sitting activities' and 'Bedroom' (Fig 4.18 and 4.19 on previous page).

The selection criteria are defined as images from reportages of Danish homes in the categories mentioned above. Holiday homes or pictures from houses abroad, "educational interior set-ups" were excluded as well as close-up pictures without luminaires. The pictures are taken both in daylight and at night-time, so there could be a bias in guessing how luminaires are illuminating the space. However, to secure standardization in the analysis, the 
first five years were analysed together or the data was double-checked and analysed by both of authors. The pictures were indexed and numbered consecutively by year, magazine number and page number. All data collected categories are displayed in fig 4.17.

\subsubsection{ANALYSIS}

While people turn on their lights to see the world or to perform at work, people stage themselves through the illumination of their homes. The illumination is not only a luminaire design, such as Danish design icons as PH 5 or Le Klint 1(fig 4.20 and 4.21), which occurs in a social game about appearance. Illumination is also the ability to choose and orchestrate the right atmosphere in the space. It is the way light is distributed in the space, the intensity it has and if it is lively light from candlelight, fireplace or a fixed and uniform light from integrated spots or opalised shadings of luminaires. Light has the ability to accentuate parts of the space when they are highlighted and decrease areas into darker parts of the space and thereby narrow the effect of the lit area by creating a contrast.

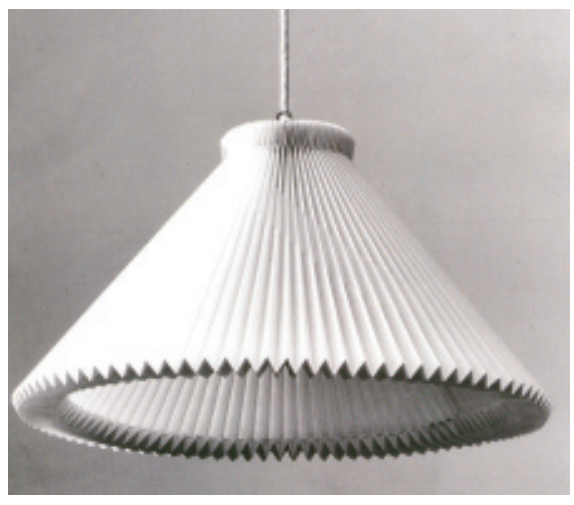

4.21

Fig. 4.20

Le Klint 1 (Dalby, 2008)

Fig. 4.21

PH 5 luminaire designed by Poul Henningsen, (Hansen, Jørgensen et al. 1994 p. 275)

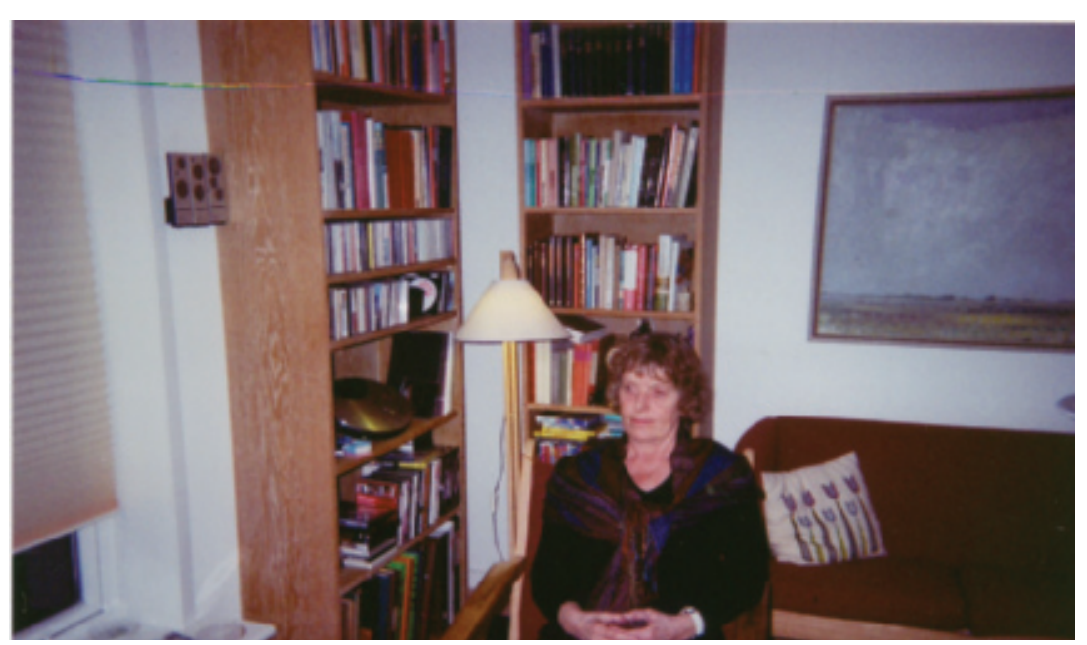


Some trends remain the same in the choice of luminaire design, as all magazines displayed classical luminaires from Louis Poulsen Lighting and Le Klint. But during the study, it became clear that over a period of 50 years the trends of homely illumination were changing in several different ways.

There is also a change of focus in the types of articles presented in BO BEDRE. In the beginning of the period, most reports came from Danish homes. Later, articles showed international interior trends and brought trends from other cultures into a Danish context. In the same period, the images presented in the magazine went from showing the interior of an entire space to showing details by focusing on objects or arrangements of objects in the space. In the period from $2000-2003$, the "do it yourself" interior design was drawn instead of shown in pictures. We did not include these pictures in the study.

It turned out that there was a huge variation in the number of registrations over the years, which could be explained by the economical situation. The analysis has, however, not taken the economic situation of the Danish society into consideration or its influence on what is displayed in BO BEDRE.It also seems to be a movement from "do it yourself" articles to articles showing interior trends. Also during the period, BO BEDRE has displayed homes of famous people. There is a change in the type of famous people; architects, musicians, atheletes and latest kitchen chefs. This reflects a common tendency and trend in the society.

There could be a bias in evaluating pictures and not being present in the space. The evaluation is limited to the seen illumination and can be influenced by the photographer's editing skills and personal view on the atmosphere. There is also a difference in production and layout in the pictures and magazine throughout the period.

To highlight some of the results in the study, the space for relaxation is relevant. The information on this space is relevant to the design of hospital ward lighting, since the patient uses most of their time in this space. The patients are supposed to relax when possible, and the information on light in the space, which we use for relaxation, can be helpful in designing a new space for relaxation or in the living room. 


\section{Relaxation/sitting activities}

In the table, the relaxation space is noted as Living room. The sitting activity is the 'working space' and therefore not included. The spaces for relaxation seem to go from a "compact" spatial composition in the 1960s to an "open" composition in the first years of 2000. In the 1960s, the interior design of the living room included warm colours, soft shapes, small windows and compact visual information. In the 1980s, interior design was inspired by the machines and the material combination was surfaces of glass, metal frames, leather with an elementary colour scheme as black, white, yellow, blue, and red. In the late 1990s, daylight becomes the focus and windows get bigger and floor-to-ceiling glass panels are the newest trend. The neutral colour scheme is beige-in-beige or white-in-white, and the spatial composition of the living room has a more 'open' atmosphere. The data collected on the relaxation space or the living room was of interest for evaluation. This space was evaluated in the study of preferences and this study wanted to evaluate the trend through the last 50 years and confirm of the hypothesis of a Danish tradition placing the most light in the 'Centre Light Zone'.

\section{'High Light Zone', 'Centre Light Zone' and 'Low Light Zone'}

The analysis of light zones divided into a 'High Light Zone', 'Centre Light Zone' and a 'Low Light Zone' confirmed what we expected: a majority of registrations placed in the 'Centre Light Zone' in the category horizontal light zones. Figure 4.22 amd 4.23 shows that most of the light in the living room is in the category 'Centre Light Zone'. The lowest recorded amount of light in the horizontal center zone is recorded in 1990-1994 at $47 \%$. The highest recorded registrations of light in the horizontal 'Centre Light Zone' were from 1966-1970 with $86 \%$. Why there is a change in horizontal placement of the light zones through the years is not a part of this study. Perhaps another study could investigate the connection between lighting technique and horizontal light zones, and confirm the assumption that new technology could have an impact on the trend. In the reviews of the magazine, it was noticed that the strong halogen spots in up lights were introduced in the late 1980s and used throughout the 1990s. The period is followed by the trend of halogen spots integrated in the ceiling while the 'High Light Zone', still has around $1 / 3$ of the luminaires. Figure 4.22 display the horizontal 


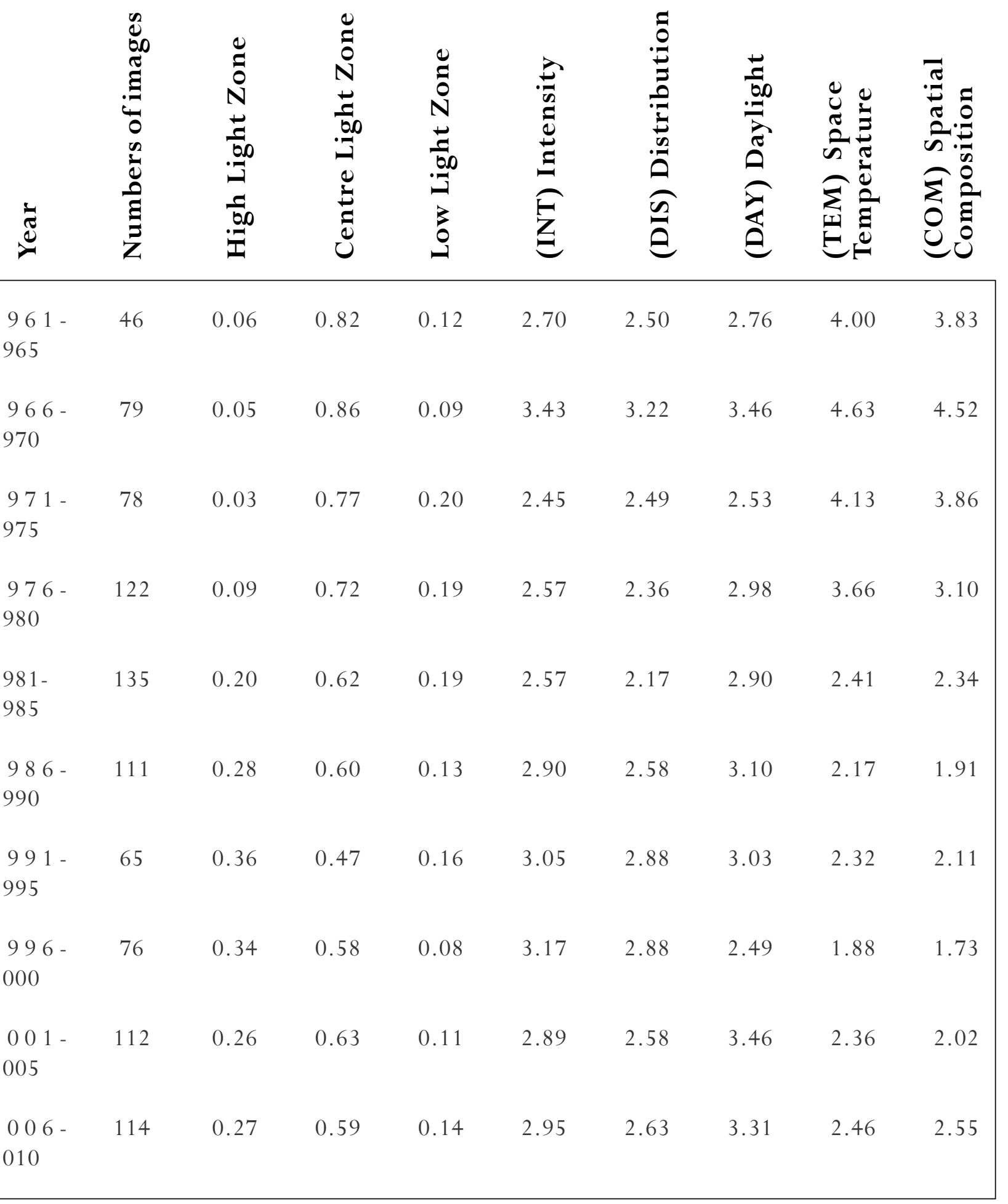


Fig. 4.22.

The Table present the data $\mathrm{Col}-$ lected for Living rooms. 'Numbers of registrations', 'percentage of luminaires' placed in a 'High Light Zone', 'Centre Light Zone' and a 'Low Light Zone'. (INT) Intensity, (DIS) Distribution, (DAY) Daylight, (TEM) Space Temperature, and (COM) Composition. All distributed in year groups of five.

Fig. 4.23.

A visual table representing light zones in living room from 1961 2010 into 'High Light Zone', 'Centre Light Zone' and a 'Low Light Zone'. All distributed in year groups of five.

Green: 'High Light Zone'

Red: 'Centre Light Zone'

Blue: 'Low Light Zone'. arrangement of luminaires split into 'High Light Zone', 'Centre Light Zone' and 'Low Light Zone'. Vertically in the table, the year groups is displayed as well as the numbers of registration in each group.

\section{'Light Appearance' and 'Space Appearance' relation- ship.}

The study of the relationship between 'Light Appearance' and space appearance can contribute to explaining the role of light and 'Space Appearance' in the evaluation of the atmosphere. The category 'Light appearance' consists of three evaluations: the intensity of light (INT), the distribution the light (DIS) and lastly the daylight contribution (DAY). The 'Space Appearance' consists of two sub-evaluations. The first evaluation in this category is the temperature of space (TEM) and secondly the spatial composition of space (COM).

The aim of combining these two categories in the evaluation is to find connections between the categories, whether the connections exist and what their impact of it is.

Figure 4.22 displays the year ranges and the appearance of light and space categories. The highest registration of TEM is 4.63 in 1966-1970. This means a focus on the different textures in the interior and less focus on plane surfaces. The shapes of objects are soft and the colours are neutral to warm. It can also be a space in warm colours,

4.23

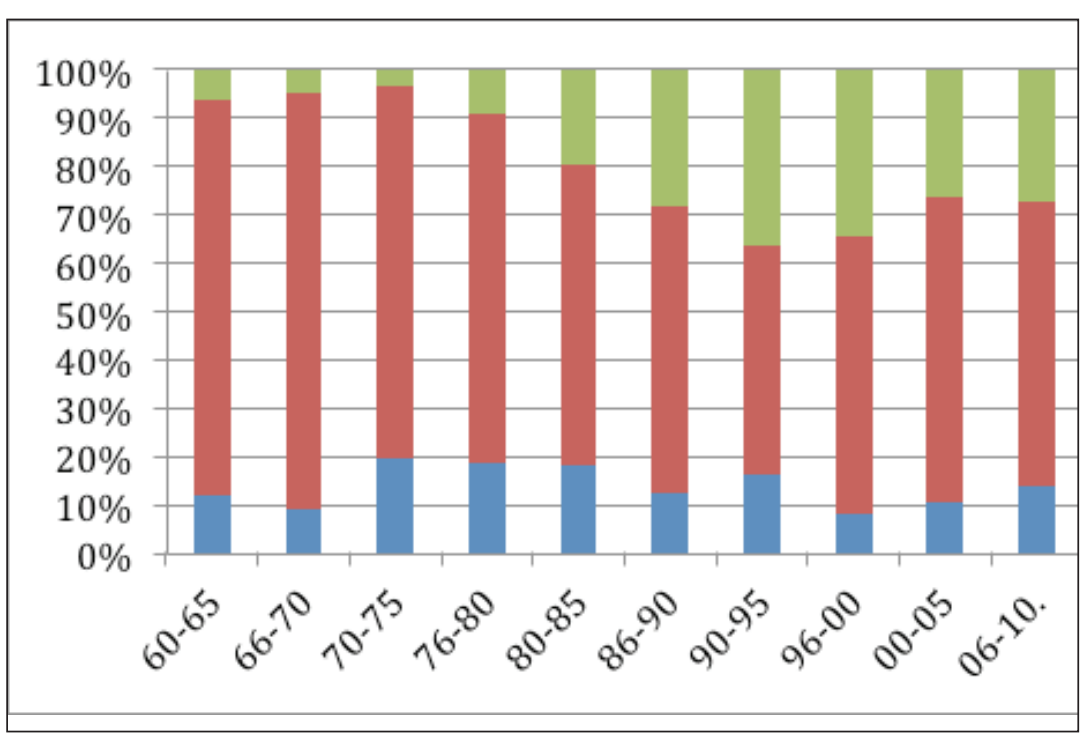


soft shapes, surfaces with heavy textures and many different materials.

In 1996-2000, the TEM registration is 1.88, which represents a space with cold colours and not hard or soft shapes of objects. Some structures on the surfaces and non-reflective materials are used.

The change from $4.63-1.88$ TEM and from a very warm to a cold visual temperature is a quite conspicuous difference in atmosphere. In the interior design of spaces in the late 1990s, minimalism was trendy and focus on textiles was low. Clear lines and shapes and no confusing textiles were in focus, and the ruling trend was being surrounded by space and minimal visual impressions. The interior design creating white-on-white or beige living seems to end in the beginning of 2000, and in 2006-2010 the curve moves to 2.46 again. This means that more colours and variations in texture and shapes are introduced again. The information in INT displays the lowest registration in 1971-1975 with 2.45. This number is translated to a dim lighting with a focus on some parts of the space. The registration is similar to the years after and lasts until 1985, but there is a huge jump in the period just before 1966-1970 where the number is 3.43. The study does not tell why this jump is so huge, and to me the result is unclear, as my visual memory did not recognise this huge variation. Instead, it was noticed that INT in the late 1990s was high and noted at 3.17 , which is a space with enough light to see all space without seeing details. Light intensity and visual temperature seem roughly to be the opposite of each other in the 50 years examined. When the high light intensity is the lowest, the spatial temperature is highest, and when the visual temperature is lowest, the light intensity is high.

The COM goes from its highest in 1966-1970 with 4.52, to the lowest registration of 1.73 in 1996 - 2000. This result follows the TEM in the period, which could indicate that the visual impression of the space temperature can be affected by the spatial composition. Low space temperature is connected to low spatial composition, and high spatial composition is connected to high visual space temperature.

When looking at DIS, almost the same trend is recorded. Results from 2.17 in 1981-1985, which is a space where two or three small, defined light zones are illuminated by 
spots. The highest registration is at 3.22 in $1966-1970$, which is a varied light distribution with light shaded illumination, comparable with Le Klint's folded lampshades.

Even though in the beginning of the chapter, it was told that the daylight contribution in homes changes during the period, we could not see that in this study. In the periods 2001-2005 and 1966-1970 registrations were both at 3.46 and the highest numbers recorded. The lowest registration of 2.49 was in the period 1996-2000 and thereby circling around 3.0, which is light distribution from windows comparable with traditional "Dannebrogs" windows. We know that 1980s' architecture was small quadratic windows (translation of the so-called "glughuls" arkitektur in Danish) to the late 1090s, and in the beginning of the 21 th century the floor-to-ceiling panels were introduced in the architecture. This study did not support this knowledge, maybe because the pictures are mostly taken with sidelight and not backlight. The focus on daylight contribution may not being evaluated accurately enough and thereby be misleading.

The following figure (4.24) display the relationships between light appearance (INT, DIS, DAY) and space appearance (COM, TEM) in the period 1961-2010. 


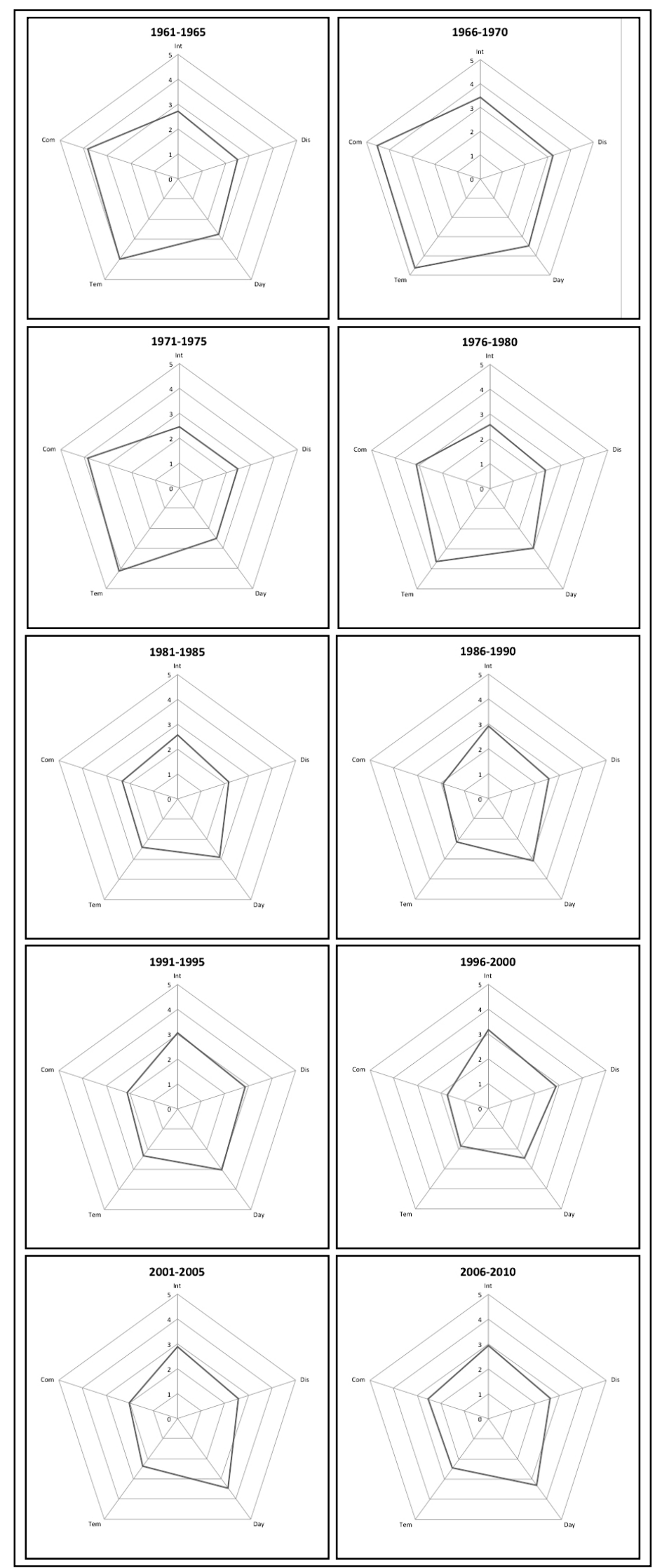

4.24

Fig. 4.24

Spider web illustration of the relationship between INT, DIS, DAY, TEMP and COM from 1961-2010. 


\subsubsection{SUMMARY OF TREND STUDY}

In the trend study, we concluded that trends as INT, DIS, TEMP and COM changed in the period 1961-2010. INT went from low in the beginning and got higher until the late 1990s. In the period 2001-2005, the curve changed from getting lower again to maybe being stable to maybe getting lower again. We need more information and more years to go on, before this can be concluded. DIS went from 2.7 in 1981-1985 to 3.22 in $1966-1970$, which means that in the $1980 \mathrm{~s}$, the illumination was more focused than in the 1960s and later. The TEM and COM followed each other from very warm and compact interior design in the 1960 s to colder and more open in the beginning of the 1990s. In the late 1990s, the TEM was very cold, but hereafter the curve turned again, getting warmer in the beginning of 2000. The same trend concerns the COM, but not to the same extent as TEM, the COM is still open.

The result of the study of luminaires in 'High Light Zone', 'Centre Light Zone' and 'Low Light Zone' supported the hypothesis of most luminaires being placed in the 'Centre Light Zone'.

From the two first periods, 1966 to 1971 , over $86 \%$ of the light was arranged in 'Centre Light Zone', 5\% in 'High Light Zone' and $9 \%$ in the 'Low Light Zone'. So, over $90 \%$ of the light was placed in 'Centre Light Zone' or 'Low Light Zone'. Looking at the TEM and COM, INT, DIS and DAY, the highest registrations are also made in this period.

Comparing the results from the horizontal light zone with the appearance of light and space, it is noted that 1966 1970 has most luminaires in the 'Centre Light Zone' of the space. It is also the highest registrations in all the appearances of light and space (INT, DIS, DAY, TEMP and COM). The question of why this is the result is not clear enough to be valid knowledge. The INT and DIS can have an impact on each other; the daylight should not be affected by the placement of the luminaires. But when it comes to the visual impression of the space temperature and spatial composition, the evaluation of the 'Space Appearance' can be affected by the horizontal placement of the luminaire in a way that if the light is placed lower in the space, the space appears warmer and more compact and less open and cold. But further study needs to be done to back-up this hypothesis. 


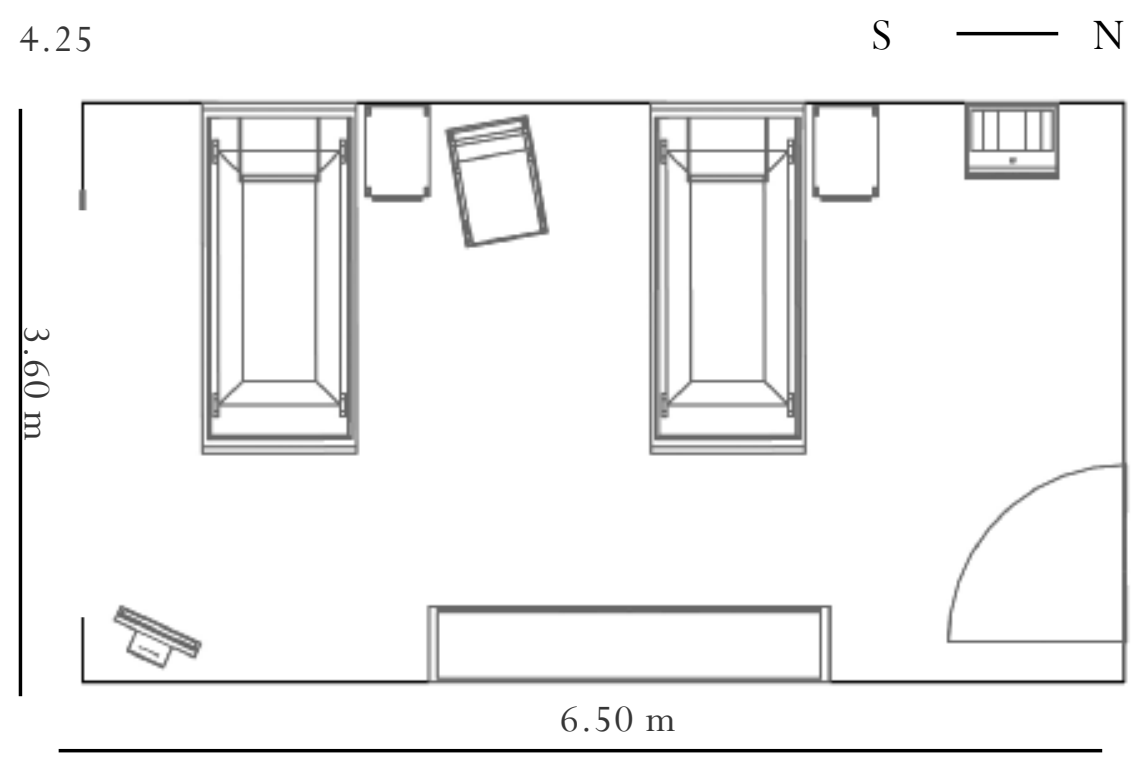




\subsection{USER ZONES AT THE WARD}

The three first explorative studies seek to answer questions on light preferences, lighting trends and personal experience of being hospitalized. This study seeks to clear up the question on how the ward is used by the different users. By defining user zones in the hospital ward, the lighting design can be adjusted to the main user of the space instead of discriminating in favour of the staff, as we claim today's lighting design is (Thuesen, Stidsen et all 2011). When studying standards and recommendations for lighting in hospital environments, they often suggest a uniform light distribution from the ceiling to facilitate the needs of the staff. At the same time, the standards recommend a lighting design, which supports the patients' feeling of a homely and pleasant atmosphere. And from the explorative studies we know that homely light in a Danish context is not a uniform light distributed from the ceiling. However, they also point out that the light should not disrupt the patient's wellbeing.

The diverse approaches do not seem consistent in today's hospital wards. The quality and quantity of light in wards highly depend on the activity of the space as well as the expectation for light in these kinds of spaces. The staff needs task lighting in various ways in a'public sphere' and the patient needs a homelike 'private sphere' for relaxation. These two approaches of private and public illumination are not often similar, but this study seeks to clarify the use of the ward with the purpose of providing more user specific illumination that support the different user needs and preferences. Therefore, the study presents an approach, which divides the hospital ward into three user zones: 'Rehabilitation Zone', 'Nursing Zone' and 'Passage Zone'. The tripartition is based on the idea that the light can be uptimized for the main activity in the space. Thereby, it leads to a refining of the lighting design in a way so it has the ability to support the different user needs and preferences for illumination.

The study was carried out at Odense University Hospital, Department of Orthopedically Surgery (O3), Denmark

Fig 4.25

Floorplan of hospital ward at Odense University Hospital in October 2010. The ward was a two-bed ward similar to the ward in the admission study and the ward in which the experimental study was installed (fig 4.25). In a ward at a orthopedically surgery department, the staff is often 
summoned because the patients need help getting in and out of bed or in other ways need supervising. Therefore, the nurses seem to be quite busy throughout the day. The length of the study is chosen to be one day as the purpose is to get an idea of how the ward is used by the staff. The main focus in this thesis is the patient's view on the light atmosphere at the ward, so this study is supposed to contribute with knowledge on the staff's workflow and therefore more secondary. The collected data is not enough data to proof anything, just a pre-study to get an idea of how workflow in a hospital ward can be recorded and analysed without disturbing the staff when not needed.

The choice of defining the staff zone instead of patient zone is based on the fact that the patient is in the space all day and the staff "only" visits the ward in shorter periods throughout the day. By defining the staff zone, the staff lighting can be limited and adjusted to support their needs when they are present at the ward. At all other times, the patient can be in control of the illumination and visitors can act as "the helping hand".

Although the hospital ward is a 24-hour, seven days a week working environment for the staff with different tasks and working patterns, the staff should be defined as the nurses and not the cleaning staff or other kind of staff. It is the staff taking care of the patients that has our focus and interest.

There are 20 beds at $\mathrm{O} 3$ and 31 staff members both nurses and public health workers. Collecting information on the workflow can be done in different ways. As presented in the preference study, the staff was interviewed so as to get an idea of what kind of work the nurses carry out $\mathrm{O} 3$, and what they found problematic as well as satisfying in using the ward and light. One thing is the informant way of looking at oneself; another thing is observation by a third person. In the interviews, the nurses told that they were using all the space. The nurses told:

"We use all the space and that demands a lot of light to support our functions. If you are taking care of a person not feeling well, it demands light. Perhaps the patient should have the possibility to turn off the ceiling light when staff leaves the ward....... We are not thinking the same way. If you take these wards in our unit, many of our colleagues do not think that OUR illumina- 
tion is disturbing the patients when we are leaving the ward. At the night shift, we depend on the light, but not as much as in day shifts. It is important to have a concentrated light around the patients, and that this concentrated light is the only light turned on and not the ceiling luminaires. If there is an acutely ill patient, we turn on all the lights at the ward, but there are other tasks to take care of around the patient at night time." (Nørgaard 2010)

In that way, the staff members distinguish between patient illumination and staff illumination, and point out one of the central issues. Patients need to be in control of the light, so they can turn it off when staff leaves the space, because the staff is not aware that it can be disturbing to the patients.

The nurses were aware of the issue of light disturbing the patients at nighttime. They need light for visual demanding tasks, but prefer illumination not to be disturbing patients' sleep. This is also a central problem in the illumination of the ward.

\subsubsection{METHOD}

To collect data on use of a small space as the hospital ward is not easy. There are many different ways to gather information concerning behaviour flow of work situations (Suenson, Harder et al. 2010, Millonig, Schechtner 2005). It can be difficult to create knowledge on how nurses use the ward, since they are aware of being observed or noticed. Therefore, unobtrusive methods of observations are chosen to avoid unusual behaviour of the nurses and thereby attempt to avoid the risk "observer effects" (Millonig, Gartner 2008). One of the methods of clarifying the use of spaces is a questionnaire survey. Questionnaire surveys can provide comparatively large samples and allow the collection and analysis of data within a short amount of time. The human behaviour, however, can hardly be mapped and can only be interpreted by verbal structures. Another category of surveys is direct observation, such as mapping or tracking. These surveys can be done in many different ways, the simplest one being manual observations that are recorded by notes and drawings.

Monitoring by video is another way to analyse and interpret human behaviour (Millonig, Schechtner 2005). This method was also tried during the admission study, but since we were not "normal" patients, the video would not 
be trustworthy in that way. There are also limitations with using video as the view of space for observation can be limited. This limitation is not present because the ward is a small space, but observations by video cannot be used in wards because of the privacy of the patients needs to be respected. Therefore, newly developed tools for gathering information were found, where human behaviour can be mapped by digitally based localization technologies. An example of this kind of technology could be satellite-based technology GPS (Global Positioning System), which can gather data within a very large study area. For indoor observations, the GPS system is insufficient as data basis because of the lack of signal between receivers and satellites. (Millonig, Gartner 2008, Suenson, Harder et al. 2010).

An alternative to the GPS system is the RFID (Radio Frequency Identification) technology. The RFID system uses radio waves instead of satellites to identify people and objects. So, it is possible to use the technology indoors contrary to GPS. The RFID technology is still a new tool for tracking indoor behaviour and therefore, the data collected by this technology can be more complicated to gather and interpret than GPS at the point of writing (Suenson, Harder et al. 2010, Millonig, Schechtner 2005, Simonsen, 2010). With the order of improving the study, different techniques were used. The combination of manual observation and digital tracking with RFID clarifies both the flow in space and the functions related to the space. Therefore, the staff's use of the ward is studied both by RFID technology and visual observations. This combination of methods and tools are therefore picked for further studies of the staff behaviour at the ward.

The RFID technology is based on receivers (LOMMYS) and senders (TAGS). A signal is sent out every 30 seconds from the tag, and a registration is made when the LOMMYS is within the radius of the signal. It is also registered when the LOMMYS are out the radius of the TAGS. The radius of the TAGS can be calibrated to fit different set-ups (Simonsen 2010). An experimental set-up of the TAGS and radius of signal are seen in figure 4.26. All staff members with an errand at the ward or who had contact with the patients inside the ward carried a LOMMY in their pocket. The LOMMYS were numbered from 1 to 5 . The set-up indicates the time when the staff entered or left the ward and if they are situated near bed 1 or 2 . The investigation 
thereby indicates the staff's work situation at the ward and if they are situated near the hospital beds. The tracking is supplemented by visual observations for a whole day together with a day of hospitalization as a patient, where the different work related assignments are recorded. The time scope of the investigation with RFID is from 10.30 to 18.00 .

Fig. 4.26

The placement of TAGS in the ward and their radius

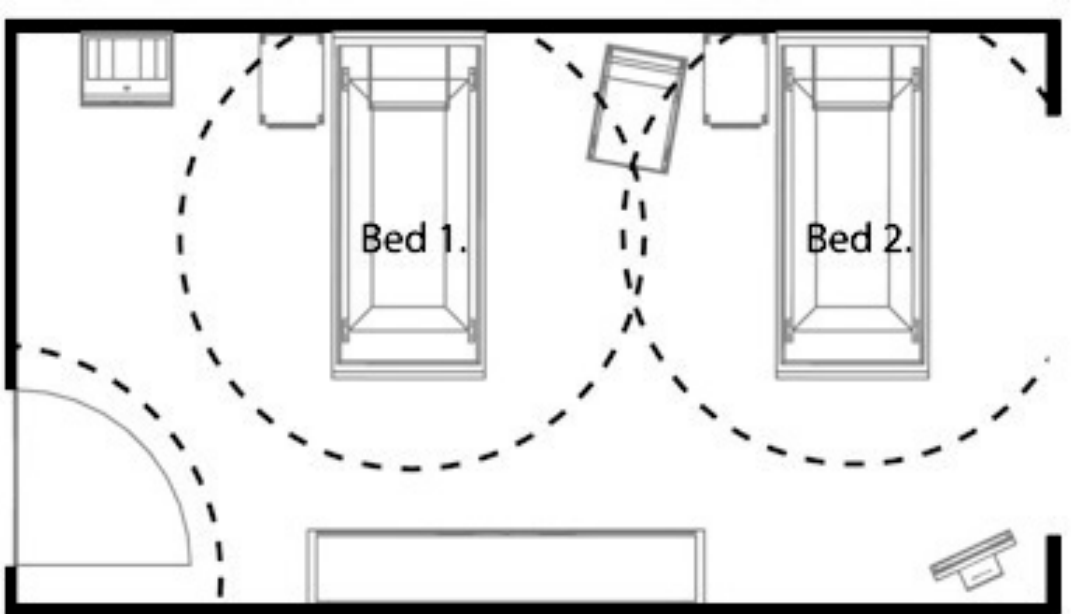


4.27

\begin{tabular}{|l|l|l|l|l|l|}
\hline $\begin{array}{l}\text { Lommy } \\
\text { no. }\end{array}$ & $\begin{array}{l}\text { Entering } \\
\text { ward }\end{array}$ & $\begin{array}{l}\text { Time at } \\
\text { bed no. } \\
1\end{array}$ & $\begin{array}{l}\text { Time at } \\
\text { bed no. } \\
2\end{array}$ & $\begin{array}{l}\text { Leaving } \\
\text { ward }\end{array}$ & $\begin{array}{l}\text { Time } \\
\text { inside } \\
\text { ward }\end{array}$ \\
\hline 1 & 11.00 & $3 \mathrm{~min}$ & & 11.03 & $3 \mathrm{~min}$ \\
\hline 1 & 11.04 & $1 \mathrm{~min}$ & & 11.05 & $1 \mathrm{~min}$ \\
\hline 2 & 12.08 & $2 \mathrm{~min}$ & & 12.10 & $2 \mathrm{~min}$ \\
\hline 3 & 12.10 & & $2 \mathrm{~min}$ & 12.12 & $2 \mathrm{~min}$ \\
\hline 3 & 12.24 & $1 \mathrm{~min}$ & $1 \mathrm{~min}$ & 12.26 & $2 \mathrm{~min}$ \\
\hline 2 & 14.38 & & $3 \mathrm{~min}$ & 14.41 & $3 \mathrm{~min}$ \\
\hline 1 & 14.38 & & $2 \mathrm{~min}$ & 14.40 & $2 \mathrm{~min}$ \\
\hline 4 & 16.36 & & $5 \mathrm{~min}$ & 16.41 & $5 \mathrm{~min}$ \\
\hline 5 & 16.47 & $8 \mathrm{~min}$ & $14 \mathrm{~min}$ & 17.09 & $22 \mathrm{~min}$ \\
\hline 5 & 17.39 & & $2 \mathrm{~min}$ & 17.41 & $2 \mathrm{~min}$ \\
\hline
\end{tabular}

\subsubsection{ANALYSIS OF WORKFLOW}

The study shows that the staff used a large amount of short periods (1-5 minutes) of their time at the ward, whereas the frequency of longer periods (6 - 30 minutes) was smaller. The results can be seen in illustration. The observations indicated that the staff in the long periods dealt with mobilization and training of the patient while short periods in the ward were mainly concentrated around calls from the patients and food serving. In the investigation period, five different members of the staff entered the ward and the numbers of visits was ten. The visit is counted as one staff member at the ward but the staff member can be both one and two patients. The registration occurs when the staff enters and leaves the ward.

Dividing the ward into zones was done in order to display the functional differences of the space and thereby create knowledge on the use of the ward as a guideline for the design of user supportive illumination. The zoning makes it possible to design adversity in the light setting and still fulfil the requirements concerning light and visual tasks for all users (Dansk Standardiserings råd Nov 1983). The combination of tracking and observation makes it possible to divide the ward into different zones. The zones are seen as simplification of the complexity of the ward. Therefore, work situations can occur where they do not fit these categories, as it is a simplification and a design trying to take the diversity seriously without creating a design too complex. The activity in the ward could be divided into three categories or zones, as illustrated in fig 4.28. The first zone is the 'Zone for nurses'
Fig 4.27

The table display the result of the RFID tracking of the staff. 
work and related activities. This 'Nursing Zone' is the area just around the beds. The second zone is the 'Rehabilitation Zone'. The area lies around the beds as well as between the beds, where the chairs and tables are placed. Lastly, a 'Passage Zone' which is the walking and activity area in front of the beds; the space where people walk around to get from the bed to the corridor etc.

Nursing zone

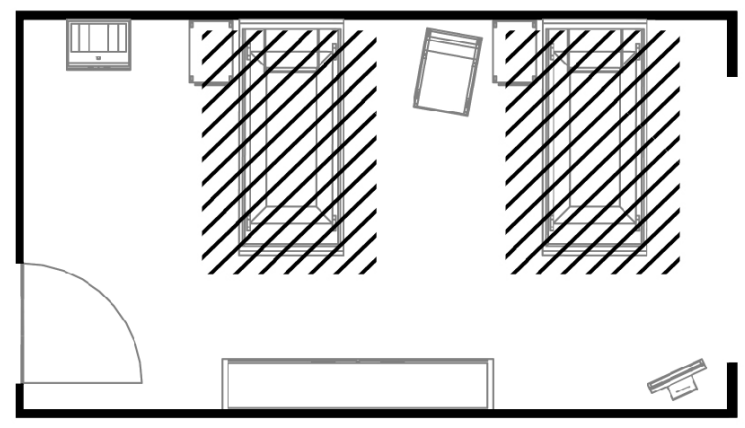

Rehabilitation zone

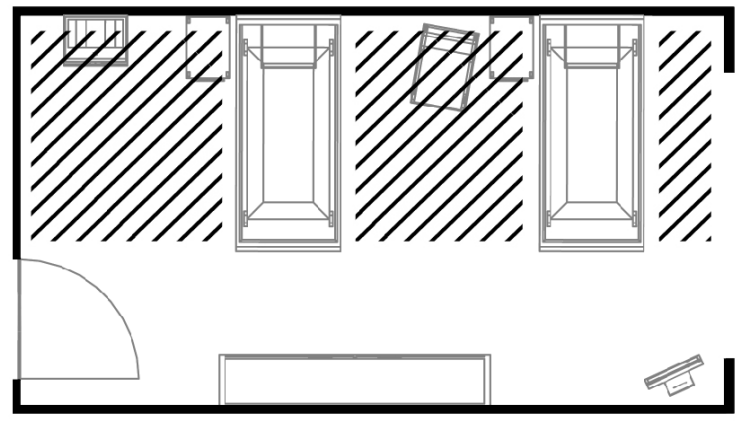

Fig. 4.28

The 'Nursing Zone', 'Rehabilitation Zone' and the 'Passage Zone'.

\section{Passage zone}

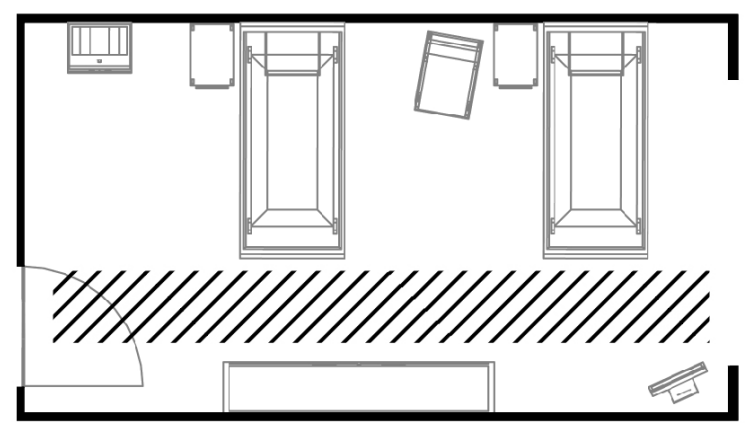


The high frequency of short stays strengthens the problems of staff leaving illumination turned on when they leave the ward. This problem can lead to overlighting of the ward, and at worst be uncomfortable for the patients. The problem is also based in the immobility of the patients, which makes them unable to turn off the light themselves (Fagerhults 2003). A better understanding of the use of lighting control in hospital wards can also be important in connection to energy savings, improving the work environments of staff and provide a supportive illumination for the patients. This study concentrates on the workflow of the staff and thereby only mentions that a more "user adapted" illumination can affect the energy aspect as well. But a solution to this problem needs further examination.

Dividing the ward into working zone for nurses, corridor area and space for relaxation illustrates that the illumination does not need to be uniformly distributed at the ward. The illumination can vary from zone to zone according to the quantity and quality of light needed and preferred by the main user of the space. It indicates that high demanding visual tasks are situated near the beds or in the area near the beds. Difficult visual tasks demand high intensity of light depending on the task. The guidelines for treatment and examination of patients state a minimum of 300 lux and regulations state a need for at least 500 lux (Lang 2003, Dansk Standardiserings råd Nov 1983, Dansk Standardiserings råd 2005). This number is estimated as sufficient to solve the visual task for the staff and patients. It can be discussed if there is a need for 500 lux at O3, but in case there is need for an illumination supporting examination, the light level on 500 lux is preferred. It is interesting that the regulation does not recommend a general illumination of 300 lux provided by a luminaire of good colour rendering at $\mathrm{Ra} 80$. Then an additional work luminaire could provide a more direct light, better in quality in both direction and colour rendering ( $\mathrm{Ra} 95$ ).

Thereby the illumination is improved by directing the light, making it is easier to see details on skin etc. The high intensity of light should therefore be concentrated in the 'Nursing Zone' and nearby the beds. The light level in the 'Rehabilitation zone' is recommended to be between 200 and 300 lux. This number is estimated as sufficient to solve the visual tasks for staff and patients. 
The 'Passage Zone' does not need the same light level as the 'Nursing Zone' according to the staff needs. The stated efficiency of the illumination in such areas is recommended at light level around 50 to a 100-lux, while the area does not contain any high demanding visual tasks (Lang 2003). In cleaning situations, the whole ward requires a light level on minimum 200 lux. In this way, the illumination needs a kind of uniformity to fulfil this recommendation. But again, it is still short periods of the day where this is needed and mostly during daytime. It is well known that the need for light at wintertime demands more artificial light.

Before we argue for a horizontal tripartition of the space in order to be able to provide a suitable light atmosphere for both patients and staff, there is also a need for a division of the space on a vertical plan to fully unfold the potential of zoning. In figure 4.29, light levels are shown in the three vertical zones; 'Nursing Zone', 'Rehabilitation zone'and 'Passage Zone'. The distribution of light levels is placed according to the zones.

In this way, the illumination of the ward can be more specific according to user needs and preferences, and there is visible way of zoning the ward to optimize the illumination and light atmosphere at the ward.

Fig 4.29

The light levels in 'Nursing Zone', 'Rehabilitation Zone' and 'Passage Zone'

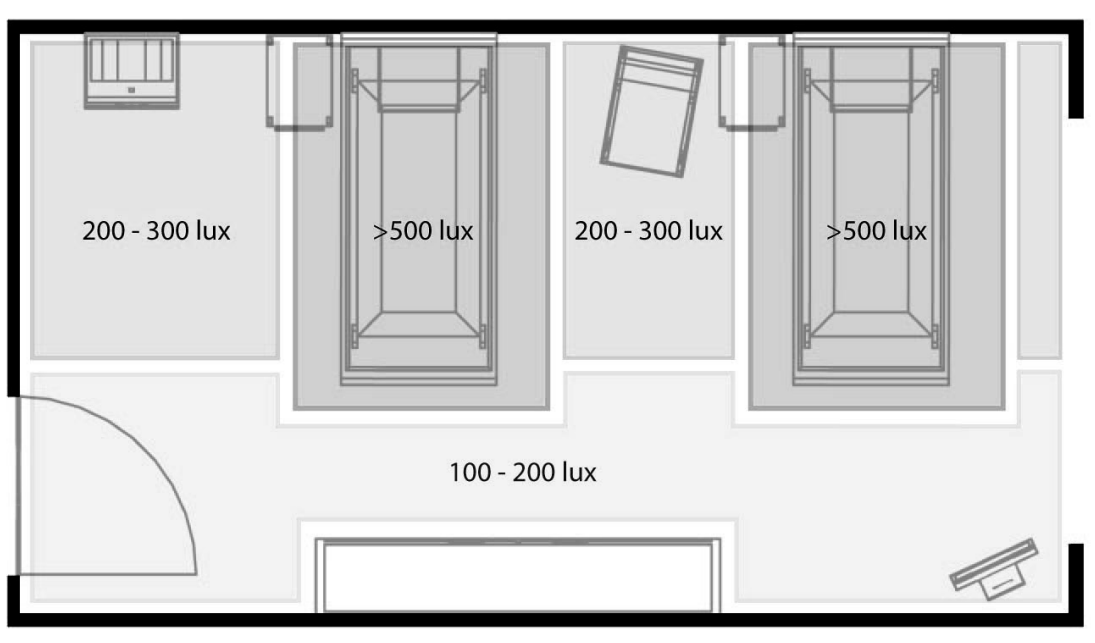




\subsubsection{SUMMERY OF WARD ZONING.}

The goal of this study was to analyse workflow of staff in the ward by zoning the area into more user specific zones. In this manner, the study can be used as guideline for the lighting design presented in the experimental study. While the study is based on too little data collected on one day, the study only indicates that RFID tracking of staff workflow combined with unstructured observations can contribute with knowledge on how the ward is used by the staff. The staff's tasks at the ward combined with the time used at the ward clarified the functionality of the space seen from the staff's point of view. It illustrates that a supportive illumination at the ward can benefit from a vertical division of the space into zones. The zones represent an illumination adjusted to a 'Nursing Zone', a 'Rehabilitation Zone' and lastly a 'Passage Zone'. The benefit of zoning the ward is to create a less uniform illumination supporting the patient needs for a pleasurable and homelike illumination.

By analysing the staff needs for light, the task lighting or work lighting can be limited to staff zone lighting and another lighting scenarios for patients and visitors. In so doing, the illumination can be more specific and thereby improve preferences, needs and furthermore maybe even reduce energy. This assumption is based on the hypothesis that the use of light is user specific and does thereby not necessarily need uniform illumination. An example could be when a patient is relaxing in the bed watching TV. Then there is no need for uniform illumination from eight fluorescent light tubes in the ceiling. The highest demand for light is in the areas at the hospital bed and nearby the bed, and the lowest is in the 'Passage Zones' in front of the door. The RFID technology is used to analyse the space by producing quantitative data that can be interpreted and used as a guideline for the development of a lighting design concept for hospital wards. But as the study is small in scale and only based on little information, the data only gives an indication of how the ward is used. For more reliable results, tracking and observations need to be made for a longer period of time with a higher level of set-up.

\subsection{SUMMARY OF EXPLORATIVE STUD- IES}

All four explorative studies (admission, preferences, trends and zoning) generated new ideas to the lighting 
concept in different ways. The preference study contributed with information on patient preferences for light in the private sphere, and it suggests a tripartition in light distribution into a 'High Lighting Zone', a 'Centre Lighting Zone' and a 'Low Lighting Zone'. The analysis showed that the light preferences for sedentary activities mostly placed in the 'Centre Lighting Zone' and for standing activities in the 'High Lighting Zone'. To separate the staff and patient needs for light, the user characteristic of the staff is having standing activities at the ward and the patients having sedentary activity most of the time spent at the ward. Therefore, this information is included in the experimental study presented in chapter 5 .

The information gained through the study of trends is summarised so as to support the preference study, according to the horizontal tripartition of the space. Italso points out a connection between the experience of a warmer and more compact appearance of the space when the light is placed in a center or low lighting zone. There is a minimum of visual stimuli at the ward and the space therefore quickly gets boring or visual read. The appearance of the space could benefit from being accentuated by the light instead of having a uniform illumination pointing at everything and thereby nothing in the space. The study also created knowledge on how light is distributed on a vertical plan by placing luminaires near the walls and not in the center of the space.

A personal experience of being at the ward as well as zoning the ward into user zones also contributed with useable knowledge in the design process. A zoning of the vertically plan made it visible that the staff needs for light could be divided into a'Nursing Zone', a 'Rehabilitation Zone' and a 'Passage Zone'. In that way, the ward can have a user specific illumination based on tasks. The control of light at the ward is important, so the patient can be in control of the light when they are the main user of the space and the staff can change the illumination to staff lighting, when task lighting is needed.

The chapter of experimental character presents the development of the lighting concept for hospital wards based on the information gained through the state of the art and explorative studies. 

5. EXPERIMENTAL STUDY 
In the previous chapters on light atmosphere, theoretical and visual aspects were discussed and preferences and trends explored. The 'Model of Light Atmosphere' was introduced as an appropriate approach to evaluate light atmosphere as it contained discussions on the experience of light atmosphere and thereby also included aspects such as sociocultural impact on an experience.

In chapter four, the sociocultural aspect of light atmosphere was discussed in order to find preferences for light atmosphere as well as lighting trends in the period 1961-2010.

The information gained from the explorative studies of a Danish cultural approach to light atmosphere provided information to the experimental study in a way so the lighting design presented in this chapter is based on a sociocultural understanding of light atmosphere for hospital wards. In so doing, there is a distinction between the design process and visual presentation of the design. The design process combines all the chapters where different subjects are discussed in order to make a lighting design suitable for hospital wards. The design process is explained in the previous chapters. The present chapter (Chapter 5) revolving the experimental character explicates the knowledge gained from the explorative studies (Chapter 4); from the introduction of the field of light atmosphere (Chapter 1) to the study on light atmosphere (Chapter 3 ). Hereby chapter 5 is an application of the gained knowledge and a way of presenting a design concept based on the 'Model of Light Atmosphere', and not seen as the whole design process. The experimental study presents the design concept in a visual presentation. First, 'Model of Light Atmosphere' presents specific information used in the lighting concept and then the experimental set-up is displayed with visual presentation. The evaluation of light atmosphere is discussed along with the questionnaire created to gain knowledge on the experience of the design concept. Lastly, the methods for evaluation are discussed and findings are displayed.

Throughout the design process, articles have been written discussing the aspects of a light atmosphere concept. The article 'Design proposal for pleasurable light atmosphere in hospital wards' (Stidsen, Kirkegaard et al. 
2010) presents the background of the design concept. The article 'Design parameters for evaluating light atmosphere in hospital wards' (Stidsen, Kirkegaard et al. 2010) discusses methods to evaluate a design concept of ward lighting. The patient preferences for light is explored in the study of homely light (Stidsen, Bjerrum et al. 2011, Stidsen, Kirkegaard et al. 2012_b) as well as lighting trends found in (Stidsen, Kirkegaard et al. 2012_b)Therefore, this section uses the findings from sub-studies in the design concept.

\subsection{STAGES IN LIGHTING PROFESSION}

Through the years there have been different main themes and interests in lighting design and lighting research. According to (Cuttle 2010, Cuttle 2010, Goodman 2009) measurements for defining quality in lighting need to be discussed in new ways. (Cuttle 2010) observes that the discussion on lighting quality has gone through two different stages and claims that a new look at future specifications and measurements of lighting is needed. The first stage represents the quality in lighting defined by measuring a uniform illumination over a horizontal plane. The second stage focuses on human needs and wellbeing. But while the second stage is based on visual performance and biological effect, (Cuttle 2010) argued that the second stage failed to achieve its objective and that there is a need for third stage. The third stage is based on the assumption that there is a reality where lighting regulations can be applied well, but still do not meet the user's expectations and is therefore not experienced as a better quality. The user needs to perceive a space as adequately lit. The light we see is reflected in the surroundings and there is a cultural approach to evaluating light. Therefore, (Cuttle 2010) sees an essential difference from the first, second and third stage and switches from assessing the light incident on planes to assessing light arriving at the eye. According to the third stage of lighting profession, we need to evaluate the reflected light arriving to the eye from the surrounding room and be aware of expectations and pre-understandings of light quality.

Looking at how the lighting profession deals with lighting criteria, Zumtobel Staff presented a Lighting Handbook, which introduced two categories of Quality Criteria in 
Lighting (Zumtobel Staff handbook). The first category is the 'Traditional Quality Criteria'(Harmonious Brightness Distribution, Glare Limitation, Sufficient Illumination Level, Avoidance of Reflection, Good Modelling, Correct Light Colour, and an Appropriate Colour Rendition). Hereafter, the Handbook presents the 'New Quality Criteria' (Zumtobel Staff handbook) as the quality of changing lighting situations, having personal control, energy efficiency and integration of daylight.Zumtobel underlines light as an important interior design element and claims that the goal for lighting in healthcare settings should be that they create encouraging, relaxing and rehabilitating facilitates, and the lighting should create a 'Feel-Good Atmosphere'. This new criterion for lighting design seems to support the approach of this study as they contribute to the design by being 'User Focused' and putting the use of light in the centre of the design.

The experimental study presented in this chapter is based in the third stage, accepting that many aspects of the experience are based on experience and expectations for light. Therefore, the study also introduces a new tradition trying to describe new aspects important for the evaluation of lighting design. While the study seeks to be innovative in its field, it also needs to be described and discussed during the process in order to develop reasonable information on light atmosphere in a Danish context.

The following sections present the 'Model of Light Atmosphere' as a tool to describe the lighting concept. Hereafter, a visual presentation of the design is displayed, and lastly the evaluation process is discussed and findings are presented.

\subsection{LIGHT ATMOSPHERE IN HOSPITAL WARDS}

In order to describe the experimental set-up, the 'Model of Light Atmosphere' is used to display the important information gained through the light atmosphere studies. The chapter seeks to avoid a replication of the chapter on light atmosphere but instead point out important aspects used in the experimental set-up. Therefore, this section displays facts on the different aspects of light atmosphere and present what is important for this unique 


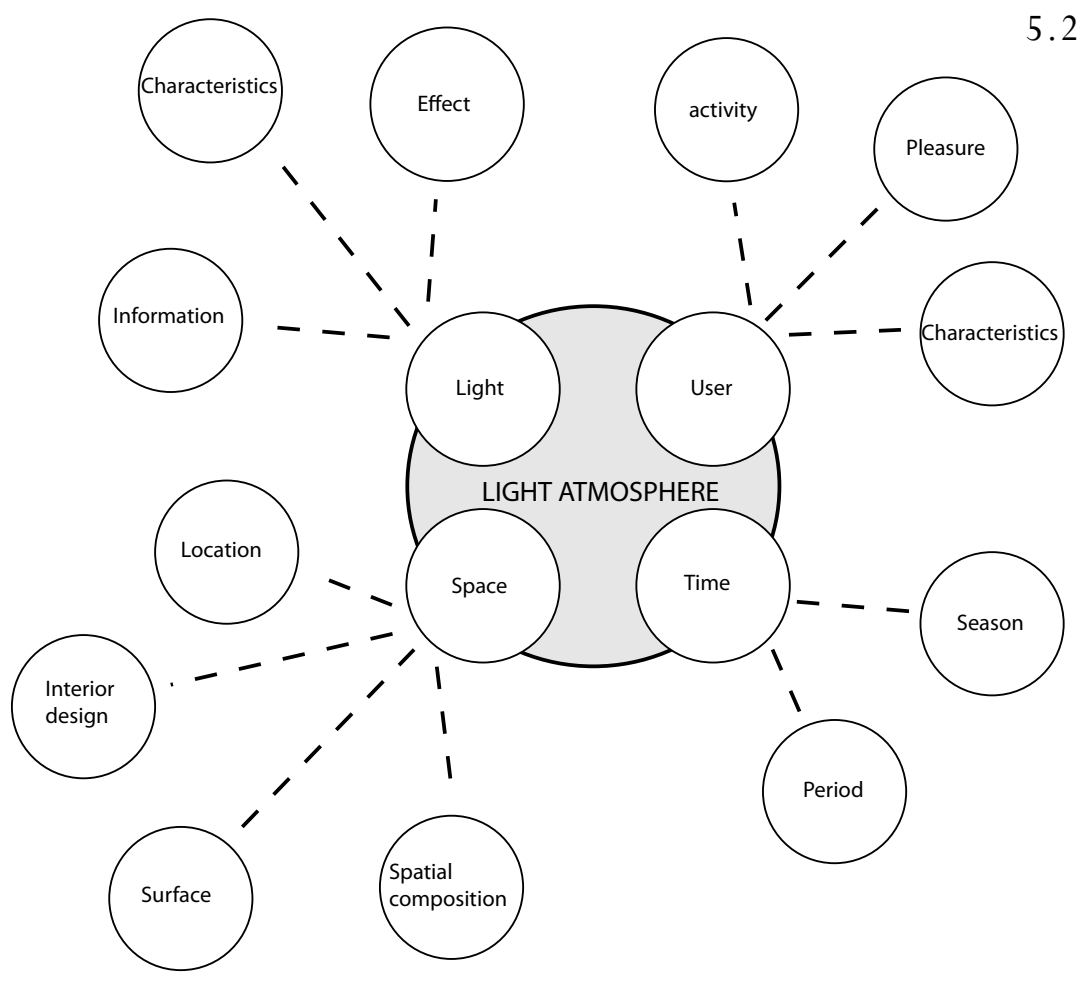

situation. The lighting design in a specific hospital ward in Odense with the experimental set-up is studied. The process of describing the facts or discussions on each aspect is presented similar to the presentation of the model in the chapter 'On Light Atmosphere'.

\subsubsection{THE USER}

The category 'User' is a part of 'Model of Light Atmosphere' and contains the three subtopics: 'User characteristics', 'User activity' and 'User pleasure'.

\section{User characteristic}

The users of the hospital can be divided into three groups 'Patients', 'Staff' and 'Visitors' (Stidsen, Kirkegaard et al. 2009). The common feature for 'Patients' is that it is a situation with patients needing a hip or knee operation, all admitted with scheduled operations. This means that the patients admitted to the department are prepared for the assignment and what will happen dwuring the

Fig. 5.2

'Model of Light Atmosphere.' admission. According to the nurses, the age group of patients is between 60-80 years old. The 'Staff' can be divided into three subgroups: caretakers, cleaners or 
porters. These subgroups naturally have different needs and preferences. The 'staff' work is not comparable, but their common needs require sufficient light supporting their work (Dansk Standardiserings råd nov 1983, Dansk Standardiserings råd 2005). 'Visitor' can be defined as family and friends. Their needs and requests are also important to include in the design concept. In some situations their needs are like patients and in others like the staff, because they are guests and at the same time often help staff serve food or in other ways being the helping hand. Therefore, according to needs for light, the light can be arranged to two user groups: the 'staff' and the 'Patients'. For this experimental study, the evaluation is based on the patients' point of view, but still all users of the space are taken into considerations in the lighting concept. Therefore, it is important to define the different activities taking place in the space.

\section{User activity}

The activities for 'Patients' are based on the information from the explorative study of being hospitalized. The activities found relevant to include in this experimental study are mainly recovery activities. The patients are recovering from surgery and are prepared to go home. Patients use most time sitting in the hospital bed or the chair beside the bed. The activities include 'reading books', 'solving crosswords', 'having conversations' with 'staff' or 'visitors' or 'watching TV'. So, the 'Patients' use the hospital bed as the place for relaxation as well as the place for sleeping, eating, having guests etc. 'Patients' are expected to do physical exercises every day and follow a rehabilitation programme. The programme begins with being able to stand up and walk. Then it progresses to walking on stairs, using the bathroom etc. Things that could be problematic, because the patients are so tired after the operation. From the interview with 'Patients' it was clear that light is not recognized as an important parameter in the experience of a hospitalization.

Through the 'Patients' interviews we also found that they are aware of the ward atmosphere, which they experienced as boring, white, clinical and not cosy. Some of the problem mentioned by the patients was that they felt they disturbed the other patient if they had a need for light at night time. They did not want to turn on the light, but was afraid of falling if they did not. 
In this experimental study the 'Staff' is seen as the caretakers, nurses and doctors. We find their needs for light as representative for all staff member needs, because the doctors and nurses handle the most demanding visual tasks at the ward. At the same time, the doctors and nurses are also the most involved with the patients who are the focus in this study. The 'Staff' needs sufficient lighting from a uniform light distribution from above supported by specific task lighting.

From the interviews we know that nurses had problems seeing details when examining 'Patients' feet or knees. The light distribution from the luminaire fixed to the panel behind the bed did not reach the foot area and thereby did not support the need for light all over the ward. The nurses therefore carried a flashlight in their pocket for this purpose as well as for causing less disturbance at night time. The nurses were as well as aware of the night light problem but still need light to navigate in the ward. The 'Staff' also mentioned that they liked to be able to improve the conditions for the patients, and maybe be able to provide a cosier light atmosphere at the ward when needed.

\section{User pleasure}

The main reason for improving the ward atmosphere is to create support for the 'user's' need for a pleasurable environment. As presented in the study on atmosphere in chapter 3 , there are different kinds of pleasure to support. The 'Physical Pleasures' have to support the patients' need to follow a daily rhythm at the ward. Lightning also needs to be arranged without glare or other visual discomfort. This is well defined in DS703(Dansk Standardiserings råd nov 1983). 'Psycho Pleasure' is e.g. the expectations for light. Information on this is elaborated in the study of preferences for light in homes (Stidsen, Bjerrum et al. 2011, Stidsen, Kirkegaard et al. 2012). Here it was found reasonable to provide a horizontal tripartition of the space as well as arrange the luminaires near the walls. In that way, the illumination could support light for 'Upstanding Activities', 'Sedentary Activities', 'Dinner', 'Relaxing', 'Watching TV' etc.

The 'Socio Pleasure' can be obtained by creating a light that supports communication when social activities are taking place at the ward, as discussed in the chapter on light atmosphere. When the staff delivers a professional communication, the staff and patients need a ward at- 
mosphere with a more professional or public tone and a less homely and intimate tone. 'Ideo pleasure' should be common for all users at the ward and as the study on light atmosphere displayed, light is referred as something positive and a common way of supporting a cosy atmosphere/ Hygge. But common misunderstanding of terms can also occur. Most of the informants had the perception of fluorescent light tubes or energy saving light bulbs as being a "cold" light. This can of course have an impact on the evaluation, although there are both high and low quality fluorescent light tubes in both warm and cold light colours. So, a fluorescent light tube is not synonymous with cold light, it can also be warm. Danes seem to have a preference for the incandescent light bulb and refer to this kind of light as the right light. It is also known that Danes use a lot of candlelight to create a cosy atmosphere. (Stidsen, Bjerrum et al. 2011, Stidsen, Kirkegaard et al. 2012_b) 


\subsubsection{THE SPACE}

The category space consists of the subcategories 'Location', 'Spatial composition', 'Interior design' and 'Surfaces'.

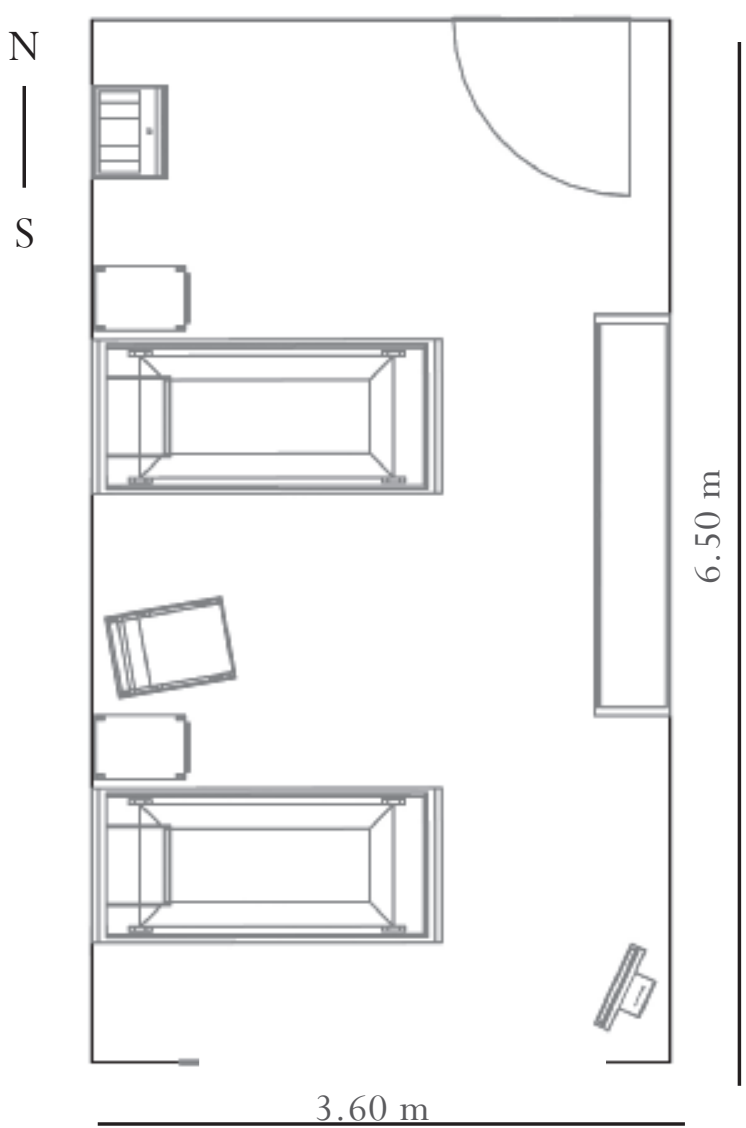

Fig. 5.3

Floorplan of the hospital ward

Fig 5.4

Image of the hospital ward in daylight

Fig 5.5 (next page)

Collection of images from the hospital ward and details from the ward (next page)

5.4

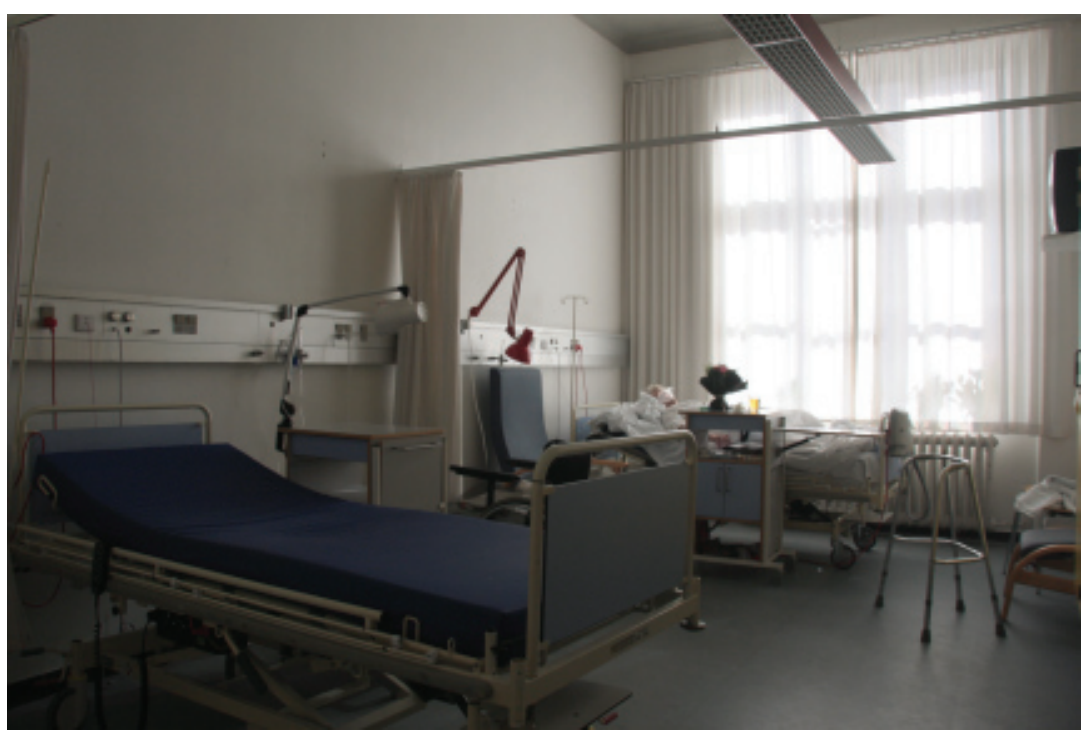



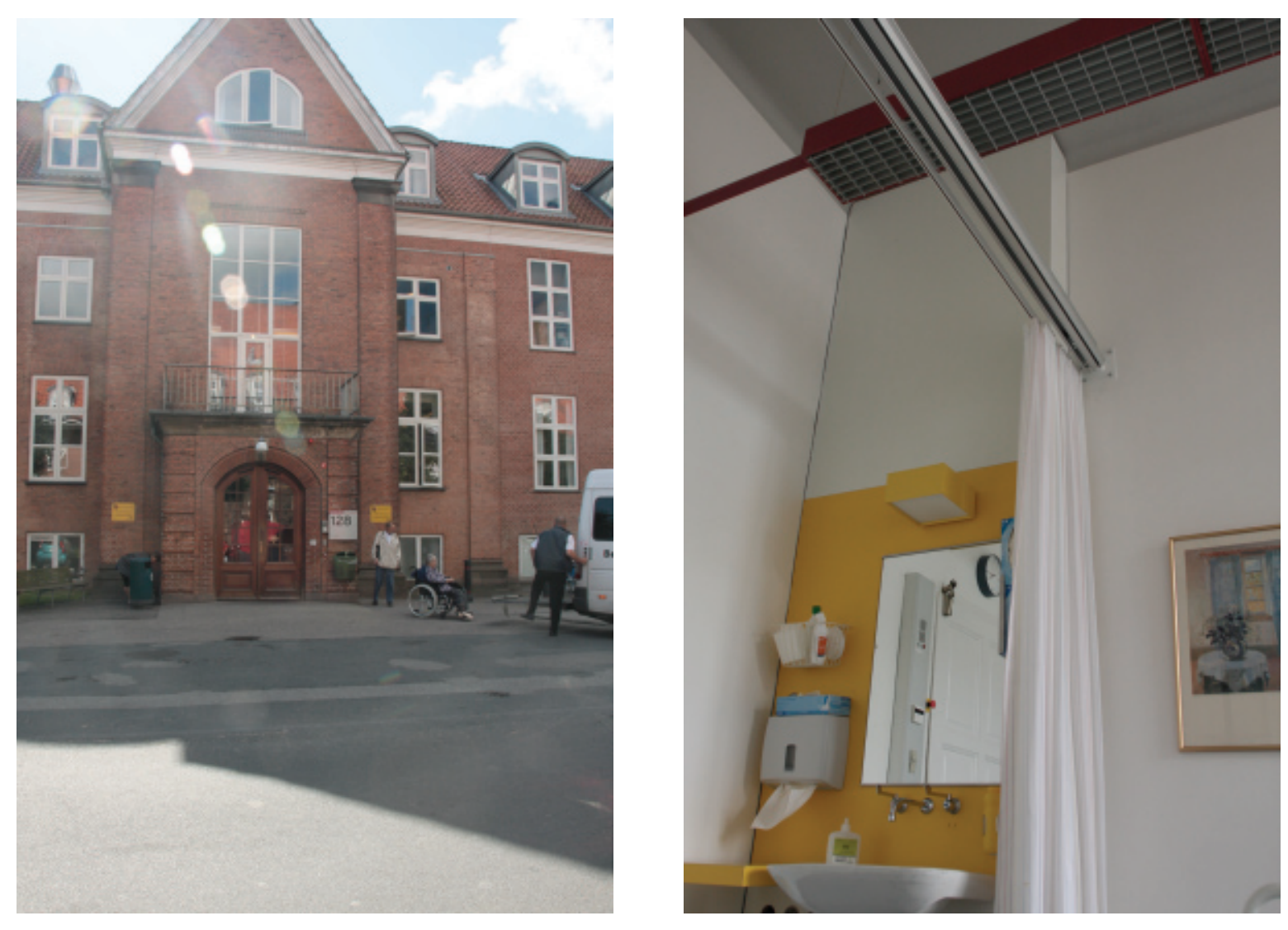

5.5
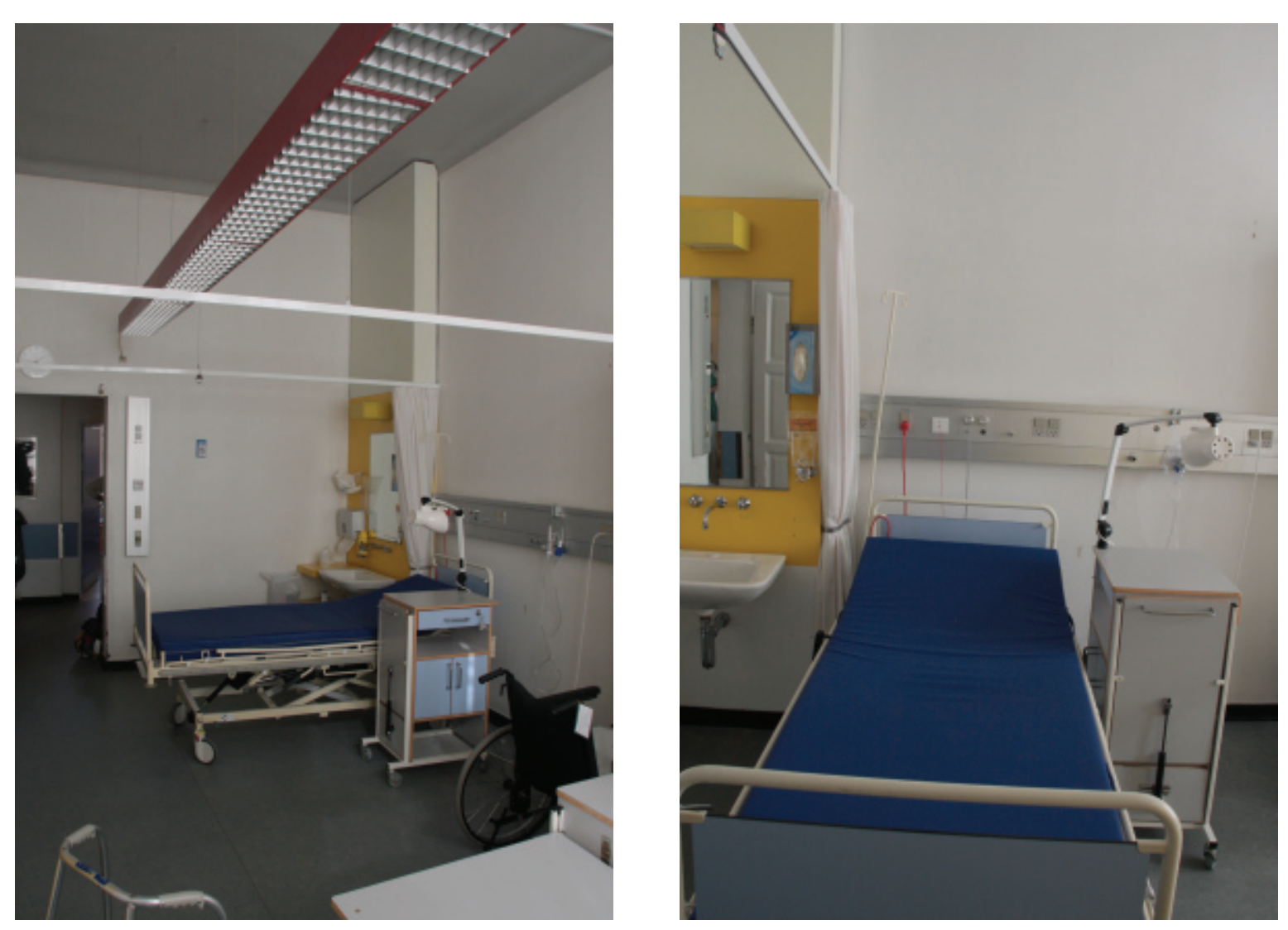

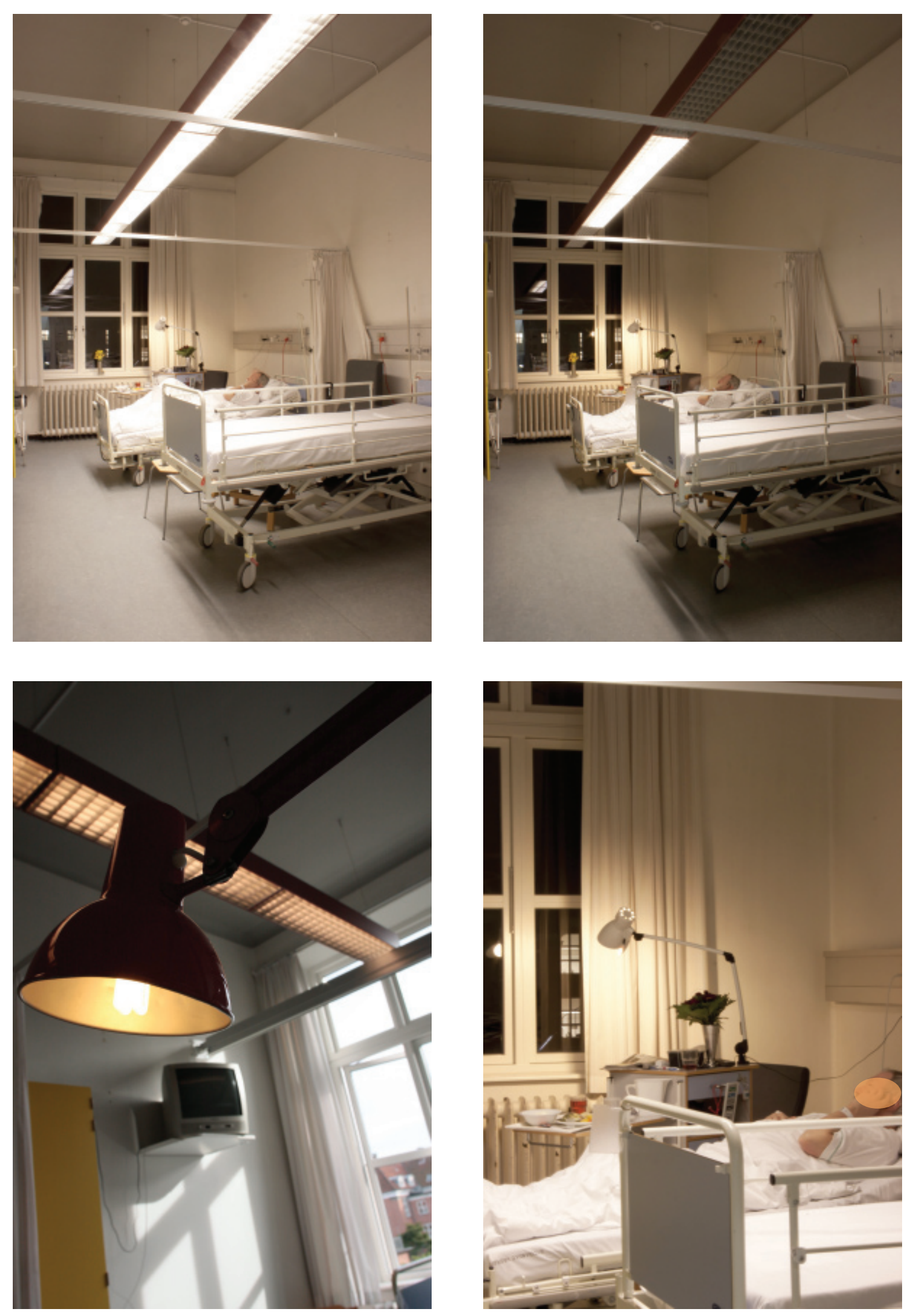


\section{Location of space}

The experimental study is located at Odense University Hospital on the island Funen in the central part of Denmark at latitude 55.38 and longitude 10.37 (Heavensabove ). The layout of the department is a long corridor with wards placed on both sides. The entrance to the department is in the middle and the information desk is just in front of the entrance. The wards used in this study are a ward with new lighting concept (hereafter called the designed ward $=\mathrm{DW}$ ) and a reference ward with traditional lighting concept (hereafter called traditional ward $=$ TW) (fig 5.7). Both wards have the same interior design except for the lighting design and both wards face south, which means that the huge window is placed at the south wall.

\section{Spatial composition of the space}

The building is designed by Gunnar Laage in 1912, and the dimension of TW and DW are similar: $6.5 \mathrm{~m} \mathrm{x} 3.6$ $\mathrm{m}=23.4 \mathrm{~m} 2$ and the ceiling height is 4 meters fig. The wards are located in the department of orthopedic surgery at Odense University Hospital (hereafter called OUH O3). The department also accommodates space for physical training (a gym) and space for visitors (living room). The living room also serves as a space for presurgery meetings. The ward must facilitate public and private activities. The space has the function of facilitating activities like confidential conversations between staff and patients or visitor and patients, therefore it can therefore be a private zone. It can also be a public or semi-public space with people passing by, staff entering the space without asking and you are placed in a bed next to a person you have never met before. To separate the situations of a private or public space, curtains can separate the ward into sub spaces consisting of two separate "bed spaces" and one space by the washbasin. The overall impression of the space is a space with low stimulating rate and is easily read. In chapter 4 , the admission study provides information on the overall impression

After few minutes, I feel bored and only the colour scheme adds something to pay attention to. The tone of the space is an old-fashioned environment with very few interesting elements. Outside the entrance of the ward in the corridor, a big blue,
Fig 5.6

The light situation of the two hospital wards comparred in the study. The Traditional ward (10) and the Designed ward illumination (4). 
printed ward number is placed beside the doors. This number suggests an interest for the aesthetics of the environment, but it is also a practical issue of navigation.

Lone Mandrup Stidsen

\section{Interior design}

The ward is a twin-bed ward with one bed placed close to the window (bed 1) and one nearest the corridor (bed two). According to the study of light optimization by zoning (Thuesen, Stidsen 2011), the space can be divided into a 'Nursing Zone', 'Relaxing Zone' and a 'Passage Zone'. The wards are divided into three private zones with curtains from wall to wall (Fig 5.7 next page)
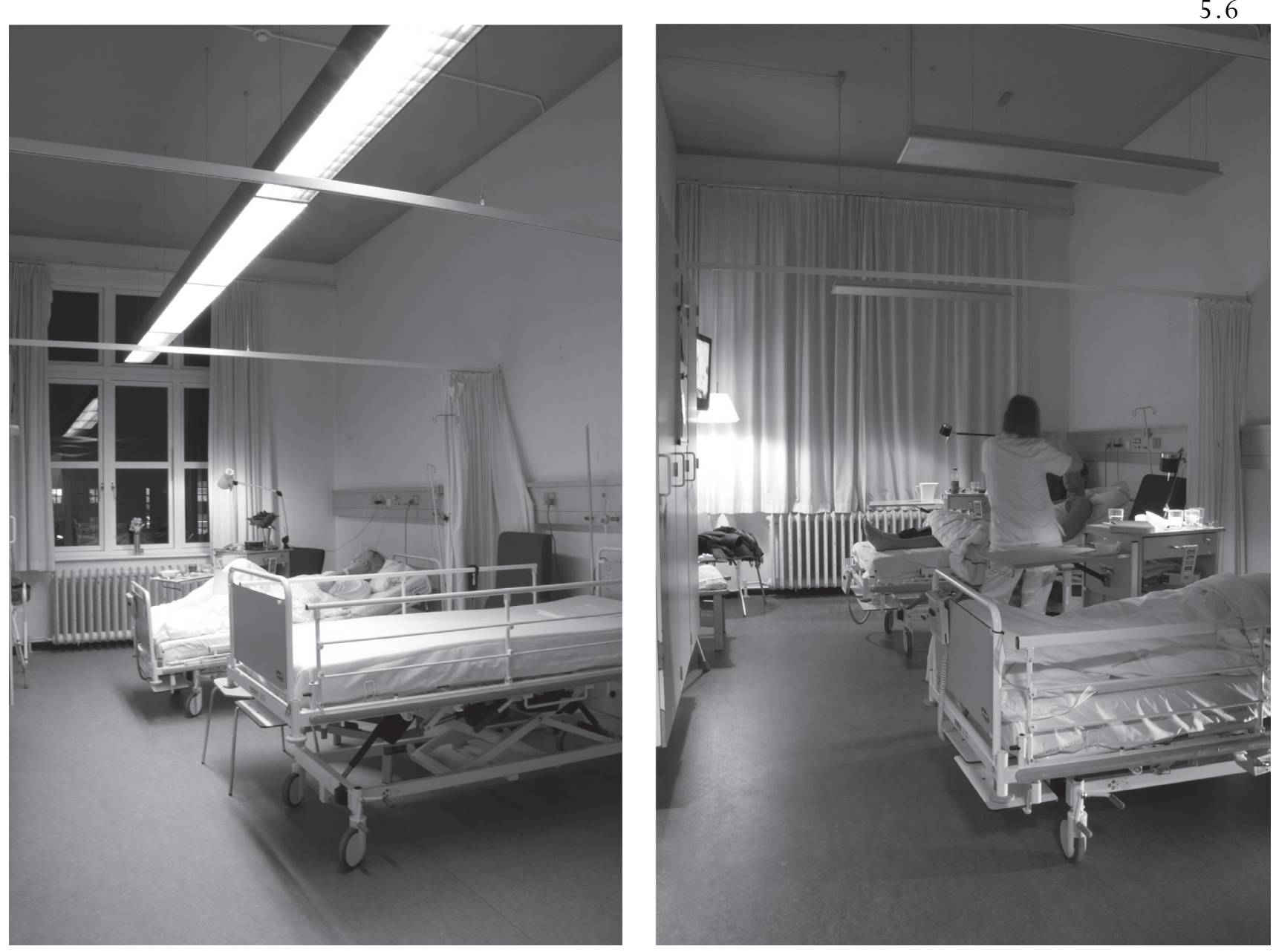


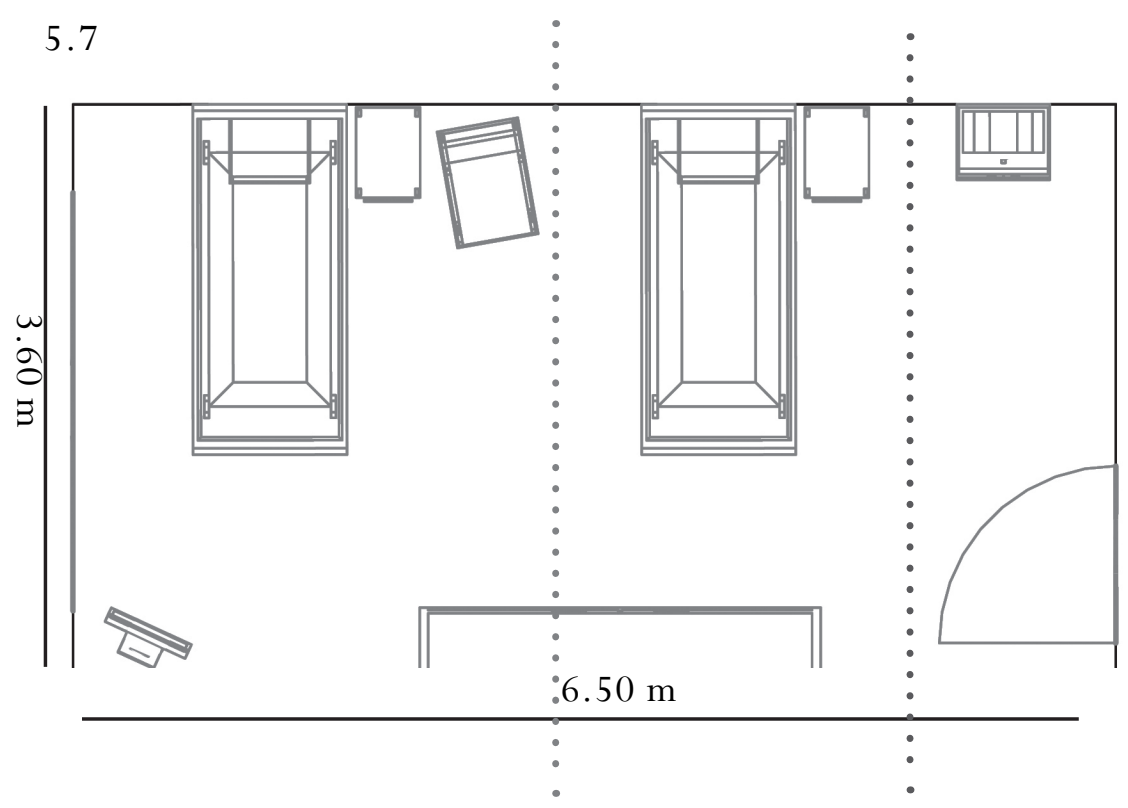

The study is a mock-up and therefore the lighting design in the DW is mounted to walls etc and not an integrated part of the space. The wards are comparable and both wards are two-bed wards and although this is not the future hospital perspective, but what is possible now. The one-bed wards are used for the weakest patients and in this way also the most unclear patients. Therefore, they may not be able to respond to a questionnaire.

Objects in the ward are two hospital beds, two bed tables, two soft chairs, a cabinet, an "art" poster, the washbasin and a TV. A lifting platform can slide along the rails, functional for both beds, is positioned at the same height as the curtains. The rails for the lifting platform, the rail for curtains and the suspended lamps give the impression of a lower ceiling height, around one meter lower than the ceiling.

The window, $2.6 \mathrm{~m} \times 2.8 \mathrm{~m}$, faces south, and the door is placed on the north side connecting the ward to a corridor with no daylight contribution.

\section{Surfaces represented in the space}

The surface character is important for the experience of the light, as the light seen is the light reflected from the surfaces in the space. In that way the light can appear warmer in a warm coloured space and colder in a space of reflective hard materials.

The ward is experienced as cold and white consisting of

Fig. 5.7

The curtains seperates the ward into three smaller rooms. 
rejecting and hard reflective surfaces. The walls and the window panels are painted white. The sheets are made of white cotton, and the ceramic washbasin is white. The floor is grey mélange linoleum, and the ceiling is painted light grey as well as the electrical panels behind the bed are metal grey. The structural works of the beds are light grey metal and the foot and headboard are light blue laminated wood. The cabinet doors and the panel behind the washbasin are yellow laminate. The door is painted blue and the chairs are upholstered in light bluish grey wool.

The curtain between the beds appears white as the curtains for the window, but looking closely at the textile design, it has rainbow coloured lines/threads to create nuances in the white surface. The suspended fixtures hanging down from the ceiling and bed lamps are red metal.

The surfaces in the space appear hygienic and glossy which means that the surfaces reflect the light in all directions and thereby diffuse shadows in the space. The variation and combination of surface textures is narrow and an important factor for the experience of the ward and why the ward appears with a minimum of stimulation and seems unfamiliar.

\subsubsection{THE TIME}

Throughout the year daylight is available at varied times at the ward. Therefore there is a "Seasonal" aspect to define. The "Period" of time a person is present in ward and thereby in the light atmosphere also needs to be defined. Time as seasonal changes

The time of the year and thereby the relevance of using artificial light supporting daylight is relevant to define in a lighting concept.

The design supports the daylight by taking over when daylight is not available. But it is also a fact that through the interviews, we found that daylight in the summer can create glare and heating problems for the patient near window. The design does not change throughout seasons and is only concerned about whether daylight is available or not. 


\section{Period of time}

In this study, the period is to be understood as the time in which the users are present at the ward, or the admission time for the patients. As the explorative study zoning the ward showed, nurses go from one lighting atmosphere in the corridor to another in the ward. The eye is sensitive to differences in light levels and thereby to different light atmospheres, which implies the illumination of the corridor should be taken into consideration. The patients spend many hours in the ward and therefore get use to the light atmosphere, and small changes of light atmosphere can have a greater effect.

The average admission time at $\mathrm{O} 3$ is three days. The ordinary procedure is as following: An "arrival day" where the patient also will have the operation and the activities are mostly waking up. Then one or two "recovery days" where activities are e.g. physiotherapy training, and at last the third day is the "going home" day. The activities at the ward are mostly going on when the patient is sitting in the bed or the chair beside the bed. Sometimes the patients leave the ward for training purposes or other activities.

\subsubsection{THE LIGHT}

Describing the light aspect, in the experience of a light atmosphere, includes the sub-topics 'Characteristics', 'Effect' and 'information' of light.

\section{Light character}

The character of light separates the daylight contribution from the light from artificial light sources. The experimental study focuses on the artificial light and evaluates only the ward illumination by artificial light. Still, daylight has an impact on the experience of artificial light as there are periods of transition between daylight and artificial light. The daylight contribution delivered from the south facing window placed $0.8 \mathrm{~m}$ above floor level is in the period of evaluation providing enough light from 8 AM to 4 PM on sunny days. On days with rain and overcast skies, the daylight contribution will not be enough and the artificial light could be needed all day. The experimental design must respond to the regulation for illumination of hospitals in Denmark. DS700 and DS703 have some requirements to respect and to elaborate on since it is not that precise. 
"For general requirements of lighting that deals with glare, luminance distribution, light geometry, light colour, flicker and illumination refers to DS 700(Dansk Standardiserings råd 2005).

The light should support the patient's needs and be shielded and arranged in a way so it does not create glare for patients in a supine position... For the remaining illumination the light colour must be selected to support the patient's needs for a pleasant and homely illumination, which in most cases means a colour temperature no higher than $3000 \mathrm{~K}$ and a relative good colour rendering Ra> 80 DS 703 (Dansk Standardiserings råd nov 1983, own translation).

While the requirement regards the colour temperature and colour rendering as the only parameters in supporting the patient's needs for a pleasant and homely illumination, the studies of preferences and trends were created. Here, it was found that it also could be a question of where the luminaires are located and how they support different activities. Therefore, the concept of a horizontal tripartition and the location near wards also needs to be tested in the concept. One of the aims of this study is to explore the needs and preferences for light in hospital wards. It is clear that this subject has to be evaluated and tests should be sone on what the impression of the ward environment is.

\section{Effect}

The different effects of light were specified 'Functional', 'Aesthetic' and 'Symbolic'.

The traditional ward lighting focuses on the functionality of the light. 'Functionality' is in this situation meant as supporting the staff's need for light and a light providing enough light for a difficult visual task. In the wards used for the experimental study, the light is distributed uniformly from suspended luminaires with fluorescent light tubes at various or discriminated light temperatures $(\mathrm{K})$. The suspended red luminaries are designed in the 1980 s and are formed as a box distributing the light down wards. The luminaire contains 8 x 40 w fluorescent light tubes and has a colour rendering at $\mathrm{Ra} 83$ and colour temperature around $3000 \mathrm{~K}$. 
By the bedside we noted red bed luminaires fixed to the aluminium panel behind the bed, but in the design process and before the evaluation of the light atmosphere, the luminaires was changed to luminaires fixed to the bed table next to the patient and thereby flexible in use. Specific mirror illumination was placed over the washbasin integrated in the yellow panel.

The light is controlled from the electrical socket placed next to the entrance of the ward and it is possible to the control is suspended light in three positions. One position is the luminaire turned on, second position is off and third position is half part of the luminaire turned on. The mirror luminaire can be turned on or off from the entrance (if it is working). The private light next to the patient can be controlled with on and off positions. For many years, the focal point has been the functionality of light defined as task lighting. It is an important issue, but compared with the awareness of light's impact on people's health and wellbeing. It is important to point at the sociocultural understanding of light as important for understanding the functionality. The term functionality must be expanded to include the sociocultural understanding of the functionality, which is often mixed up with the aesthetic effect.

The 'Aesthetic' effect could be defined as the luminaire design or an aesthetic effect of the illumination. Sometimes a luminaire design is more like an art object than a functional luminaire. An illumination can also be an art installation and an aesthetic experience as presented in the introduction chapter displaying the art of Astrid Krogh. Light can be used as a positive distractor and in the experimental study it can be a light projected to the ceiling providing stimulation for the mind. It is also possible to use luminaires, which we associate with private environment in the 'public' sphere like the ward is, or to use luminaires creating an aesthetic experience of the interplay between light and shadows. There are many possibilities for adding light as an aesthetic element at the ward. But often this effect is discarded for economic reasons.

Even though the luminaire design at TW is old-fashioned and not energy efficient, there is a holistic design approach in the choice of luminaire design at the ward. 
The suspended luminaire hanging from the ceiling is a red box and the bed luminaires are red (Now white luminaires, while there have been improvements at the ward through the study) and lastly the mirror luminaire as a yellow box referring to the yellow theme at the ward. The illumination to the DW is presented later in this chapter.

The 'Symbolic' effect of light is for example represented in the red lamps just outside the door or at the panel behind the hospital beds. When one of the red light flashes, a patient, i.e. a symbol for a patient in need of help, is calling the staff. Light can also in some situations be a symbol of danger both the red flashing light in the corridor, but also a blue flashing light on an ambulance as a symbol to other vehicles to make space for the ambulance.

\section{Information}

The daylight provides a sense of orientation according to the time of the day. Shadows indicate what time it is, e.g. in the middle of the day, shadows are close to the body. In the artificial light at Traditional ward there is a minimum of information available and turning on or off can only control the light. In the introduction of this dissertation, we introduced the question of whether artificial light can support the information on for example time. In the chapter displaying the preferences of light atmosphere, the information gained was a horizontal tripartition located near light as well as the walls. (Stidsen, Bjerrum et al. 2011, Stidsen, Kirkegaard et al. 2012_b, Stidsen, Kirkegaard et al. 2012_a).

In short, the illumination at TW is based on functionality seen from the working staff's point of view. The patient's need for a pleasant and homely illumination seem to be neglected or not seen as important. Therefore, the design appears old-fashioned and uncomfortable, unpleasant and unsuitable for patient activities such as relaxation. The most describable term seems to be a lighting "arrangement" and not a lighting "design".

The illumination for the DW deals with the issue of what pleasant illumination is and what we find comfortable. There could be a discussion on to which extent the term 'homely' is the correct term to use for a hospital ward 
and whether it can be translated directly from Danish to English. This is the background for seeking a pleasurable light atmosphere at the ward. It is therefore the goal to create lighting design comfortable for staff and pleasant for the patients. Therefore, the information from the explorative studies is implemented in the illumination of the DW and a concept based on a horizontal tripartition of the space.

\subsection{VISUAL PRESENTATION OF THE NEW LIGHTING CONCEPT}

The visual presentation in this chapter is documented using the lighting documentation program Dialux. An extract of Dialux documentation is found in the appendix 5. Therefore, the visual presentation should display the experimental set-up in a supplemental way to the Dialux documentation.

While the hospital ward is a multi-functional space and it is important to support both the patients and staffs need for light, the functional effect of the light is still in focus for the new design. However, the functional effect is not only seen as the task lighting. Functional lighting is also seen as the function of providing a pleasurable light for a patient's relaxation. In this way the function of light is seen as providing a pleasurable light atmosphere supporting the different activities in the space. The activities are defined as 'Conversations', 'Examinations', 'Watching TV', 'Eating', 'Passage at night', 'Energy boost' and 'Going to sleep'. The design concept can be presented as a 'High Lighting Scenario', a 'Centre Lighting Scenario' and 'Low Lighting Scenario’ (fig 5.8-5.12). 

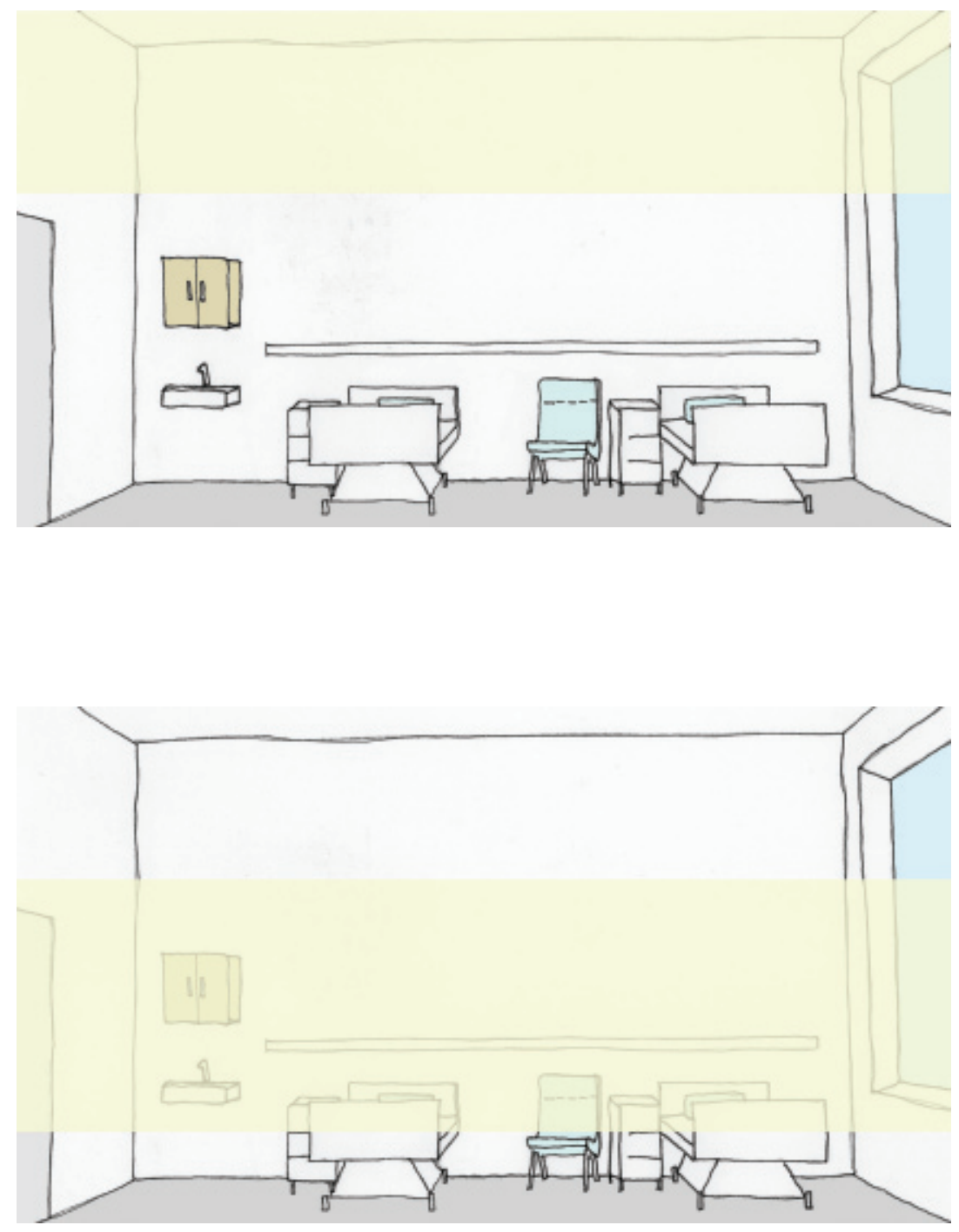

Fig. 5.8

The figures display the lighting concept containing a 'High Lighting Scenario', a 'Centre Lighting Scenario' and a 'Low Lighting Scenario'.

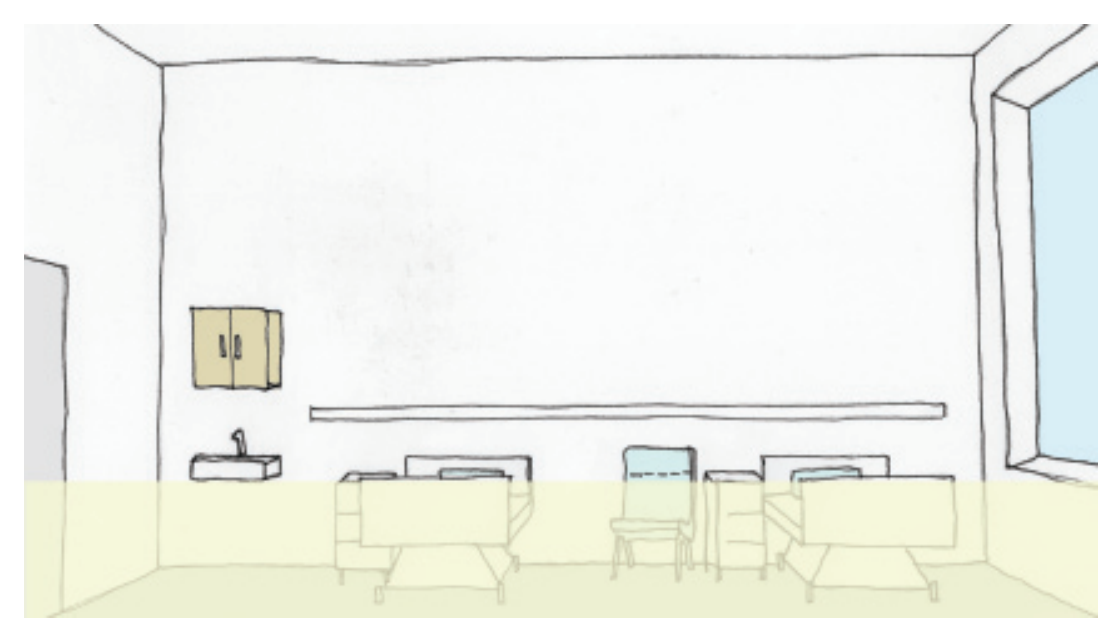




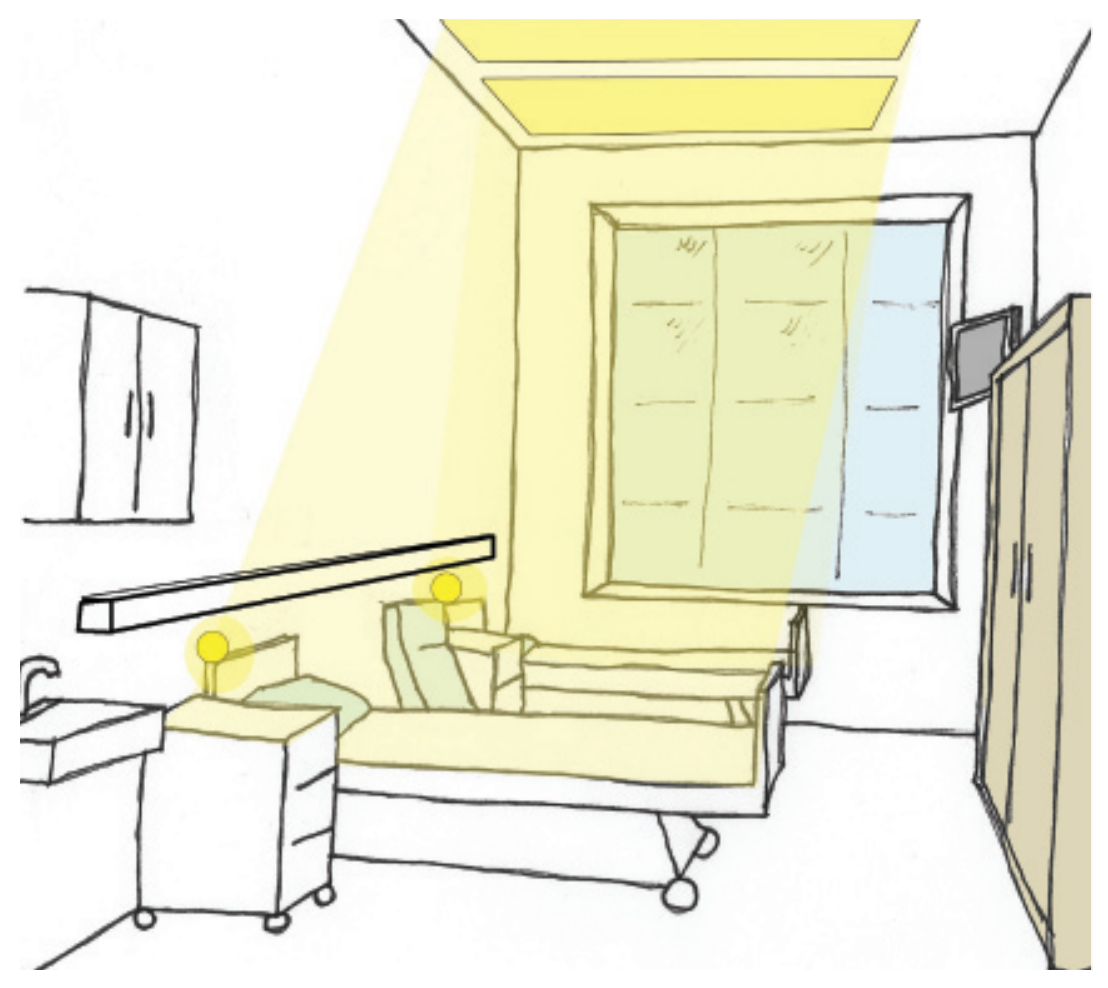

5.10

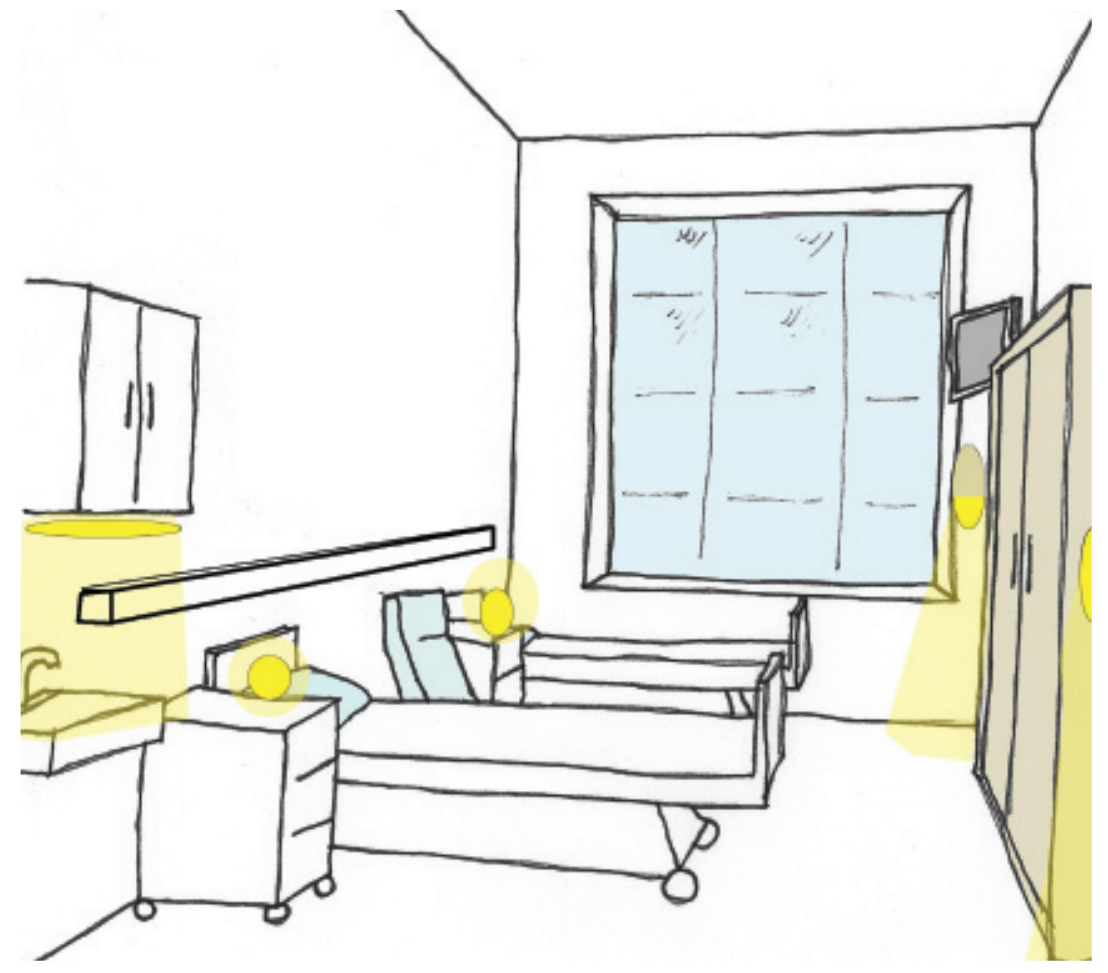

Fig 5.9

Location of luminaires in 'High Lighting Scenario'

Fig. 5.10

Location of luminaires in 'Centre Lighting Scenario'

Fig. 5.11

Location of luminaires in 'Low Lighting Scenario'

Fig 5.12

Layout for arrangement of luminaires in the designed hospital ward. 


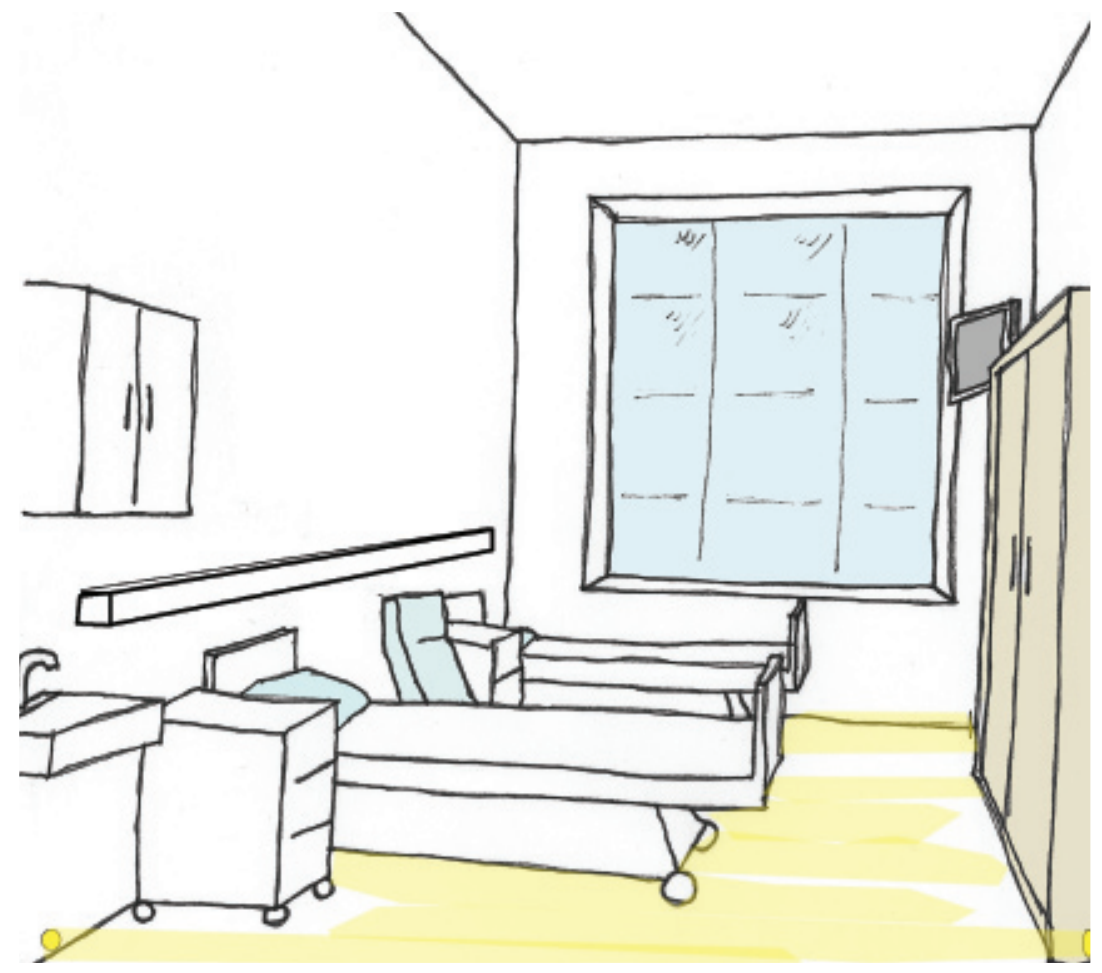

5.12

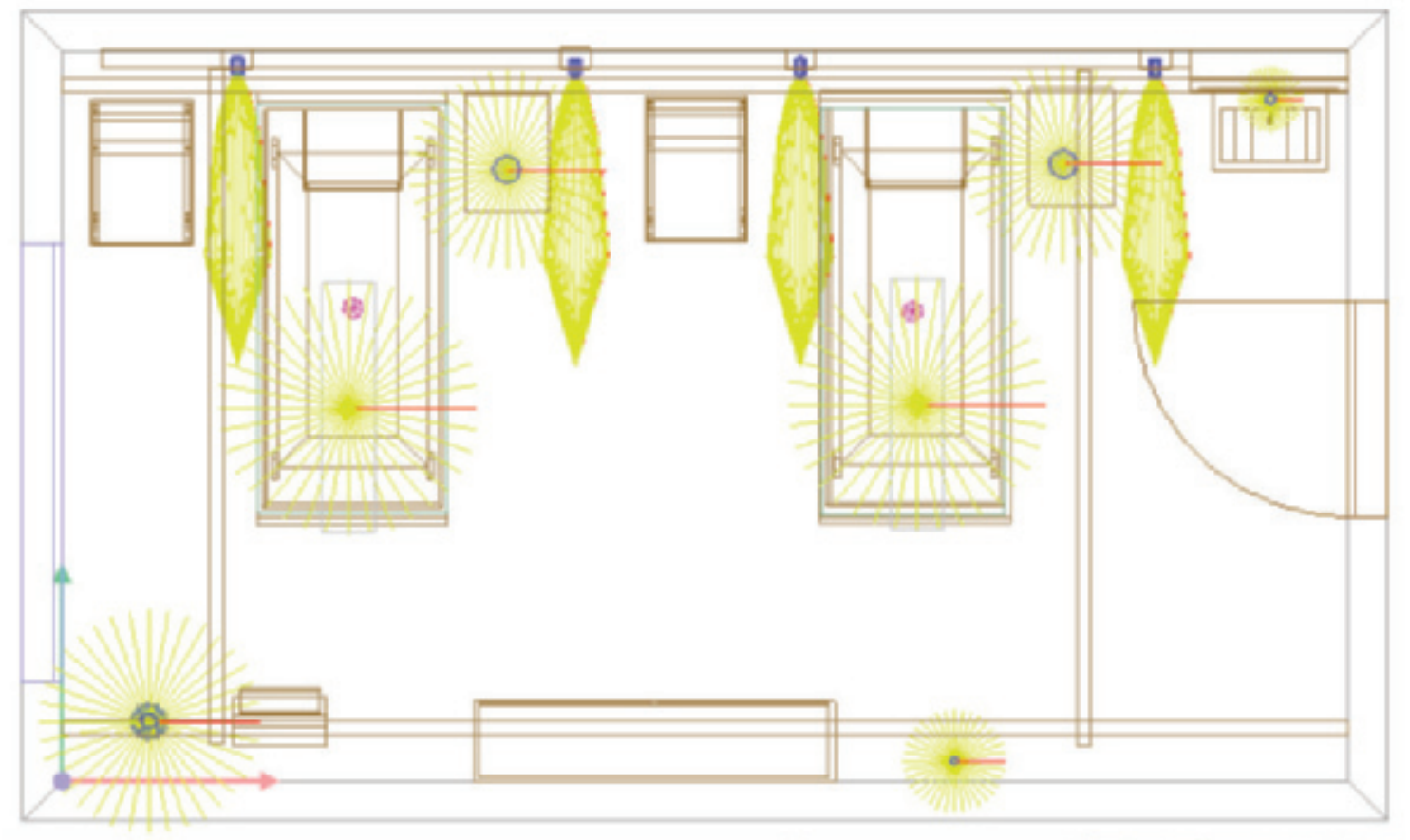




\subsection{1 'HIGH LIGHTING SCENARIO'}

The 'High Lighting Scenario' is addressed to support staff needs for work lighting. The light is distributed uniformly from the top of the space and downwards. The luminaires are placed in the upper part of the room, distributing light to the ward by using both up light and down light. In this scenario, the shadows appear small and centred around objects and users of the space. It gives an indication of daylight in the middle of the day. The lighting scenario is comparable with homely conditions where we have standing activities as working in the kitchen, walking in the hallway, cleaning etc. It is a work lighting mostly addressed for staff. Luminaires used in the High Lighting Scenario are two Philips Savio $120 \times 30$, one luminaire placed over each bed and a Savio contains three Philips MASTER TL5/TL-D. This combination provides an opportunity to change colour temperature (from $2900 \mathrm{~K}-5000 \mathrm{~K}$ ) and can include a dynamic daylight rhythm, which in this case are not being used as it only would blur the focus of the study. Because of the enormous ceiling height at the ward and in order to get 200-500 lux at bed level, we chose to hang the Savio approximately one meter down from the ceiling. To provide enough light for examining patients, the Savio luminaire is supplemented with two personal luminaires "Podium Oliver" from Massive Lighting containing halogen light 40W. This light source provides a high colour rendering $(95 \mathrm{Ra})$ and a perfect light to see details as it can be directed as needed. The 'High Lighting Scenario' is mostly supporting the staff's needs for task lighting, but it is also used to support other standing activities at the ward and providing an energy boost by distributing 500 Lux at bed level with a colour temperature at $5000 \mathrm{~K}$.

\subsection{2 'CENTRE LIGHTING SCENARIO'}

The illumination in the 'Centre Lighting Scenario' is addressed to the patients' needs for feeling a homely light atmosphere or an illumination supporting relaxing activities. The luminaires are placed near the walls and in the horizontal centre. The intensity of the light sources varies according to the activity which is presented in the next section. In this way, patients are able to arrange the light and create different light atmospheres according to mood and activity. It is not possible to illuminate a ward with candlelight, but the opportunity to illuminate 
Fig. 5.13 (Next pages)

Collection of images of the

ward illumination at DW a room in a flexible way by placing luminaires around the ward seems to have a positive impact on the different users. When it comes to creating the perfect light setting when reading or watching $\mathrm{TV}$, the illumination and light atmosphere should please the patient's comfort and prevent light reflections in the TV screen. The 'Centre Lighting Scenario' is also used by the staff regarding communication with the patients and this scenario supplies enough light to support staff activities. 'Centre Lighting Scenario' is a wall-mounted spotlight (Podium, Vilnius), placed just above an art piece next to the closet. The luminaire contains a Philips Hiro Spotlight 4 W GU10 40 gr. In the corner next to the TV, a suspended shielded pendant is hanging. The luminaire design is produced by Le Klint and named "Under Cover 2-21 medium". The light source is Philips dim able energy-saving light bulb "Philips Tornado" using 20 Watt. The luminaire "Under Cover" is designed by Philip Bro and a product that shields the traditional, folded luminaires from Le Klint so the lamp is easier to clean and thereby more suitable for use in the public sector as hospitals and restaurants etc. The cover used is designed by Graabæk-Stidsen. Over the washbasin, the integrated lamp contains a "Philips Tornado" using 20 Watt. This luminaire is not integrated in the lighting control system but is controlled separately.

\subsection{3 'LOW LIGHTING SCENARIO'}

In the 'Low lighting Scenario', the light distribution comes from wall mounted spots washing the floor with light. As the light is placed $40 \mathrm{~cm}$ above floor level, the light creates long shadows in the space, which reflects the kind of light we know from daylight situations in mornings and evenings. We also know this type of illumination from our private homes when watching TV or relaxing on the couch. The aim of this lighting scenario is to prepare patients for going to sleep or relaxing, and at the same time it is enough light for navigating at night time, when the nurses check patients' wellbeing or when the patients have to get up.

The luminaire in the 'Low lighting Scenario' uses four LED spots Philips BBG513 1xSLED400/8390 MB. Movement sensors are arranged next to the door and under the TV and in this way the entire ward. 

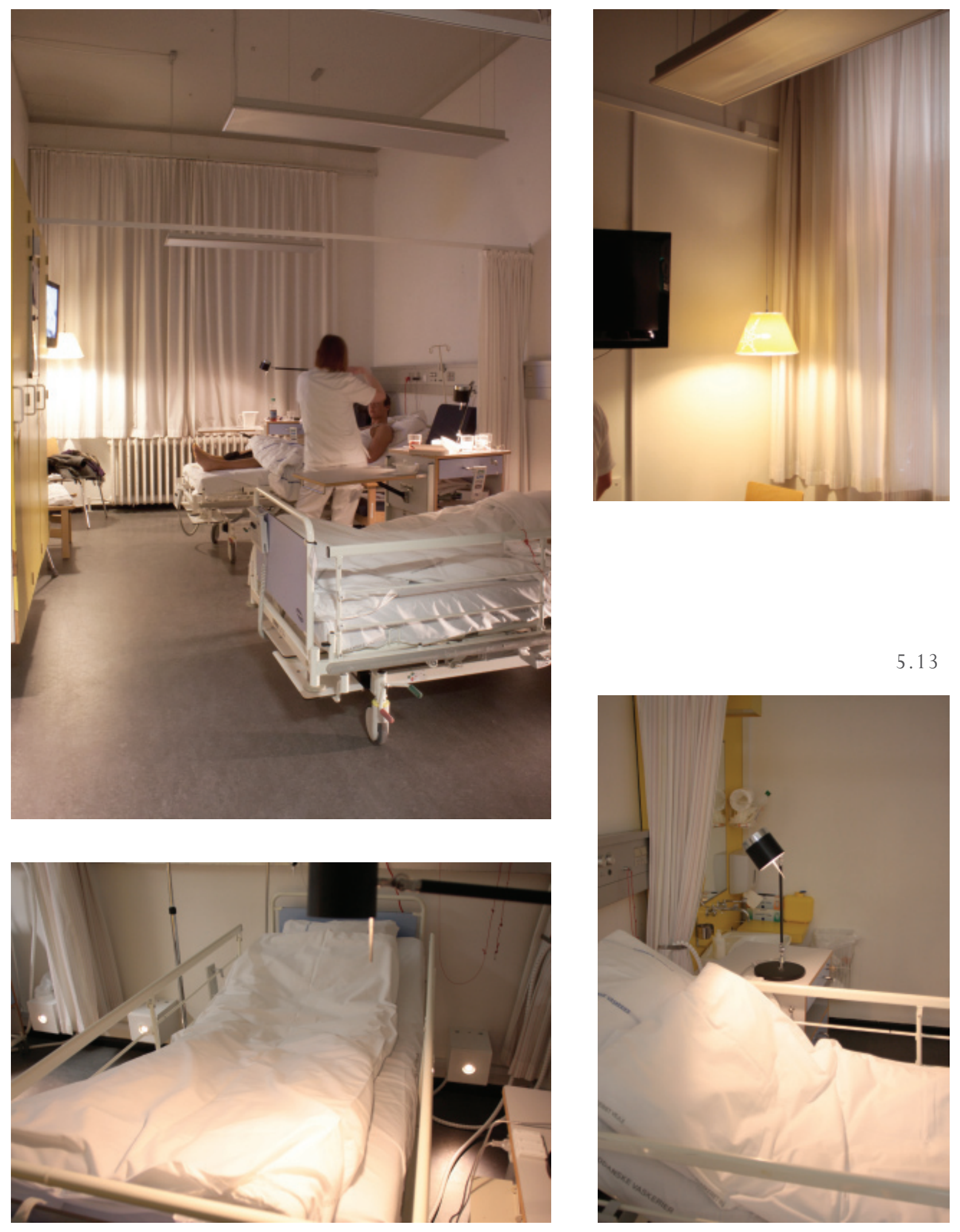

5.13

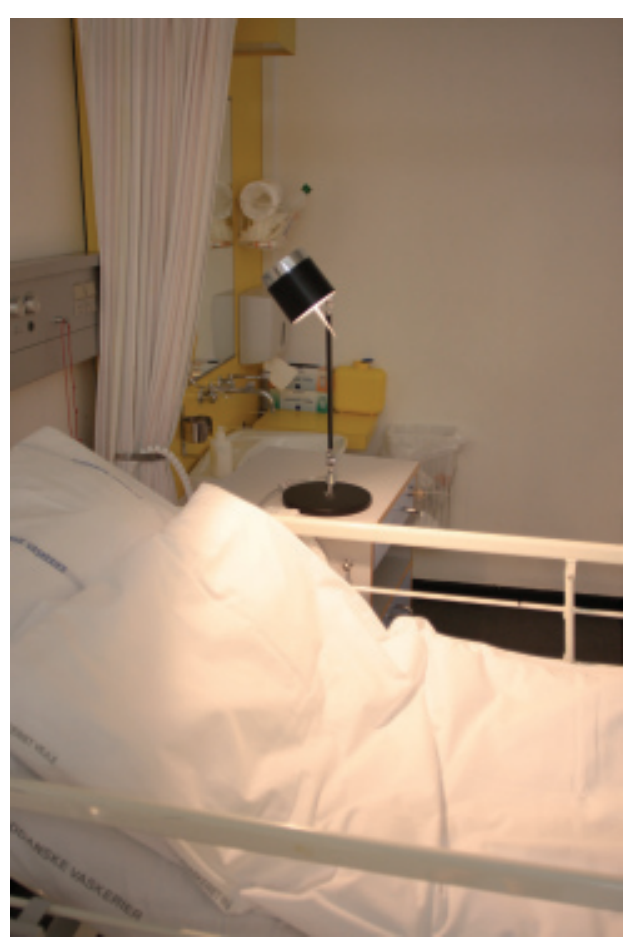



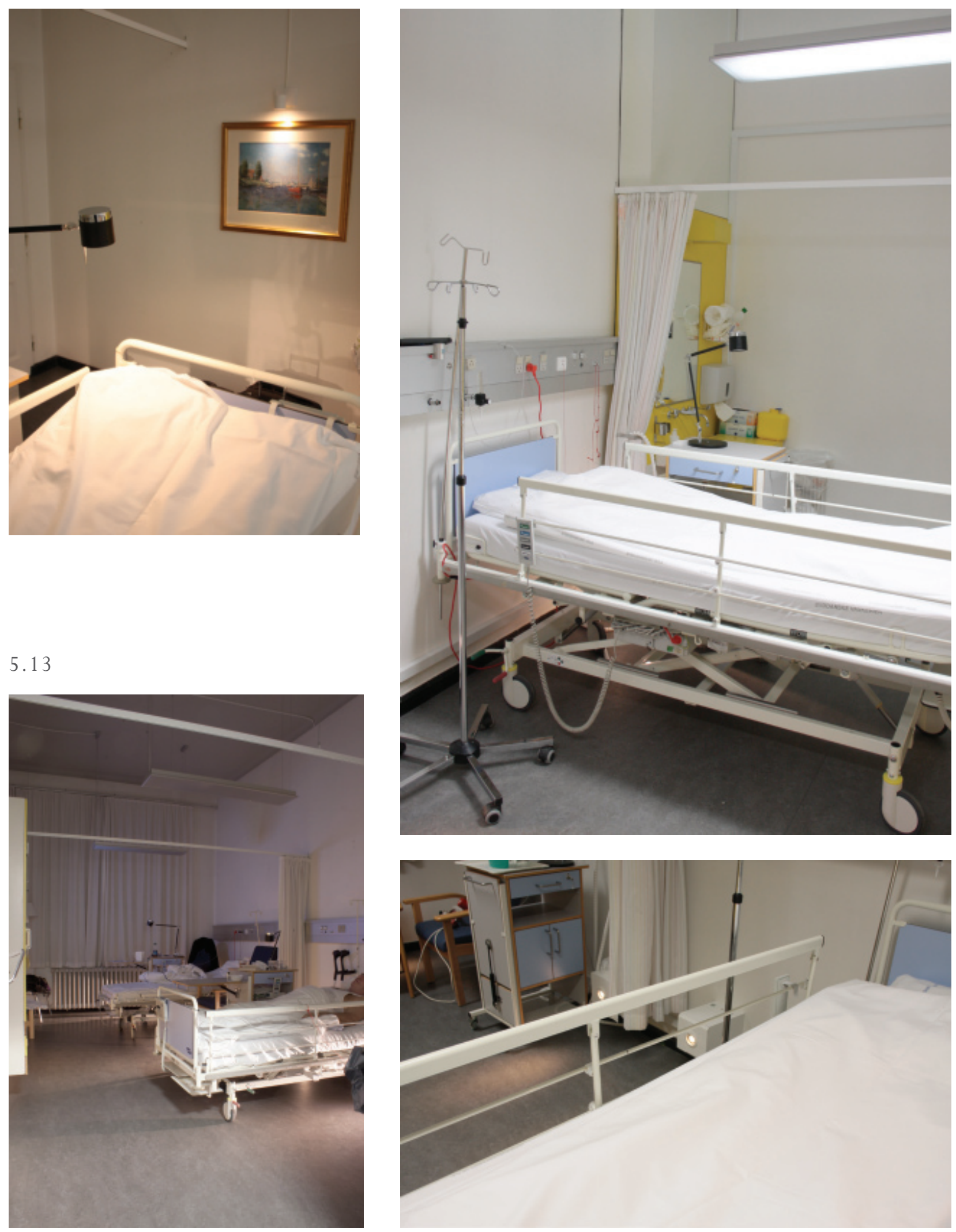

EXPERIMENTAL STUDY 


\subsubsection{LIGHTING CONTROL}

The illumination can be controlled either from the switch next to the entrance door or from the switch fixed to the bed table next to the patients. The reason why the illumination can be controlled from both places is based on the knowledge from interview with the nurses. Here, the nurses underline the importance of easy access to the light and the professional approach to help patients providing a pleasant stay at the hospital. The staff are caregivers and therefore should have the opportunity to give care in form of offering a cosy ward atmosphere. In the same interview, it was noted that there the staff turns on the light, but forget to turn it off again. The function of the lighting switch fixed to the table is to help patients be in control of the illumination and turn off the light if needed. The users have the opportunity to choose among six light settings by the door or by the bed. In (fig 5.14+5.15) the switches are displayed, and from the bedside the light settings are: 'Energy boost', 'Examination', 'Private', 'Night', ' $T V$ ', 'Conversation'. From the entrance the choices are: 'Examination', 'TV', 'Night Window', 'Night Door', 'Energy Boost Window' and 'Energy Boost Door'. In (fig 5.16) the effect from the luminaries is noted according to the lighting scenarios.

The choice of using switches instead of new technology like touch screen is based on the age of the patients. By using the new technology, some patients may be excluded in the use of the light, since most patients around 60-80 years will only find the switch familiar and know how to use it.

5.14
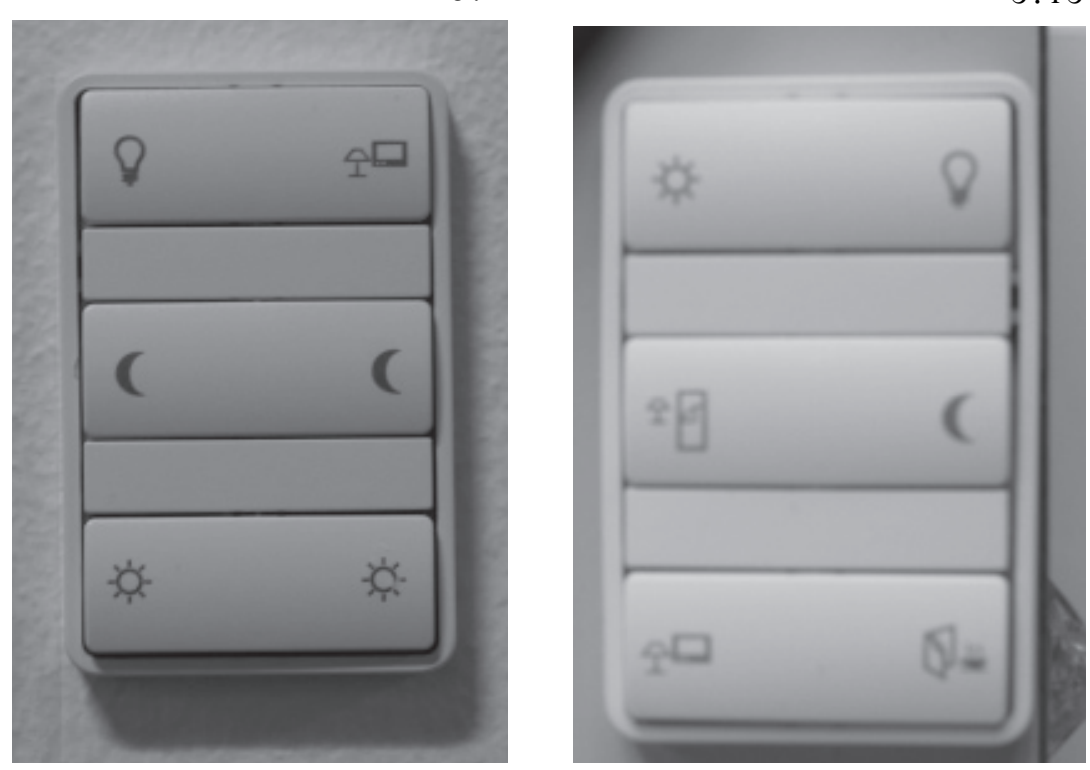

Fig. 5.14

Lighting Control (Door) examination light, TV light, turn off (bed 1), turn off (bed 2 ), energy boost (bed 1), energy boost (bed 2)

Fig 5.15

Lighting control (Bed)

Energy boost, Examination light, private light, turn off, TV light, communication light.

Fig 5.16

Percentace of light used in the lighting scenario pr luminaire 


\begin{tabular}{|lllllll|}
\hline Scene & $\begin{array}{l}\text { Ceiling } \\
\text { light }\end{array}$ & $\begin{array}{l}\text { Private } \\
\text { light }\end{array}$ & Pendant & $\begin{array}{l}\text { Wall } \\
\text { light }\end{array}$ & $\begin{array}{l}\text { Floor } \\
\text { light }\end{array}$ & Control \\
\hline $\begin{array}{l}\text { Examina- } \\
\text { tion }\end{array}$ & $\begin{array}{l}100 \% \\
3000 \mathrm{~K}\end{array}$ & $100 \%$ & $100 \%$ & $100 \%$ & $0 \%$ & $\begin{array}{l}\text { Bed and } \\
\text { entrance }\end{array}$ \\
$\begin{array}{l}\text { Energy } \\
\text { boost }\end{array}$ & $\begin{array}{l}100 \% \\
5000 \mathrm{~K}\end{array}$ & $0 \%$ & $50 \%$ & $50 \%$ & $0 \%$ & $\begin{array}{l}\text { Bed and } \\
\text { entrance }\end{array}$ \\
Night & $\begin{array}{l}30 \mathrm{~min} \\
\text { Private }\end{array}$ & $0 \%$ & $0 \%$ & $0 \%$ & $5 \%$ & $\begin{array}{l}\text { Sensor con- } \\
\text { trolled } \\
\text { Bed }\end{array}$ \\
$\begin{array}{l}\text { Conver- } \\
\text { stion }\end{array}$ & $0 \%$ & $100 \%$ & $0 \%$ & $0 \%$ & $0 \%$ & Bed \\
TV & $100 \%$ & $75 \%$ & $75 \%$ & $0 \%$ & Bed and \\
entrance
\end{tabular}

\subsubsection{SUMMERY OF THE LIGHTING CONCEPT}

The information gained through the studies on atmosphere and explorative studies is the point of departure in the design concept for hospital wards. The design concept seeks to support: examination or task lighting for staff, energy boost to patients hard to get out of the bed, a relaxing atmosphere when 'Watching $T V$ ', 'Having conversations', 'Reading' or 'Solving crosswords' or 'Eating' and lastly to provide a light for 'Going to sleep ' and a light that does not disturb the other patient, when it has to be turned on at night time. The two lighting controls each have six lighting scenarios supporting the activities and the main user of the space is able to control the light from the position where it is needed. The concept consists of a vertical grid locating the luminaires near the walls and a horizontal tripartition dividing the space in three zones: 'High Lighting Zone', 'Centre Light Zone' and 'Low Light Zone'. Most of the luminaires are placed in the "centre" zone. The light distributions are modulated into the room through lampshades supplied with down lights distributed to the place where needed. In that way the lighting design should be able to create an atmosphere at the ward supporting the patient's needs for a pleasant and homely illumination. But it has to be evaluated as it is still only working in theory and in design thinking. Therefore, a test of the real world experiment has to be evaluated by patients. 


\subsection{EVALUATING LIGHT ATMOSPHERE IN HOSPITAL WARDS}

The lighting design is in this study defined as the illumination and thereby the way light is distributed at the ward and not the luminaire design. Before the evaluation is presented, it is also important to remember that the study is partly financed by Philips, which means that Philips supported the study by delivering the technical equipment such as luminaires and lighting control. A luminaire from Le Klint was added to the concept in order to add more homelike atmosphere. Staff members of Philips also helped with technical assistance to the experimental set-up. In that way the result should be seen as the study it is and not as a Philips Lighting concept, as it only is based on the author's ideas and not representative for Philips lighting concepts.

In the search for relevant methods for evaluating light atmosphere, the methods seem limited and narrow in perspective. The goal was to find a method usable for a lighting design based on a sociocultural understanding. While the search for method was unsuccessful, the goal was to create a suitable questionnaire evaluating all aspects of the light atmosphere by combining methods. The inspiration was found in the trend study where images were mapped in order to detect subcategories of light atmosphere. The model of light atmosphere also contributed to knowledge of what is important in an evaluation.

Other more well-known and acknowledged methods were also studied. (Sommer, Sommer 1997, Sommer, Sommer 2002) suggest an evaluation as a systematic observational study over a period of time. (Sommer, Sommer 1997, Sommer, Sommer 2002) mentioned two components of a scientific body of knowledge. First, they introduce the "Empirical research" where measurement of observable events, and people's responses to questionnaires or individual characteristics are measured by a personality inventory. The other component they present is "Theory" as information that is sense-based and concerns what we directly see, hear, touch, smell or taste. This method can provide a picture of how the illumination is used by the users compared to the per- 
sonality inventory. The method is interesting as it can display deeper understanding of the connection between empiric and theory, but also a time-consuming project in this study. (Hawkes, Loe et al. 1979) used semantic differential scaling for measuring subjective preferences. Hawkes claims that subjects prefer other ways than regular recessed luminaires as illumination in their office and suggests that complexity and brightness together is what people want.

(Houser 2003) measured subjective responses to interior lighting by using paired comparisons and semantic differential scaling. To use more than one method evaluating the atmosphere seems perfect for this study as it is a subject not often discussed, and therefore there is a change of catching the bias in misunderstanding of the subject.

(Flynn, Subisat 1978, Flynn, AIA/FIES. et al. 1977, Flynn 1988) used Semantic Differential Scaling (DS) and Multidimensional Scaling (MDS), mapping procedures in the study of subjective responses to colours of "white" light produced by commonly available electric light sources in interior spaces. Flynn points out three main categories of impression that are of particular interest for the evaluation of light(Flynn 1979)First, the "Perceptual category", which is the impression of visual clarity, spaciousness, spatial complexity, colour tone and glare. Second category is "Behaviour Setting" as impression of public vs. private space and relaxing vs. tense space. "The overall preferences" as impression of references (like/dislike) and of pleasantness. Again the tactic is to use results from different methods. This information is inspiring for the study of light atmosphere, because there could be a problem of evaluating an atmosphere in words only.

In 1968, Moos developed the Ward Atmosphere Scale (WAS) as an instrument for measuring the important variables of the milieu (Moos, Shelton et al. 1973). The WAS is re-evaluated and proved to be stable by (Friis 1986), and a manual for testing the WAS is published in 1974 and third version published in 1996 (Moos 1974). The WAS is a social Climate Scale and a scoring system composed of 10 subscales that measure the actual, preferred and expected treatment environments of hospitalbased psychiatric programs. The subscale includes three 
different dimensions "relationship", "personal growth" and "system maintenance". The WAS is interesting according to measure subjective response of patients, but not usable in this experiment because the focus is on atmosphere between people and individual personal growth among patients. Environmental aspects in experiencing an atmosphere or light atmosphere are not prioritized in a useful way for this study.

All in all, there are several interesting studies showing different aspects of the effect of light or atmosphere and different evaluation methods useable as inspiration to develop a questionnaire suitable for the evaluation of light atmosphere in hospital wards. To make sure the evaluation of light atmosphere was evaluating the light according to the 'Model of Light Atmosphere', the model also was a part of the questionnaire design as well as educational books presenting recommendations for lighting design (Bean 2004, Tregenza, Loe 2009, Cuttle 2008, Russel 1995, Liljenfors 1999). The analysis chart from the trend study was also reviewed as guideline for asking the right questions when evaluating the light atmosphere. The study of methods evaluating a lighting design contributed with knowledge to create a draft for 'Light Atmosphere Evaluation'.

\subsubsection{LIGHT ATMOSPHERE EVALUA- TION}

'Light Atmosphere Evaluation' (hereafter called LAE) (appendix 3)questionnaire was developed based on the knowledge gained from the chapters like the introduction, on light atmosphere and the explorative studies display the full questionnaire. Presented here is the process of creating a questionnaire and validation of the method. LAE is using mix methods to evaluate the light atmosphere. Scaling methods as the Likert Scaling and Semantic Differential Scaling (psychology.ucdavis.edu ) is used to evaluate the subjective experience of the light atmosphere. A Likert Scale is a psychometric scale mostly used as questionnaires, and the scale is named after its inventor, psychologist Rensis Likert (DunnRankin, Knezek et al. 2004). The Likert Scale investigates the variation that points out the underlying of the phenomenon being investigated. The respondent specifies their level of agreement or disagreement on a sym- 
5.17

\begin{tabular}{|l|l|l|l|l|l|}
\hline & $\begin{array}{l}\text { Strongly } \\
\text { agree }\end{array}$ & Agree & $\begin{array}{l}\text { Agree or } \\
\text { disagree }\end{array}$ & Disagree & $\begin{array}{l}\text { Strongly } \\
\text { disagree }\end{array}$ \\
\hline Reading books & & & & & \\
\hline Watching TV & & & & & \\
\hline Eating & & & & & \\
\hline Having guests & & & & & \\
\hline $\begin{array}{l}\text { Communication } \\
\text { with the staff }\end{array}$ & & & & & \\
\hline Daily exercise & & & & & \\
\hline Passage at night & & & & & \\
\hline $\begin{array}{l}\text { Taking } \\
\text { medicine }\end{array}$ & & & & & \\
\hline
\end{tabular}

Fig. 5.17

example of questions in 'Light Atmosphere Evaluation' metric agree-disagree scale for a series of statements. The scale used in this experimental study is five-level scale going from strongly agree, agree, neither agree or disagree, disagree and strongly disagree. For example: Do you agree or disagree in following statement: I experience that the artificial illumination support the following situations:

The Likert scaling collects responses to specific situations as daylight contribution and the control of light, both similar to the artificial illumination.

The structure of the questionnaire is started out with general information about the patient. Information such as male or female, date and time of answering the questions, the age and ward number and the placement of the bed being nearest the window or door. Hereafter, we ask questions to ensure the informant's ability to distinguish between daylight and artificial light and the control or light. We ask almost same question three times about the level of agreement or disagreement in the following statements: I feel the daylight support activities as 'Reading books', 'Watching TV', 'Eating', 'Having guests', 'Going to sleep', 'Communicate with staff', Exercise', 'Safety when walking' and 'Taking medicine'. Then we ask the same type of questions but with the distinction from daylight that we ask in to which degree the patient feels that artificial light and lighting control supports the same activities.

The questionnaires for the two wards, the DW and TW, 
were the same for the general question and the question about daylight, artificial light and lighting control. But then we asked the patients to select a light scenario before they answered the last section of questions of atmosphere. Because of different opportunities for light control and light atmosphere, we had to make two different questionnaires for the experimental ward and the reference ward.

Then the Likert scaling method evaluated the next question concerning the patient's experience of light atmosphere at the ward. The next question evaluates the level of agreement or disagreement about how the atmosphere matches the following statements in connection to the chosen light atmosphere: I feel the space is stressing or relaxing? Do you feel you have the opportunity to create the right atmosphere in the ward? Is the ward cosy, does the ward atmosphere match the situation? Do you have the opportunity to feel private? Is the light as you like it? And do you feel you can adjust the light as you want and as you need?

To cross-check the answers, a Semantic Scaling method was used. A Semantic differential scaling is developed by (Osgoods, Charles, 1957) (psychology.ucdavis.edu ). The methods use polar adjectives, which means that it uses opposite meaning terms in each end from -3, -2, $-1,0,+1,+2,+3$. The poles patients are scaling are: relaxing vs. activating, low light level vs. high light level, uninteresting vs. interesting, disharmonic vs. harmonic, simple vs. complex, cold vs. warm, uncomfortable vs. comfortable, public vs. private, not suiting my needs vs. suiting my needs, cosy vs. not cosy and shadow less vs. shadow filled.

In the beginning, I was convinced that the light atmosphere had to be evaluated by creating a questionnaire directed to this study. However, through the process of developing the questionnaire and pre testing the understanding of the questionnaire, we found many bias, unexpected understanding of important aspect came up and different parts of the questionnaire were found unclear, dubious and at some point not valid as it was too subjective. An example could be fluorescent light tubes no matter of quality, the visual impression was cold and low quality. Another problem was that patients on TW 
misunderstood the question on lighting control because they did not understand a switch on/off as a lighting control. So even if we described it carefully, there was misunderstandings and the questionnaire needed support by a person explaining.

At first, the questionnaire was renewed hoping for more precise answers and a reduction of misunderstanding, but it was too difficult to collect questionnaires without them being misunderstood. So after pre-tests, LAE was dropped and the data collection approach renewed. The method found usable was Rikard Küller's 'Sematic Environmental Description’ (Küller 1975). In Swedish, the method is called 'Semantisk Miljö Beskrivning'- the SMB method. The method is interesting for this study as it does not ask about the light that we found problematic, but about the impression of the environment. In this way, two similar environments with only variation as the lighting design are comparable. While the illumination is still dependent on the activity in the space, we asked the patients to put the light into a specific setting before answering the questionnaire and to do it when daylight was not available.

\subsection{THE SEMANTIC ENVIRONMENT DESCRIPTION}

Küller claims that an environment needs a balance between complexity and unity and what Küller calls a balance in information rate. If an environment has a high complexity and low unity, the environment also has a high information rate. On the other hand, if the environment has a low complexity and high unity, it has a low information rate. The information rate, or balance between complexity and unity, affects how pleasant a person perceives an environment (Karlsson, Aronsson et al. 2003).

Küller developed the SMB method as a way of evaluating an environment as well as getting a better understanding of the overall impression of an environment. In studies like (Karlsson, Aronsson et al. 2003, Laike 1997, Johansson, Laike 2007), the method has been used to reveal how people assess their impression based on pleasantness and information rate. The SMB method has also been used to measure the impact of light and colour on psychological mood in a cross-cultural study of 
indoor work environment (Küller, Ballal et al. 2006). SMB claims to measure the overall impression of an environment, such as a room, a building or a landscape (Küller 1975). According to (Küller 1991), the physical environment has an impact on everyone experiencing the environment. The influence of the environment appears in a number of different ways, and Küller describes the physical environment in eight factors: 'Pleasantness', 'Complexity',' Unity', 'Enclosedness', 'Potency', 'Social Status', 'Affection' and 'Originality' (Fig 5.18)

The physical environment was assessed by means of the SMB method (Küller 1991). Data was collected with a questionnaire consisting 36 semantic scales, and the results yield an eight-factor profile of the environment. While the questionnaire did not exist in a Danish version, the translation followed this procedure. A Swedish and English version was sent to me as examples for the translation. The questionnaire was translated and doublechecked by a research assistant. Then Thorbjörn Laike

\subsection{8}

\begin{tabular}{|c|c|}
\hline 'Pleasantness' & $\begin{array}{l}\text { - Experience of comfort, } \\
\text { beauty, and security in the } \\
\text { environment. }\end{array}$ \\
\hline 'Complexity' & $\begin{array}{l}\text { - Experience of the live- } \\
\text { liness and variety of the } \\
\text { environment. }\end{array}$ \\
\hline 'Unity' & $\begin{array}{l}\text { - How well the various } \\
\text { components in the envi- } \\
\text { ronment fit together. }\end{array}$ \\
\hline 'Enclosedness' & $\begin{array}{l}\text { - Size, extent and degree } \\
\text { of demarction. }\end{array}$ \\
\hline 'Potency' & $\begin{array}{l}\text { - Degree of intrinsic force } \\
\text { in the environment }\end{array}$ \\
\hline 'Social Status' & $\begin{array}{l}\text {-Economic and social } \\
\text { evaluation of the environ- } \\
\text { ment. }\end{array}$ \\
\hline 'Affection' & $\begin{array}{l}\text { - Age astect including a } \\
\text { sense of identity }\end{array}$ \\
\hline 'Originality' & $\begin{array}{l}\text { - The parameter unusual } \\
\text { and surprising in the envi- } \\
\text { ronment }\end{array}$ \\
\hline
\end{tabular}

Fig. 5.18

The Eight factors in the ' $\mathrm{Se}$ mantic Environemental Description'.

Fig. 5.19

Questions in the eight factor profile. 
and Marianne Küller from Environmental Psychology at the University of Lund went through the translation, commenting and was again revised by us. In this way, misunderstandings of the words was minimised and a Danish questionnaire approved. The eight-factor profile and the question asked using semantic differential scaling is displayed in fig 5.19

\begin{tabular}{|c|c|}
\hline Factor & Item \\
\hline 'Pleasantness' & $\begin{array}{l}\text { Ugly (-) } \\
\text { Stimulation } \\
\text { Secure } \\
\text { Borring (-) } \\
\text { Idyllic } \\
\text { Good } \\
\text { Pleasant } \\
\text { Brutal (-) }\end{array}$ \\
\hline 'Complexity' & $\begin{array}{l}\text { Motley } \\
\text { Composite } \\
\text { Lively } \\
\text { Subdued (-) }\end{array}$ \\
\hline 'Unity' & $\begin{array}{l}\text { Consistent } \\
\text { Whole } \\
\text { Functional } \\
\text { Of pure style }\end{array}$ \\
\hline 'Enclosedness' & $\begin{array}{l}\text { Closed } \\
\text { Airy (-) } \\
\text { Demarcated } \\
\text { Open }\end{array}$ \\
\hline 'Potency' & $\begin{array}{l}\text { Fragile (-) } \\
\text { Potent } \\
\text { Masculine } \\
\text { Feminine (-) }\end{array}$ \\
\hline 'Social Status' & $\begin{array}{l}\text { Expensive } \\
\text { Lavish } \\
\text { Well-kept } \\
\text { Simple }\end{array}$ \\
\hline 'Affection' & $\begin{array}{l}\text { Modern (-) } \\
\text { Timeless } \\
\text { New (-) } \\
\text { Aged }\end{array}$ \\
\hline 'Originality' & $\begin{array}{l}\text { Curious } \\
\text { Surprising } \\
\text { Ordinary } \\
\text { Special }\end{array}$ \\
\hline
\end{tabular}




\subsubsection{DATA COLLECTION}

To avoid bias in the evaluation, several aspects were taken into consideration. First of all, it was important to see if the new lighting design improved the experience of a pleasurable light atmosphere compared to the traditional light atmosphere at the ward. Therefore, the experimental study consists of a ward with "New lighting design" called DW and a control room with the existing "Traditional lighting" called TW. The two wards are comparable and similar with the only difference being the illumination. The wards have the almost same location. They are at the same floor level, in same direction and the beds have same positions as well as same colour scheme. It is also possible to deliver and collect questionnaires at the same time, although the daylight did not have an impact on the answers while they were collected when it was dark.

The collection of data went on in the autumn 2011(Oct - Nov) where a pre-evaluation was collected to see the methods using LAE and SMB method. The first idea was to use mixed methods and collect both LAE and SMB as a way to check and validate the result. In the pre-test, the participants were both staff and patients as we just wanted to prove the method and needed to test the questionnaires. Questionnaires collected at DW are called SMB4 or LAE4, and questionnaires collected on ward 10 are called SMB10 or LAE10. The questionnaires was answered when it was dark and there was a need for artificial illumination in order to get plausible answers.

\begin{tabular}{|lll|}
\hline 5.20 & & \\
TW & SMB Method & LAE method \\
& 6 & 11 \\
DW & 6 & 11 \\
\hline
\end{tabular}

In the pre-test evaluation, the LAE questionnaire was found too difficult to answer. There were problems with patients mixing up the questions of daylight, artificial light and lighting control. Patients at TW did not answer the question on lighting control because they did not understand that a switch is a simple lighting control. At the same time, the amount of questions was found too many which is why it ended up with a data collection using the questionnaire SMB, and the LAE method was taken out of the project away.
Fig. 5.20

Test data collection. Numbers of answers from LAE and SMB methods. 
To secure a continuous and proper data collection a medicine student was paid to deliver and collect the questionnaires. In the test evaluation, it was also clear that the nurses found the method incomprehensible or irrelevant. It was seen as a burden for them to deliver and collect questionnaires which is why it was decided to pay a medicine student to collect data in the period. At first the nurses tried to deliver and collect questionnaires, but since this did not work out for different reasons, the procedure was that the questionnaire was delivered and collected on the second day of the admission if possible. When the student delivered the questionnaire, she waited in the corridor while the patients were answering the questions. The questionnaire was delivered at night time when there was a need for artificial illumination, and the patient was asked to be placed in the bed.

The medicine student was asked to deliver the questionnaire and turn on 'Communication' illumination at DW. At TW, she turned on the suspended luminaire as well as the bed luminaire also asking the patient to sit in the bed while answering. The medicine student was allowed to explain that the survey was a part of the improvement process in building the new hospitals in Denmark, but she was not allowed to explain anything about the light or participate in a discussion of the ward environment. The patients spent around 10-15 min on the questionnaire, and the medicine student collected the questionnaire immediately as she experienced questionnaires disappearing or not being answered when she waited to collect the questionnaire the following day.

One of the problems experienced in the data collection was that the student found it problematic that the patient was too tired for show interest in the light situation.

The quality of the chosen luminaires at bed side was too fragile and not suitable for a public environment because the joints got loose and slack. Some of the patients got help from visitors to read the questions but not to answer them, and there were problems with the lighting control as the bed luminaire was connected to the panel behind the patient, and sometimes the plug has to be connected before it worked.

Cables cross the floor and are in the way when moving the bed. The light is too warm, not specified if it is the 


\begin{tabular}{|lll|}
\hline & DW & TW \\
\hline Total answes & 16 & 16 \\
Male/ Female & $4 / 12$ & $3 / 13$ \\
$16-30$ years & 3 & 3 \\
$31-45$ years & 2 & 1 \\
$46-60$ years & 1 & 1 \\
$61-75$ years & 6 & 7 \\
$76-90$ years & 4 & 4 \\
\hline
\end{tabular}

5.22

\begin{tabular}{|lcc|}
\hline & DW & TW \\
\hline 'Pleasantness' & 4.59 & 3.85 \\
'Complexity' & 3.81 & 3.18 \\
'Unity' & 5.09 & 3.37 \\
'Enclosedness' & 3.12 & 4.03 \\
'Potency' & 4.34 & 4.34 \\
'Social Status' & 4.14 & 2.69 \\
'Affection' & 3.42 & 5.08 \\
'Originality' & 3.89 & 2.93 ' \\
\hline
\end{tabular}

Fig. 5.21

Table displaying the participants age and gender on DW and TW.

Fig. 5.22

Mean value in eight factor profile of SMB method.

Fig 5.23

Graph displaying the result dashed line: DW full line: TW 
heat from the halogen or if the light colour is too low. One note was on the light level being too high by using the floor luminaires, and lastly the suspended luminaires provided too intense a light and caused too large a light level gab at the ward.

\subsubsection{RESULTS}

The profile of the respondents is presented in illustration. The group consists of 16 persons on each ward. 4 males and 12 females at DW and 3 males, and 13 females at TW. At both wards most answers are from patients in the age group of 61-75 years old.

Patients in the two wards had and gave different impression ratings on the semantic scale of the environmental description. Although the wards and the group were comparable and similar except from the lighting, it was proven that light has an impact on the impression of the ward and light can be designed in a way so it affects the impression of the ward. While the ' $T V$ scenario' was the only illumination evaluated, the study did not evaluate the whole lighting concept, but only the light for relaxation activities like 'Watching $T V$ ' etc. The result should therefore also been seen in connection to the activity 'Watching $T V$ '. The result of the eight-factor profile is presented infig $5.22+5.23$.

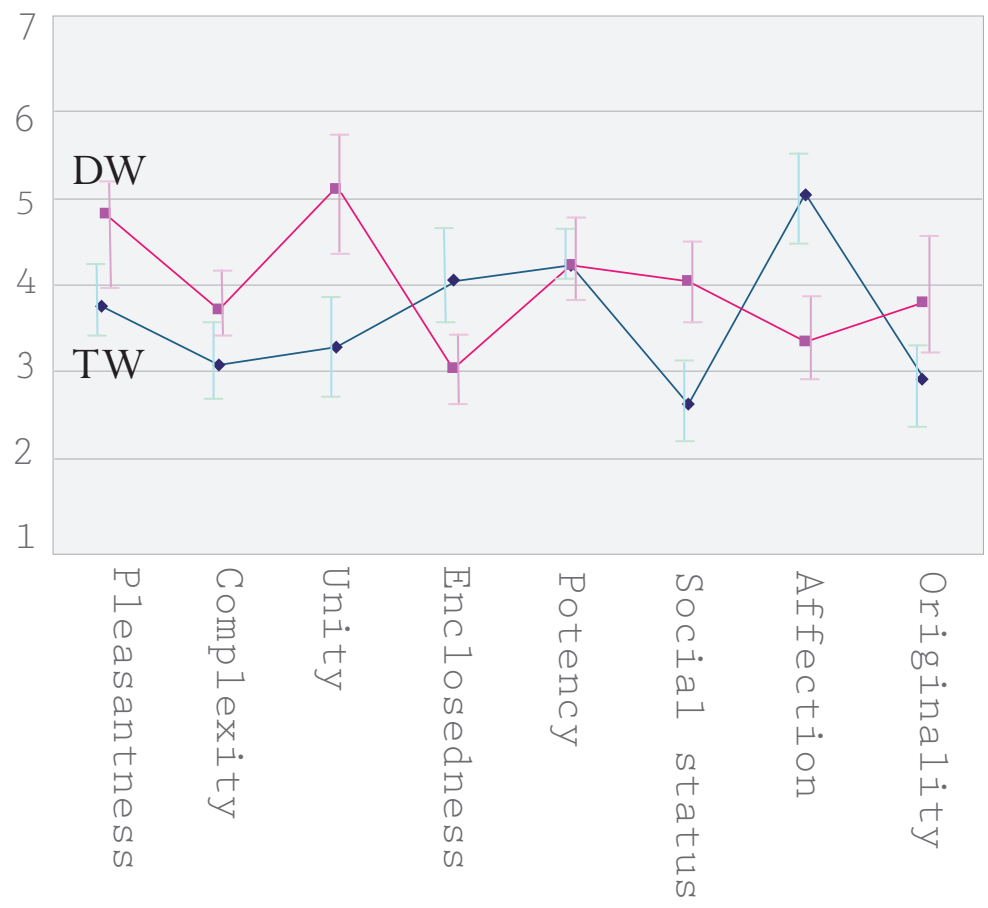


. The result shows that:

'Pleasantness': the DW was rated higher than TW

'Complexity': The DW was rated higher than TW

'Unity' : The impression of unity was rated higher at DW than TW.

'Enclosedness': TW was rated higher than DW

'Potency': The potency of the ward was experienced in the same way

'Social Status': The DW was significantly higher than TW

'Affection': The TW was significantly higher than DW

'Originality': DW was significantly higher than TW

Many things affect pleasantness. It is not easy to find general statements to explain and predict pleasantness. However, the balance between complexity and unity could affect pleasantness. If the level is too high on unity and too low on complexity, the ward could be perceived as boring and uninteresting and therefore not pleasant. And oppositely if the environment is too low on unity and too high on complexity, the ward could be experienced as too messy with conflicting information. The study did not show significant differences in the impression of pleasantness, even though we expected to it. The reason could be that it is not pleasant at all to be in a hospital ward and perhaps the light has a too little effect to change the impression of pleasantness. The furnishing and combination of materials are still the same. So, even though it can be seen in the scaling that the wards are evaluated differently and shows that it is more pleasant at DW, the result is not significantly higher than TW.

Complexity is a question of the how detailed the environment is. In the experimental set-up, the DW was rated higher in complexity as well as higher in unity. A high complexity and a high unity can mean that the impression of the space is more detailed and that the different parts fit together. The level of complexity of a ward 
can be discussed, but in this situation a higher level of complexity is seen as beneficial, because there is low stimulation from the environment resulting in a boring environment or a fast read environment. So, to create a higher complexity means to create a more stimulating environment.

The unity is an assessment on how different parts seem fit and function together. In this way, if a space is experienced as balanced and in harmony, the unity score is high. This factor is essential for a designer as the unity result tells if the design fit to the space and the way you want the participant to experience the space. Of course only if the purpose of the design is to create a balanced or harmonious design, otherwise it failed. The result showed a significantly higher score in unity at DW than TW, which means that the impression of DW fit together in a better way than at TW and thereby a more balanced environment is experienced at DW.

Enclosedness could of course be affected by the actual size of the space, the colours, the materials in the space etc. But TW and DW were similar except for the illumination, and therefore it evaluates the enclosedness, which the light creates in the space. The impression of the DW was experienced as less enclosed than TW. So, illumination at TW provided a higher score in enclosedness, which can be both positive and negative. Normally openness and airy spaces are experienced as positive, but in this case at a hospital ward, it is not to say if the patient preferred an open or enclosed space like a cave like feeling. The situation can be more similar with the TV scenario known from the homes (L. M. Stidsen, Kirkegaard, \& Bjerrum, 2012; L. Stidsen, Bjerrum, Kirkegaard, Thuesen, \& Fisker, 2011). So, the result shows that the spaces feel more open at TW than DW and not whether this is good or bad. It is plausible, however, that it is good to have lower enclosedness, because it is what Danes choose when they illuminate the private sphere in the area of 'Watching $T V$ '

Potency of the space is experienced at the exact same level on the scale, which could be based on the words used in the questionnaire. The evaluation of masculine or feminine qualities in a space is unfamiliar with words used in our language when we talk about an environment. 
Perhaps the result shows that the light has no effect on the experience of the potency of a space.

Social status is rated higher in DW than TW. This result can be affected by the new lighting equipment installed at DW and old lighting equipment at TW since the result does not tell that much. For next study it would be preferred to install a new lighting concept in one space and then replace the old equipment at the traditional ward with new luminaires in same positions. But the result can also have references to the way we use light in private and public settings. Normally, public settings are illuminated using the 'High Lighting Scenario' and private settings using the 'Centre Lighting Scenario'. In this way the public spheres can be seen with a lower status than private spheres, because it is often not designed or arranged in an aesthetic way, but in a practical manner. Where light is designed using location of light in different horizontal light zones in a public sphere, it can be read as more designed and thereby more expensive. This can have an effect on the participants' impression of the ward.

Affection is influenced by what is well known to the participants (Küller, 1975). TW was significant higher than DW, which is obvious because the illumination at TW is one of the ways we are used to see the illumination at a ward and therefore what we expect. The other traditional way of illuminating a ward is to place an up light behind the headboard of the bed, distributing a reflected, uniform diffuse light at the ward. The DW is illuminated with demarcated light zones around the ward and therefore untraditional resulting in a lower affection score. The luminaires were also new and therefore could have an impact on the level on affection. The new luminaries used at the ward could also affect originality, but it is also the way of arranging light at a hospital ward, which can be seen in originality where DW is higher rated than TW. Objects with high social status are often considered to be more original (Küller, 1975) which can also be seen in this study as DW is higher rated in both social status and originality, but the result on originality is not significantly higher, so it can also be discussed.

The higher score in 'Pleasantness' represent an environment experienced as more stimulating, secure, idyllic,
Fig 5.23

Results of data collection 


\begin{tabular}{|c|c|c|c|c|c|c|c|c|}
\hline \multicolumn{5}{|c|}{ DESCRIPTIVES } & \multicolumn{2}{|c|}{$\begin{array}{l}\text { 95\% CONFIDENCE } \\
\text { INTERVAL FOR MEAN }\end{array}$} & \multirow[b]{2}{*}{ MINIMUN } & \multirow[b]{2}{*}{ И MAXMUM } \\
\hline & N & $\begin{array}{l}\text { MEAN } \\
\text { DEVIAT }\end{array}$ & $\begin{array}{l}\text { STD. } \\
\text { ION } / \text {. }\end{array}$ & $\begin{array}{r}\text { STD } \\
\text { RROR }\end{array}$ & $\begin{array}{l}\text { LOWER } \\
\text { BOUND }\end{array}$ & $\begin{array}{l}\text { UPPER } \\
\text { BOUND }\end{array}$ & & \\
\hline \multicolumn{9}{|c|}{ PLEASANTNESS } \\
\hline TW & 16 & 3,83 & 0,74 & 0,19 & 3,45 & 4,24 & 2,65 & 5,25 \\
\hline DW & 16 & 4,59 & 1,22 & 0,30 & 3,94 & 5,24 & 2,00 & 6,45 \\
\hline TOTAL & 32 & 4,22 & 1,06 & 0,19 & 3,84 & 4,60 & 2,00 & 6,45 \\
\hline \multicolumn{9}{|c|}{ COMPLEXITY } \\
\hline TW & 16 & 3,16 & 0,85 & 0,21 & 2,70 & 3,61 & 1,75 & 5,00 \\
\hline DW & 16 & 3,81 & 0,63 & 0,16 & 3,47 & 4,15 & 2,75 & 4,75 \\
\hline TOTAL & 32 & 3,48 & 0,81 & 0,14 & 3,19 & 3,76 & 1,75 & 5,00 \\
\hline \multicolumn{9}{|l|}{ UNITY } \\
\hline TW & 16 & 3,37 & 1,13 & 0,28 & 2,77 & 3,97 & 1,63 & 5,25 \\
\hline DW & 16 & 5,09 & 1,20 & 0,30 & 4,45 & 5,73 & 2,75 & 7,00 \\
\hline TOTAL & 32 & 4,23 & 1,44 & 0,26 & 3,71 & 4,75 & 1,63 & 7,00 \\
\hline \multicolumn{9}{|c|}{ ENCLOSEDNESS } \\
\hline TW & 16 & 4,03 & 0,71 & 0,18 & 3,66 & 4,41 & 2,25 & 5,40 \\
\hline DW & 16 & 3,12 & 0,91 & 0,23 & 2,63 & 3,61 & 1,00 & 4,25 \\
\hline TOTAL & 32 & 3,58 & 0,93 & 0,16 & 3,24 & 3,91 & 1,00 & 5,40 \\
\hline \multicolumn{9}{|c|}{ POTENCY } \\
\hline TW & 16 & 4,34 & 0,53 & 0,13 & 4,06 & 4,62 & 3,25 & 5,50 \\
\hline DW & 16 & 4,34 & 0,86 & 0,21 & 3,88 & 4,80 & 3,00 & 6,00 \\
\hline TOTAL & 32 & 4,34 & 0,70 & 0,12 & 4,09 & 4,59 & 3,00 & 6,00 \\
\hline \multicolumn{9}{|c|}{ SOCIAL STATUS } \\
\hline TW & 16 & 2,69 & 0,69 & 0,17 & 2,32 & 3,06 & 1,23 & 4,00 \\
\hline DW & 16 & 4,14 & 0,91 & 0,23 & 3,66 & 4,63 & 2,75 & 6,50 \\
\hline TOTAL & 32 & 3,42 & 1,09 & 0,19 & 3,02 & 3,81 & 1,23 & 6,50 \\
\hline \multicolumn{9}{|c|}{ AFFECTION } \\
\hline TW & 16 & 5,08 & 0,86 & 0,22 & 4,62 & 5,54 & 3,85 & 6,85 \\
\hline DW & 16 & 3,42 & 0,90 & 0,23 & 2,94 & 3,90 & 1,75 & 5,00 \\
\hline TOTAL & 32 & 4,25 & 1,21 & 0,21 & 3,81 & 4,69 & 1,75 & 6,85 \\
\hline \multicolumn{9}{|c|}{ ORIGINALITY } \\
\hline TW & 16 & 2,93 & 0,96 & 0,24 & 2,42 & 3,44 & 1,00 & 5,50 \\
\hline DW & 16 & 3,89 & 1,21 & 0,30 & 3,25 & 4,54 & 2,00 & 7,00 \\
\hline TOTAL & 32 & 3,41 & 1,18 & 0,21 & 2,98 & 3,84 & 1,00 & 7,00 \\
\hline
\end{tabular}


good, pleasant and less ugly, boring and brutal. The patients also experienced a higher complexity in the designed ward, which also was intended while the traditional ward was experienced as too little stimulation. The designed ward is in that way experienced as more motley, composite, lively and less subdued. A higher complexity could provide a more stimulating environment, but too high complexity could provide an over stimulating environment and a confusing space. So, the fact that the designed ward is experienced as more complex is only a good result, while the complexity in the traditional ward is low or middle.

Based on the ANOVA test results at next page display significant differences were found between DW and TW for Unity $(\mathrm{F}(1,30)=17.4, \mathrm{p}<0.001)$, Social Status $(\mathrm{F}(1,30)=25.1, \mathrm{p}<0.001)$, Enclosedness $(\mathrm{F}(1,30)$ $=10.1, \mathrm{p}<0.01)$ and Affection $(\mathrm{F}(1,30)=28.1, \mathrm{p}$ $<0.001)$.

The 'Unity' factor is also central in the experience of everything fitting together as a hole, and as Cold pointed out the environmental coherence is essential for understanding the environment. The designed ward is in that way experienced as more consistent, more as a whole, more functional and more pure of style.

The experience of enclosedness is lower in the design ward than the traditional ward. That means that the traditional ward is experienced as demarcated and closed, and the design ward is experienced as more open and airy.

The factor evaluating the potency of the space is similar in the two wards. In that way the ward is experienced as similar when asking whether the ward felt fragile, potent, masculine and feminine. Evaluating the social status of the space, the new ward is experienced as more expensive, lavish and well kept and less simple than the traditional ward. The fact that the new designed space is filled with new equipment and the traditional ward is filled with old equipment could mean a biased result of this factor.

The affection is at the traditional ward experienced as more timeless and aged which is understood as being 
Fig. 5.24

ANOVA test of the results recognized as a traditional illumination of the ward and the expected illumination. The traditional ward is therefore also experienced as less modern and new.

The final evaluated factor is the originality of the experience of the space. Here the new designed ward is experienced as more curious, surprising and special and less ordinary than the traditional ward.

\begin{tabular}{|c|c|c|c|c|c|c|}
\hline \multicolumn{7}{|c|}{ ANOVA } \\
\hline & & Sum of Squares & df & Mean Square & $\mathrm{F}$ & Sig. \\
\hline \multirow[t]{3}{*}{ Pleasantness } & Between Groups & 4,41 & 1 & 4,41 & 4,34 & 0,046 \\
\hline & Within Groups & 30,50 & 30 & 1,02 & & \\
\hline & Total & 34,90 & 31 & & & \\
\hline \multirow[t]{3}{*}{ Complexity } & Between Groups & 3,41 & 1 & 3,41 & 6,04 & 0,020 \\
\hline & Within Groups & 16,92 & 30 & 0,56 & & \\
\hline & Total & 20,33 & 31 & & & \\
\hline \multirow[t]{3}{*}{ Unity } & Between Groups & 23,63 & 1 & 23,63 & 17,34 & 0,000 \\
\hline & Within Groups & 40,89 & 30 & 1,36 & & \\
\hline & Total & 64,51 & 31 & & & \\
\hline \multirow[t]{3}{*}{ Enclosedness } & Between Groups & 6,68 & 1 & 6,68 & 10,01 & 0,004 \\
\hline & Within Groups & 20,01 & 30 & 0,67 & & \\
\hline & Total & 26,688 & 31 & & & \\
\hline \multirow[t]{3}{*}{ Potency } & Between Groups & 0,00 & 1 & 0,00 & 0,00 & 0,997 \\
\hline & Within Groups & 15,18 & 30 & 0,51 & & \\
\hline & Total & 15,18 & 31 & & & \\
\hline \multirow[t]{3}{*}{ Social Status } & Between Groups & 16,90 & 1 & 16,90 & 25,84 & 0,000 \\
\hline & Within Groups & 19,62 & 30 & 0,65 & & \\
\hline & Total & 36,53 & 31 & & & \\
\hline \multirow[t]{3}{*}{ Affection } & Between Groups & 21,97 & 1 & 21,97 & 28,12 & 0,000 \\
\hline & Within Groups & 23,43 & 30 & 0,78 & & \\
\hline & Total & 45,40 & 31 & & & \\
\hline \multirow[t]{3}{*}{ Originality } & Between Groups & 7,49 & 1 & 7,49 & 6,26 & 0,018 \\
\hline & Within Groups & 35,90 & 30 & 1,20 & & \\
\hline & Total & 43,39 & 31 & & & \\
\hline
\end{tabular}




\subsubsection{SUMMARY}

The experimental study concerns design based on knowledge gained from the study of atmosphere, explorative studies of preferences and trends for illumination.

The 'Model of Light Atmosphere' is used as a tool for describing the physical frame of the experimental study, the patients' needs and preferences, the time aspect as well as for discussion of the regulation of light in hospital design.

The design process results in a lighting concept emphasising a horizontal tripartition of the space and design in a 'High Lighting Scenario', 'Centre Lighting Scenario' and a 'Low Lighting Scenario'. The main goal of arranging the illumination in three different horizontal lighting scenarios was to be able to create a lighting concept that supports both staff and patients' needs and preferences. The 'High Lighting Scenario' supports the work situation and creates an active atmosphere at the ward. The 'High Lighting Scenario' supports mostly the 'Sedentary activities' as 'Conversations', 'Watching TV', 'Reading books 'and 'Relaxation' in general. The 'Centre Lighting Scenario' is inspired of the homely illumination and the Danish tradition of arranging the luminaires in a 'Low Lighting Scenario'. The 'Low Lighting Scenario' creates long shadows in the space and is in that way representing the beginning or end of the day. In the same way, the 'High Lighting Scenario' has references to the middle of the day when the sun is in zenith, and the 'Centre Lighting Scenario' represents the variation of light given when different luminaires are turned on and how we use it at home.

To evaluate the lighting concept, patients responded to a questionnaire dealing with the experience of the space and not only the illumination. First the LAE method was developed to evaluate the experimental set-up. However, there were too many biases in the questionnaire, the 'Semantic Environmental Describtion' developed by Rikard Küller were used to evaluate the study. The evaluation took place in November 2011 - March 2012 at Odense University Hospital, Department of Orthopaedic Surgery in ward with lighting design (DW)and a traditional ward illumination (TW). The new lighting concept was installed in (DW) and a control room arranged in (TW). 
The results showed that in the eight-factor profile of SMB model, DW had a higher score in 'Pleasantness', 'Complexity', 'Unity', 'Social Status' and 'Originality'. The TW has the highest score in enclosedness and affection. In the question of the potency of the ward, both wards have the same score. This result is not surprising according to the intention of the design. The aim of the lighting concept was to create a more pleasant environment by illuminating the ward in three horizontal lighting scenarios. The respondents experienced a more pleasant ward and it is therefore seen as a success from the patients' point of view. However, the study did not evaluate the nurses' experience of the ward. 

6. CLOSING<smiles></smiles> 
The closing of this thesis begins with a short summary of the previous chapters. Hereafter a final conclusion is presented followed by a discussion of the process and suggestions for future research.

\subsection{SUMMARY:}

The introduction to the Light Atmosphere Chapter $\mathbf{1}$ opens with a presentation of the context to which light atmosphere is related. The context of the $\mathrm{PhD}$ study is Danish hospital wards why the introduction also shortly presents the history of hospital design in Denmark. The different characteristics of the hospital design evolve from machinery hospitals to a new era now where building design has its point of departure in the user needs. Thereby the experience of a hospital stay is important and because this is new, it also requires more research. Looking into the area of lighting design, the arrangement of luminaires seems to be the same no matter which hospital is studied. The illumination of hospital wards seems unchanged throughout history even though during the last few years some new light installations have been installed in hospitals around Denmark. But it is all a designer's suggestion for what a suitable lighting design is. There are only few research studies on lighting design in hospital wards from which to learn. So, findings are few, even though it is interesting what the new lighting design approach can bring.

The new approaches often focus on the dynamic of light, the light ambience or the change of colours in the light; all designs orchestrated with the aim of supporting the patients or staff's need for humanizing hospital environments. The interest for dynamic lighting is first of all presented as an illumination supporting the circadian rhythm, but the term "dynamic light" is interpreted in many ways and so the term is undefined.

This research elaborates on the dynamic light in another way, but still with the aim of innovating and challenging the traditional way of doing lighting design. Therefore, the study is based in what Cuttle called the 'third stage' of lighting or Zumtobels 'New Criteria' in lighting design. The $\mathrm{PhD}$ thesis deals with the experience of light, by looking at the shadow patterns in an illuminated space. The project also elaborates on the user's perspective in experiencing 
the illumination of a hospital ward. Therefore, the thesis interferes with the complex design field by presenting an experimental lighting design study based on explorative studies and identifying important parameters in the experience of light atmosphere.

The Danish interest for light, luminaires and light's impact on health is not new, and for many years there has been an interest in the topic. Still, we do not know much about Danish light preferences and the Danish cultural approach to light. Therefore, documentation of preferences and trends of light atmosphere seem beneficial in the process of creating a new lighting concept. The explorative studies deal with the understanding of terms 'homely illumination' and 'pleasurable light atmosphere', because the regulation for light in hospital wards prescribe it as important for patients' experience of admission. All in all, the $\mathrm{PhD}$ thesis has an interest in questioning the traditional way of creating lighting design for hospital wards and points out sociocultural considerations to include in a lighting design.

In Chapter 2, a presentation of the methodology of the study is displayed and discussed. Using Groat and Wang's model clarifying the 'Systems of inquiry', 'Strategies' and 'Tactics' in the study seems appropriate as it is a method developed for describing methodology in architecture.

The 'Systems of inquiry' presents the authors pre-understanding of the study as an iterative process. Schöns' terms 'reflection in action' and 'knowledge in action' defines the designer's position of doing research, and thereby it defines a frame for the study. Here, the designer's 'repertoire' is the foundation of the process and underlying basis for understanding and the actions in the study. There is a tacit knowledge in the way light atmosphere is created, and the tacit knowledge is described and sought to be made visible in order to explain the complex field of interrelated aspects in dealing with light atmosphere.

'Strategies' present how mixed methods and multi-strategy design can be used in a design research project. Both quantitative and qualitative strategies are used within the same research program as supplement for each other and with the purpose of testing the validity of results or findings. 'Tactics' present how to gain knowledge. Presenting literature and visual studies of light atmosphere is the 
first step in the creation of 'Model of Light Atmosphere', and then the function of 'Model of Light Atmosphere' is used to create the structure of the thesis as well as a tool in the design process of creating a lighting design, pointing at aspects to specify.

After the presentstion of the model, building the content of the 'Model of Light Atmosphere' explorative studies is carried out in order to expand one's pre-understanding of the subject. Methods such as semi-structured interviews, RFID tracking, visual analysis of pictures and behavioural observations are used to explore unknown or undocumented aspects of light atmosphere. An experimental design study of a lighting concept for hospital wards is designed in order to test some of the ideas from the explorative study and also as a tool to provide new information to the study of light atmosphere. Finally, patients evaluate the experimental study by answering a questionnaire using the Semantic Differential Scaling.

Chapter 3 elaborates on the term Light Atmosphere to get an idea of the theoretical and visual approach. The chapter introduces the 'Model of Light Atmosphere' and shows important aspects of the model. At first, light atmosphere is introduced as a vague term. An example is that the atmosphere is often used as a stamp of approval for beautiful architecture or as an exceptionally good experience. Hereafter the term atmosphere is put into an architectural approach using Zumthor and Pallasma as examples. Both architects handle the concept of atmosphere in visual and theoretical ways and point out sensorial experience as essential for the experience of a design, and claims that architecture must have a positive stimulation of the senses. within further exploration of atmosphere, studies of the philosopher Gernot Böhme's 'Concept of atmosphere' expand the preunderstanding of atmosphere. Böhme's approach contributed with knowledge of the importance of bodily presence in in experiencing an atmosphere and points out atmosphere as something in between a subject and a space. Dalsgaard and Kortbek later expanded Böhme's model, by adding 'Others' and 'Technology' as well as a 'Timeline' to the model. Still, the model seems to need an addition asthe 'sociocultural' aspect is seen as important and is not represented in the model. 
'Model of Light Atmosphere' is applied to explain the complex area of research in lighting by displaying the important aspects of an evaluation of light atmosphere. The first aspect introduces the 'User' aspect. The topics are defined as 'Pleasure', 'Activity' and 'Characteristic'. Then the 'Space' aspect is discussed and split into topics as 'Location', 'Spatial Composition', and 'Interior Design' and 'Surface' character. Thirdly, 'Light' is represented by 'Characteristic', 'Effect' and 'Information'. Fourthly, 'Time' displays time as 'seasons' and 'periods'. While the 'Model of Light Atmosphere' is also going to be used as a design tool, the model building requested more information on several parts of the aspects before it was useable for designing light for hospital wards. Again the 'sociocultural' aspect is displayed as essential for the experience of a light atmosphere and in need of further exploration.

Chapter 4 elaborates on the sociocultural aspect and presents explorative studies. It seeks to display what is important knowledge for a design study in the context of hospital ward lighting in Denmark.

The chapter starts out presenting a personal experience or personal observation of a hospital stay. Observations from an admission to the hospital ward are described and the experience of being a patient for one day and night described. In connection to the study of ward atmosphere, physical measurements, registration of surfaces and daylight contribution are defined and findings from interviews with staff and patients are as well described. Findings from the study showed a need for personal empowerment by controlling the illumination at the ward. One practicality by using light in the ward is a twisting motion when patients need to adjust the bed luminaire. The patient cannot turn on the lamp without twisting the body, which is a problematic action for a patient suffering from e.g. hip fracture etc. The patients need to walk to the door for change light setting for the general illumination. This can also have an impact on the patient's way of using light in different situations. The study also contributed with knowledge on daily activities at the ward as well as the study provides an impression on what goes on at a hospital ward.

The second explorative study presented a study of preference for light atmosphere in Danish homes. The preference 
study contributed with knowledge on the use of light for specific activities in the Danish homes. The activities evaluated are based on the findings in the admission study, and the preference study is made in order to get inspiration to how light can be used to create a homely atmosphere in the private sphere. The knowledge gained from the study contributed with information on the sociocultural aspect of light in a Danish context and defined the type of illumination Danes are familiar with when they are 'Watching TV', 'Having Dinner', 'Reading Books', 'Solving Crosswords', 'Going to Bed' and performing 'Upstanding Activities' in the home. The findings of this explorative study of preferences in Danish homes shows that light can be divided into a lighting concept presenting a horizontal tripartition of the space. In that way, light can support different activities by providing light in a 'High Lighting Scenario' and, for other activities, light can be arranged in a 'Centre Light Scenario' or 'Low Lighting Scenario'.

For 'Sedentary Activities' like 'Relaxation', 'Reading Books', 'Solving Crosswords', 'Having Conversations' and 'Dinner' etc., the light preferences were light zones in the 'Centre Lighting Scenario' or 'Low Lighting Scenario'. For 'Upstanding Activities' like 'Working in the Kitchen', using the 'Bathroom' or 'Corridor', the light is arranged in the 'High Lighting Scenario’.

The findings request an expansion of the understanding of lighting quality to include knowledge on socio cultural aspect by defining the expectations for light in the specific context. This could be done by arranging luminaires at different heights according the activity in the space. In that way, the illumination should be supportive for the diverse activities at the ward. Another result of the preference study is a vertical partition of the space, dividing the space into zones as 'Near the Wall Zone' and 'Centre Zone'. In the preference study, it became clear that most light is located near the walls. If light is placed in the centre of the space, it is often used to create an overview of the space or for upstanding activities. Often these spaces were working areas, 'passages', 'bathrooms' etc.

The suggestion for arranging light in a horizontal and vertical grid also questions the effect of lighting trends. Is the illumination found in the study an image of the moment or is it a traditional way of arranging light in Danish 
homes? Therefore, a third study was created to explore illumination trends in Danish homes by mapping images in the Danish interior design magazine BO BEDRE (Better Living).

The third study presents an analysis of 3500 images displaying trends of homely light atmosphere. The data is collected in 50 volumes of the BO BEDRE magazine in the period 1961-2010.937 registrations from the living room were analysed using semantic differential scaling, in order to provide information on the horizontal and vertical arrangement of luminaires in the living room in Danish homes. The 'Living room ' was chosen because it is the space for relaxation and the space where inspiration for hospital ward lighting easily could be explored. The information presented in the study is trends on 'Light Appearance' and 'Space Appearance' which are collated. Information on the location of luminaires in a 'High Lighting Scenario', 'Centre Lighting Scenario' and 'Low Lighting Scenario' is also compared during the period 1961-2010.

In the analysis, it became clear that the trends of light location in 'High Lighting Scenario', the 'Centre Light Scenario' and 'Low Light Scenario' as well as the 'Light Appearance' and 'Space Appearance' in the living room changed in different ways during the period.

The findings on arrangement of luminaires in a horizontal tripartition supported the expectations of most light in the 'Living room' is located in the 'Centre Lighting Scenario' or 'Low Lighting Scenario'. This trend of locating light low in the 'Living room' is common throughout the studied period. The result also showed that there is a slight change in 'Light Appearance' (INT, DIS and DAY) and clear difference in 'Space Appearance' (TEM and COM).

It was not possible to see significant interrelations between 'Light Appearance' and 'Space Appearance' which caused slight variation in 'Light Intensity'. But a comparison between 'Space Appearance' and location in the horizontal tripartition seems interesting for study, because where the light in a 'High Lighting Scenario' increases, the TEM and COM in 'Space Appearance' decrease. So, where the space appearance is high and experienced as warm and varied in texture and complexity, there is a little light in the 'High Lighting Scenario' and where the 'Space Appear- 
ance' is experienced as low, and the light is located in the 'High Lighting Scenario'.

In that way, inspiration for the arrangement of luminaires is documented and the three studies together provided information on preferences for light and what homely can be translated into when it comes to lighting. But looking at the ward as the context of the study, the diversity of users of the ward having diverse needs and preferences for light as it is a working area for upstanding activities as well as the space for 'Relaxation' and 'Sedentary Activities', a fourth explorative study was performed. It was created to generate information on how the ward is used by the different user groups. By defining user zones, the illumination could be optimized to the main user group of the space, so the light supports the staff when needed and the patients when needed.

The general activity for the staff is standing activities at the ward for few minutes. The patients spend most time in the ward and mostly with 'Sedentary Activities' being placed in the bed and chair next to the bed. The activities are 'Relaxation', 'Conversation', and 'Watching TV'. The zoning suggests a division of the space into a 'Nursing Zone', a 'Rehabilitation Zone' and a 'Passage Zone' on the vertical plan. In that way, it was possible to create user specific illumination based on user activities. The finding of the zoning study created new perspectives, because the user centred light created a need for user control of the light. Both patients and staff need to be in control of the light when they are the main user of the space.

The explorative studies support each other as well as expand the understanding of the need and preferences for light at a hospital ward. The finding contributed with knowledge on homely illumination, ready to be used as inspiration in the design process of creating a lighting design for hospital wards. It is still, however, a theoretical concept not tested in a real world study. Therefore, an experimental study is designed.

The experimental study (Chapter 5) is design based on the knowledge gained from the study of atmosphere, the explorative studies of preferences, trends for illumination and the zoning and experience of the ward. The 'Model of Light Atmosphere 'is used as a tool for describing the physi- 
cal frame of the experimental study and thereby presents specific aspects like 'User', 'Space', 'Light' and 'Time' in connection with hospital ward lighting in a Danish context.

The designed lighting concept emphasizes the horizontal tripartition of the space and arranges the luminaries in a 'High Lighting Scenario', a 'Centre Lighting Scenario' and a 'Low Lighting Scenario'. The main goal of arranging the illumination in three different horizontal lighting scenarios was to be able to create a lighting concept supporting both staff and patients needs and preferences. The 'High Lighting Scenario' supports the staff working situation and 'Upstanding Activities' and thereby creates an active atmosphere at the ward. The 'Centre Lighting Scenario' supports mostly the 'Sedentary Activities' like 'Conversations', 'Watching TV', 'Reading Books' and 'Relaxation' in general. The 'Centre Lighting Scenario' is inspired by the homely illumination and the Danish tradition of placing luminaires in a central, horizontal band with many light zones to choose between. The goal of providing a 'Low Lighting Scenario' is the night light or light for going to sleep. The 'Low Lighting Scenario' creates long shadows in the space and in that way tells a story of being in the beginning or the end of the day. In the same way, the 'High Lighting Scenario' has references to the middle of the day when the sun is in zenith, and the 'Centre Lighting Scenario' represents the variation of light it can give, when different luminaires is turned on and as we use it at home.

To evaluate the lighting concept, patients were responding to a questionnaire dealing with the experience of the space and not only the illumination. The questionnaire 'Light Atmosphere Evaluation' was developed by the author in order to evaluate the specific experimental set-up, but it was found too difficult to create a useable questionnaire specific for the hospital ward illumination as there were too many biases in the questionnaire. Therefore, the 'Semantic Environmental Describtion' (SMB method) developed by Rikard Küller was chosen for the evaluation of the patients' impression of the ward atmosphere. Patients did the comparative study of a 'Traditional Ward illumination' (TW) and a 'Designed Ward illumination' (DW).

The results showed that in the eight-factor profile of SMB, patients at DW rated a higher score in 'Pleasantness', 'Complexity', 'Unity', 'Social Status' and 'Originality'. Patients at 
TW rated the highest score in 'Enclosedness' and 'Affection'. Regarding 'Potency' of the ward, both wards had the same rating. This result was not surprising according to the intention of the design. In the ANOVA test, the evaluation on 'Unity', 'Social Status', Enclosedness' and 'Affection' was found significant. Thereby it could not be confirmed that DW was found more pleasant than TW. It was shown, however, that the patients' impression on DW fitted better than patients in TW.

\subsection{CONLUSION}

This thesis has its point of departure in a cultural understand of lighting quality. It contributes with knowledge on the Danish sociocultural lighting approach to light. The study concentrates on developing a new stage of lighting practice and lighting research defined by Cuttle as the third stage. The third stage of lighting is needed in order to explore new ways of evaluating the light experience and the light atmosphere. The third stage thereby takes note of how different experiences and expectations for light can impact the evaluation of the light and of how lighting design is created. The present $\mathrm{PhD}$ study concentrates on describing and creating light atmosphere in the context of hospital design in Denmark. Here, the regulation for light in hospital wards among other important issues requires that light has to support patient's need for a 'Pleasurable' and 'Homely' illumination. These terms are discussed, explored and displayed in different ways.

Although the terms 'Pleasurable' and 'Homely' illumination are non-defined terms in connection to light, the PhD study systematically describes the first goal of identifying important criteria for the experience of light atmosphere in hospital wards. The 'Model of Light Atmosphere' is used as a successful way to systematically describe an experience of light atmosphere even though the model cannot be seen as a final version. The model still needs to be refined and elaborated as many terms are still undefined and in the third stage of lighting profession. The different categories in the model also have more or less references to back up the importance of the subject described. Still, the model has its legitimacy in the discussion of light atmosphere as it discusses light in a more holistic way including a sociocultural parameter in the discussion. Thereby, the model is seen more like a contribution to a discussion on light 
atmosphere and a tool for specificity in defining important aspects of an evaluation of light atmosphere, and not as a complete result or a method for defining light atmosphere completely, since this never can be explained fully.

The way 'Model of Light Atmosphere' is kept central in the study, structuring the PhD study. During the project, the model was refined and functioned as a tool for clearing up undefined aspects and worked as a tool in the design process. The 'Model of Light Atmosphere' is seen as a successful tool to get around important aspects of a lighting design although it is not enough to create a lighting design. Aspects such as energy consumption and daylight contribution are not adequately taken into consideration in this study. The study concentrates on the knowledge contribution on the sociocultural aspect of the cost of other important aspects. So, the 'Model of Light Atmosphere' is seen as success in the third stage of lighting design where knowledge has to be generated. The model is not, however, a complete guide for designing a pleasurable light atmosphere in general. A design of light atmosphere must be created according to the specific situation, space and time as well as to the specific types of users. In that way, the 'Model of Light Atmosphere' contributed to knowledge on what to include in the design process of lighting design, but for a designer to be responsible when creating high quality lighting design, other aspects, e.g use of energy, need more attention in the model.

The 'Model of Light Atmosphere' pointed out important aspects to investigate before a lighting design can be created for a hospital design. The 'Sociocultural' aspect is not defined and is an important aspect to explore since there were too many conflicts between the intention of regulation for light in hospital wards ('Pleasurable' and 'Homely' illumination) and the real experience of ward illumination. To fulfil the regulation for hospital lighting in an appropriate way, the terms 'Pleasurable' and 'Homely' needed to be explored in the context of Danish hospital lighting.

To answer the second research question or second aim of the study about patients' need for light at the ward and preferences for light in the relaxing area of the private sphere, explorative studies are carried out and put into a historical context of light atmosphere in a fifty-year period. 
The goal of creating explorative studies is to expand our own understanding of the subjects studied, and to gain new information of the design process; information based on reality and not our own assumptions on what is needed. The findings of explorative studies are mostly suggestions on what to be aware of in the process of designing light, and the findings are seen as a part of the argumentation for the design concept.

The admission study contributed with new knowledge on the use of a hospital ward and what daily activities at a hospital ward are. Activities as 'Sedentary activities', ' $U_{p-}$ standing activities', 'Dinner', 'Watching TV', 'Going to Sleep', and 'Having guests' are defined, because preferences for these activities are going to be explored in the study of preferences. It also pointed out the lighting control as essential and the handling of light as important if a lighting design should support the patient's needs. The explorative studies therefore investigated patient's preferences for light in a homely context. The result of the study is an interpretation on how light is used in different activity defined areas in a private home in Denmark. While the Danish culture has a penchant for light, illumination and luminaire design, the study of light preferences expands the understanding of how light is used to create a pleasurable light atmosphere in Danish homes. The findings were that light is arranged in a 'High Light Scenario' with 'Upstanding Activities', and 'Centre Light Scenario' or 'Low Lighting Scenario' with 'Sedentary Activities', 'Going to sleep', and 'Watching $T V$ '. It was also found that light is used differently from everyday use to 'Having guests' where more light was lit. Findings included that the Danes' way of creating a cosy environment include candlelight and a low light level. The information on the horizontal placement of light in the 'Living room' expanded the understanding of light and pointed out the horizontal placement as one of the lighting techniques important in the way light is arranged in a Danish home. The vertical placement of luminaires placed near the walls also provided information on how Danes prefer light in their homes. The findings from the preference study expanded the understanding on homely light, and while the information was found interesting and innovative, a third explorative study was arranged. Therefore, the next explorative study displayed fifty years of trends for light atmosphere in the living 
room by analysing images from the Danish interior design magazine BO BEDRE. Here, the location of light in a horizontal tripartition was displayed, and the findings supported the suggestions from the study of preferences that most light in a Danish living room is located in the 'Centre Lighting Scenario' and 'Low Lighting Scenario'. The study also displayed findings of light atmosphere trends during fifty years, showing that most light is located in a 'Centre Lighting Scenario'.

Last, an explorative study displayed findings of how a hospital ward is used by staff members. Even though the data from the study is not enough to present a valid result, the study suggests optimizing light according to three zones: 'Nursing Zone', 'Relaxation Zone' and 'Passage Zone'. By splitting the ward in the three zones, light can be optimized for the main user of the zone and thereby be more comfortable for all users.

All in all, the explorative studies helped expand the understanding of the hospital ward as a space, the use of the ward and activities going on at the ward. I also helped create knowledge on preferences for light in homes and to document how light has been located for the last fifty years.

The new knowledge is an indication of how the arrangement of light can be used to create a homely sphere. It is documentation on how lighting trend has been presented in Danish living rooms for 50 years according to BO BEDRE. It is reasonable to believe that the way of arranging light in a 'High Lighting Scenario', 'Centre Lighting Scenario' or 'Low Lighting Scenario' in a Danish home could affect the impression of illumination in public spaces or other environments than the home. As presented in the chapter on light atmosphere, we have an early experience of spaces, and unconsciously we compare them with later experiences. Thereby, our architectural understanding lies in our childhood in our youth (Zumthor 2006). This could be the reason why an unfamiliar illumination can be experienced as less pleasant. However, we are also familiar with a 'High Lighting Scenario' in the public sphere, which could also have an impact on the impression of the ward lighting. Since the explorative studies did not answer how hospital light is experienced, an experimental set-up was installed at a hospital ward at Odense University Hospital. 
The experimental set-up is arranged as a comparative study between a ward with new lighting design and a ward having traditional ward lighting. The Semantic Environmental Description (SMB method) was used to gain knowledge on patients' impressions of the ward. Most important was the information on a higher impression of 'Unity' at the ward with the lighting design based on the 'Model of Light Atmosphere' and the concept of arranging light in a 'High Lighting Scenario', 'Centre Lighting Scenario' and 'Low Lighting Scenario'.

So, a general conclusion is to highlight the concept of locating light in a horizontal tripartition of a space and arrange the light according to the activities taking place in the space. The 'Model of Light Atmosphere' can be used as tool to create the lighting design in hospital wards, and eventhough the model is not tested in other contexts, it is likely that it can work as a design tool, why it helps define the specific design context. The explorative studies and the suggestions of creating a tripartion of the space into 'High Lighting Scenario', 'Centre Lighting Scenario' and a 'Low Lighting Scenario' helped innovating the traditional lighting design at the wards, and the patients confirmed that the impression of the space is affected by the lighting design and that it provides 'Unity' in the impression of the ward.

\subsection{DISCUSSION AND FUTURE RE- SEARCH}

The process of doing a PhD has been challenging and full of interesting, unknown tasks to explore and handle. Coming from a practical educational training as a designer, the entire writing task has been a challenge and an ongoing task to learn and refine. As seen in the papers, there is a learning process of expressing the complex field of sensory descriptions of light atmosphere. Perhaps some words are used in a wrong way or could be expressed more precisely with other terms. Subsequently, there are future improvements on refining the use of language, since the sophistication of using words has an impact on the understanding of the subject and in this case in the understanding of describing sensory qualities and sociocultural aspects of light.

The design research approach to investigate light atmosphere in hospital wards and exploring the term in order to innovate it, seems to be successful. Successful mean- 
ing that during the study, new knowledge was created and combined information in new ways of exploring the sensory qualities of light. Sometimes the process has been indescribable in the moment when the ideas surfaced. Often I knew that something needed to be explored and that the study could benefit from trusting the repetoire that I have built being a designer. To create 'Knowledge in action' and trust own 'Repetoire' was not always easy, but in the end I believe that it can be seen in the study and the process that I have trusted my own skills and kept the study close to the designers' discipline. By trusting my own skills and contributing personally in the design study, it is often a good way of being innovative, since nobody has taken the same route before.

The new knowledge gained was included in a lighting concept tested in the setting where it was addressed. But being a study trying to innovate an area, the research can also be seen as a "messy affair" providing many new questions and no final results. The results of the study are perhaps new questions, but the questions asked can be a result, because they can contribute to the discussion on lighting design and point out a neglected area in lighting design. I also see the sociocultural aspect of light as a new area in lighting design. Therefore, the thesis is a contribution to the third stage of lighting research as requested by (Cuttle 2010).

During the process of creating this flexible study, it has been presented in various settings in order to challenge the project from different disciplinary fields of research and design. The reason for challenging the study and discussing the topics was to refine the study as well as learn to argue for a multidisciplinary field as lighting design is. In periods it has been difficult to keep to my own disciplines being a designer, since the study needed information on light from disciplines as e.g. architecture, interior design, anthropology, engineering, medicine and environmental psychology. Trying to learn the essential parts of each discipline knowing that you only hit the surface of each discipline is not always an easy position, because every discipline is interesting and important to include in the study. A study of light like this would benefit from multidisciplinary collaboration, but it has only been possible in some of the explorative studies to collaborate with other disciplines although it is still a kind of multi-disciplinary collaboration to have a supervisor from another field of knowledge. 
Doing a study in a disciplinary field demands knowledge on methodology from the different fields of knowledge as well as good communications skills if it is going to be successful. The approach has been to test the hypothesis from as many disciplines as possible, and of course the theme is seen more interesting for some disciplines than others. In general, there has been an understanding for the PhD project and I have met an interest for discussing the subject everywhere I went. In a way, the project benefitted from being a innovative study, because it is obvious for the discussion partners that the project needs to be discussed and that everyone can contribute with knowledge to the project.

At the same time, a design approach to the study of light atmosphere can be experienced as weak and problematic as it seeks to include all elements in one project and one person to be the expert in all disciplines included in the study. Therefore, the design approach is both seen as the strength and weakness of a study.

There are a manifold of future studies interesting for studying light atmosphere at hospital wards or in other contexts. The 'Model of Light Atmosphere' can be elaborated and there are still many undefined sociocultural aspects to study. Therefore, the model can be refined again with new, defined aspects. The present study evaluates the hospital ward lighting, but other areas at the hospital also need to be defined, and many other public areas could benefit from being analysed and innovated according to use of light. Being educated as a teacher, school often comes to my mind and would be interesting to work on light as a pedagogical tool in the learning process of kids, since there are ongoing discussions at the moment on different styles of learning in the schools. The psychiatric hospitals are also an interesting place to define light's sensory effect, since patients' sensitivity in connection to the physical environment depend on their diagnosis. In that way, it is interesting to explore the effect of light in order to minimize sensory stimuli at a ward or to evaluate the effect of artificial light with a daylight rhythm in order to explore the effect of light on patients with destructive behaviour turning night into day and reverse.

In the exchange study at Lund's University and the experience with the Environmental Psychology, I was challenged 
in how an experience of a space could be evaluated and how the chosen evaluation has an impact on the result. I found it interesting that the impression of a space could be put into numbers and thereby be comparable in different ways. Combining both qualitative and quantitative methods in the developing process is important if the design is to be taken seriously at the same level as other disciplines using evaluative numbers. The study has its best qualities in the design process where the scene is staged and where the design concept is developed. The evaluation of the design could perhaps be evaluated successfully in other ways and thereby also display other results or find other interesting discussions, but the purpose was to create a practice oriented research project and to find a way to qualify a design process. In that perspective, the study is in general successful. 

7. BIBLIOGRAPHY 
ABILDGAARD, I., 2009. Dagslysstemning på de mørke gange. Ugeskrift for læger, (171 (8):664),.

ADENIJI, T., 2006. Mood lighting assist patient healing. Health Estate Journal, 2, pp. 49.

ALBERTSEN, N., 1999. Urbane atmosfærer. Sosiologi I DAG, (4), pp. 5-29.

ALFREDSDOTTIR, R., 2002. Atmosphere in the ward environment: a vulnerable dynamic phenomenon. The Royal College of Nursing Institute, London

ALTIMIER, L.B., 2004. Healing Environments: For Patients and Providers. Newborn and Infant Nursing Reviews, 3(2), pp. 89.

BEAN, R., 2004. Lighting -interior and exterior. Oxford, UK: Architectural Press.

BENJAMIN MEDIA, , Bo Bedre Medie info. Available: http: / / www.benjamin.dk/article/79741-bo-bedre-medieinfo.

BILLE, M., 2010. Lyskultur. Magasinet Humaniora, 25, pp. 30-34.

BILLE, M., 2008. Chapter 7: The luminosity of Protection, Department of Anthropology, University of London.

BILLE, M. and SØRENSEN, T.F., 2007. Anthropology of Luminosity: The Agency of Light. Journal of Material Culture, (12), pp. 263.

BIRNBAUM, D., 1999. Eyes \& notes on the sun. In: D. ZYMAN, R. LACKNER and C. SEIDEL, eds, James Turrell the other horizon. Ostfildern-Ruit, Germany: MAK, Cantz Verlag,

BJERRUM, A., 2008. Thoughts of hospital illumination.

BÖHME, G., 2012. Conference: "Understanding Atmosphere - Culture, materiality and the texture of the inbetween", Aarhus. Aarhus: 
BÖHME, G., 2007. Atmosfære, -den kropslige tilstedeværelses rum og rummet som fremstillingsmedium. Atmosfære - Den krospslige tilstedeværelses rum og rummet som fremstillings medium + Atmosfære: forbindelsen mellem musik og arkitektur hinsides fysikken. København: Kunstakademiets Arkitektskole, pp. 3.

BÖHME, G., 2007. Atmosfære: Forbindelsen mellem musik og arkitektur hinsides fysikken. ATMOSFÆRE. Den kropslige tilstedeværelses rum og rummet som fremstillingsmedium + Atmosfære: Forbindelsen mellem musik og arkitektur hinsides fysikken. København: Kunstakademiets Arkitektskole, pp. 21.

BÖHME, G., 1993. Atmosphere as the Fundamental Concept of a New Aesthetics, Sage.

BÖHME, G., Atmosphere as the subject of matter of architecture. The Space of Bodily presence and space as a medium of representation. pp. 398-406.

BOTFELDT, M., 2005. Skyggen ud af skyggen. Kolding: Kolding School of Design.

BOYCE, P.R., 2009. The impact of light in buildings on human health, 2nd Conference on Sustainable Healthy Building, 2009.

BOYCE, P.R., 2004. Lighting research for interiors: the beginning of the end or the end of the beginning. Lighting Research Technology, (36,4), pp. 283-294.

BOYCE, P.R., 2003. Human Factors in lighting. 2nd Edition edn. London and New York: Taylor \& Francis, Taylor and Francis group,.

BOYCE, P.R., VEITCH, J.A., NEWSHAM, G.R., JONES, C.C., HEERWAGEN, J., MYER, M. and HUNTER, C.M., 2006. Occupant use of switching and dimming controls in offices. Lighting Research Technology, 38,4, pp. 358.

BRENNAN, J., 2007. Effects of Light on humans. Lighting Journal, $72(\mathrm{nr} 3)$, .

BUTLER, D.L. and BINER, P.M., 1987. Preferred Lighting Levels: Variability among Settings, Behaviors, and In- 
dividuals. Environment and Behavior, 19(6), pp. 695-721.

CARR, S.J. and DABBS, J.M.J., 1974). The Effects of lighting, Distances and Intimacy of Topic on Verbal and Visual Behavior. Sociometry, Vol. 37,(No. 4), pp. 592-600.

CHRISTOFFERSEN, J., 2010-last update, HVad ved vi, og hvad er det nye. Available: www.lysnet.dk.

CHRISTOFFERSEN, J., 2006. Lys, sundhed og velvære. LYS, (nr 1.), pp. 15.

CLAUSEN, H., 2009. Light and communication - nature as referece in lighting design. Denmark: meldof:hansen.

CLAUSEN, H., 1999. Mærk lyset! Lys, (1), pp. 30.

COLD, B., KOLSTAD, A. and LARSSÆTHER, S., 1998. Aesthetics, Well-being and Health. 1. edn. Oslo: Norsk Form Center for Design, Architecture and the Build Evironment.

CONINCK-SMITH, N., 1989. Skolen ved sundet - 50 år. Arkitekten, 3(2), pp. 25-31.

CUTTLE, C., 2010. Towards the third stage of the lighting profession. Lighting Research and Technology, 42, pp. 73-93.

CUTTLE, C., 2008. Lighting by design. second edn. Oxford, UK: Architectural Press.

CUTTLE, K., 2010. Opinion: Lighting criteria for the future. Lighting Research and Technology, 42(270),.

DALKE, H., LITTLEFAIR, P.J. and LOE, D.L., 2004. Lighting and colour for hospital design. England: TSO.

DALKE, H., LITTLEFAIR, J., NIEMANN, E., CAMGOZ, N., STEADMAN, G., HILL, S. and STOTT, L., 2006. Colour and lighting in hospital design. Optics \& Laser Technology (343-365), (38), pp. 343-365.

DALSGAARD, P. and KORTBEK, K.J., 2008. Staging Urban Atmospheres in interaction design. Engaging artifacts, 
DANIEL, I., 2012. Conference: Understanding Atmospheres. UClture, materiality and the texture of the inbetween.

DANMARKS RADIO, , 4th of july. Available: http:/ / www. dr.dk/nyheder / htm/baggrund/tema2005/Tyskerne\%20 har\%20overgivet\%20sig/111.htmaug 2012].

DANSK STANDARDISERINGS RÅD, nov 1983. Dansk Standard 703 - Retningslinier for kunstig belysning i sygehuse (Directions for lighting in hospitals). 703. Dansk Standardiseringsråd.

DANSK STANDARDISERINGS RÅD, 2005. Dansk Standard 700 - Kunstig belysning i arbejdslokaler (artificial lighiting in workrooms). DS 700. Dansk Standardiseringsråd.

DANSKE REGIONER, Godt Sygehus Byggeri. Available: http: / / www.godtsygehusbyggeri.dk/Maal\%20 og\%20styring / Kort \% 20fortalt \%20om\%20sygehusbyggerierne/Hvorfor $\% 20$ bygger $\% 20$ regionerne $\% 20$ nye $\% 20$ sygehuse.aspx .

DANSKE REGIONER, Godt Sygehus Byggeri. Available: http: / / www.godtsygehusbyggeri.dk/Maal\%20 og\%20styring / Kort \% 20fortalt\%20om\%20sygehusbyggerierne/Hvorfor $\% 20$ bygger $\% 20$ regionerne $\% 20$ nye $\% 20$ sygehuse.aspx.

DIRCKINCK-HOLMFELD，K., HORNUNG，P.M., DAMGAARD-SØRENSEN, H. and HESLET, L., 2007. Sansernes Hospital. 1 edn. Lars Heslet og Arkitektens Forlag, 20007.

DMI, Solskinstimer i DK. Available: http://www. $\mathrm{dmi}$.dk/dmi/index/danmark/klimanormaler.htm [23.10.2012, 2012].

DUNN-RANKIN, P., KNEZEK, G.A., WALLACE, S. and ZHANG, S., 2004. Scaling methods. 2 edn. Mahwah, N.J.: Lawrence Erlbaum Associates.

ELIASSON, O., 2011-last update, Your Rainbow Panorama. Available: http://www.aros.dk/samlingen/yourrainbow-panorama/. 
FAGERHULTS, B., 2003. The importance of Good Lighting. Technology \& services, Business Briefing: Hospital Engineering \& FAcilities Mangement, , pp. 1-4.

FERNANDEZ, P., GIBOREU, A. and FOTOYNONT, M., 2010. The Light in the hospitality industry from light perception to lighting conception, 2nd CIE Expert Symposium on Appearance: "When appearance meets lighting" 2010, pp. 129-131.

FLYNN, J.E., 1988. Lighting-design decisions as interventions in human visual space. In: J.L. NASAR, ed, Environmental Aesthetics - Theory, Research \&applications. 2. edn. New York: Cambridge University Press, pp. 156.

FLYNN, J.E., 1979. A guide to methodology procedures for measuring subjective impressions in lighting. Journal of the Illuminating Engineering Society, .

FLYNN, J.E., AIA /FIES. and SPENCER, T.J., 1977. The effects of light source color on user impression and satisfaction. Journal of the Illuminating Engineering Society, , pp. 167.

FLYNN, J.E. and SUBISAT, G., 1978. A procedure for qualitative study of light level variations and system performance. Journal of the Illuminating Engineering Society, 8, pp. 28-35.

FOQUÉ, R., LAMMINEUR, M. and FOQUÉ-DENKENSADRIAENSSENS, A.N., 1995. Designing for patients: a strategy for introducing human scale in hospital design. Design Studies, 16, pp. 29.

FRANDSEN, A.K., MULLINS, M., RYHL, C., FOLMER, M.B., FICH, L.B., ØIEN, T.B. and SØRENSEN, N.L., 2009. Helende Arkitektur.

FRIIS, S., 1986. Measurements of the perceived ward milieu: a reevalutation of the Ward Atmosphere Scale. Acta Psychiatrica Scandinavica, 73, pp. 589-599.

FRIIS, S., 1986. Characteristics of a good ward atmosphere. Acta Psychiatrica Scandinavica, 74, pp. 469-473.

GALASIU, A.D. and VEITCH, J., 2006. Occupants pref- 
erences and satisfaction with the luminous environment and control system in daylit offices: a literature review. Energy and Buildings, 38, pp. 728-742.

GARNET, J., 2011. On the Cultural history of Nordic light and lighting. In: N. SØRENSEN and P.N. HAUG, eds, Nordic Light .Interpretations in architecture. First edn. Denmark: Nordlys committee, pp. 6-12.

GARNET, J., 1993. Anden i lampan - Etnologisk perspektiv på ljus och mörker. Stockholm: Carlsson Bokförlag. GIFFORD, R., 1988. Light, Decor, Arousal, comfort and communication. Journal of Environmental Psychology, 8, pp. 177-189.

GLIND, I.V.D., ROODE, S.D. and GOOSSENSEN, A., 2007. Do patients in hospitals benefit from single rooms? A litterature review. Healthy Policy, 8(84), pp. 153.

GOODMAN, T.M., 2009. Measurement and specification of lighting; a look at the future. Lighting Research Technology, (41), pp. 229-243.

GROAT, L. and WANG, D., 2002. Architectural Research methods. US: John Wiley \& Sons, Inc.

GURURA, H., MCDONALD, L.W. and DALKE, H., 2004. Background: An essential factor in colour harmony, 2004.

HANSEN, O., JØRGENSEN, S. and JØRSTIAN, T., 1994. Lysets kvalitet. In: T. JØRSTIAN and P.E.M. NIELSEN, eds, Tænd! PH lampens historie. København: Gyldendal, pp. 59-75.

HANSEN, O., JØRGENSEN, S. and JØRSTIAN, T., 1994. Tænd! Lampens historie. second edn. Denmark: Louis Poulsen.

HASTRUP, K., 2010. "Introduktion - Den antropologiske videnskab". "Introduktion - Den antropologiske videnskab”. DK: Hans Reitzels Forlag, .

HAWKES, J.R., LOE, D.L. and ROWLAND, E., 1979. A note towards the understanding of lighting quality. Journal of the Illuminating Engineering Society, 8(2), pp. 111-120. 
HEAVENS-ABOVE, , Latitude and Longitude Odense University Hospital. Available: http: / / www.heavens-above. com/LocationFrom GoogleMaps.aspx?lat=0\&lng $=0 \&$ loc $=$ Unspecified $\&$ alt $=0 \& \mathrm{tz}=\mathrm{CET}$.

HEIDEGGER, M., , Hermeneutic Cicle. Available: (http://en.wikipedia.org/wiki/Hermeneutic_circle).

HØJLUND, S., 2008. Man kan ikke se det udefra. Århus: Århus Universitets Forlag, .

HORNBY, A.S., TURNBULL, J., LEA, D., PARKINSON, D., PHILLIPS, P., FRANCIS, B., WEBB, S.W., BULL, V. and ASHBY, M., eds, 2010. Oxford Advanced Learner's Dictionary of current English. Eight edition edn. Oxford University Press.

HOUSER, K.W., 2003. Measuring the subjective response to interior lighting:paired comparisons and semantic differential scaling. Lighting Research Technology, $(35,3)$, pp. 183-198.

INGENIØREN, , Farvet lys er sundt for sygplejesker og patienter. Available: ing.dk/artikel/115581farvet-lys - er - sundt-for-sygeplejesker-og-pa tienter?itm_source $=$ feed $\&$ utm_medium $=$ rrs\&utm_ campaign=nyheder [17 january, 2011].

JANSENS, J., 2006. Lagom är bäsk - om belysning och färgsättning på kontor. In: K. FRIDELL, ed, Forskara och Praktiker om Ljus, Färg och seende. Stockholm: Formas, pp. 197.

JENSEN, T.K. and JOHNSEN, T.J., 2009. Forståelse og dømmekraft i mødet mellem borger og professionel. Sundhedsfremme i teori og praksis. 2. edn. Århus, Denmark: Forlaget Philosophia, pp. 15.

JENSEN, T.K. and JOHNSEN, T.J., 2009. Sundhed og sundhedsfremme. Sundhedsfremme i teori og praksis. Second edn. Århus, Denmark: Forlaget Philosophia, pp. 71 .

JOHANSSON, M. and LAIKE, T., 2007. Intention to Respond to Local Wind Turbines: The role of Attitudes and Visueal Perception. Wind Energy, 10, pp. 435-451.

JORDAN, P.W., 2000. Designing Pleasurable Products. 
Taylor and Francis Group.

JORDAN, P.W., 2000. The four pleasures. Designing Pleasurable Products - an introduction to the new human factor. London and Philidelphia: Taylor and Francis Group, pp. 11.

JÖRGENSEN, K.N., RÖMMA, V. and RUNDMO, T., 2009. Associations between ward atmosphere, patient satisfaction and outcome. Journal of Phsychiatric and mental Health Nurcing, 16, pp. 113-120.

KAPLAN, R., 1985. The analysis of perception via preferences: a strategy for studying how the environment is perceived. Landscape Planning, 12, pp. 161-176.

KAPLAN, S. and KAPLAN, R., 2009. Creating a larger role for environmental psychology: The Reasonable Person Model as an integrative framework. Journal of Environmental Psychology, 29, pp. 329-339.

KAPLAN, S. and KAPLAN, R., 2003. Health, supportive environments, and the Reasonable Person Model. American Journal of Public Health, 93(9), pp. 1489.

KARLSSON, B.S.A., ARONSSON, N. and SVENSSON, K.A., 2003. Using Semantic Environment Descripsion as a tool to evaluate car interiors. Ergonomics, 46(13/14), pp. 1408-1422.

KLAREN, U., 2012. Natural Experiences and Physical Abstractions - On epistomology of Light and colour.

KNEZ, I., 2001. Effects of colour of light on nonvisual Psychological processes. Journal of environmental Psychology, (21), pp. 201-208.

KNEZ, I. and ENMARKER, I., 1998. Effects of Office Lighting on mood and Cognitive Performance And A Gender Effect on Work-xRelated Judgement. , pp. 553.

KNEZ, I. and KERS, C., 2000. Effect of indoor lighting, GEnder, and Age on Mood and Cognitive Performance. Environment and Behavior, 32(6), pp. 817-831.

KÜLLER, R., 2006. Färg, Ljus och Menniska - et 
miljøpsykologisk perspektiv. In: K. FRIDELL, ed, Forskara och Praktiker om Färg, Ljus och seende, Stockholm: Formas, pp. 185.

KÜLLER, R., BALLAL, S., LAIKE, T., MIKELLIDES, B. and TONELLO, G., 2006. The impact of light and colour on psychological mood: a cross-cultural study of indoor work environemt. Ergonomics, 49(14), pp. 1496-1507.

KÜLLER, R., 1991. Environmental Assesment from a Neuropsychiatrical perspective. In:T. GÄRLING and G.W. EVANS, eds, Environment, Cognition, and Action: An integrated approach. New York: Oxford University Press, pp. $111-147$.

KÜLLER, R., 1975. Semantisk miljöbeskrivning (SMB). Stockholm: Psykologiförlaget.

KÜLLER, R., 1972. A semantic model for describing perceived environment. [Stockholm]: Rotobeckman.

KVALE, S., 2009. Interview, - en introduktion til det kvalitative forskningsinterview. Interview -- en introduktion til det kvalitative forskningsinterview. Hans Reitzels forlag, .

LAIKE, T., 1997. The impact of daycare environments on children's mood and behavior. Scandinavian Journal of Psychology, 38, pp. 209-218.

LAMBERT, J.M., 2003. Martin Heidegger Kunstværkets oprindelse. Moderne Tænkere. Gyldendal, pp. 20-46.

LANG, S., 2003. good Lighting for Healthcare Buildings. Technology \& services, Business Briefing: Hospital Engineering \& FAcilities Mangement, .

LESLIE, R. and CONWAY, K.M., 1996. The Lighting Pattern Book for Homes. Rensselaer Polytechnic Institute, Troy, New York: McGraw-Hill.

LILJEFORS, A., 2004. Ljus och färg i seendets rum. Forskere og praktikere om Färg Ljus Rum. 1. edn. Stockholm: Kunsdtjänst Formas, pp. 220-240.

LILJENFORS, A., 1999. Lighting - Visually and Phusically 
(V/P Lighting Theory Basic lighting Knowledge). priliminary rev 05 edn. Stockholm: Anders Liljenfors, Lighting Department School of Architecture, KTH.

LIU, Y. and JANG, S., 2009. The effect of dining atmospheric: An extended Mehrabian-Russell model. International Journal of Hospitality Management, (28), pp. 494-503.

LOE, D.L. and ROWLANDS, E., 1996. The art and science of lighting: A strategy for lighting design. Lighting Research Technology, 28, pp. 153-164.

LOE, D. and PERRY, M., 2000. Hospital in the best light: an introduction to hospital lighting. IP 14/00. United Kingdom: BRE.

LOGADÓTTIR, A. and CHRISTOFFERSEN, J., 2008. Individual dynamic lighting control in a daylit space, , 17.-22. august 2008, Denmark 2008.

LORENZ, S.G., 2007. The Potential of the Patient Room to Promote Healing and Well-being in Patients and Nurses. An integrative Review of Research. Holistic Nursing practice, .

LUC 11, 3., Bible.

LUND, N., 2008. 3. Den danske tradition. In: N. 'LUND, ed, Nordisk Arkitektur. 3. edn. København: Arkitektens forlag, pp. 56-86.

MADSEN, M., 2002. Lysrum - som begreb of redskab. København: Kunstakademiets arkitektskole.

MADSEN, M., ,

Light-zone(s): as Concept and Tool. Available: http:// www. thedaylightsite.com / filebank/Light-zones\%20 as\%20Concept\%20and\%20Tool\%20_EAAE\%20paper. pdf [03.07, 2011].

MALKIN, J., 2008. A visual reference for evidence-based design. Concord, CA: Center for Health Design.

MALNAR, J.M. and VODVARKA, F., 2004. The light fantastic. Sensory Design. Minnasota: University of Minna- 
sota Press, pp. 199.

MARPILLERO, S., 2006. James Carpenter - Environmental refractions. Basel: Birkhäuser- Publishers for Architecture, P.O. Box 1333, CH-4010 Basel, Switzerland, Part of Springer Science+Business Media.

MARTINY, K., 2006. Vinterdepressioner. Lys, (1), .

MCCLUGHAN, C.L.B., ASPINALL, P.A. and WEBB, R.S., 1999. The impact of lighting on mood. Lighting Research Technology, 7(31), pp. 88 .

MILLET, M.S., 1996. Light Revealing Architecture. New Jersey: John Wiley \& Sons Inc.

MILLONIG, A. and GARTNER, G., 2008. Exploring Human Spatio-Temporal Behaviour Patterns. The cartogrphy and Geographic Information Society, , pp. 1.12.

MILLONIG, A. and SCHECHTNER, K., 2005. Developing Landmark-based Pedestrian Navigation Systems, Proceedings of the 8th International IEEE Conference on Intelligent Transportation Systems Vienna, Austria 2005, pp. 197-201.

MOEN, V., , Helsingor Psychiatric hospital by JDS architects. Available: http: / / www.dailytonic.com/psychiatrichospital-in-helsingor-denmark-by-jds-architects-dk/ .

MØLlER, M., 2006. Døgnrytmer. Lys, (1), pp. 20.

MOOS, R., 1974. Ward Atmosphere Scale, Manual, Test Booklets and Scoring Key.

MOOS, R., SHELTON, R. and PETTY, C., 1973. Perceived ward climate and treatment outcome. Journal of Abnormal Psychology, 82(2), pp. 291-298.

MULLINS, M., 2009. Helende Arkitektur - Healing Architecture.

NEWSHAM, G.R., RICHARDSON, C., BLANCHET, C. and VEITCH, J.A., 2005. Lighting quality research using rendered images of offices. Lighting Research Technology, 22(37,2), pp. 93. 
NICKL-WELLER, C. and NICKL, H., 2009. Masterpiecs Hospital Architecture + Deisgn. Braun Publishing AG.

NØRGAARD, H., 2010. Interview with staff. Odense Univesity Hospital: .

Osgood EC; Suci GJ \& Tannenbaum PH (1957). The measurement of meaning. Urbana,

University of Illinois Press.

OUH, Patient information. Odense Universitets hospital.

PAE, J.Y., 2009. The effect of hotel guest room lighting on consumers emotional states, preferences and behavioral intentions. master of interior design, The graduate school edn. University of Florida: University of Florida.

PALLASMA, J., 2005. The eyes of the skin - architecture and the Senses. England: John Wiley \& Sons Ltd.

PALLASMA, J., , Identity, Intimacy and Domicile. Notes on the phenomenology of home. Available: www.2.uiah. fi/opintoasiat/history2/e_ident.htm 3 november 2007].

PHILIPS LIGHTING, , Adaptive Healing Room. Available: http: / / www.pdesigni.com/news / show / 3032 [25.08.2012, .

PHILIPS LIGHTING, Dynamic Lighting. Available: http: / / www.lighting.philips.com/main/lightcommunity/trends/dynamic_lighting/index.wpd.

PHILIPS LIGHTING, , Healwell. Available: http: / /www. lighting.philips.co.uk/application_areas/healthcare/healwell.wpd [25.08.2012, .

PHILIPS LIGHTING, Light and atmosphere - Discover the secrets of Home Lighting. Philips.

PSYCHOLOGY.UCDAVIS.EDU, , Scaling: Semantic Differential. Available: http: / / psychology.ucdavis.edu/sommerb/sommerdemo/scaling/semdiff.htm.

QUARTIER, K. and VAN CLEEMPOEL, K., 2008. The influence of lighting in the build environment: a study 
to analyse human behavior and perception as measured by mood and observation. , 26-29. aug, 2008 2008, pp. 367-369.

QUARTIER, K., VANRIE, J. and CLEEMPOEL, K.V., 2010. Atmospheric lighting in supermarkets, 2nd CIE Expert Symposium on Appearance - "When appearance meets lighting” 2010, pp. 126-128.

RASHID, M. and ZIMRING, C., 2008. A Review of the Empirical Literature on the relationships Between Indoor Environment and Stress in Health Care and Office Settings: Problems and Prospects of Sharing Evidence. Environment and Behavior, 40(151), pp. 151.

RASMUSSEN, E. and ØSTERGAARD, P., 2009. Samfundsvidenskabelige metoder - En introduktion. 2 edn. Odense M: Authors and Syddansk Universitetsforlag.

RASMUSSEN, S.E., 1957. Om at opleve arkitektur. Denmark: Fonden til udgivelse af arkitekturværker Arkitektskolen Aarhus.

RASMUSSEN, T.H., 1996. Kroppens Filosofi Maurice Merleau-Ponty. 1. edn. Copenhagen: Semi-Forlaget.

REA, M.S., Light - Much More Than Vision.

REA, M., 2006. A Second Kind of Light. OPN, .

REGION SYDDANMARK., , Sengestuen.

ROBSON, C., 2011. Real World Research. third edn. United Kingdom: John Wiley \& Sons Ltd.

ROSSBERG, J.I. and FRIIS, S., 2004. Patient's and Staff's Perception of the Psychiatric Ward Environment.

ROWLANDS, J. and NOBLE, S., 2008. How does the environment impact on the quality of life of advanced cancer patients? A qualitative study with implications for ward design. Palliative Medicine, 6(22), pp. 768.

RUBOW, C., 2010. Samtalen - interviewet som deltagerobservation. Ind i verden.

RUSSEL, B., H., 1995. Research Methods in Anthropol- 
ogy. Qualitative and Quantitative Approaches. AltaMira Press.

RYBAKKEN, D., , Lighting artist. Available: http: / / www. danielrybakken.com/Daniel_Rybakken.html27.09.2012].

SANDSTRÖM, M., BERGQUIST, U., KÜLLER, R., LAIKE, T., OTTOSON, A. and WIBOM, R., 2002. Belysning och Hälse - en kundskapöversikt med fokus på ljusets modulation, spektralfördelning och dess kronobiologiska betydelse. :4. Arbetslivsinstitutet.

SCHIVELBUSCH, W., 1995. Disenchanted Night - the industrialization of light in the nineteenth century. Wolfgang Schivelbusch and The University of California Press 1988.

SCHÖN, D.A., 2009. Den reflekterende praktiker, hvordan professionelle tænker, når de arbejder. 1. udgave 4 . oplag edn. Århus: Forlaget Klim.

SEEBERG, J., 2009. Forsknings kvalitative fundament. Tidskrift for Forskning i Sygdom og Samfund, 10: Metodologi, pp. 17.

SELMER, B., 1998. Overvejelser om gyldighed og etnografisk metode. Afdeling for Etnografi og Socialantropologi, Aarhus Universitet.

SIMONSEN, A.K., 2010. Indendørs sporing wha RFIDteknologi. Aalborg: Aalborg University.

SIMPSON, M., 2004. Modern Lighting for Today's Healthcare. Official journal of the Institution of Lighting Engineers, 4, pp. 16.

SOMMER, R. and SOMMER, B., 2002. Behavioral Reasearch Tools and Techniqes. New York Oxford: Oxford University press.

SOMMER, B. and SOMMER, R., 1997. Multimethod Approach. A practical Guide to BEhavioral Research - Tools and Techniques. fourth edn. Oxford, UK: Oxford University Press', pp. 1-7.

SØRENSEN, A.H., Beskidte Tanker. , pp. 117. 
SØRENSEN, N. and HAUG, P.N., eds, 2011. Nordic Light - Interpretations in architecture. first edn. Denmark: Nordlys committee.

STAMPS, A.E., LLL., 2007. Mystery of Environmental Mystery: Effects of Light, Occlusion, and Depth of View. Environment and Behavior, 166-197(36), pp. 166.

STIDSEN, L., KIRKEGAARD, P.H. and FISKER, A.M., 2010. Design proposal for pleasurable light atmosphere in hospital wards, , 11-12. nov 2010 2010, Knemesi, pp. 366.

STIDSEN, L., KIRKEGAARD, P.H. and FISKER, A.M., 2010. DESIGN PARAMTERES FOR EVALUATING LIGHT SETTINGS AND LIGHT ATMOSPHERE IN HOSPITAL WARDS, 2nd CIE Expert Symposium on Appearance, When Appearance meets Lighting, 8-10 okt. 2010 2010, Ibe-Biv, pp. 136.

STIDSEN, L., BJERRUM, H.S., KIRKEGAARD, P.H., THUESEN, N. and FISKER, A.M., 2011. Patients Light Preferences in Hospital Wards - relatet to Light Atmosphere in Danish Homes. , may 2011 2011, Witt Press, pp. 211-223.

STIDSEN, L., KIRKEGAARD, P.H., FISKER, A.M. and JENSEN, R., 2009. Lighting Quality in Wards - Design Parameters for a Pleasurable Light Atmosphere. Y.A. DE KORT W., W.A. IJSSELSTEIJN, I.M.L.C. VOGELS, M.P.J. AARTS, A.D. TENNER and K.C.H.J. SMOLDERS, eds. In: Adjunkt proceedings. Experiencing Light 2009, International conference on the Effect of Light on Wellbeing, 26-27 Okt 2009, pp. 31.

STIDSEN, L.M., KIRKEGAARD, P.H. and THUESEN, N., 2012_A. Mapping Light Atmosphere - seen through the Danish interior magazine BO BEDRE.

STIDSEN, L.M., KIRKEGAARD, P.H. and BJERRUM, H., 2012_B. On Lighting of Hospital Wards - A cultural approach using light preferences as inspiration for the deisng concept.

STIDSEN, L.M., KIRKEGAARD, P.H. and LAIKE, T., 2012_C. Experiencing Hospital Ward Lighting - Using Semantic Environmental Description (SMB-method). 
STUHLMILLER, C.M., 1998. Understanding Seasonal Affective Disorder and Experiences in Northern Norway. Journal of Nursing Scholarship, 30(2), pp. 151-156.

SUENSON, V., HARDER, H., TRADISAUSKAS, N., SIMONSEN, A.K. and KNUDSTRUP, M., 2010. Walking the library. Aalborg: Aalborg University.

SYGEHUS LILLEBÆLT, Helbredende lys på Intensiv. Available: www.sygehuslillebaelt.dk/wm334761 [01 december, 2011].

THE DANISH ILLUMINATION ENGINEERING SOCIETY, 2004. Right Light in the home.

THE SOCIETY OF LIGHT AND LIGHTING, 2008. Lighting Guide 2: Hospitals and health care buildings. London: CIBSE.

THUESEN, N., STIDSEN, L., KIRKEGAARD, P.H., HARDER, V. and SUENSON, V., 2011. Optimizing lighting design for hospital wards by defining user zones, $\mathrm{K}$. DOMKE and C.A. BREBBIA, eds. In: Light in Engineering Architecture and the Environment, 2011 2011, Witt Press, pp. 199-211.

TREGENZA, P. and LOE, D., 2009. The design of lighting. 2. editopn edn. 2 Park Square, Milton Park, Abingdon, Oxon, OX14 4RN: Taylor \& Francis, Taylor and Francis group,.

TURRELL, J., 1999. James Turrell the othter horizon. Wien: MAK- Österreichisches Museum für angewandte Kunst.

ULRICH, R.S., 1983. View Through a Window May Influence Recovery from Surgery. Science, 224, pp. 420.

ULRICH, R.S. and ZIMRING, C., 2008. A Review of the Research Literature on Evidence-Based Healthcare Design. Health Environment Research \& Design Journal, 1(3), pp. 101-165.

ULRICH, R. and ZIMRING, C., 2004. The Role of the Physical Environment in the Hospital of the 21st Century: A Once-in-a-Lifetime Opportunity. The Center for Health Design. 
VALBERG, A., 2012. Perception of Light and Colour.

VEITCH, J.A., 2008. Investigation and Influencing How Buildings Affect Health: Interdisciplinary Endeavours.

VEITCH, J.A., 2001. Psychological Prosesses Influencing Lighting Quality. Journal of the Illuminating Engineering Society, 16(30), pp. 124.

VEITCH, J.A. and GIFFORD, R., 1996. Assessing Beliefs about Lighting Effects on Health, Performance, Mood, and Social Behavior. Environment and Behavior, 28 no. 4, pp. 446.

VEITCH, J.A. and NEWSHAM, G.R., 1998. Determinatns of Lighting Quality I: State of science. , 19971998.

VEITCH, J., 2006. Lighting for Well-being: a revolution in lighting, 2nd CIE Expert Symposium on Lighitng and Health 2006.

VEITCH, J., 2004. What's new in lighting research? The broad view, , April 1-3 2004, National Research Council of Canada Institute for Research in Construction.

VIJK, H., 2012. Nordic Light and colour in health care environment.

VIJK, H., 2006. Färg som stöd och stimulans in vårdmiljön. In: K.F. ANTER, ed, Forskere och praktiker om färg ljus rum. Stockholm: Forskningsrådet för miljö, areella näringar och samhällsbyggande, Formas, pp. 213-228.

VOGELS, I., Atmosphere Metrics: a tool to quantify perceived atmpsphere. Paper edn. Philips Research Europe, High Tech Campus, Eindhoven.: .

VOLF, C., 2010. Light and the Aesthetics of the Perception, NSE 2010 -Envoronment, Aesthetics and the Art. Annual Conferences of the Nordic Society for Aesthetics. 2010 .

WADEL, C., 1991. Feltarbeid i egen kultur. Flekkefjord: Hegland Trykkeri A/S. 
WIKIPEDIA, , Atmosphere (architectural and spatial design). Available: http: / / en.wikipedia.org/wiki / Atmosphere_(architecture_and_spatial_design) [09.02, 2012].

WIKIPEDIA, , Likert Scaling.

WIKIPEDIA, , Odense Universitets sygehus. Available: http: / / da.wikipedia.org/wiki/Odense_Universitetshospital [10.10, 2012].

WIKIPEDIA., , Hermeneutic Circle. Available: http:// en.wikipedia.org/wiki/Hermeneutic_circle25.08.2012].

WIKIPEDIA., , Jevndøgn. Available: http:/ / no. wikipedia. org/wiki/Jevndøgn.

WINTHER, I.W., 2007. Hjemlighed - kulturfænomenologiske studier. Dansk Sociologi, 19(4), pp. 132.

WINTHER, I.W., 2006. Hjemlighed - Kulturfænomenologiske studier. København: Danmarks Pædagogiske Universitet.

WOTTON, E., 1986. Daylight and windows in hospital wards. Lighting Design + Application, .

ZIMRING, C. and BOSCH, S., 2008. Buliding the Evidence Base for Evidence-Based Design; Editors' introduction. Environment and Behavior, (40), pp. 147.

ZUMTHOR, P., 2008. Peter Zumthor Therme Vals. second edn. Zurich: Verlag Scheidegger \& Spoess AG.

ZUMTHOR, P., 2006. Atmospheres - Architectural Environments - Surrounding objects. Birkhäuser- Publishers for Architecture, P.O. Box 1333, CH-4010 Basel, Switzerland, Part of Springer Science+Business Media.

ZUMTHOR, P., 2006. Thinking architecture. 2.edition (expanded) edn. P.O. Box 1333, CH-4010 Basel, Switzerland, Part of Springer Science+Business Media: Birkhäuser- Publishers for Architecture,

ZUMTOBEL, 2004-last update, The Lighting Handbook [Homepage of www.Zumtobel.com], [Online]. Available: 1 st. 



\subsection{APPENDIX}

Letter to informants

(In danish) 


\section{LYS OG TRIVSEL \\ En phd. undersøgelse omkring brug af lys}

Er du i pensionsalderen eller ældre, og vil du hjælpe os i en undersøgelse omkring brug af lys i hverdagen, så vil vi meget gerne interviewe dig.

\section{Målet}

Interviewet skal bidrage til et phd projekt, der skal forbedre kunstlyset på fremtidens hospitaler. Her er der et ønske om at skabe en mere behagelig atmosfære på sengestuerne og opnå en mere privathed som patient. Der er tegn på, at lyset påvirker sengestuens atmosfære og oplevelsen af sengestuen i forskellige hverdagssituationer. Derfor har vi brug for information om, hvordan vi bruger lys i hverdagen derhjemme, hvor vi er private. Disse informationer kan så bruges som inspiration til et lysdesign, der skal testes på Odense Universitets Hospital.

\section{Ingen forkundskaber:}

Lys er et forholdsvist svært emne at tale om. Vi bruger lys på forskellig vis, og mange gange indretter vi os intuitivt uden præcist at vide hvorfor. Det, vi alle har til fælles, er, at vi bruger lamper og vinduer som lyskilder i vores bolig. Man skal ikke have en speciel viden om lys for at deltage i projektet, og man skal heller ikke have en speciel viden om design, eller kunne begrunde hvorfor man bruger lys som man gør. Vi vil bare gerne se og høre, hvor du har lyset tændt, når du laver forskellige ting.
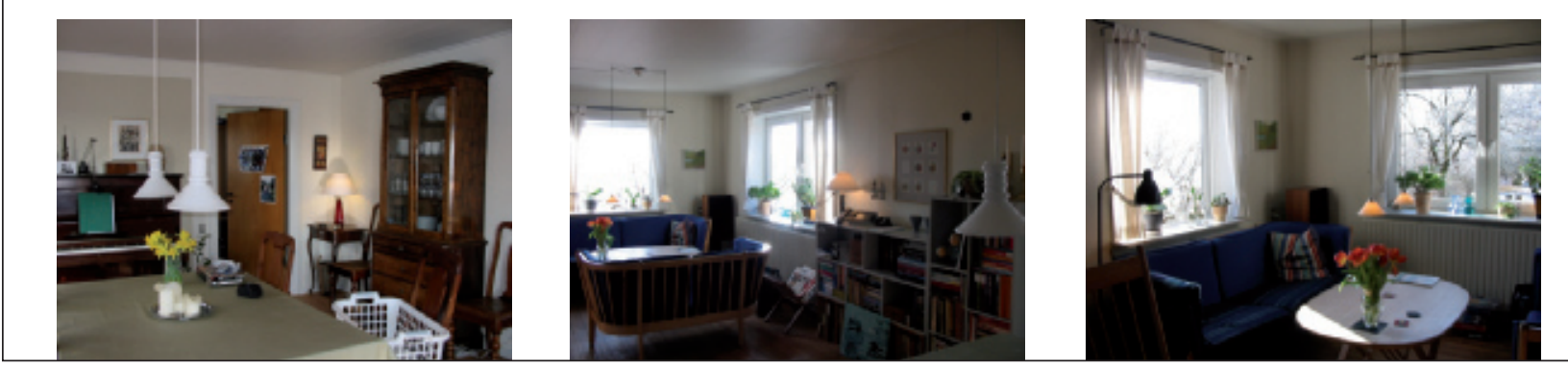
For at deltage kræver det altså kun, at du er interesseret i at vise os, hvordan du bor med lys og i ord og billeder være med i undersøgelsen om, hvordan man bruger lys i hverdagen.

Nederst på siden kan du se nogle billeder fra et test interview.

\section{Det, du siger ja til,}

er, at vi sender dig et engangskamera og flere informationer, der kan guide dig gennem processen.

\section{I hovedtræk vil vi bede dig om at}

- tage billeder af, hvor du har placeret dine lamper i din bolig

- sende filmen til os (i en vedlagt frankeret svarkuvert)

- blive interviewet i din bolig

Vil du hjælpe os? Så ring eller skriv til os.

Med venlig hilsen

\section{Lone Stidsen}

Phd. Studerende, Lysdesign, AAU

Tlf: 31237008

E-mail: Is@civil.aau.dk
Henriette Bjerrum

Antropolog

forskningsassistent AAU

TIf.: 51391373

E-mail: henriettes@privat.dk
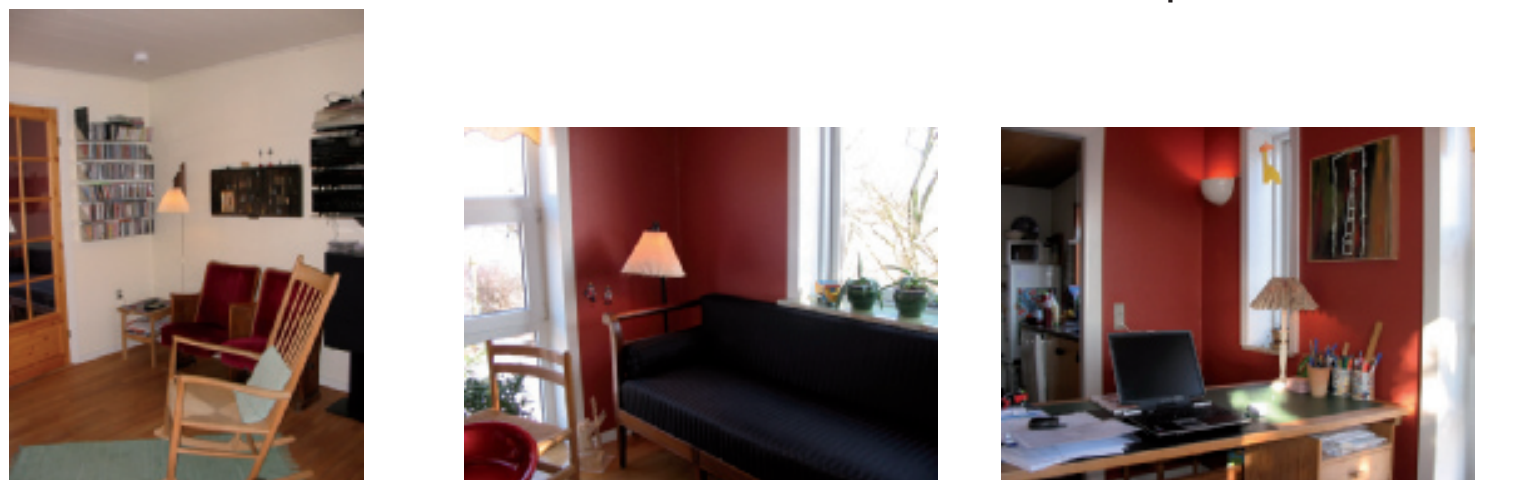



\section{BO BEDRE ANALYSIS CHART}

\section{LIGHT APPEARANCE}

\section{'Intensity'}

The estimation is based on a general impression on artificial light level in the room ranked on a scale from 1 to 5, where

1)Dim light level

2)Dim lighting with an focus on some parts of the space

3)Enough light to see all the space without seeing details

4) Enough light to see many details in the space

5) Too bright and uncomfortable to be in the space

\section{'Light Distribution'}

The light distribution in the space is ranked on a 5 points scale going from

1) One small defined light zone illuminated by spots

2)Two or three small defined light zones illuminated by spots

3) A varied light distribution with light shaded illumination, comparable with Le Klint folded lampshades

4) Many light zones merges and many types of luminaires are distributing the light almost uniform

5) Uniform light distribution where all light zone merges and the light are distributed from many places in the ceiling.

\section{'Daylight contribution'}

The contribution on daylight in the space is important for the use of artificial light. In dark rooms with only a little daylight access, the artificial light gets more important. The daylight contribution is ranked on five points scale going from

1) No windows and only a small daylight contribution reflecting from other rooms

2) Small windows with only a small daylight contribution

3) Light distribution from windows comparable with traditional Danish windows the Dannebrog window

4) Larger windows with contributing with a lot of daylight

5) Window facades or Garden rooms contributing with daylight from all sides.
Fig 8.1

Photo from Bo Bedre Magasines representing Dim light level (1 on the scale)

Fig 8.2

Photo from Bo Bedre Magasines representing too brigh level (5 on the scale).

Fig 8.3 Photo from Bo Bedre Magasines representing One small defined light zone illuminated by spots ( 1 on the scale)

Fig 8.4

Photo from Bo Bedre Magasines representing uniform light distribution where all light zone merges and the light are distributed from many places in the ceiling (5 on the scale).

Fig 8.5

Photo from Bo Bedre Magasines representing: No windows and only a small daylight contribution reflecting from other rooms (1 on the scale)

Fig 8.6

Photo from Bo Bedre Magasines representing window facades or Garden rooms contributing with daylight from all sides. (5 on the scale) 
8.1

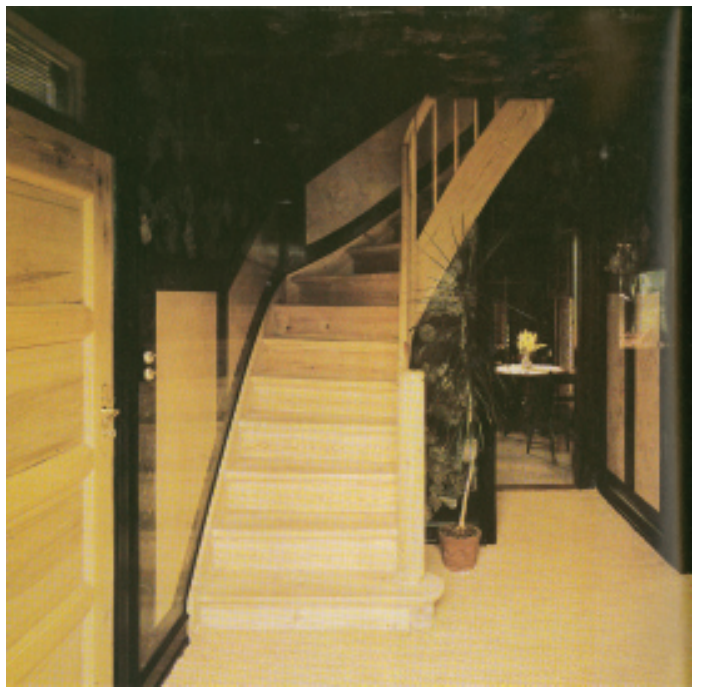

8.3

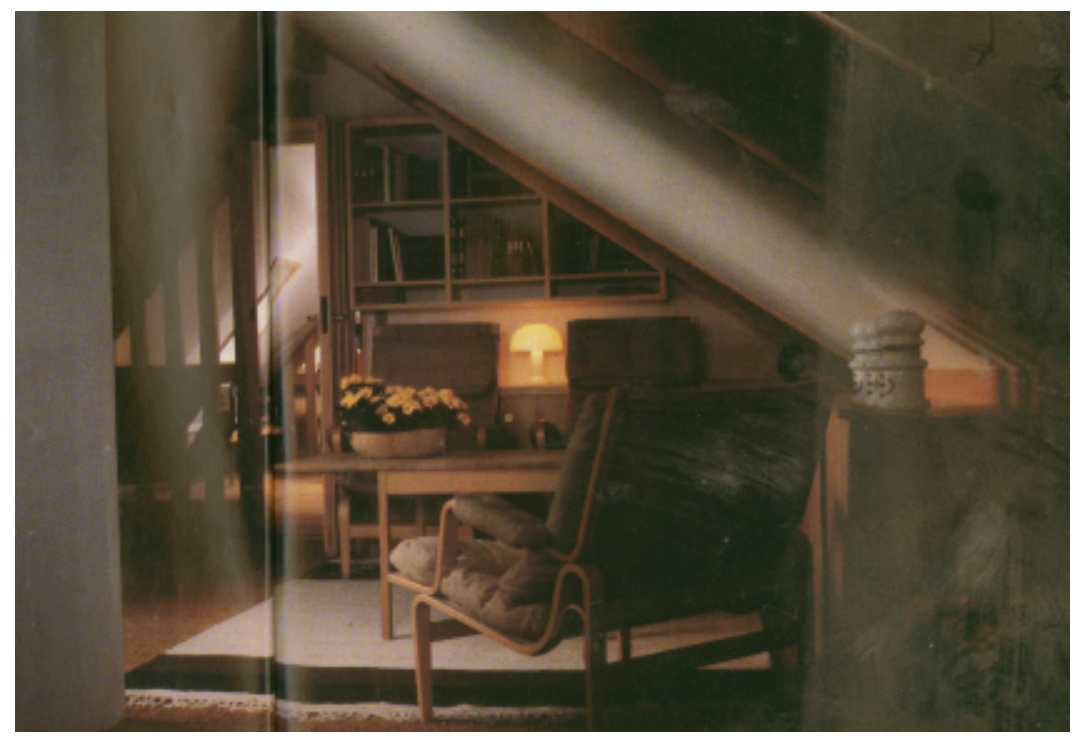

8.5

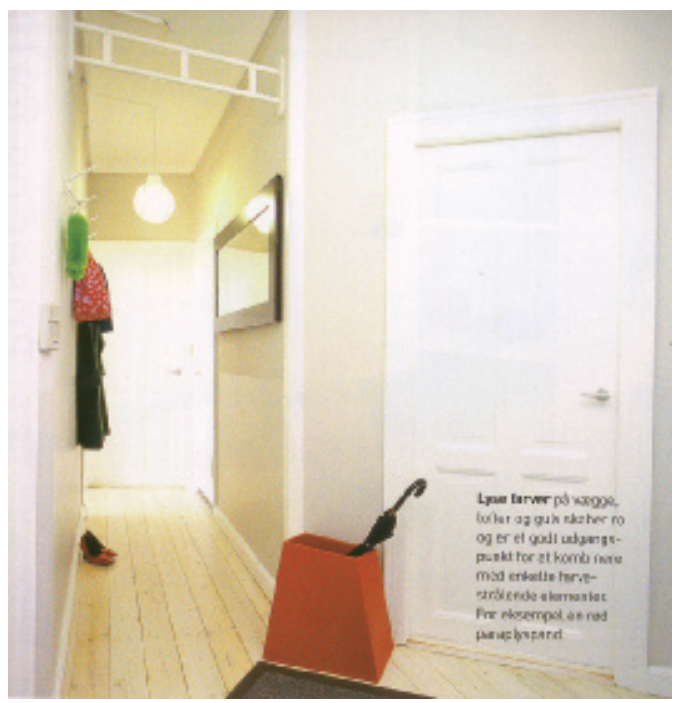

8.2

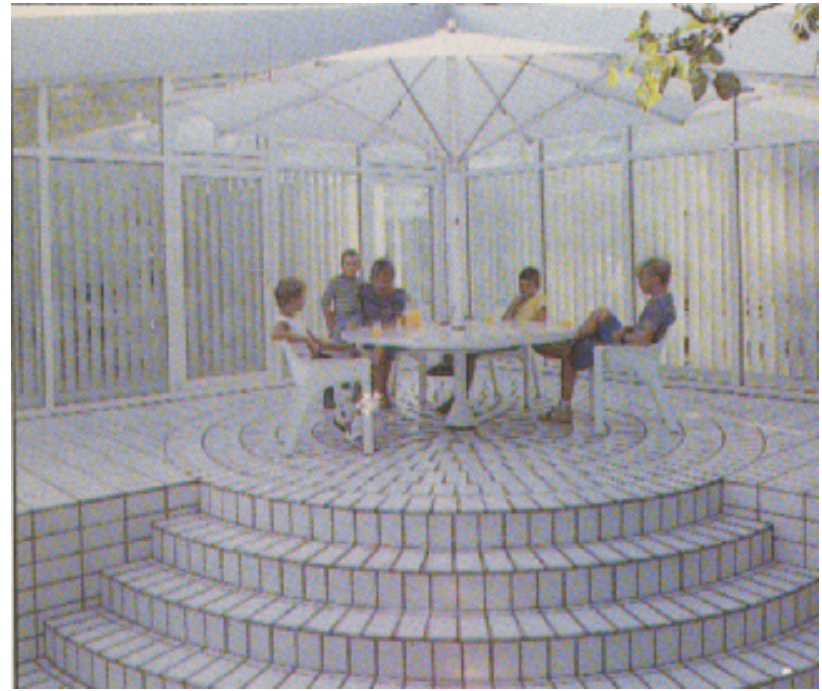

8.4

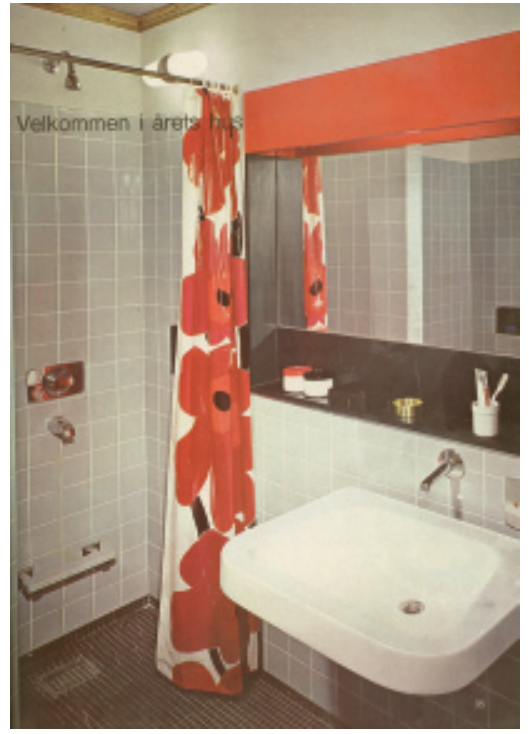

8.6

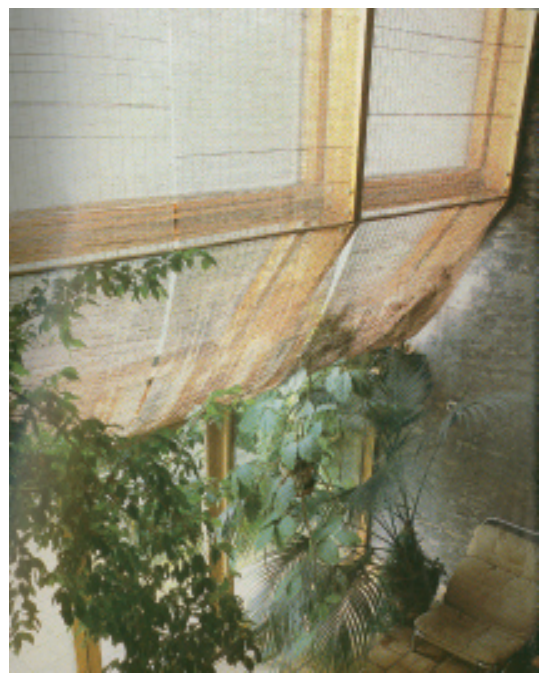

APPENDIX 2 


\section{SPACE APPEARANCE}

\section{'Visual temperature'}

The visual temperature of the space is based a general impression of the space and a combination of several parameters as warm or cold colors, amount of material as steel or soft wool, the shape of objects in the room as hard glass table top or a soft woolen sofa.

The scale is going from:

1) Cold colors, hard and angular materials, shapes of objects and plane surfaces

2) Cold colors, softer shapes of objects and some structures and non reflective materials

3) Neutral colors soft shapes of objects, varied types of textures and surfaces

4) Focus on the different textures in the interior and less focus on plane surfaces. Soft shapes of objects and neutral to warm colors in the interior design

5) Warm colors, soft shapes, surfaces with heavy textures and many different materials are used.

\section{'Spatial composition'}

The spatial composition of a space is also interesting to study, because it has an impact of the experience if it gives the expression of being enclosed or open in access. Time to read the signals in the space. The definitions of the 5-point ranking are:

1) An huge open space with simple furnishing and simple shape of the room

2) Simple furnishing and shapes in a smaller space

3) Enough furniture in a space to give an expression of being balanced interior design and not minimalistic.

4) Relative compact furnishing with complicated shapes and decoration

5) Enclosing space with a overloaded furnishing

\section{LUMINAIRE EFFECT}

\section{'Shadow effect'}

The shadow effect of the luminaire is showing how the transition from light to shadow appears. The 5 points ranking is defined as:

1) The transition from light to dark do not exist illumination coming from an unshielded luminaire.
Fig 8.7

Photo from Bo Bedre Magasines representing: Cold colors, hard and angular materials, shapes of objects and plane surfaces ( 1 on the scale)

Fig 8.8

Photo from Bo Bedre Magasines representing warm colors, soft shapes, surfaces with heavy textures and many different materials are used ( 5 on the scale).

Fig 8.9

Photo from Bo Bedre Magasines representing: A huge open space with simple furnishing and simple shape of the room (1 on the scale)

Fig 8.10

Photo from Bo Bedre Magasines representing enclosing space with a overloaded furnishing (5 on the scale).

Fig 8.11

Photo from Bo Bedre Magasines representing: The transition from light to dark do not exist illumination coming from an unshielded luminaire (1 on the scale).

Fig 8.12

Photo from Bo Bedre Magasines representing clear demarcation between light and dark ( 5 on the scale). 
8.7

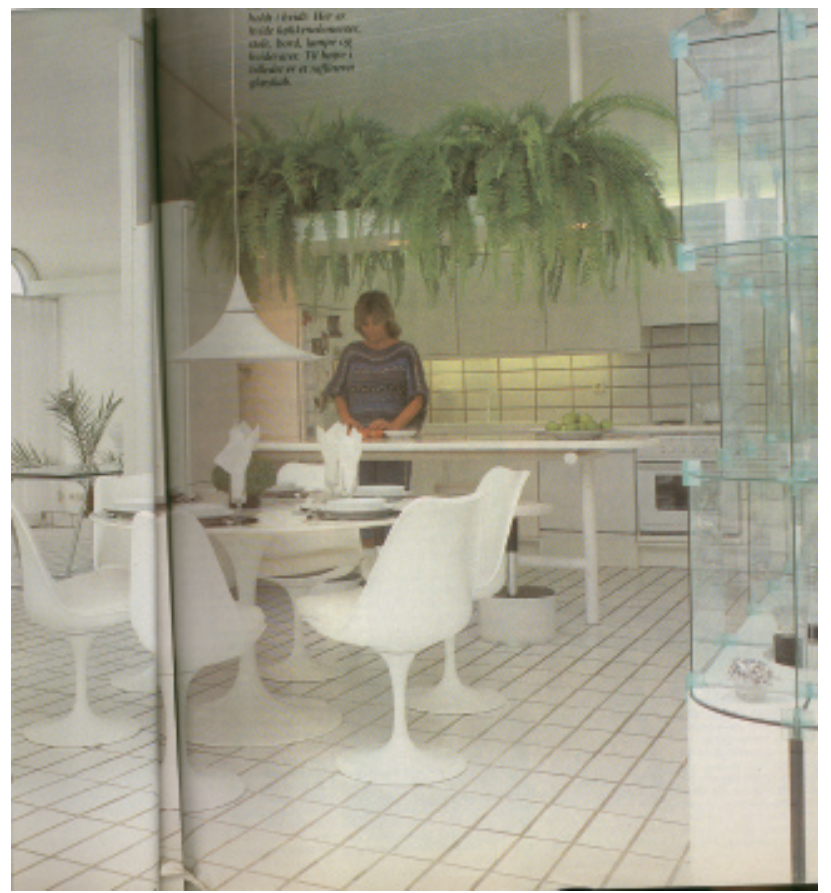

8.9

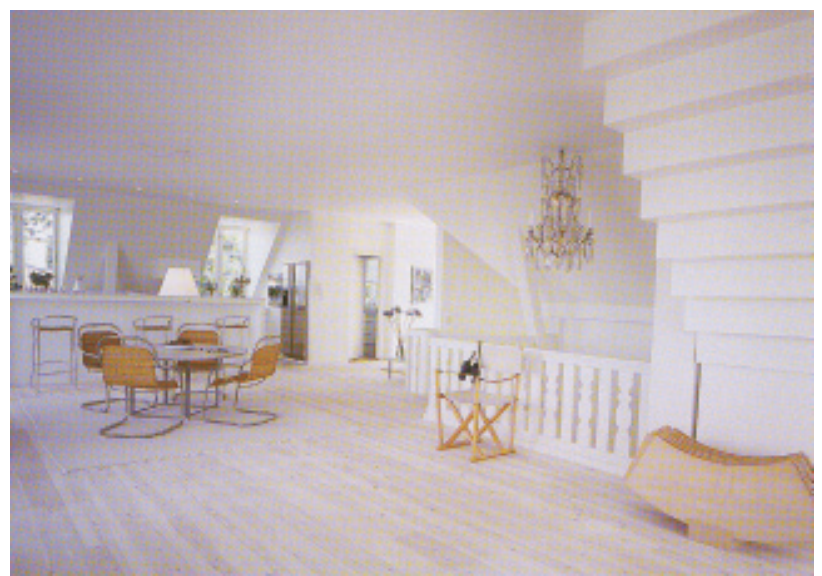

8.11

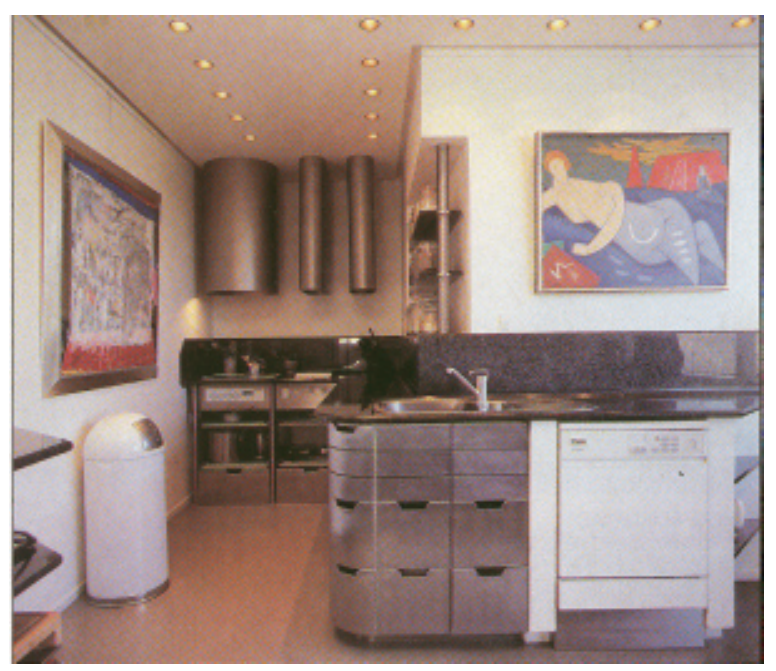

8.8

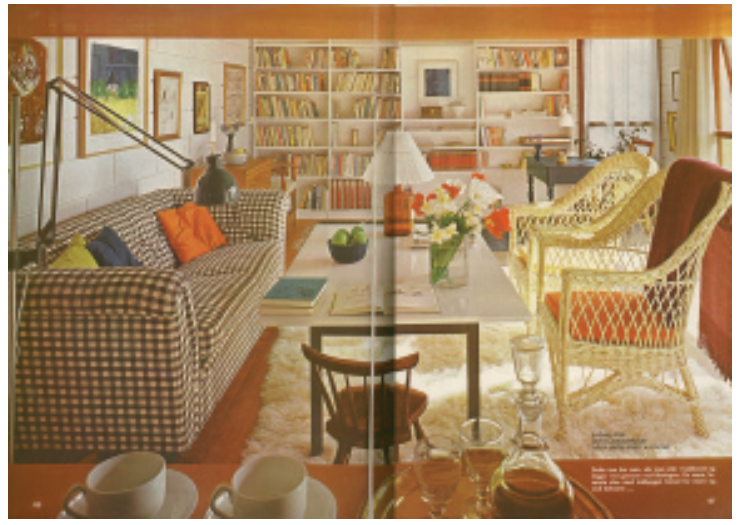

8.10

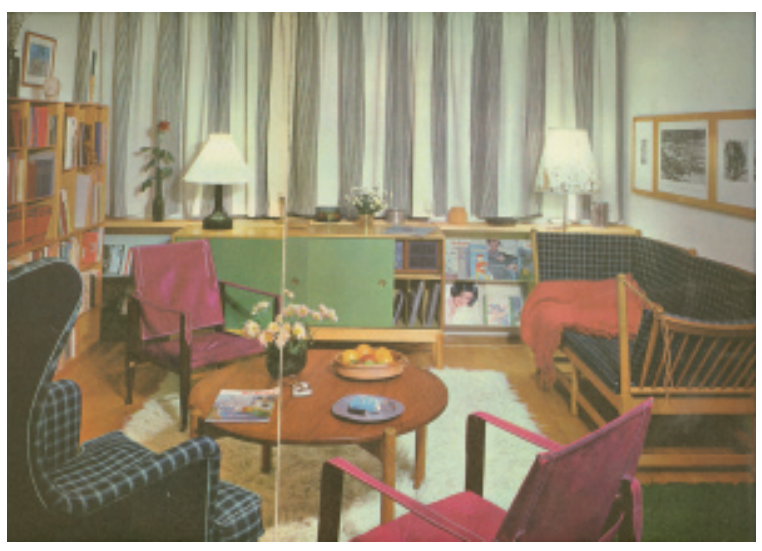

8.12

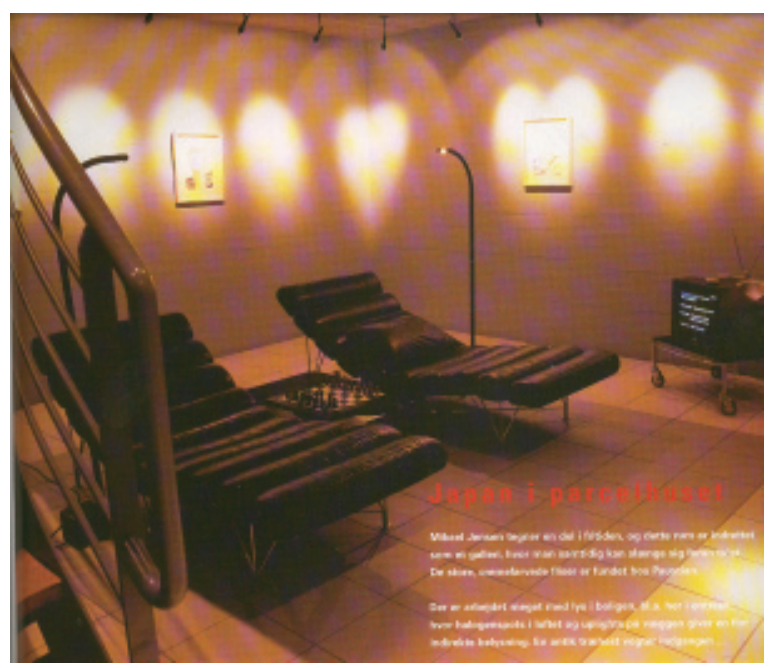


2)The transition from light to dark can be observed, ut there are only a week change in intensity

3) Perceptible shadow transition

4) Perceptible and sharper transition between light and dark

5) Clear demarcation between light and dark

\section{'Design focus'}

Reading BO BEDRE as a trend magazine the focus on the design of the lamp will always have a focus. Through the data collection we found some consistently used design objects that cam be termed as Danish classic design lamps. An example could be the PH 5 designed by Poul Henningsen or Le Klint 1 designed by Tage Klint. These designs have been displayed in the magazine consistently through the 50 years. The definition of focus on design is not a matter of classicality or who the designers are but a matter of how the focus on the lamp is. Is the lamp a design taking focus in the picture or is it more neutral design and the furniture or the space taking the focus. The 5 points scale goes from:

1) The design is invisible and the lamp is integrated in walls or ceilings and the focus are on the function not the aesthetics

2) The design is not impor tant but visible. The function is in focus and the aesthetics not important.

3) Equal focus on the function and the aesthetics of the lamp.

4) The design and the aesthetic impression of the lamp are important and visible. The lamp are noticed and a significant part of the overall impression. The function is giving light, but not so important in which way the light is distributed.

5) The lamp is an aesthetic object and important for the impression of the space. The function is almost unimportant.

\section{'Lighting technique'}

The definition of lighting technique are split into 6 categories defined as:

1) Downlight

2) Mainly downlight

3) Uniform light

4) Up- and downlight

5) Mainly uplight

6) Uplight 


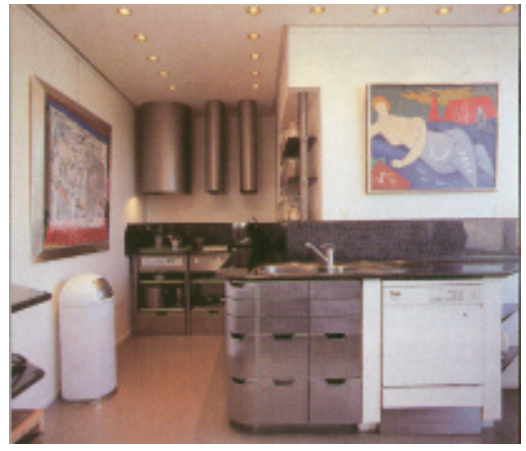

Fig. 8.13

Photo from Bo Bedre Magasines representing: The design is invisible and the lamp is integrated in walls or ceilings and the focus are on the function not the aesthetics (1 on the scale).

Fig. 8.14

Photo from Bo Bedre Magasines representing: the lamp is an aesthetic object and important for the impression of the space. The function is almost unimportant ( 5 on the scale).

Fig. 8.15

Illustrates lighting techniques. illustration by Silla Herbst www. lysviden.dk
1) Downlight
2) Mainly downlight
3) Uniform light
4) Up- and downlight
5) Mainly uplight
6) Uplight

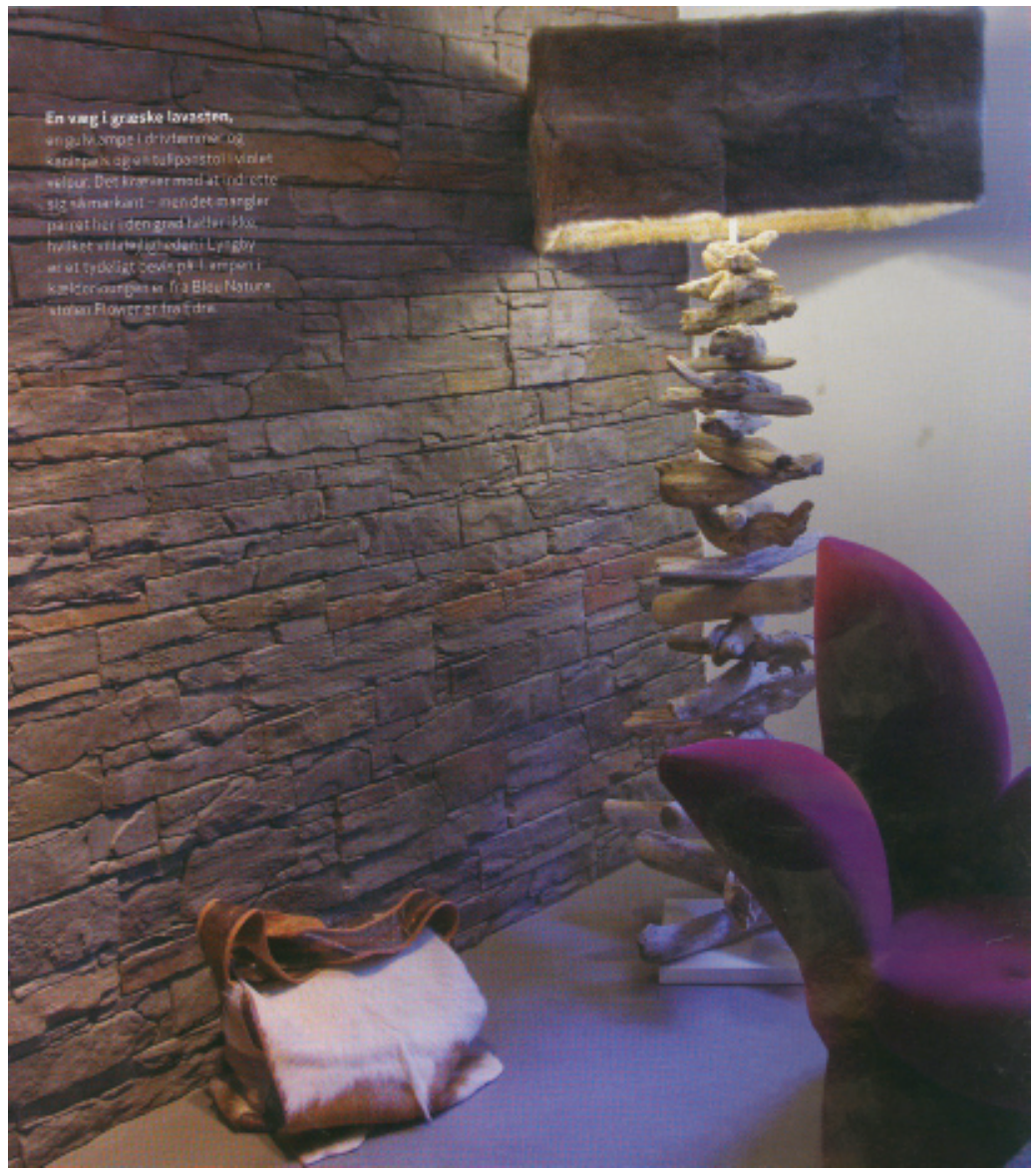

8.15
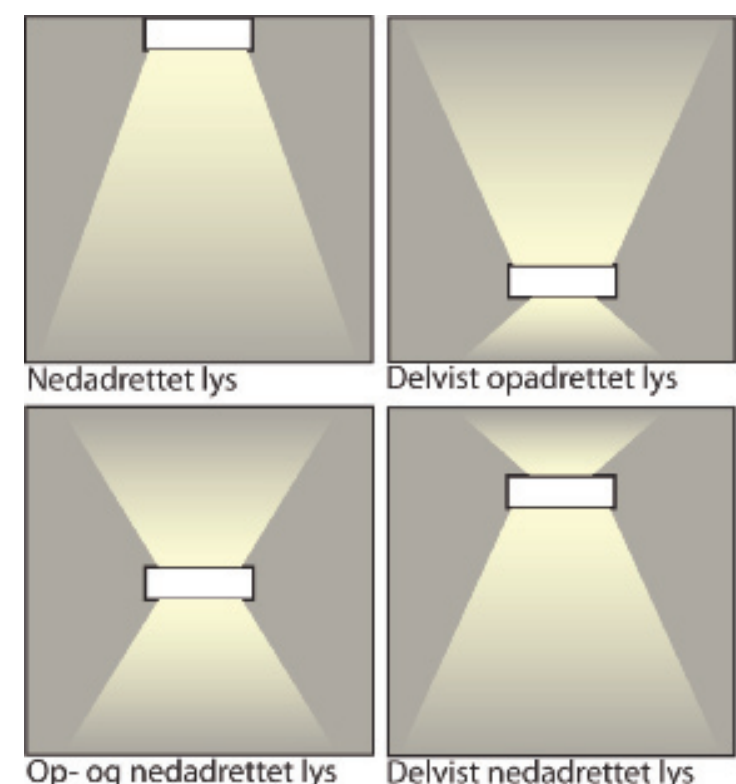

Delvist opadrettet lys

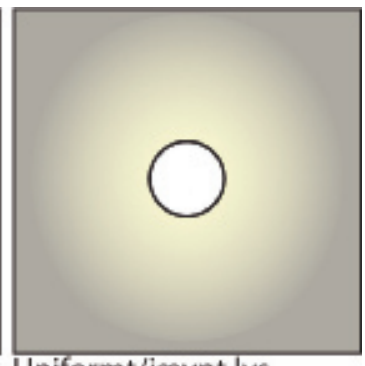

Uniformt/jævnt lys
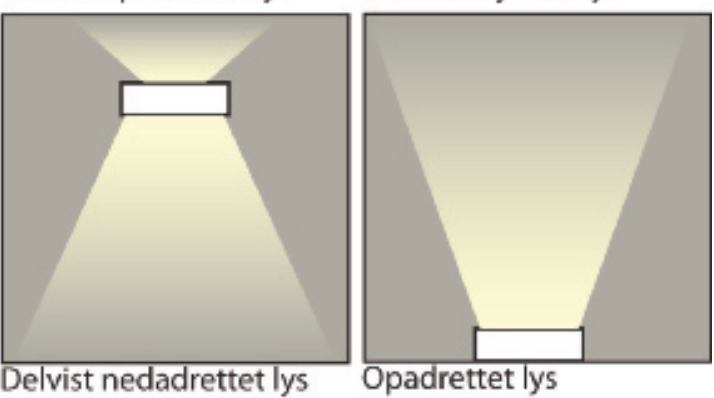

Opadrettet lys 


\section{ROOM DEFINITION:}

The Light atmosphere depends on the activities going on in the space. The light atmosphere in a living room should support activities as reading, seeing TV and the light atmosphere in a kitchen should support standing activities cooking etc. The following categories is found appropriate in the study of preferences for light atmosphere as presented earlier in this chapter and defined as

\section{'Living room':}

The Living room is defined as the space for relaxing moments. It can be the sofa or a armchair. The perfect place for activities as reading, watching Television, have guests for coffee or an intimate talk with close friends.

\section{'Dinner room':}

The place for having dinner could be in the kitchen or in the living or dining room. The dinner room is defined as a table surrounded by chairs and is the place where it is obvious to serve a dinner.

\section{'Standing activities':}

Upstanding activities could be the kitchen or maybe the scullery or workshop with similar and comparable activities. In Bo Bedre mostly of the data is collected in kitchens.

\section{'Bathroom':}

The definition includes all kinds of bathrooms with toilet and washbasin. It can include a place for shower, bathtub or even Jacuzzi, but do not include rooms for swimming pools.

\section{'Multifunctional':}

The multifunctional space is in this analyze mostly teenagers or children's room, but the definition is a room including area for relaxing and for work, maybe including bookcases, armchair, changing table or children's furniture.

\section{'Corridor':}

The definition on corridor is a hallway, corridor or even a walking area in connecting other rooms being a part of the living room. The essential is that room is qualified as a space for walking. 


\section{'Sitting activities':}

The definition of the space of sitting activities is primary the home office, sewing or worktable. The space can be a part of the living room or maybe a part of the multifunctional room. The separation of being a part of the multifunctional room or sitting activities depends on the analyzed picture. Close - up pictures of working table is in this category, but if room type is more visible and other spaces included in the picture the subject is assigned the appropriate category.

\section{'Bedroom':}

The definition on a bedroom is the place for sleeping. It can be master bedroom, guest rooms or children's bedroom. The main focus in this category is the bed and the area around the bed.

\section{LIGHT ZONES}

\section{'Horisontal Light Zones'}

The data collection the allocation of luminaires is important for the atmosphere in the space because the shadows appears different if the light is distributed from a ceiling mounted luminaire or from a floor lamp. The composition of shadows in the space is a similar parameter as light in the experience of light atmosphere. It was listed as a horizontal tripartition of the space. A 'Low Light Zone', 'Centre Light Zone' and 'High Light Zone'.

'Vertical light zone'

The vertical division of the space in a bipartition was also listed as 'By the walls' and 'Centre of the room'.

\section{'Numbers of luminaires inhorisontal Light zone'}

We also listed the numbers in 'Low Light Zone', 'Centre Light Zone' and 'High Light Zone'.

to get information on how how many luminaires the light distribution came from.

\section{'Numbers of luminaires in vertical light zone'}

The number of luminaires in the vertical partition of the space was also listed as in the groups 'By the walls' and 'Centre of the room'.

\section{'Pictures'}

It was noted if the picture were taken in daytime or night- 
time. Most of the pictures were taken in daytime, but in the sixties and seventies some picture were made whithout daylight contribution.

\section{'Report Focus'}

There was made a separation between a "report or interviewing people articles" and "Do it yourself articles" In this article we only included reports and interviews of Danish homes.

The article attached presents point out the trend of light atmosphere spaces for relaxation. the definition of a space for relaxation is in this case a soft and pleasurable sofa arrangement or an armchair. A relaxing place for activities as reading area, watching $\mathrm{TV}$ or having guests for coffee., not to mix up with sitting activities as the working place or dining areas.

The evaluated parameters for this category are "Light Appearance" (light level, light distribution, daylight composition) and "Space Appearance" (the spatial composition and the visual temperature) over the period of 50 years. The horizontal and vertical arrangements of the luminaires were also noted to se a connection between arrangement of light and the "tone" and atmosphere of the space. 


\subsection{APPENDIX}

LAE questionnaire (In danish) Developed by Lone Mandrup Stidsen. First the questionnaire for teh designed ward and then for the traditional ward 


\section{QUESTIONNAIRE DESIGNED WARD}

LAE

CLone Mandrup Stidsen, Aalborg

\section{INSTRUKTION SENGESTUE 4}

Vi bedømmer vores omgivelser på forskellig vis. Noget kan være mere eller mindre pænt og behageligt, eller noget oplever vi mere som dele end en helhed. Det er muligt at bedømme vores omgivelser på forskellig vis. Man kan feks vurdere, om man er enig eller uenig i forskellige udsagn, eller om man synes, at omgivelserne er interessante eller uinteressante.

Dette spørgeskema indeholder skalaer, hvor vi gerne vil have din bedømmelse af, hvordan du oplever sengestuens belysning i forskellige situationer.

Eks:

Hvor enig eller uenig er du i følgende udsagn? Jeg oplever den kunstige belysning som behageligt lige nu:

uenig

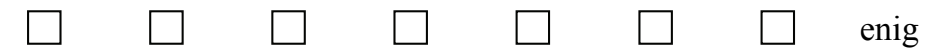

Markeringen sker ved at sætte kryds i en af ruderne. Skalaen har 7 trin. Ruden længst til venstre markere en uenighed i udsagnet og ruden længst til højre enighed i udsagnet.

Samtlige markeringer skal udføres, mens du befinder dig på sengestuen og når det er mørkt udenfor. Lyset skal indstilles på symbolet . Hvis sengelampen ikke tændes automatisk, skal den tændes på kontakten der sidder på ledningen.

Udfyld først informationerne nederst på denne side. Vend derefter bladet, og begynd spørgeskemaet.

Seng ved vindue Seng ved dør Dato: tid:

Alder: 


\section{QUESTIONNAIRE DESIGNED WARD}

1. Hvilket LYSBEHOV du har lige nu?

Afslappende $\square \quad \square \quad \square \quad \square \quad \square \quad \square \quad \square \quad \square \quad$ aktiverende

2. Hvor enig eller uenig er du i følgende udsagn: Jeg oplever

KUNSTLYSET som behageligt lige nu i forhold til disse aktiviteter:

\begin{tabular}{|c|c|c|c|c|c|c|c|c|}
\hline \multicolumn{9}{|c|}{ Læse bøger } \\
\hline uenig & $\square$ & $\square$ & $\square$ & $\square$ & $\square$ & $\square$ & $\square$ & enig \\
\hline \multicolumn{9}{|c|}{ Se TV } \\
\hline uenig & $\square$ & $\square$ & $\square$ & $\square$ & $\square$ & $\square$ & $\square$ & enig \\
\hline \multicolumn{9}{|c|}{ Spise } \\
\hline uenig & $\square$ & $\square$ & $\square$ & $\square$ & $\square$ & $\square$ & $\square$ & enig \\
\hline \multicolumn{9}{|c|}{ Have gæster på besøg } \\
\hline uenig & $\square$ & $\square$ & $\square$ & $\square$ & $\square$ & $\square$ & $\square$ & enig \\
\hline \multicolumn{9}{|c|}{ Gå til ro } \\
\hline uenig & $\square$ & $\square$ & $\square$ & $\square$ & $\square$ & $\square$ & $\square$ & enig \\
\hline \multicolumn{9}{|c|}{ Kommunikere med personalet } \\
\hline uenig & $\square$ & $\square$ & $\square$ & $\square$ & $\square$ & $\square$ & $\square$ & enig \\
\hline \multicolumn{9}{|c|}{ Udføre daglige øvelser } \\
\hline uenig & $\square$ & $\square$ & $\square$ & $\square$ & $\square$ & $\square$ & $\square$ & enig \\
\hline
\end{tabular}




\section{QUESTIONNAIRE DESIGNED WARD}

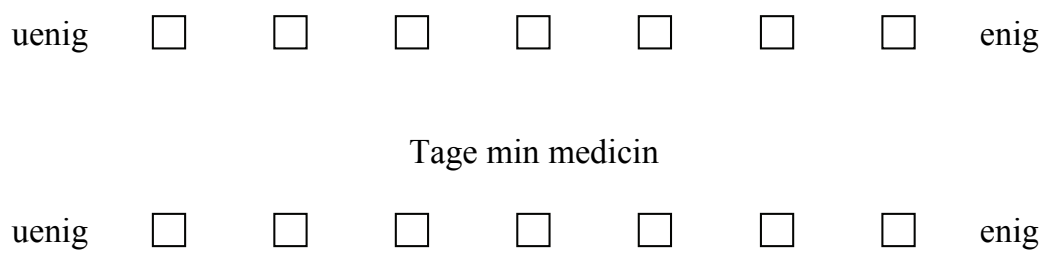

3. Hvor enig eller uenig er du i følgende udsagn: Jeg oplever LYSSTYRRINGEN som behageligt lige nu i forhold til disse aktiviteter: (tænd og sluk på en kontakt er også en lysstyring)

Læse bøger

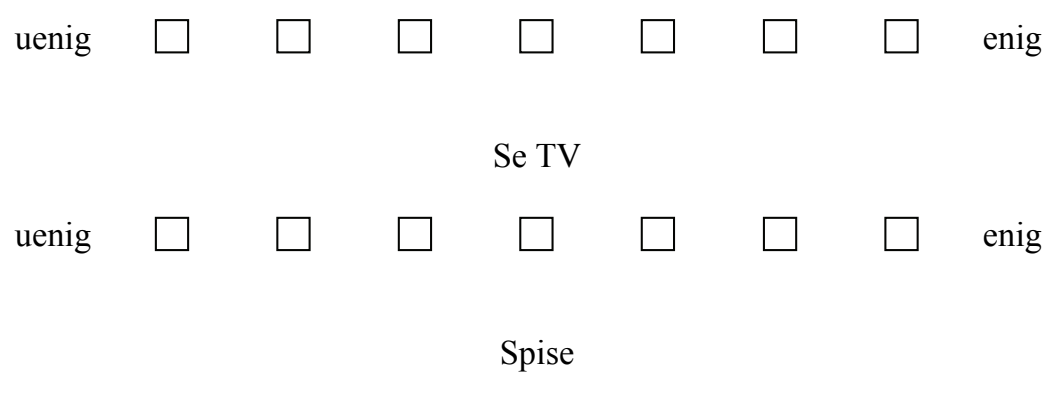

uenig $\square \quad \square \quad \square \quad \square \quad \square \quad \square \quad \square \quad$ enig Have gæster på besøg

uenig $\square \quad \square \quad \square \quad \square \quad \square \quad \square \quad \square \quad \square \quad$ enig Gå til ro

uenig $\square \quad \square \quad \square \quad \square \quad \square \quad \square \quad \square \quad \square \quad$ enig Kommunikere med personalet

uenig $\square \quad \square \quad \square \quad \square \quad \square \quad \square \quad \square \quad$ enig Udføre daglige øvelser

uenig $\square \quad \square \quad \square \quad \square \quad \square \quad \square \quad \square \quad$ enig 


\section{QUESTIONNAIRE DESIGNED WARD}

Sikkerhed når jeg går

uenig

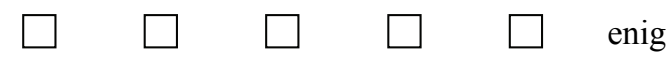

Tage min medicin

uenig

Tage min medicin

(20)

$\square$

$\square \quad \square \quad \square \quad \square \quad \square \quad$ enig

4. Hvor enig eller uenig er du i, at oplevelsen af rummets ATMOSFAERE lige nu stemmer overens med folgende udsagn:

Rummet er stressende at opholde sig i

uenig $\square \quad \square \quad \square \quad \square \quad \square \quad \square \quad \square \quad$ enig

Jeg har mulighed for at gøre rummet hyggeligt

uenig $\square \quad \square \quad \square \quad \square \quad \square \quad \square \quad \square \quad$ enig

Rummet passer til situationen

uenig $\square \quad \square \quad \square \quad \square \quad \square \quad \square \quad \square \quad$ enig

Jeg har mulighed for at være privat

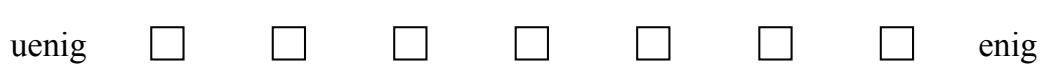

Lyset kan være på den måde, jeg godt kan lide

uenig $\square \quad \square \quad \square \quad \square \quad \square \quad \square \quad \square \quad$ enig

Jeg kan betjene lyset efter behov

uenig $\square \quad \square \quad \square \quad \square \quad \square \quad \square \quad \square \quad$ enig

5. Skalaen for de næste spørgsmål har en anden karakter. Skalaen består af 2 modpoler, og du skal sætte et kryds i det felt, der svare til din oplevelse af sengestuen. 


\section{QUESTIONNAIRE DESIGNED WARD}

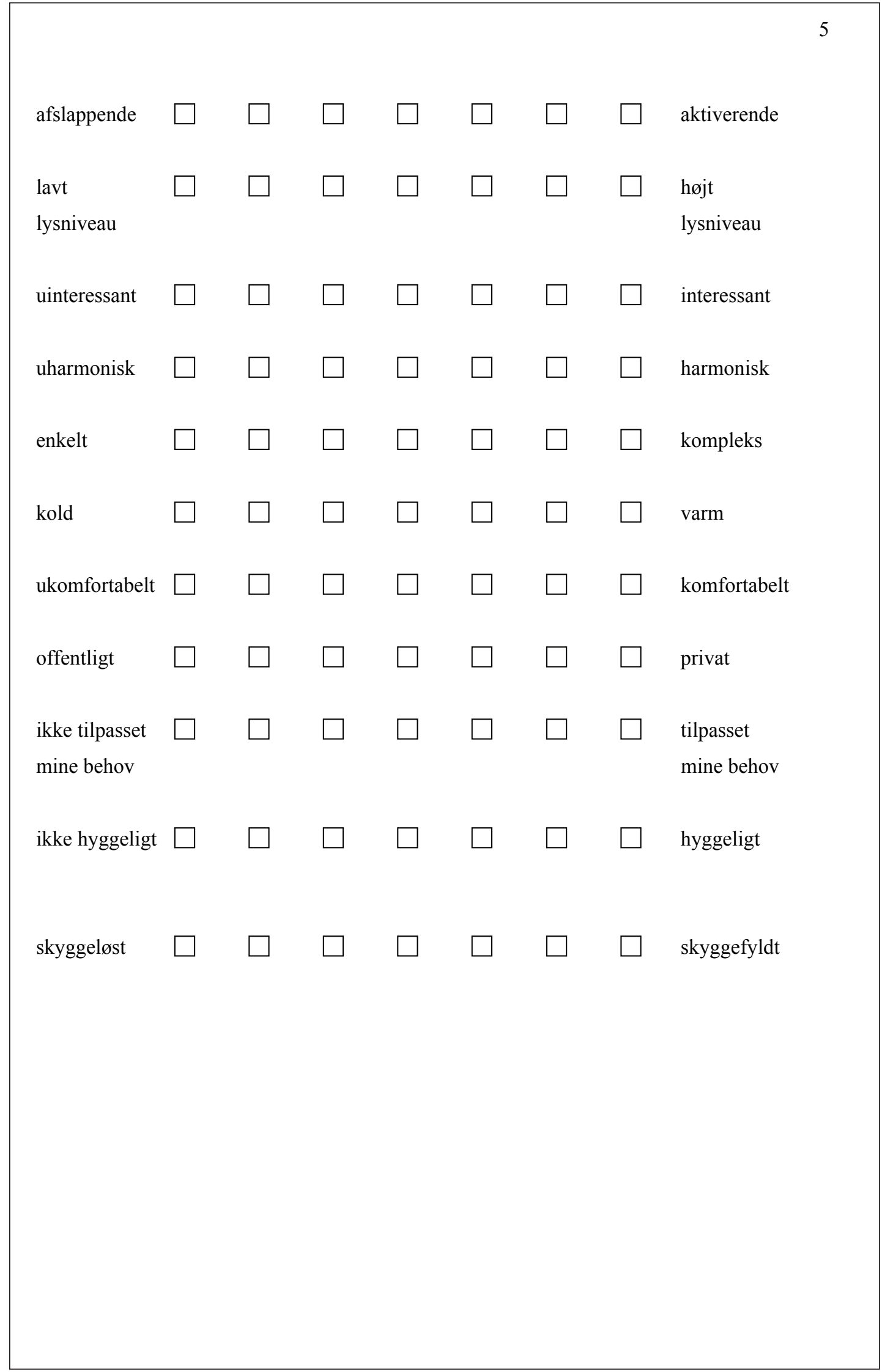




\section{QUESTIONNAIRE TRADITIONAL WARD}

LAE

CLone Mandrup Stidsen, Aalborg

\section{INSTRUKTION SENGESTUE 10}

Vi bedømmer vores omgivelser på forskellig vis. Noget kan være mere eller mindre pænt og behageligt, eller noget oplever vi mere som dele end en helhed. Det er muligt at bedømme vores omgivelser på forskellig vis. Man kan feks vurdere, om man er enig eller uenig i forskellige udsagn, eller om man synes, at omgivelserne er interessante eller uinteressante.

Dette spørgeskema indeholder skalaer, hvor vi gerne vil have din bedømmelse af, hvordan du oplever sengestuens belysning i forskellige situationer.

Eks:

Hvor enig eller uenig er du i følgende udsagn? Jeg oplever den kunstige belysning som behageligt lige nu:

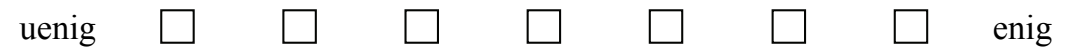

Markeringen sker ved at sætte kryds i en af ruderne. Skalaen har 7 trin. Ruden længst til venstre markere en uenighed i udsagnet og ruden længst til højre enighed i udsagnet.

Samtlige markeringer skal udføres, mens du befinder dig på sengestuen og når det er mørkt udenfor og der skal være tændt for loftlampen og sengelampen.

Udfyld først informationerne nederst på denne side. Vend derefter bladet, og begynd spørgeskemaet.

Seng ved vindue Seng ved dør Dato: tid:

Alder: 


\section{QUESTIONNAIRE TRADITIONAL WARD}

1. Hvilket LYSBEHOV du har lige nu?

Afslappende $\square \quad \square \quad \square \quad \square \quad \square \quad \square \quad \square \quad \square \quad$ aktiverende

2. I hvilken grad synes du at belysningen understotter dette behov?

lidt $\square \quad \square \quad \square \quad \square \quad \square \quad \square \quad \square \quad$ meget

3. Hvor enig eller uenig er du i følgende udsagn: Jeg oplever

KUNSTLYSET som behageligt lige nu i forhold til disse aktiviteter

Læse bøger

uenig $\square \quad \square \quad \square \quad \square \quad \square \quad \square \quad \square \quad$ enig

Se TV

uenig $\square \quad \square \quad \square \quad \square \quad \square \quad \square \quad \square \quad$ enig

Spise

uenig $\square \quad \square \quad \square \quad \square \quad \square \quad \square \quad \square \quad$ enig

Have gæster på besøg

uenig $\square \quad \square \quad \square \quad \square \quad \square \quad \square \quad \square \quad$ enig

Gå til ro

uenig $\square \quad \square \quad \square \quad \square \quad \square \quad \square \quad \square \quad$ enig

Kommunikere med personalet

uenig $\square \quad \square \quad \square \quad \square \quad \square \quad \square \quad \square \quad$ enig 


\section{QUESTIONNAIRE TRADITIONAL WARD}

Udføre daglige øvelser

uenig $\square \quad \square \quad \square \quad \square \quad \square \quad \square \quad \square \quad$ enig

Sikkerhed når jeg går

uenig $\square \quad \square \quad \square \quad \square \quad \square \quad \square \quad \square \quad$ enig

Tage min medicin

uenig $\square \quad \square \quad \square \quad \square \quad \square \quad \square \quad \square \quad$ enig

4. Hvor enig eller uenig er du i følgende udsagn: Jeg oplever LYS-

STYRRINGEN som behageligt lige nu i forhold til disse aktiviteter:

(tænd og sluk på en kontakt er også en lysstyring)

Læse bøger

uenig $\square \quad \square \quad \square \quad \square \quad \square \quad \square \quad \square \quad$ enig

Se TV

uenig $\square \quad \square \quad \square \quad \square \quad \square \quad \square \quad \square \quad$ enig

Spise

uenig $\quad \square \quad \square \quad \square \quad \square \quad \square \quad \square \quad \square \quad$ enig

Have gæster på besøg

uenig $\square \quad \square \quad \square \quad \square \quad \square \quad \square \quad \square \quad$ enig

Gå til ro

uenig $\square \quad \square \quad \square \quad \square \quad \square \quad \square \quad \square \quad$ enig 


\section{QUESTIONNAIRE TRADITIONAL WARD}

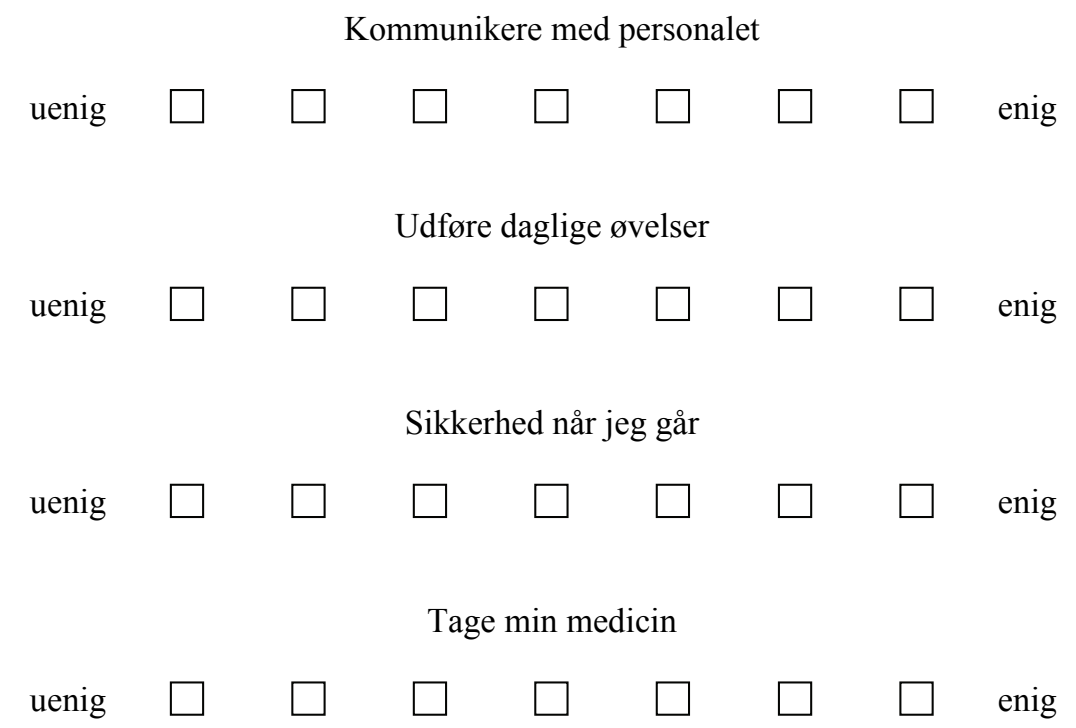

5. Hvor enig eller uenig er $\mathrm{du} i$, at oplevelsen af rummets ATMOSF ERE lige nu stemmer overens med følgende udsagn:

Rummet er stressende at opholde sig i

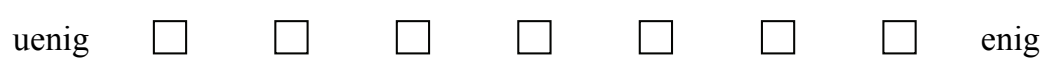

Jeg har mulighed for at gøre rummet hyggeligt

uenig $\square \quad \square \quad \square \quad \square \quad \square \quad \square \quad \square \quad \square \quad$ enig

Rummet passer til situationen

uenig $\square \quad \square \quad \square \quad \square \quad \square \quad \square \quad \square \quad \square \quad$ enig

Jeg har mulighed for at være privat

uenig $\square \quad \square \quad \square \quad \square \quad \square \quad \square \quad \square \quad \square \quad$ enig 


\section{QUESTIONNAIRE TRADITIONAL WARD}

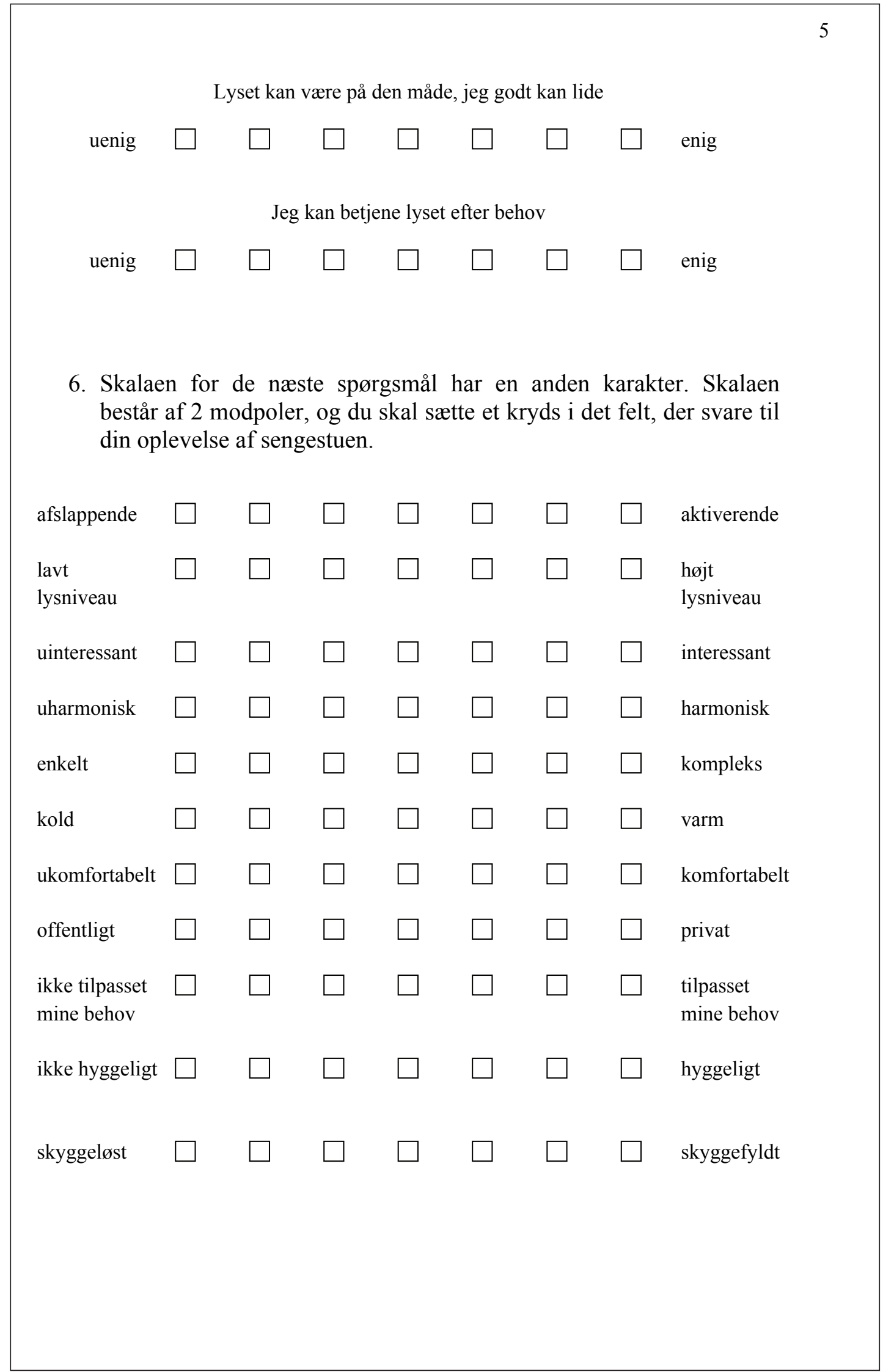





\subsection{APPENDIX}

SMB -model developed by Rikard Küller.

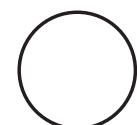

(In danish)

First the questionnaire to the Designed ward and then the first page on traditional ward, while the other pages are the same. 


\section{QUESTIONNAIRE DESIGNED WARD}

OUH_SMB

CRikard Küller, Lund

\section{INSTRUKTION SENGESTUE 4}

Det er muligt at bedømme vores omgivelser på forskellig vis. Man kan f.eks vurdere, om det er mere eller mindre stort, mere eller mindre pænt eller mere eller mindre som en helhed.

Dette hæfte indeholder et antal bedømmelsesskalaer. Du skal markere, hvordan du oplever omgivelserne, du befinder dig i de forskellige situationer.

Her er et eksempel på en bedømmelsesskala:

STOR

lidt

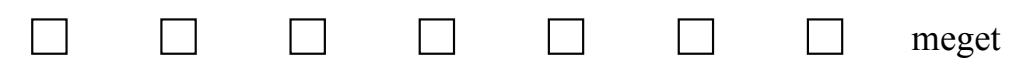

Umiddelbart ovenfor skalaen står, hvilken egenskab i miljøet skalaen referer til (Stor). Markeringen sker ved at sætte kryds i en af ruderne. Skalaen har 7 trin. Ruden længst til venstre indeholder lidt og ruden længst til højre meget af egenskaben.

Samtlige markeringer skal udføres, mens du befinder dig i omgivelserne og når det er mørkt udenfor og du har tændt for lyset med symbolet

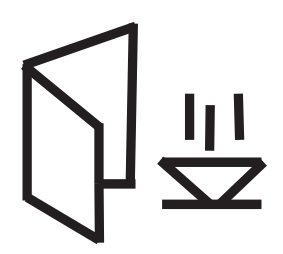

Udfyld først informationerne nederst på denne side. Vend derefter bladet, og begynd spørgeskemaet.

Dato:

Tidspunkt

Mand $\square$ Kvinde Alder: 


\section{QUESTIONNAIRE DESIGNED WARD}

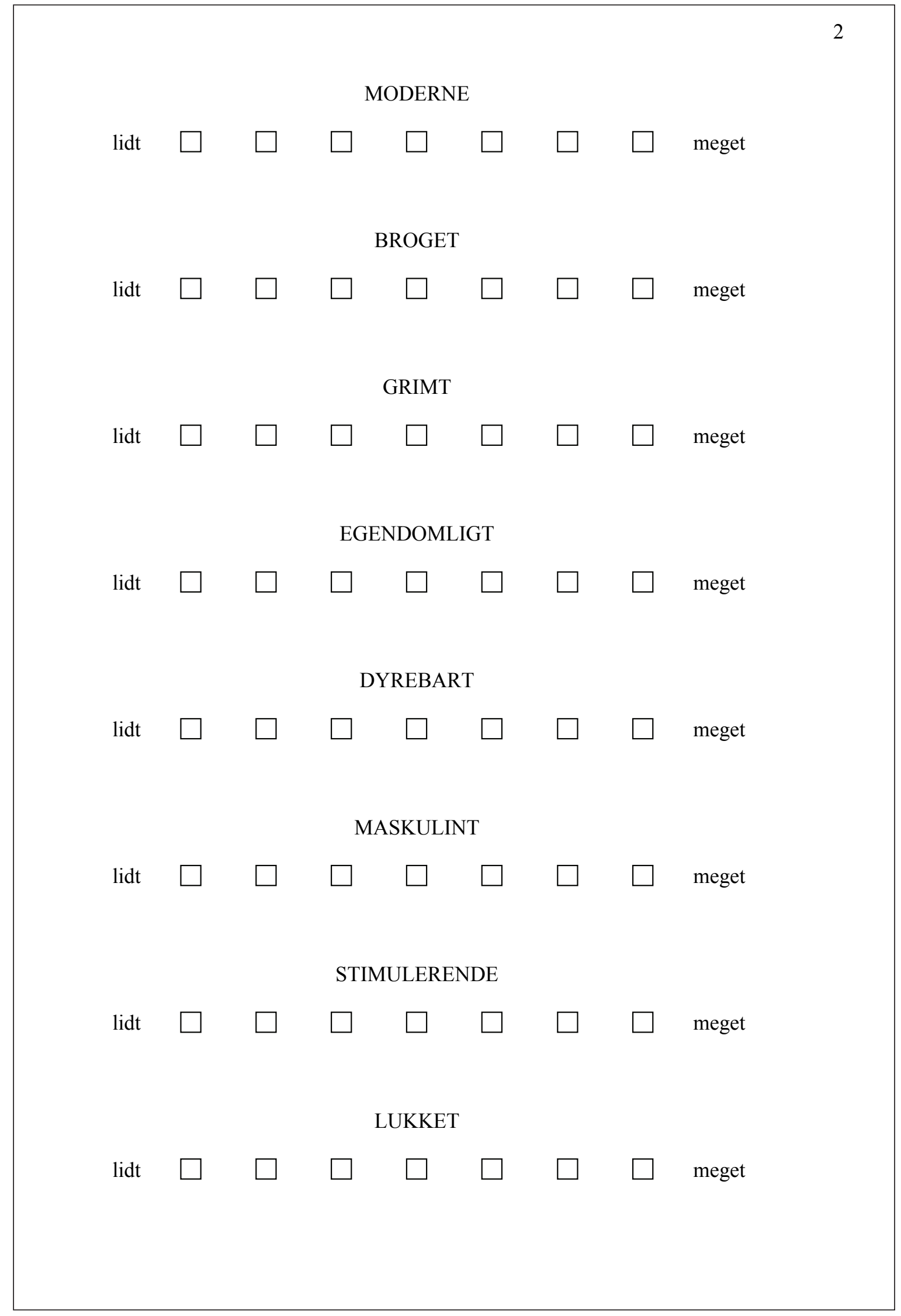




\section{QUESTIONNAIRE DESIGNED WARD}

FUNKTIONELT

lidt $\square \quad \square \quad \square \quad \square \quad \square \quad \square \quad \square \quad \square \quad$ meget

VELHOLDT

lidt $\square \quad \square \quad \square \quad \square \quad \square \quad \square \quad \square \quad \square \quad$ meget

\section{ALMINDELIGT}

lidt $\square \quad \square \quad \square \quad \square \quad \square \quad \square \quad \square \quad \square \quad$ meget TRYGT

lidt $\square \quad \square \quad \square \quad \square \quad \square \quad \square \quad \square \quad \square \quad$ meget STILRENT

lidt $\square \quad \square \quad \square \quad \square \quad \square \quad \square \quad \square \quad \square \quad$ meget

KEDELIGT

lidt $\square \quad \square \quad \square \quad \square \quad \square \quad \square \quad \square \quad$ meget SKRØBELIGT

lidt $\square \quad \square \quad \square \quad \square \quad \square \quad \square \quad \square \quad$ meget DÆMPET

lidt $\square \quad \square \quad \square \quad \square \quad \square \quad \square \quad \square \quad$ meget 


\section{QUESTIONNAIRE DESIGNED WARD}

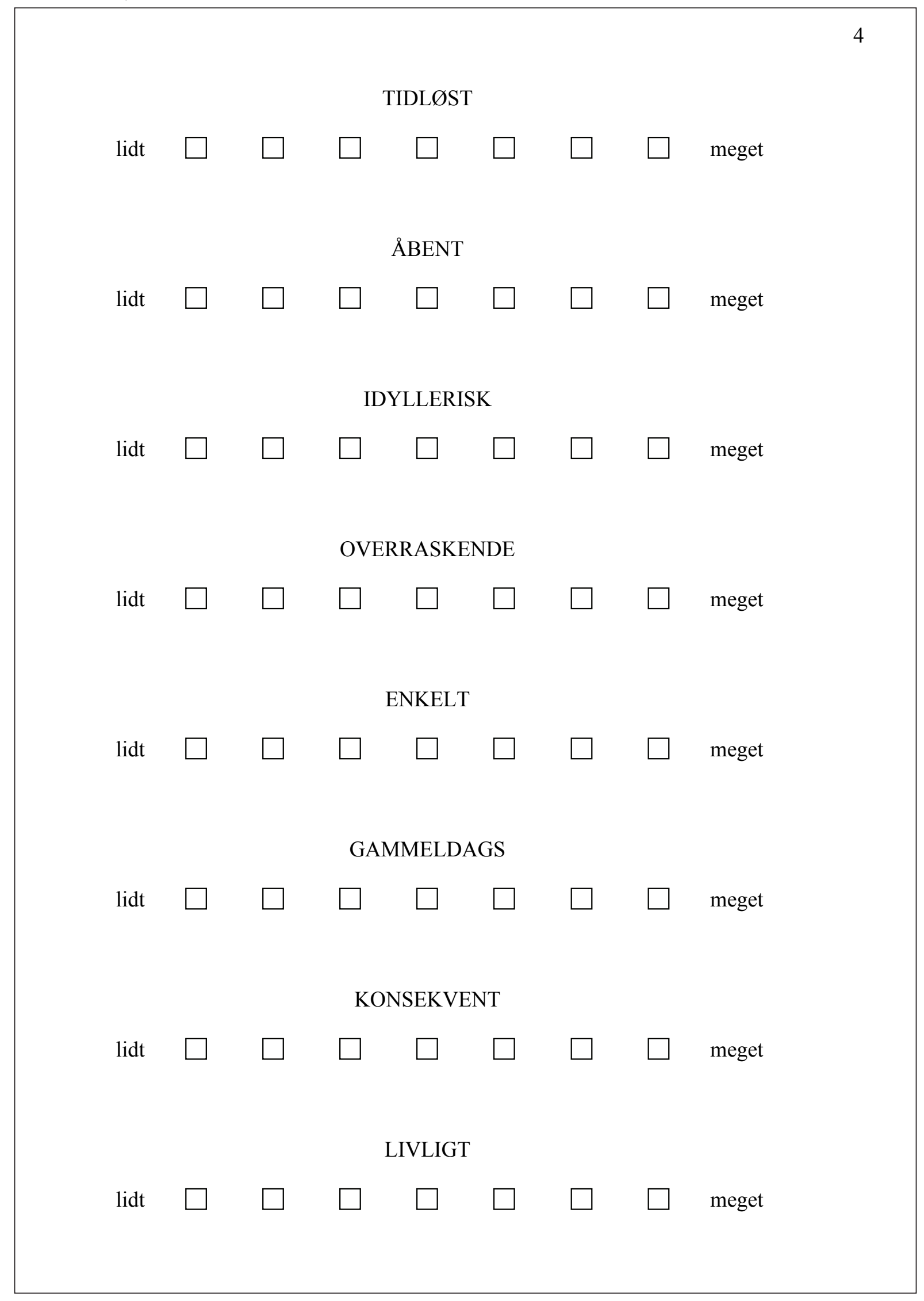




\section{QUESTIONNAIRE DESIGNED WARD}

GODT

lidt $\square \quad \square \quad \square \quad \square \quad \square \quad \square \quad \square \quad$ meget

AFGRÆNSET

lidt $\square \quad \square \quad \square \quad \square \quad \square \quad \square \quad \square \quad \square \quad$ meget

\section{KRAFTFULDT}

lidt $\square \quad \square \quad \square \quad \square \quad \square \quad \square \quad \square \quad \square \quad$ meget NYT

lidt $\square \quad \square \quad \square \quad \square \quad \square \quad \square \quad \square \quad$ meget OVERDÅDIGT

lidt $\square \quad \square \quad \square \quad \square \quad \square \quad \square \quad \square \quad \square \quad$ meget SAMMENSAT

lidt $\square \quad \square \quad \square \quad \square \quad \square \quad \square \quad \square \quad$ meget BEHAGELIGT

lidt $\square \quad \square \quad \square \quad \square \quad \square \quad \square \quad \square \quad$ meget FEMININT

lidt $\square \quad \square \quad \square \quad \square \quad \square \quad \square \quad \square \quad$ meget 
INSTRUKTIONS DESIGNED WARD

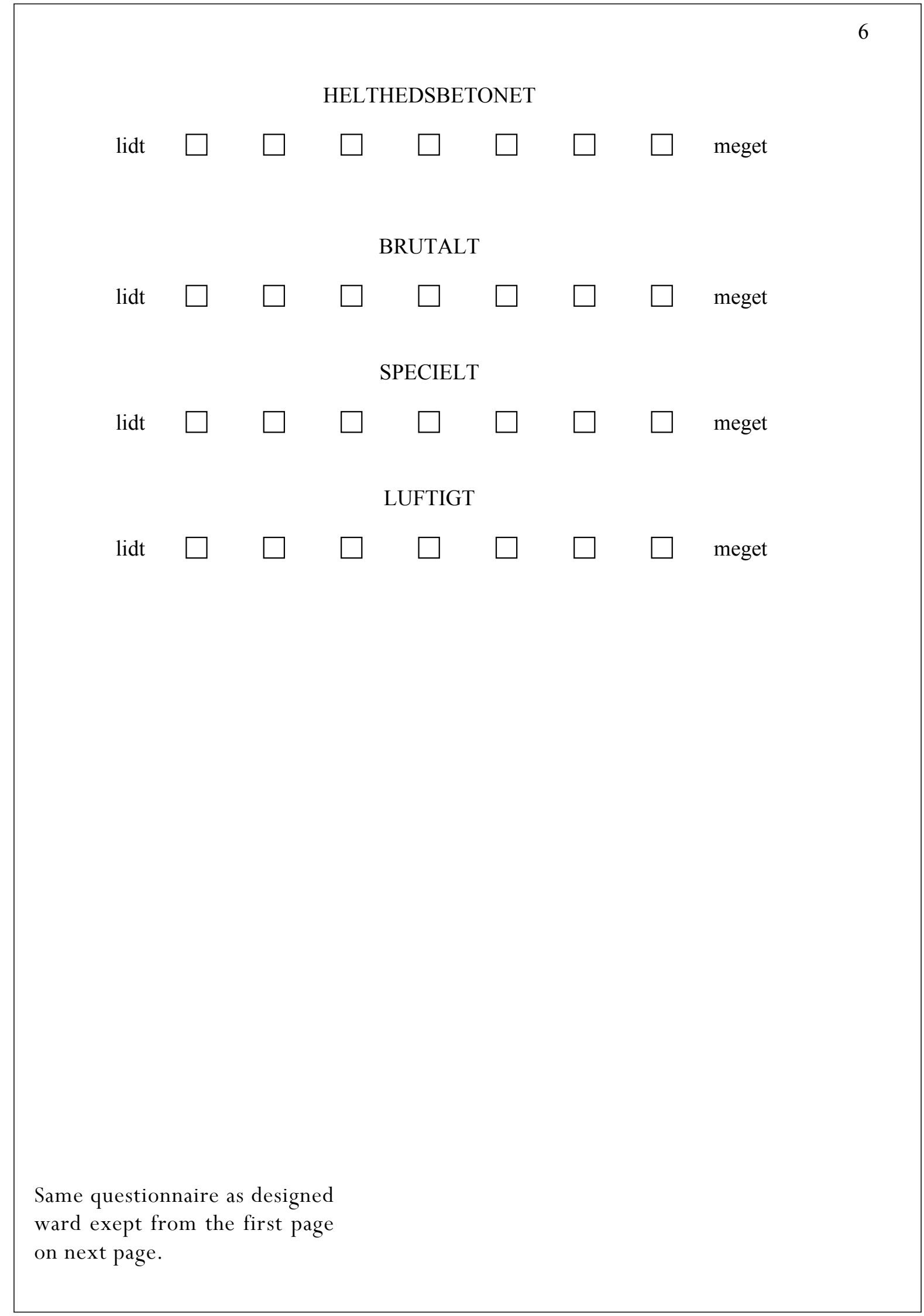




\section{INSTRUKTIONS TRADITIONAL WARD}

OUH_SMB

CRikard Küller, Lund

\section{INSTRUKTION SENGESTUE 10}

Det er muligt at bedømme vores omgivelser på forskellig vis. Man kan f.eks vurdere, om det er mere eller mindre stort, mere eller mindre pænt eller mere eller mindre som en helhed.

Dette hæfte indeholder et antal bedømmelsesskalaer. Du skal markere, hvordan du oplever omgivelserne, du befinder dig i de forskellige situationer.

Her er et eksempel på en bedømmelsesskala:

STOR

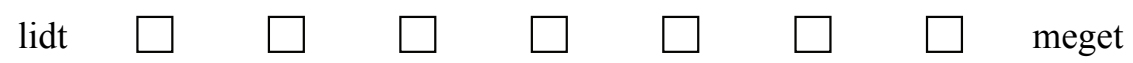

Umiddelbart ovenfor skalaen står, hvilken egenskab i miljøet skalaen referer til (Stor).

Markeringen sker ved at sætte kryds i en af ruderne. Skalaen har 7 trin. Ruden længst til venstre indeholder lidt og ruden længst til højre meget af egenskaben.

Samtlige markeringer skal udføres, mens du befinder dig i omgivelserne og når det er mørkt udenfor og du har tændt for loftslyset og sengelampen

Udfyld først informationerne nederst på denne side. Vend derefter bladet, og begynd spørgeskemaet.

Dato:

Tidspunkt

Mand $\square$ Kvinde

Alder: 


\subsection{APPENDIX}

Selected files from Dialux documentation.

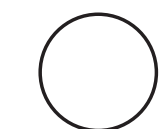

(In danish) 


\section{Odense Universitets Hospital}

Evaluering af Belysning på sengestue i forbindelse med phd projekt.

\section{Afdeling $\mathrm{O} 3$ (Ortopaedkirurgisk afdeling)}
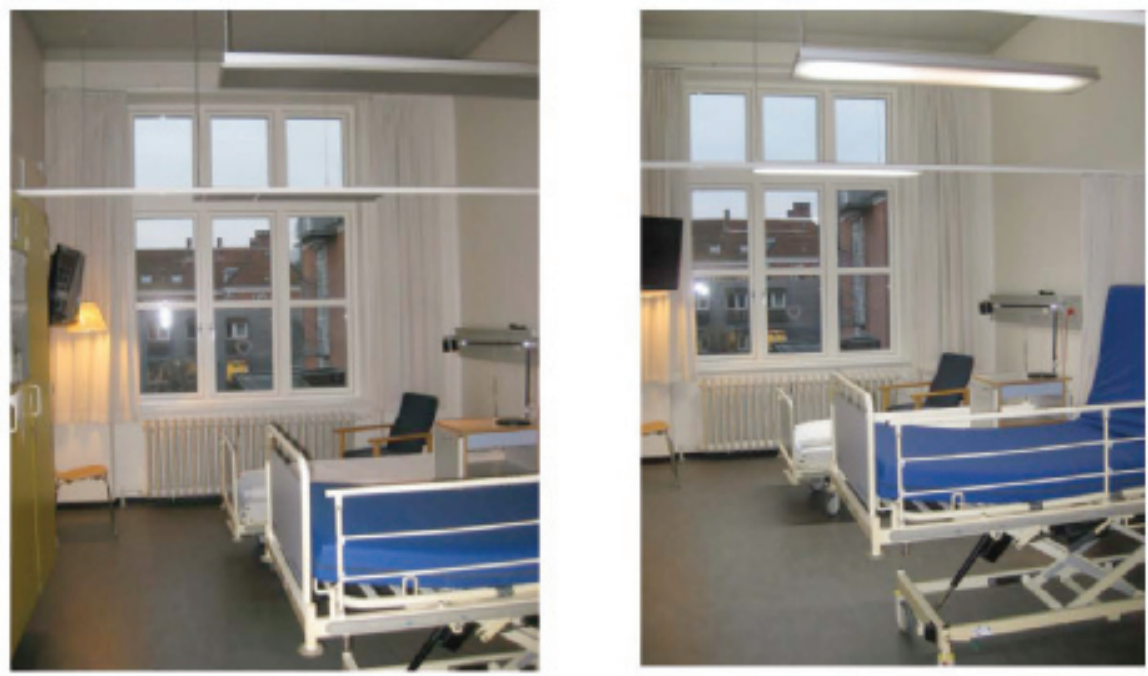

Partner for Contact: Poul Henning Kirkegaard/ Anne Marie Lund

Order No: : 01

Company: Aalborg Universitet /Philips

Customer No.: 1

Dato: 31.08 .2012

Designer: Lone Stidsen 


\section{PATIENT PERSONLIGT LYS}

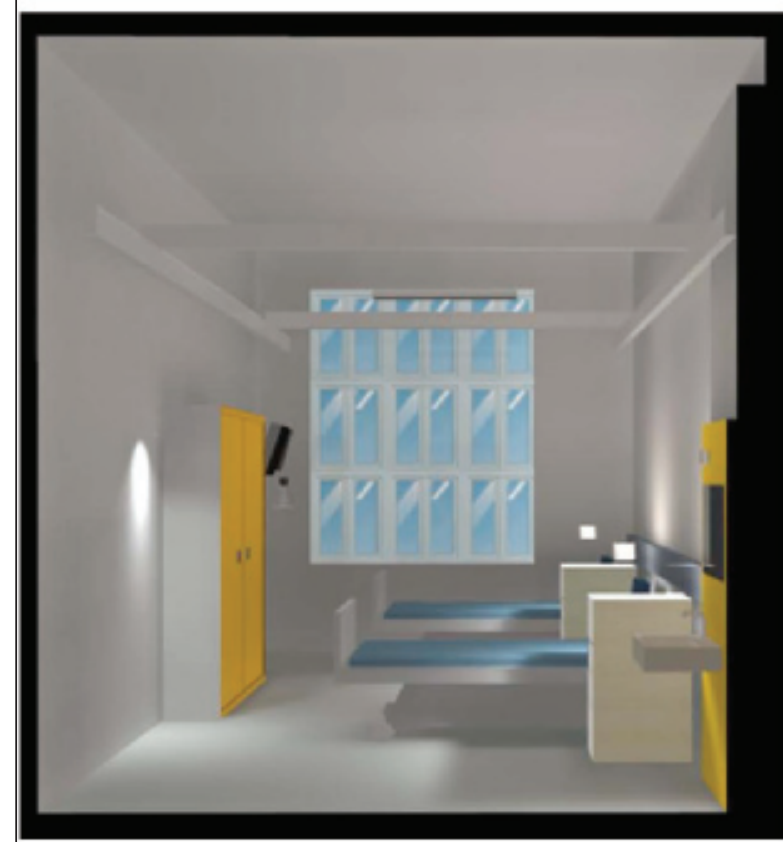

\section{ENERGIBOOST 1}

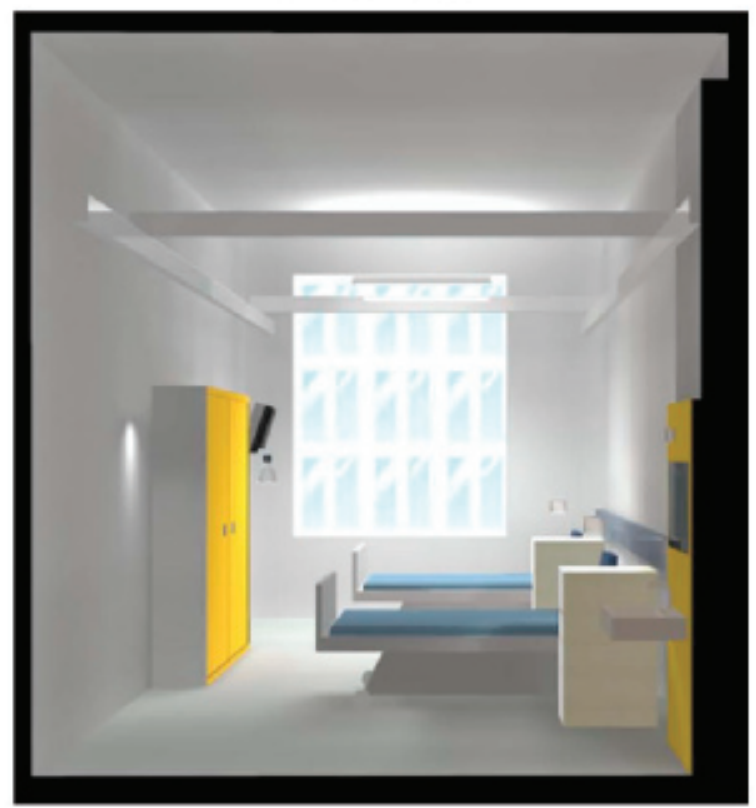

NATLYS

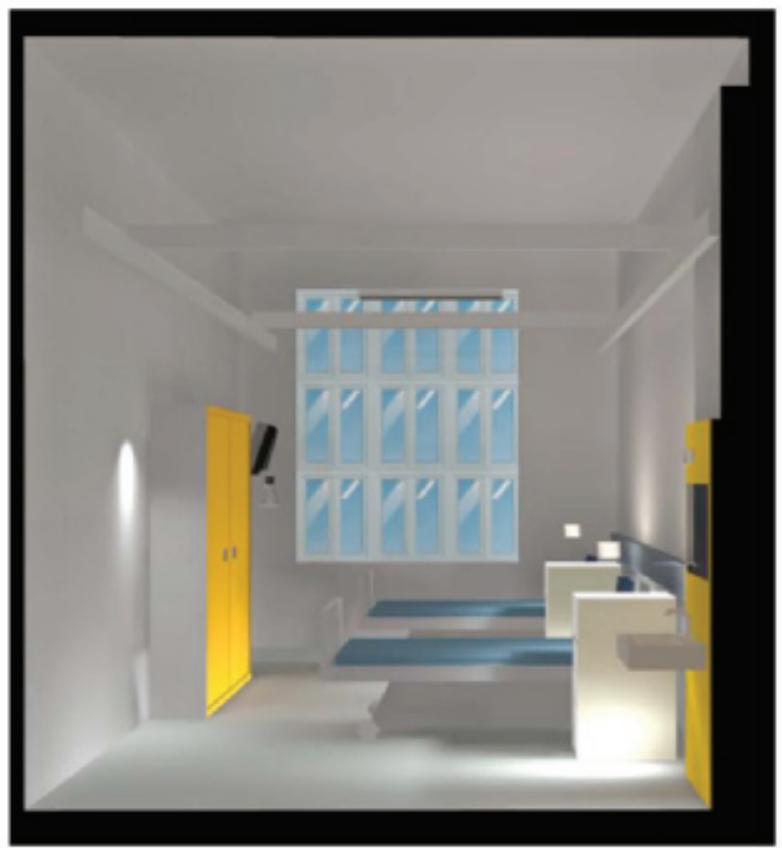

ENERGIBOOST 2

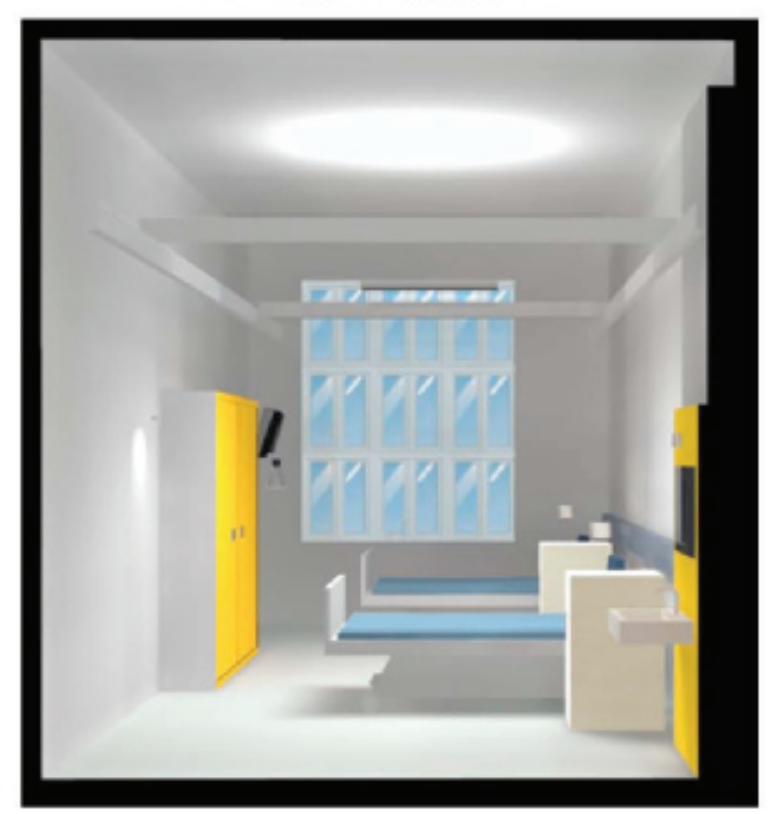




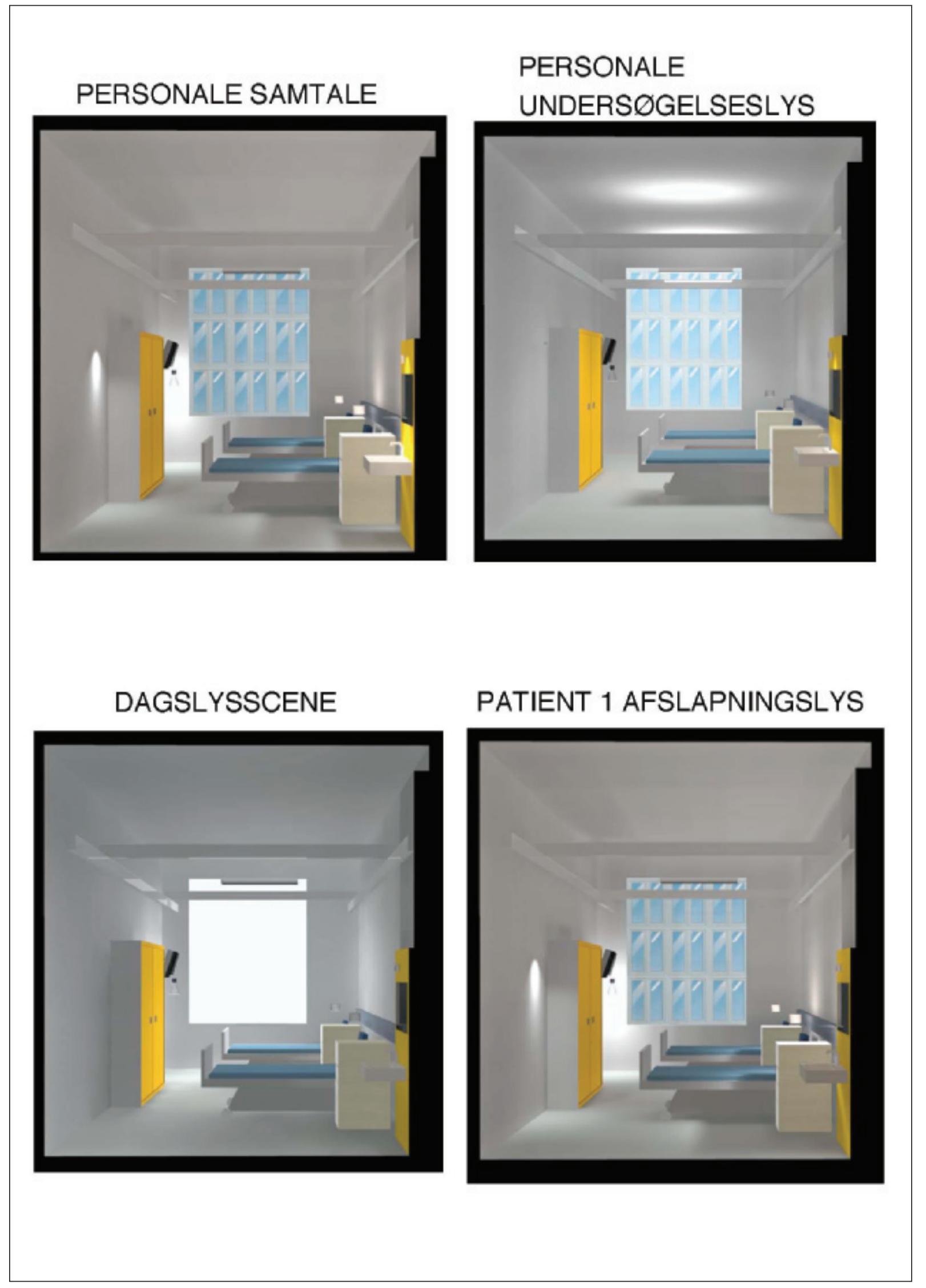




\section{PATIENT 2 AFSLAPNINGSLYS}
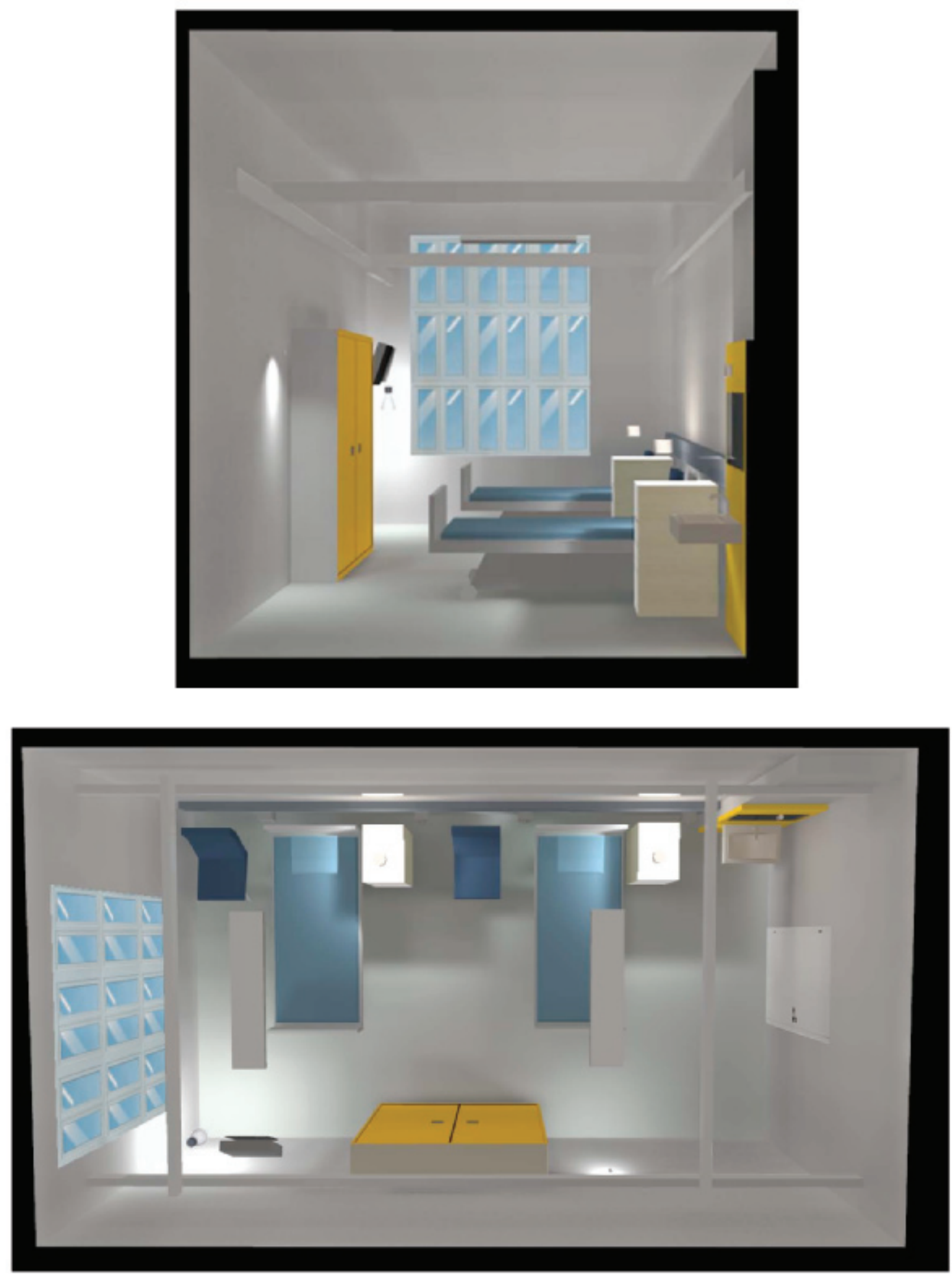
Lysstrøm (Armatur): $106 \mathrm{Im}$

Lysstrøm (Lamper): $125 \mathrm{Im}$

Effekt incl. fork.: $4.0 \mathrm{~W}$

Armaturklassifikation iht. CIE: 100

CIE Flux-kode: $89 \quad 100 \quad 100 \quad 100 \quad 85$

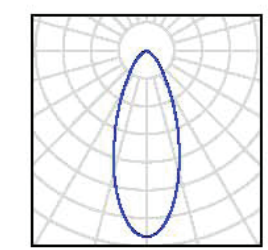

Udstyr: $1 \mathrm{x}$ Brugerdefineret (Korrektionsfaktor $1.000)$.

4 Antal

Philips BBG513 1xSLED400/830 MB

Artikel-nr::

Lysstrøm (Armatur): $389 \mathrm{Im}$

Lysstrøm (Lamper): $659 \mathrm{~lm}$

Effekt incl fork: $11.0 \mathrm{~W}$

Armaturklassifikation int. CIE: 100

CIE Flux-kode: $93 \quad 98 \quad 10010061$

Udstyr: 1 x SLED400/830/- (Korrektionsfaktor

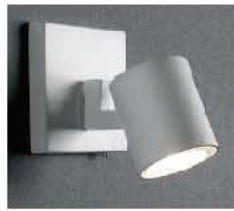

1.000).

1 Antal Le Klint Undercover pendel $\mathrm{m} / 20 \mathrm{~W}$ Tornado sparepære

Lysstrøm (Armatur): $1028 \mathrm{Im}$

Lysstrøm (Lamper): $1155 \mathrm{~lm}$

Effekt incl. fork.: $20.0 \mathrm{~W}$

Armaturklassifikation int. CIE: 57

CIE Flux-kode: $46 \quad 67845789$

Udstyr: $1 \mathrm{x}$ Brugerdefineret (Korrektionsfaktor
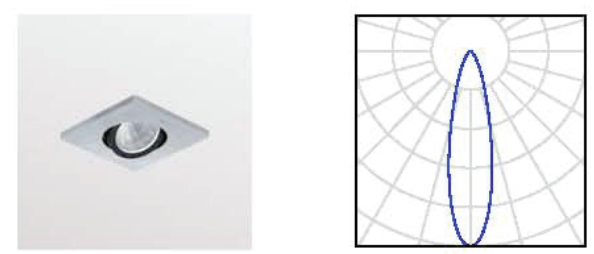

$1.000,20$ W Tornado)

\section{Oliver bordlampe $\mathrm{m} / 40 \mathrm{~W}$ halogen}

Lysstrøm (Armatur): $490 \mathrm{Im}$

Lysstrøm (Lamper): $490 \mathrm{Im}$

Effekt incl. fork.: $40.0 \mathrm{~W}$

Armaturklassifikation iht. CIE: 100

CIE Flux-kode: 6995100100100

Udstyr: 1 x Brugerdefineret (Korrektionsfaktor

1.000).
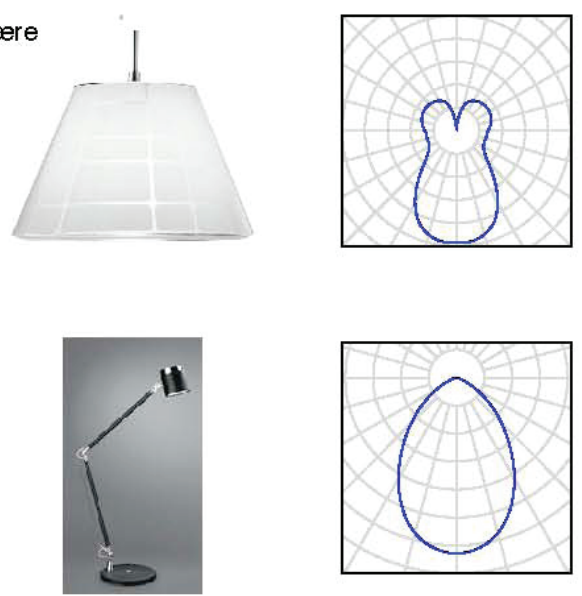

1 Antal Sparepære i spejlarmatur

Lysstrøm (Armatur): $250 \mathrm{Im}$

Lysstrøm (Lamper): $250 \mathrm{~lm}$

Effekt incl. fork: $6.2 \mathrm{~W}$

Armaturklassifikation iht. CIE: 100

CIE Flux-kode: $93 \quad 98 \quad 10099103$

Udstyr: 1 x MasterLED-25-7W-2700

(Korrektionsfaktor 1.000).

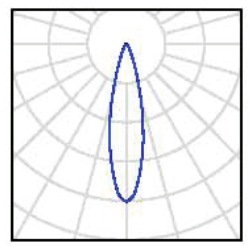


2 Antal Philips TPS772 3xTL5-54W/865/827/865 HFD AC-MLO

Artikel-nr.

Lysstrøm (Armatur): $8936 \mathrm{Im}$

Lysstrøm (Lamper): $12951 \mathrm{Im}$

Effekt incl. fork.: $178.0 \mathrm{~W}$

Armaturklassifikation iht. CIE: 70

CIE Flux-kode: 7396997069

Udstyr: 3 x TL5-54W/865/827/865

(Korrektionsfaktor 1.000).

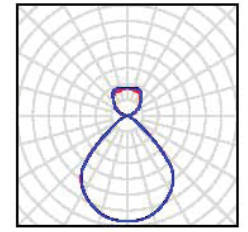




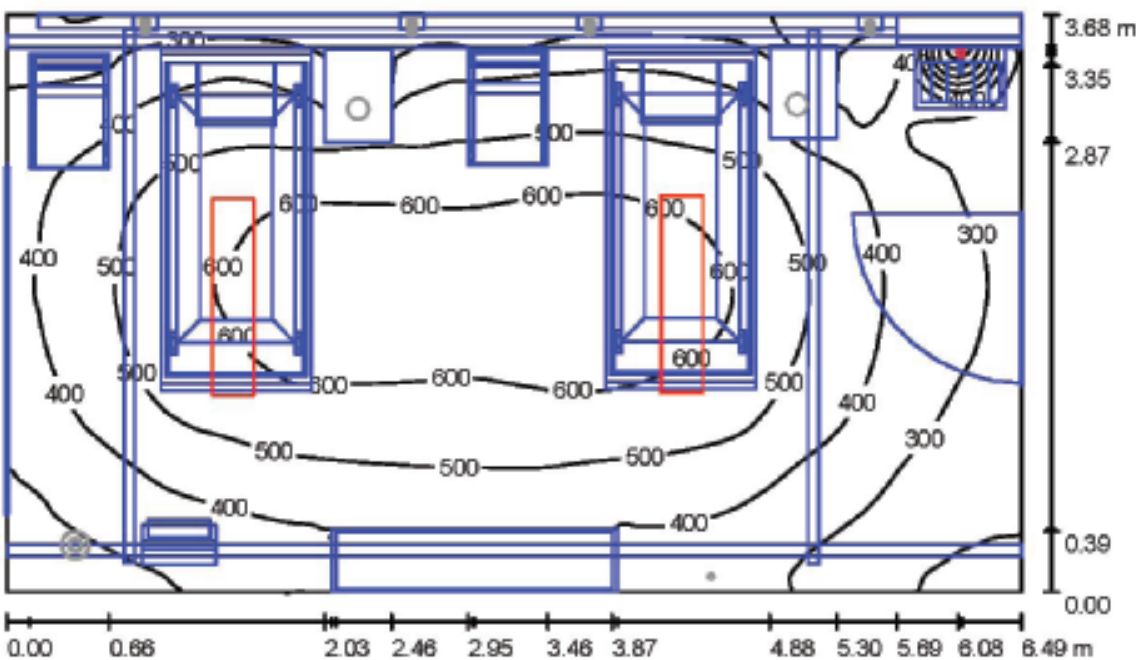

Rumhøjde: $3.939 \mathrm{~m}$, Vedigeholdelsesfaktor: 0.80

Værdier i Lux, Málestok 1:48

\begin{tabular}{|c|c|c|c|c|c|}
\hline Flade & $\rho[\%]$ & $E_{m}[\mathrm{bx}]$ & $E_{\min }[\mid x]$ & $E_{\max }[\mathrm{Dx}]$ & $E_{\min } / E_{m}$ \\
\hline Workplane & $t$ & 445 & 92 & 1052 & 0.206 \\
\hline Floor & 45 & 245 & 29 & 471 & 0.120 \\
\hline Ceiling & 78 & 277 & 88 & 1298 & 0.317 \\
\hline Vægge (4) & 69 & 143 & 13 & 266 & $t$ \\
\hline
\end{tabular}

Workplane:

$\begin{array}{ll}\text { Højde: } & 0.850 \mathrm{~m} \\ \text { Beregningsnet: } & 128 \times 128 \text { Punkter } \\ \text { Randomrade: } & 0.000 \mathrm{~m}\end{array}$

\section{Armaturstykliste}

\begin{tabular}{|c|c|c|c|c|c|}
\hline Nr. & Antal & Betegnelse (Korrektionsfaktor) & $\Phi($ Armatur) $[\mathrm{Im}]$ & $\Phi$ (Lamper) [Im] & $\mathrm{P}[\mathrm{W}]$ \\
\hline 1 & 1 & Sparepæere i spejlarmatur & 250 & 250 & 6.2 \\
\hline 2 & 2 & $\begin{array}{l}\text { Philips TPST7̇2 3xTL5-54W/865/827/865 HFD } \\
\text { AC-MLO (1.000) }\end{array}$ & 8936 & 12951 & 178.0 \\
\hline
\end{tabular}

Specifik tilsluttet effekt: $15.18 \mathrm{~W} / \mathrm{m}^{2}=3.41 \mathrm{~W} / \mathrm{m}^{2} / 100 \mathrm{Ix}$ (Grundilade: $23.86 \mathrm{~m}^{2}$ ) 
Sengestue 10 / dagslys scene / Sammenfatning

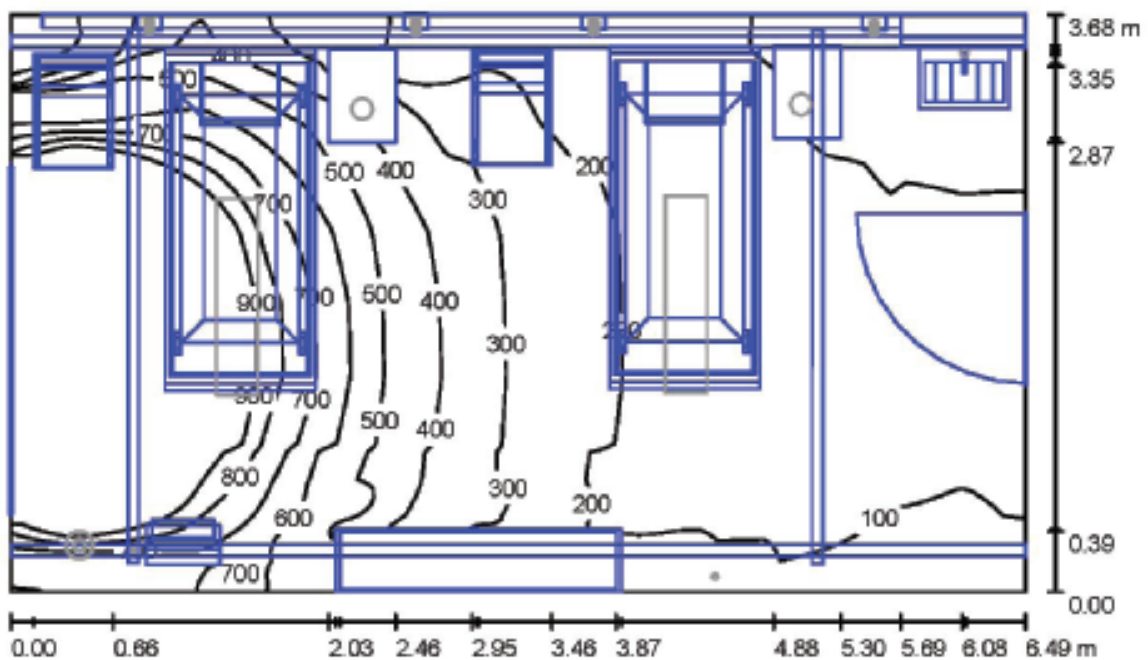

Rumhøjde: 3.939 m, Vedigeholdelsesfaktor: 0.80

Værdier i Lux, Mâlestok 1:48

\begin{tabular}{|c|c|c|c|c|c|}
\hline Flade & $\rho[\%]$ & $E_{m}[\mathrm{~lx}]$ & $E_{\min }[\mid x]$ & $E_{\max }[\mathrm{bx}]$ & $E_{\min } / E_{m}$ \\
\hline Workplane & $t$ & 463 & 42 & 2217 & 0.090 \\
\hline Floor & 45 & 240 & 24 & 782 & 0.099 \\
\hline Ceiling & 78 & 90 & 46 & 164 & 0.513 \\
\hline Vægge (4) & 69 & 139 & 9.95 & 651 & \\
\hline
\end{tabular}

Workplane:

$\begin{array}{ll}\text { Højde: } & 0.850 \mathrm{~m} \\ \text { Beregningsnet: } & 128 \times 128 \text { Punkter } \\ \text { Randomrade: } & 0.000 \mathrm{~m}\end{array}$

Ren dagslysscene, ingen belysningsarmaturer i brug 


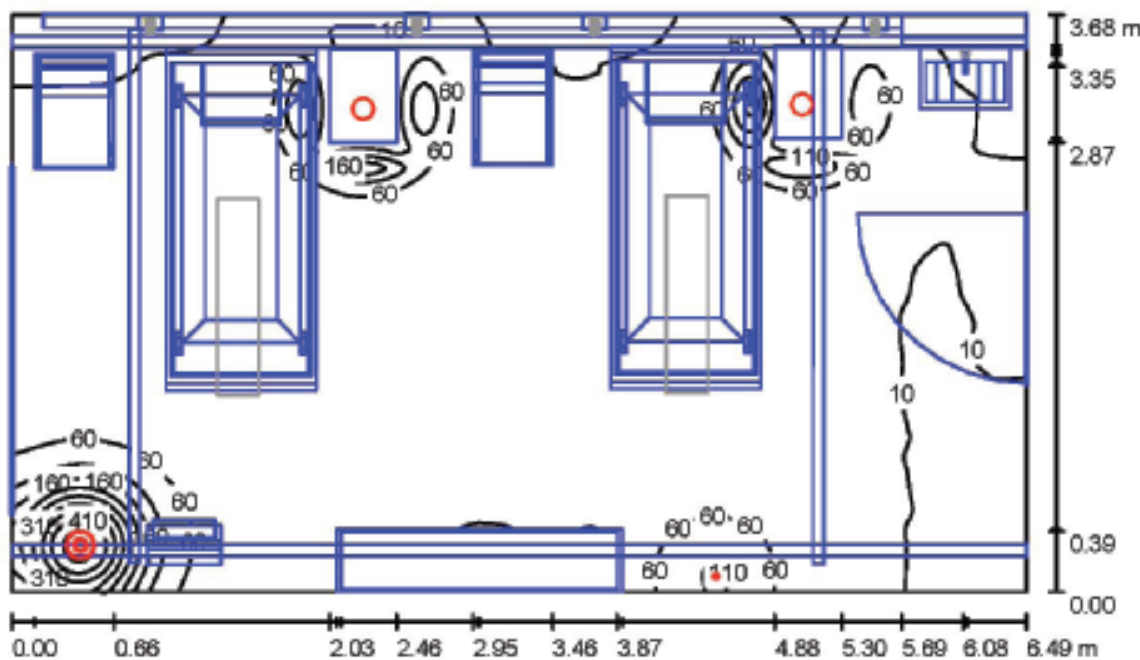

Rumhøjde: $3.939 \mathrm{~m}$, Vedigeholdelsesfaktor: 0.80

Værdier i Lux, Mălestok 1:48

\begin{tabular}{l|rrrrr} 
Flade & $\rho[\%]$ & $E_{m}[\mathrm{~lx}]$ & $\mathrm{E}_{\min }[\mathrm{lx}]$ & $\mathrm{E}_{\max }[\mathrm{lx}]$ & $\mathrm{E}_{\min } / \mathrm{E}_{\mathrm{m}}$ \\
\hline Workplane & $I$ & 31 & 5.96 & 501 & 0.195 \\
Floor & 45 & 17 & 1.82 & 103 & 0.106 \\
Ceiling & 78 & 16 & 9.42 & 21 & 0.573 \\
Vægge (4) & 69 & 19 & 0.93 & 512 & $I$
\end{tabular}

Workplane:

$\begin{array}{ll}\text { Højde: } & 0.850 \mathrm{~m} \\ \text { Beregningsnet: } & 128 \times 128 \text { Punkter } \\ \text { Randomrade: } & 0.000 \mathrm{~m}\end{array}$

\section{Armaturstykliste}

\begin{tabular}{r|rlrrr} 
Nr. & Antal & Betegnelse (Korrektionsfaktor) & $\Phi$ (Armatur) [lm] & $\Phi$ (Lamper) [Im] & $P[\mathrm{~W}]$ \\
\hline 1 & 1 & HIRO spotlight 4W GU10 40 gr & 106 & 125 & 4.0 \\
2 & 1 & Le Klint Undercover pendel m/2OW Tornado sparepæere & 1028 & 1155 & 20.0 \\
3 & 2 & Oliver bordlampe m/40W halogen & 490 & 490 & 40.0 \\
\hline
\end{tabular}

Specifik tilsluttet effekt: $4.36 \mathrm{~W} / \mathrm{m}^{2}=14.23 \mathrm{~W} / \mathrm{m}^{2} / 100 \mathrm{l} \times\left(\right.$ Grundflade: $23.86 \mathrm{~m}^{2}$ ) 
E-mail is Qchill.asu ck

Sengestue 10 / Patient 1_Personligt lys / Sammenfatning

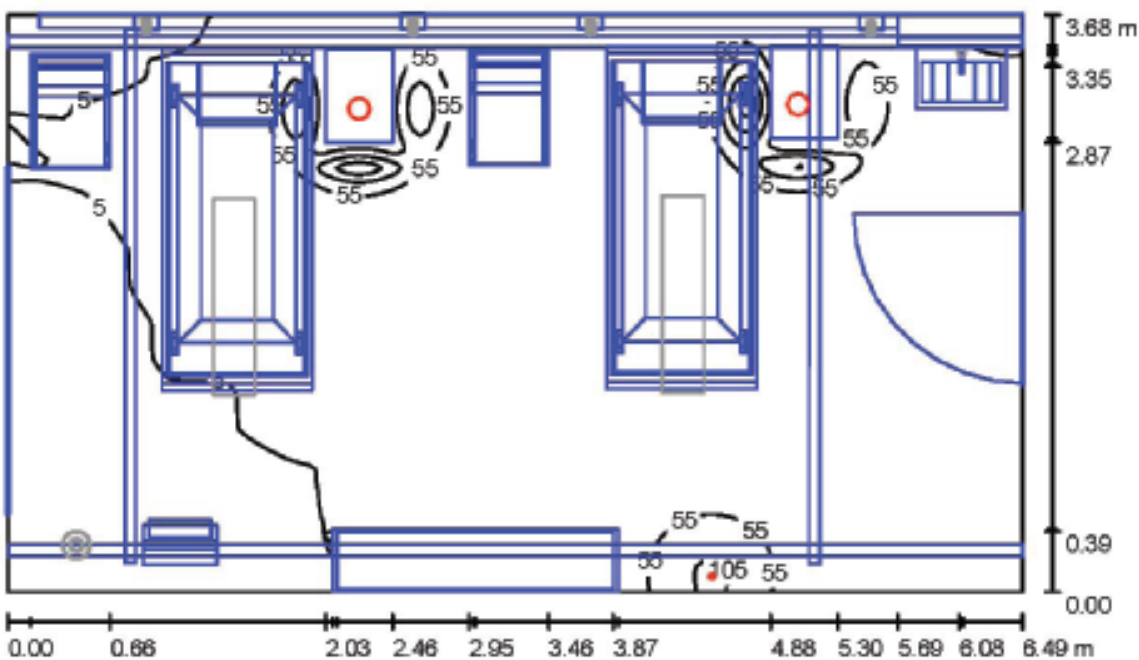

Rumhøjde: $3.939 \mathrm{~m}$, Vedigeholdelsesfaktor: 0.80

Værdier i Lux, Mălestok 1:48

\begin{tabular}{l|rrrrr} 
Flade & $\rho[\%]$ & $E_{m}[\mathrm{kx}]$ & $E_{\min }[\mathrm{x}]$ & $\mathrm{E}_{\max }[\mathrm{x}]$ & $\mathrm{E}_{\min } / \mathrm{E}_{\mathrm{m}}$ \\
\hline Workplane & $I$ & 15 & 3.41 & 293 & 0.224 \\
Floor & 45 & 7.56 & 1.09 & 43 & 0.144 \\
Ceiling & 78 & 11 & 5.24 & 16 & 0.496 \\
Vægge (4) & 69 & 8.25 & 0.53 & 411 & $I$
\end{tabular}

Workplane:

Højde:

$0.850 \mathrm{~m}$

Beregningsnet: $\quad 128 \times 128$ Punkter

Randomrade:

$0.000 \mathrm{~m}$

\section{Armaturstykliste}

\begin{tabular}{r|rlrrr} 
Nr. & Antal & Betegnelse (Korrektionsfaktor) & $\Phi$ (Armatur) [Im] & $\Phi$ (Lamper) [Im] & $P[\mathrm{~W}]$ \\
\hline 1 & 1 & HIRO spotlight 4W GU10 40 gr & 106 & 125 & 4.0 \\
2 & 2 & Oliver bordlampe m/40W halogen & 490 & 490 & 40.0 \\
\hline FEndrede tolkakkn data & Samlet: & 1086 & Samlet: & 1105 & 84.0
\end{tabular}

Specifik tilsluttet effekt: $3.52 \mathrm{~W} / \mathrm{m}^{2}=23.05 \mathrm{~W} / \mathrm{m}^{2} / 100 \mathrm{~lx}$ (Grundflade: $23.86 \mathrm{~m}^{2}$ ) 


\section{Odense Universitets Hospital}

Evaluering af Belysning på sengestue i forbindelse med phd projekt.

\section{Afdeling $\mathrm{O} 3$ (Ortopaedkirurgisk afdeling)}
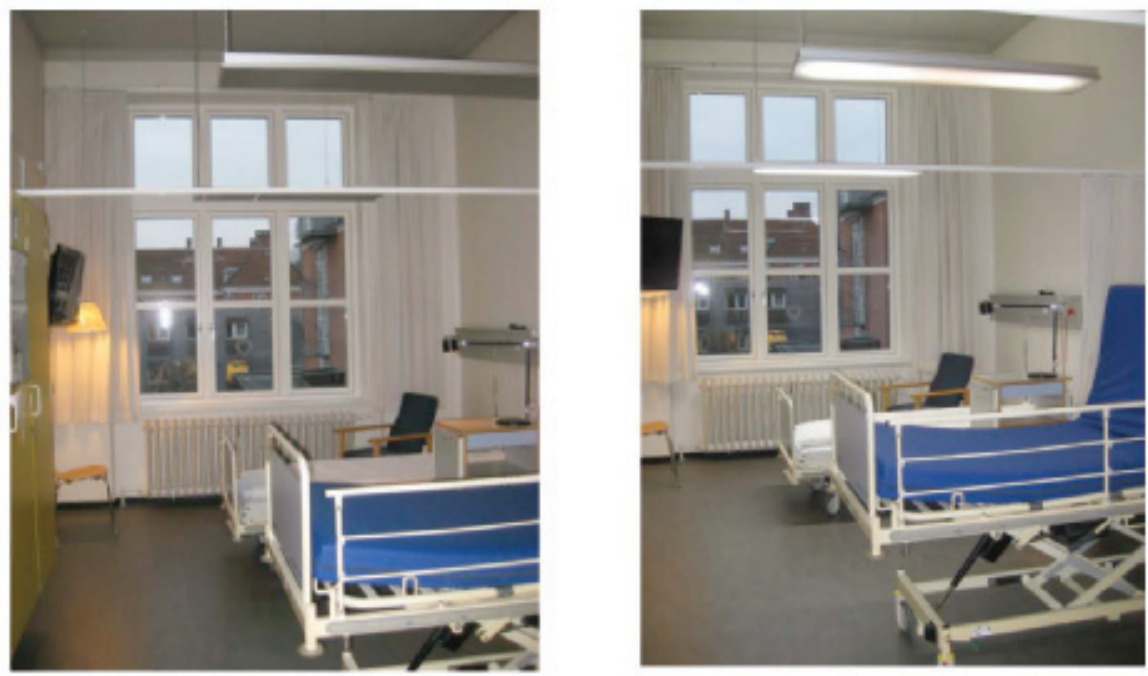

Partner for Contact: Poul Henning Kirkegaard/ Anne Marie Lund

Order No: : 01

Company: Aalborg Universitet /Philips

Customer No.: 1

Dato: 31.08 .2012

Designer: Lone Stidsen 


\subsection{APPENDIX}

Room Categorisation in Sansernes Hospital

(In Danish) 
Mentalt billede

I. Det sublime rum

II. Det kvalificerede rum

III. Det indifferente rum

et suppressive rum

V. Det usunde rum
Følelse

Samlet vurdering

Mentalt billede

Følelse

Samlet vurdering

Mentalt billede

Følelse

Samlet vurdering

Mentalt billede

Følelse

Samlet vurdering

Mentalt billede

Følelse

Samlet vurdering 
Lyst og stort rum med stilhed og klart lys

Behagelig og inspirerende følelse

Højtideligt, inspirerende, storartet og smukt

Man forsvinder i rummets storhed

Orden, regelmæssighed, gennemarbejdet

indretning med oplivende farver

Behagelig og tryg fornemmelse

Oplivende og imødekommende

Hverken smukt eller grimt eller frastødende, nærmest ligegyldigt

Fremmedgjorthed

Ligegyldigt rum

Kniber med at orientere sig på grund af diffust lys og indretning, der ikke er gennemtænkt

Hverken kroppen eller sindet finder hvile

Utryg fornemmelse

Forvirrende rumoplevelse
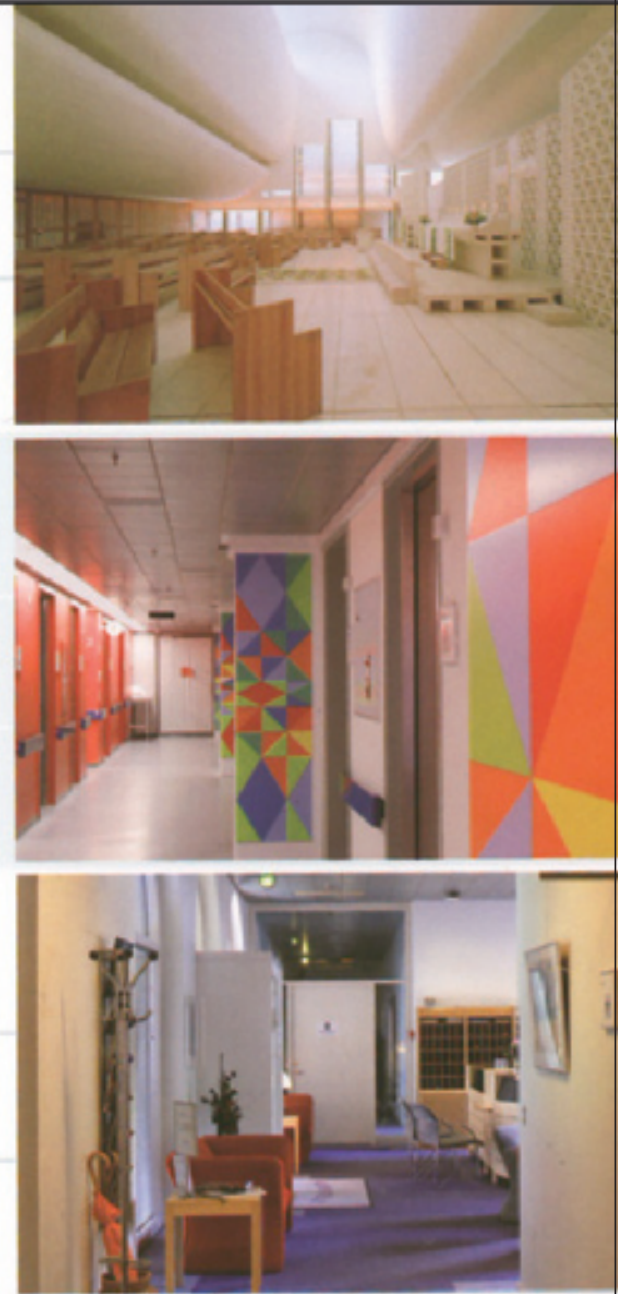

Porvirrende rumoplevelse

Mørkt, rodet og forvirrende rum.

Lugten ser ud til at være præget af mados og dunst

Frastødende og kvalmt rum

Det uhygiejniske rum giver kvalme og madlede
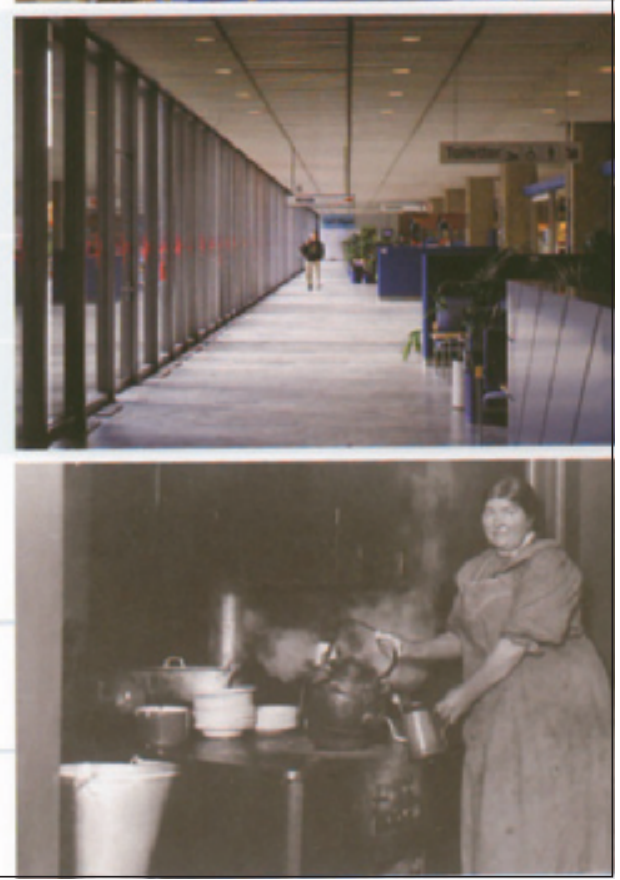
